\title{
TESTES DE CONDUTIVIDADE ELÉTRICA E DE LIXIVIAÇÃO DE POTÁSSIO PARA AVALIAÇÃO DO VIGOR DE SEMENTES DE SOJA (Glycine max (L.) MERRILL)
}

DENISE CUNHA FERNANDES DOS SANTOS DIAS

Engenheiro Agrônomo

\author{
Orientador: Prof. Dr. JÚLIO MARCOS FILHO
}

Tese apresentada à Escola Superior de Agricultura "Luiz de Queiroz", da Universidade de São Paulo, para obtenção do título de Doutor em Agronomia. Área de concentração: Fitotecnia.

P I R A C I C A B A

Estado de São Paulo - Brasil

Março - 1994 
Ficha catalografica preparada pela Seçăo de Livros da Divisăo de Biblioteca e Documentaçăo - FCLQ/USF

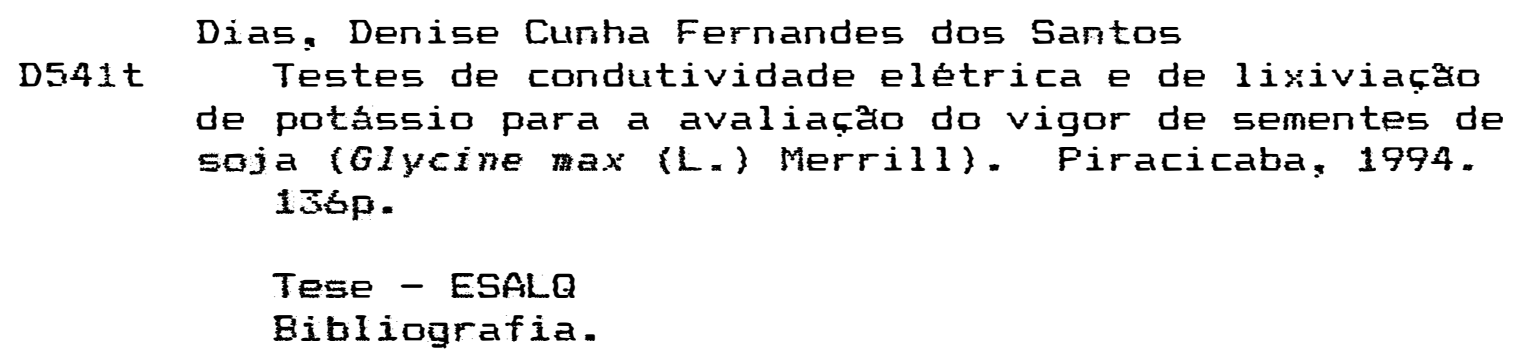

1. Semente - Condutividade elétrica - Teste 2. Se mente - Lixiviaçăo de potássio - Teste 3. Semente Vigor - Avaliaçăo 4. Soja - Semente - Qualidade I. Es cola Superior de Agricultura Luiz de Queiroz, Firacicaba

CDD 633.34

631.521 


\section{TESTES DE CONDUTIVIDADE ELÉTRICA E DE LIXIVIAÇÃO DE POTÁSSIO PARA AVALIAÇÃO DO VIGOR DE SEMENTES \\ DE SOJA (Glycine max (L.) MERRILL)}

DENISE CUNHA FERNANDES DOS SANTOS DIAS

Aprovada em: 06.04.94.

Comissão Julgadora:

Prof. Dr. Júlio Marcos Filho

ESALQ/USP

Prof. Dr. Sílvio Moure Cicero

ESALQ/USP

Prof. Dr. Roberval Daiton Vieira

FCAV/UNESP

Dr. José de Barros França Neto

EMBRAPA/CNPSO

Dr. Francisco Carlos Krzyzanowski

EMBRAPA/CNPSo

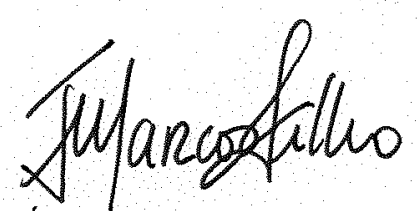

Prof Dr. JÚLIO MARCOS FILHO

Orientador 
À minha avó Maria Dolores (in memoriam) Aos meus pais Inácio e Maria Etelvina Ao Toni, Pedro e Raquel pelo amor que me dedicam sempre. 


\section{AGRADECIMENTOS}

Ao Prof. Dr. Júlio Marcos Filho pelo constante apoio, orientação e pelo valioso estímulo.

Aos professores Francisco Ferraz de Toledo, Sílvio Moure Cícero e Walter Rodrigues da Silva pela atenção e ensinamentos transmitidos.

Aos engenheiros-agrônomos Ana Dionísia C. L. Novembre e Helena M. C. P. Chamma pela amizade e apoio durante o transcorrer do curso.

Ao Prof. Dr. Décio Barbin pela coloraboração no planejamento da análise estatística.

Ao Prof. Dr. Quirino A. C. Carmelo e às laboratoristas Nivanda M. Moura e Lurdes D. Gonzalez pelo apoio durante a execução das análises no Laboratório de Nutrição Mineral de Plantas.

Aos funcionários do Departamento de Agricultura, em especial a Ilze Helena D. Neves e Hodair Bonzatto Júnior pelos serviços prestados.

Aos colegas de pós-graduação pela amizade, carinho e incentivos, em especial a Denise A. C. Billia, Gisele Herbst Vazquez, Francine Lorena Cuquel, Maria Laene M. Carvalho, Édila V. Rezende Von Pinho, Márcio Bastos Gomide, Cláudio Cavariani, Maria Cristina M. Spinola, Monalisa Diniz e Ceci C. Custódio.

À Universidade Federal de Viçosa pela concessão de afastamento para a conclusão do curso.

À professora e colega Eveline Mantovani Alvarenga pela amizade e extraordinário apoio.

À empresa Comércio e Indústria de Sementes Brejeiro pelo empréstimo do ASA-610.

À Fundação de Amparo à Pesquisa do Estado de São Paulo pelo suporte financeiro para a realização do projeto.

Ao Conselho Nacional de Pesquisa e Desenvolvimento Tecnológico - CNPq - pela bolsa de estudos concedida. 


\section{SUMÁRIO}

Página

RESUMO viii

SUMMARY $\mathrm{x}$

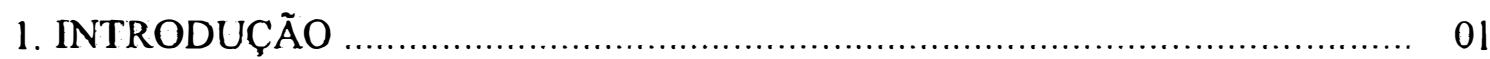

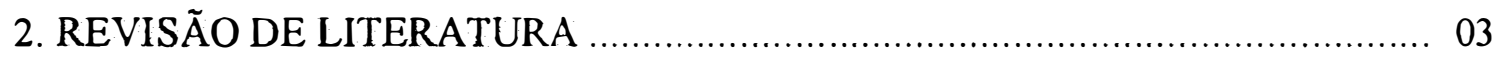

2.1.Deterioração e vigor de sementes ...................................................... 03

2.2 Avaliação do vigor das sementes ....................................................... 06

2.2.1. Testes de vigor baseados na integridade do sistema de membranas........ 08

2.2.1.1. Teste de condutividade elétrica .................................... 13

a) Condutividade elétrica de massa ............................... 13

b) Condutividade elétrica individual ................................. 20

c) Relações entre condutividade elétrica e emergência das plântulas em campo ................................................. 22

2.2.1.2. Teste de lixiviação de potássio ..................................... 25

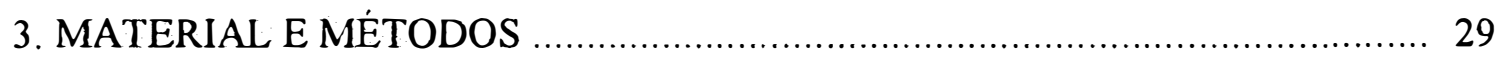

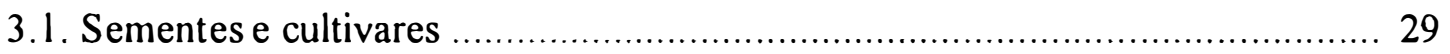

3.2. Estudo dos testes de condutividade elétrica e de lixiviação de potássio

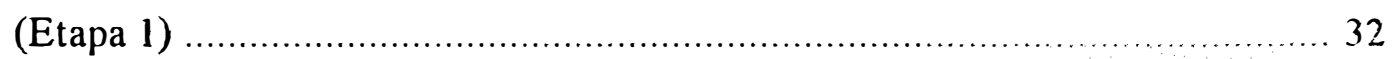

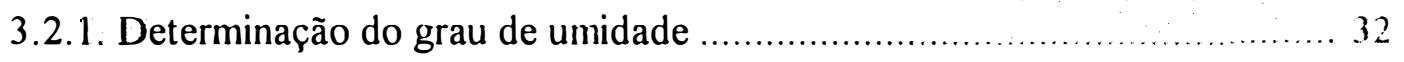

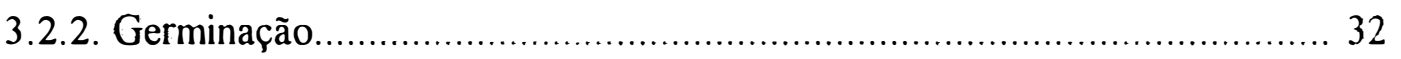

3.2.3. Primeira cntagem de germinação.................................................. 32

.2.4. Envelhecimento artificial ........................................................... 32

3.2.5. Condutividade elétrica de massa - CE I.......................................... 33

3.2.6. Condutividade elétrica de massa - CE II......................................... 33.

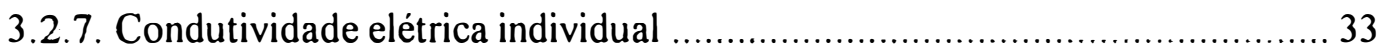

3.2.8. Lixiviação de potássio - KI e KII ................................................ 34

3.3. Comparação entre métodos para avaliação da qualidade fisiológica das

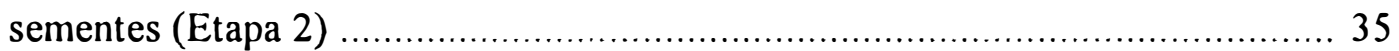

3.3.1. Determinação do grau de umidade ................................................ 35

3.3.2. Identificação de danificações mecânicas .......................................... 35 


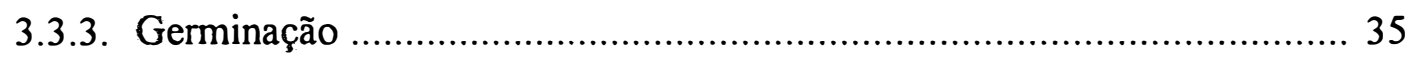

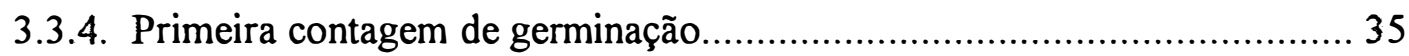

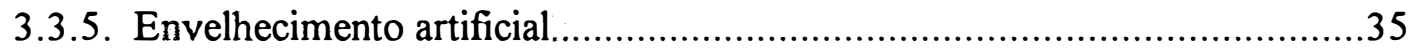

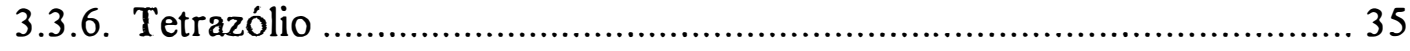

3.3.7. Condutividade elétrica de massa - CE I.......................................... 36

3.3.8. Condutividade elétrica de massa - CE II............................................ 36

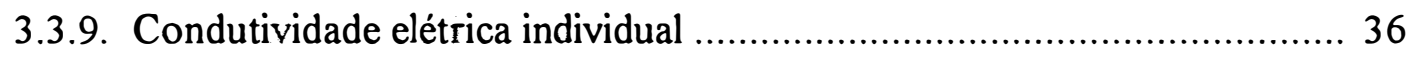

3.3.10. Lixiviação de potássio - KI e KII .................................................. 36

3.3.11. Classificação do vigor de plântulas ...................................................... 36

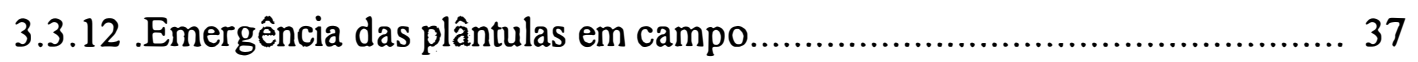

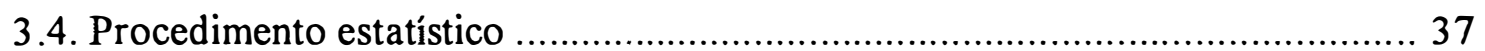

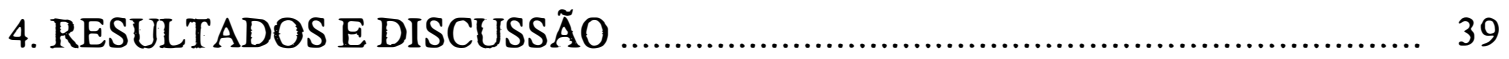

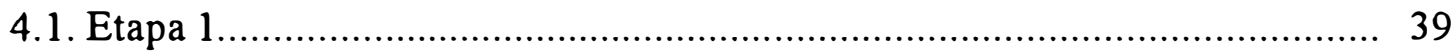

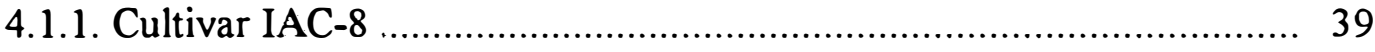

4.1.1.1. Condutividade elétrica de massa - CE I e CE II..................... 43

4.1.1.2. Condutividade elétrica individual ......................................... 46

4.1.1.3. Lixiviação de potássio - KI e KII......................................... 50

4.1.1.4. Análise comparativa entre os métodos para avaliação da qualidade fisiológica das sementes......................................... 52

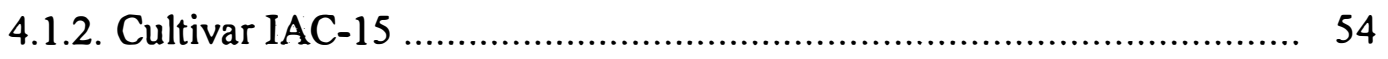

4.1.2.1. Condutividade elétrica de massa - CE I e CE II..................... 54

4.1.1.2. Condutividade elétrica individual ......................................... 60

4.1.1.3. Lixiviação de potássio - KI e KII.......................................... 63

4.1.1.4. Análise comparativa entre os métodos para avaliação da qualidade fisiológica das sementes.......................................... 65

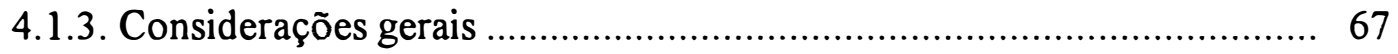

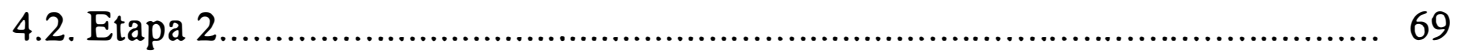

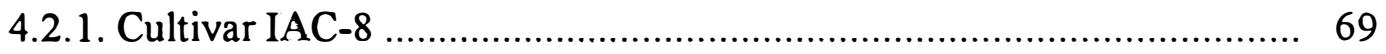

4.2.1.1. Condutividade elétrica de massa - CE I e CE II.................... 69

4.2.1.2. Condutividade elétrica individual ......................................... 75

4.2.1.3. Lixiviação de potássio - KI e KII........................................ 81

4.2.1.4. Análise comparativa entre os métodos para avaliação da qualidade fisiológica das sementes........................................... 84 


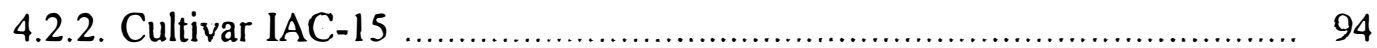

4.2.2.1. Condutividade elétrica de massa - CE I e II ...................... 97

4.2.2.2. Condutividade elétrica individual ..................................... 100

4.2.2.3. Lixiviação de potássio - KI e KII...................................... 103

4.2.2.4. Análise comparativa entre os métodos para avaliação da qualidade fisiológica das sementes..................................... 109



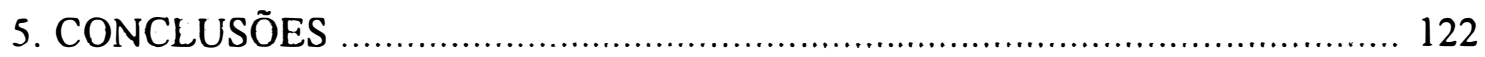

6. REFERÊNCIAS BIBLIOGRÁFICAS 


\title{
TESTES DE CONDUTIVIDADE ELÉTRICA E DE LIXIVIAÇÃO DE POTÁSSIO PARA AVALIAÇÃO DO VIGOR DE SEMENTES DE SOJA (Glycine max (L.) MERRILL)
}

\author{
Autor: Denise Cunha Fernandes dos Santos Dias \\ Orientador: Prof. Dr. Júlio Marcos Filho
}

\section{RESUMO}

O desenvolvimento de métodos simples e rápidos para a avaliação do vigor de sementes de soja (Glycine max (L.) Merrill), possibilitando uma estimativa do seu desempenho em campo, é de grande importância para o estabelecimento de programas de controle de qualidade eficientes e dinâmicos.

Neste contexto, o presente trabalho, conduzido no Laboratório de Análise de Sementes e no Campo Experimental da Escola Superior de Agricultura "Luiz de Queiroz", da Universidade de São Paulo, teve como objetivos: a) investigar a possibilidade de redução do período de condicionamento das sementes nos testes de condutividade elétrica e de lixiviação de potássio e, conseqüentemente, obter indicações mais rápidas sobre a qualidade fisiológica dos lotes; b) avaliar a eficiência das informações fornecidas pelos referidos testes comparativamente a outros métodos considerados adequados para a determinação do vigor de sementes de soja.

Para tanto, foram realizadas duas etapas de testes utilizando-se quatro lotes de sementes de soja dos cultivares IAC-8 e IAC-15. Na primeira etapa foram conduzidos, além dos testes de germinação, primeira contagem de germinação e envelhecimento artificial, estudos de condutividade elétrica de massa e individual (ASA610), empregando-se períodos de condicionamento de 4, 8, 12, 16, 20 e 24 horas, e testes de lixiviação de potássio realizados com 60, 90, 120 e 150 minutos. Nos testes de condutividade de massa e de lixiviação de potássio foram empregadas amostras de sementes não danificadas e de sementes fisicamente puras. Os procedimentos que forneceram indicações mais consistentes sobre o vigor das sementes foram, então, avaliados na segunda etapa, que constou dos seguintes testes: germinação, primeira contagem de germinação, envelhecimento artificial, tetrazólio, classificação do vigor de plântulas e emergência das plântulas em campo. 
A análise dos dados e interpretação dos resultados permitiram concluir que há possibilidade de redução no período de condicionamento das sementes de soja, no teste de condutividade elétrica de massa, sendo que os períodos de embebição mais curtos ( 8 el 2 horas) permitiram a identificação de diferenças mais acentuadas entre os lotes, enquanto que leituras realizadas a partir de 16 horas mostraram-se mais sensiveis às variações de vigor das sementes. Com relação ao teste de lixiviação de potássio, as avaliações feitas aos 90 minutos, com sementes fisicamente puras, revelaramse mais eficientes. Os referidos testes mostraram-se adequados para a identificação de lotes com diferentes níveis de vigor e potencial de emergência em campo. Já a condutividade individual (ASA-610) revelou eficiência variável de acordo com o cultivar avaliado. 


\section{ELECTRICAL CONDUCTIVITY AND POTASSIUM LEACHATE TESTS TO EVALUATION OF VIGOR SOYBEAN SEEDS (Glycine max (L.) MERRILL)}

Author: Denise Cunha Fernandes dos Santos Dias Adviser: Prof. Dr. Júlio Marcos Filho

\section{SUMMARY}

This research was carried out in the Laboratory of Seed Analysis and in the experimental field of "Escola Superior de Agricultura Luiz de Quieroz", University of São Paulo, Brazil, with the objectives: a) investigated the reduction in soaking time of seeds in the electrical conductivity and potassium leachate tests; b) to relate those test results to other indicators of soybean seed vigor.

Four seed lots of two cultivars soybean (IAC-8 and IAC-15) were used. The studies were carried out in two phases. In the first one, the following tests were conducted: standard germination, first count of standard germination, accelerated aging, and studies of bulk and individual (ASA-610) seeds conductivity, with $4,8,12,16,20$ and 24 hour of soak and potassium leachate test evaluated with 60,90 , 120 and 150 minutes. The most favorable procedures founded in this phase were evaluated in the second experiment comparing their efficiency under diferent tests. These comparisons included standard germination, first count of standard germination, accelerated aging, tetrazolium, seedling vigor classification and field emergence tests.

It was concluded that the shorter imbibition periods ( 8 and 12 hour) for the bulk conductivity test can be used for the detection of wide vigor differences, while a 16, 20 and 24 hour imbibition period can be used for identifying smaller vigor differences among soybean seed lots. The evaluation of potassium leachate after 90 minutes, with 25 pure seeds was most sensitive ones. This test and the bulk conductivity test had good potential as a rapid and efficient method of discriminate soybean seed lots of different qualities. Its use in seed quality control programs can be useful. The efficiency of the ASA-610 varied according to cultivar. 


\section{INTRODUÇÃO}

O objetivo fundamental de um sistema organizado de produção de sementes é a obtenção de materiais de alta qualidade genética, fisica, fisiológica e sanitária, permitindo que as características superiores dos cultivares, obtidos pela pesquisa, sejam disponíveis aos agricultores.

No Brasil, existem sérias preocupações com relação à qualidade fisiológica das sementes de soja, pois estas apresentam grande sensibilidade à fatores climáticos, mecânicos e patogênicos. Portanto, a demanda por sementes de alto padrão de qualidade tem exigido tecnologia moderna, eficiente e dinâmica dentro da indústria de sementes, resultando em um controle de qualidade cada vez mais efetivo.

Neste contexto, a avaliação da qualidade fisiológica das sementes é um aspecto importante a ser considerado em um programa de produção, pois a elucidação dos efeitos dos diversos fatores que possam afetar a qualidade dessas sementes depende, diretamente, da eficiência dos métodos utilizados para determiná-la. Além de fornecer informações a respeito da viabilidade das sementes, o emprego de metodologia adequada, possibilita a estimativa do vigor, do desempenho em campo e o descarte de lotes deficientes, diminuindo, portanto, riscos e prejuízos.

$\mathrm{Na}$ atualidade, um dos requisitos básicos para a avaliação do vigor das sementes refere-se à obtenção de resultados confiáveis em um período de tempo relativamente curto, uma vez que as tomadas de decisões devem ser agilizadas, principalmente no que se refere às operações de colheita, processamento e comercialização.

Dentre os métodos considerados rápidos para avaliação do vigor de sementes destacam-se os testes de condutividade elétrica, pelos sistemas de massa e individual, os quais são particularmente interessantes para a soja, fornecendo resultados em 24 horas. Além destes, o teste de lixiviação de potássio, apesar de pouco estudado, baseia-se em princípio semelhante com a vantagem adicional de proporcionar informações sobre a qualidade fisiológica dos lotes, em período de tempo consideravelmente reduzido em relação aos testes de condutividade. 
Desta forma, o presente trabalho teve como objetivo principal avaliar a possibilidade de redução no periodo de condicionamento das sementes nos testes de condutividade elétrica, e conseqüentemente, a obtenção mais rápida dos resultados. Além disso, procurou-se verificar a eficiência das informações fornecidas pelo teste de lixiviação de potássio, considerado promissor como método rápido, buscando indicar opções para uma melhor utilização desses testes nos programas de controle de qualidade exercidos pelas instituições produtoras de sementes. 


\section{REVISĀO DE LITERATURA}

\subsection{Deterioração e vigor de sementes}

A qualidade fisiológica das sementes é influenciada diretamente pelo genótipo, sendo máxima por ocasião da maturidade fisiológica; nesta fase, o peso de matéria seca, a germinação e o vigor geralmente atingem valores máximos. A partir deste momento, alterações degenerativas começam a ocorrer, de modo que a qualidade fisiológica pode ser mantida ou decrescer, dependendo das condições ambientais no período que antecede a colheita, da condução dos processos de colheita, secagem e beneficiamento e das condições de armazenamento (DELOUCHE \& BASKIN, 1973; McDONALD Jr., 1975).

A deterioração é definida como toda e qualquer transformação degenerativa na semente (ABDUL-BAKI \& ANDERSON, 1972); trata-se de um processo contínuo, de progresso variável entre espécies, entre lotes de sementes da mesma espécie e entre sementes do mesmo lote. Essas transformações podem ser de origem bioquímica, fisica ou fisiológica (DELOUCHE \& BASKIN, 1973). Portanto, o manejo adequado das sementes, de forma a minimizar a deterioração, requer o entendimento dos complexos mecanismos que a governam.

Neste sentido, ABDUL-BAKI \& ANDERSON (1972) relataram as principais manifestações fisiológicas e bioquimicas de sementes deterioradas. As primeiras referem-se a alterações na cor, perda de germinação, decréscimo à tolerância a condições sub-ótimas, alta sensibilidade a tratamentos com radiação, reduzido crescimento de plântulas, redução na germinação e aumento no número de plântulas anormais. Dentre as alterações bioquímicas os autores incluíram: mudanças na atividade enzimática e respiratória, nas vias de sintese, nas membranas, nos compostos de reserva e nos cromossomas. Por sua vez, DELOUCHE \& BASKIN (1973) relacionaram os eventos que caracterizam o processo de deterioração, numa sequência hipotética que envolve: a degradação de membranas celulares, redução das atividades respiratórias e biossintéticas, germinação mais lenta, redução no potencial de conservação, decréscimo na taxa de 
crescimento e desenvolvimento, menor uniformidade de emergência, maior sensibilidade as adversidades do ambiente, redução da emergência das plântulas em campo, aumento da ocorrência de plântulas anormais e, finalmente, perda do poder germinativo.

Embora os sintomas de deterioração, anteriores à morte da semente estejam razoavelmente bem estabelecidos, suas causas ainda não são claras, devido ao grande número de alterações citológicas e metabólicas envolvidas (ROBERTS, 1973). Assim, torna-se dificil não só o estabelecimento das primeiras causas condicionantes da deterioração como também a identificação das relações entre causa e efeito (GILL \& DELOUCHE, 1973).

A degeneração de organelas celulares acompanhada de alterações funcionais está intimamente associada à degradação das membranas, segundo ROBERTS (1973). Uma vez que a maioria das atividades celulares envolve a participação ativa do sistema de membranas, POWELL (1986) considerou que reduções na atividade enzimática e respiratória e na sintese de macromoléculas são decorrência da deterioração inicial das membranas.

A desestruturação dos sistemas de membranas a nivel celular tem sido relatada na literatura como conseqüuencia inicial da deterioração. Em virtude disto, a elucidação dos mecanismos envolvidos em tal processo se reveste de grande importância para os estudos que buscam informações sobre a perda de qualidade fisiológica das sementes.

De acordo com a literatura, as reações oxidativas são, pelo menos em parte, responsáveis pela deterioração das sementes (FLOOD \& SINCLAIR, 1981; OHLROGGE \& KERNAN, 1982, PRIESTLEY \& LEOPOLD, 1983; PRIESTLEY et al., 1985 e WILSON \& McDONALD Jr., 1986) e estas reações ocorrem por meio de auto-oxidação ou peroxidação, um processo não enzimático (HARRINGTON, 1973). Os lipidios podem ser o sítio principal desta reação, embora outros componentes celulares possam estar envolvidos (WILSON \& McDONALD Jr., 1986). A oxidação de ácidos graxos insaturados é citada, muitas vezes, como a primeira reação do processo de envelhecimento, produzindo radicais livres que, subsequentemente, atacam lipídios, proteinas e ácidos nucleicos em uma reação em cadeia (HARRINGTON, 1973). Também tem sido sugerido que as reações oxidativas do processo de envelhecimento podem envolver enzimas como as lipoxigenases, as quais mantém sua atividade em sementes de soja, mesmo em baixos níveis de água (PRIESTLEY et al., 1985); no entanto, a possibilidade da deterioração em sementes armazenadas ser induzida por processo enzimático não tem sido amplamente considerada na literatura. 
BEWLEY (1986) em extensa revisão sobre a desestruturação do sistema de membranas, comentou que a causa imediata deste evento seria a ação de grupos químicos altamente reativos denominados radicais livres, os quais segundo HARMAN \& MATTICK (1976) são formados pela oxidação de ácidos graxos insaturados em sementes envelhecidas. POWELL \& MATTHEWS (1981) encontraram evidências de redução no conteúdo total de fosfolipídios das membranas, aliada à formação de radicais livres em conseqüência da peroxidação de lipídios, tanto no início como no final do processo de envelhecimento de sementes de ervilha. Resultados semelhantes, evidenciando a peroxidação de ácidos graxos insaturados, foram demonstrados por HARMAN \& MATTICK (1976) com ervilha, PARRISH \& LEOPOLD (1978) e STEWART \& BEWLEY (1980), com soja e BASAVARAJAPPA et al. (1991), com milho.

É importante ressaltar que, em condições normais, as células possuem mecanismos capazes de suprimir a ação dos radicais livres, através de substâncias que, quando presentes, reagem com tais radicais, eliminando-os; dentre estas substâncias destacam-se os antioxidantes como o alfa-tocoferol (vitamina E) que está associado às membranas, a vitamina $\mathrm{C}$ e o beta-caroteno (BEWLEY, 1986).

BASAVARAJAPPA et al. (1991) investigando as alterações ocorridas durante o envelhecimento de sementes de milho, observaram decréscimo no nível de fosfolipídios, ascorbato e atividade da peroxidase, acompanhados de aumento na atividade da fosfolipase A, nos ácidos graxos totais e malonaldeído, fatores estes indicativos de provável peroxidação dos lipídios das membranas. Os autores evidenciaram, portanto, a perda de integridade das membranas como a primeira alteração deteriorativa de sementes de milho envelhecidas.

No entanto, a correlação entre peroxidação de lipídios e deterioração de sementes nem sempre tem sido verificada, conforme resultados de PRIESTLEY \& LEOPOLD (1979) com sementes de soja e de PEARCE \& ABDEL SAMAD (1980) com amendoim. Também PRIESTLEY et al. (1980) não detectaram a interferência dos radicais livres na deterioração de sementes. CARVALHO (1994) mencionou que, em virtude de os procedimentos químicos necessários à constatação da ocorrência da peroxidação serem complexos, muitas vezes, os resultados obtidos podem ser conflitantes.

Para MATTHEWS (1985) a elucidação das mudanças celulares iniciais relacionadas ao envelhecimento não tem sido conclusivas e as evidências de deterioração citoplasmática, na forma de degradação de membranas, são largamente 
circunstanciais, apesar deste evento ser considerado como o marco inicial da perda de viabilidade.

No entanto, pelo exame da literatura verifica-se que a desestruturação do sistema de membranas tem sido considerada, por muitos autores, como a primeira manifestação da deterioração em sementes, embora os fatores condicionantes e mecanismos envolvidos ainda não estejam completamente elucidados.

Sabe-se que o processo de deterioração, a que as sementes estão sujeitas logo após a maturidade, está diretamente relacionado com o vigor, cuja importância tem sido destacada por diversos pesquisadores, especialmente com sementes de soja, as quais são reconhecidamente problemáticas em termos de qualidade fisiológica. ABDUL-BAKI \& ANDERSON (1973) afirmaram que o vigor tem relação direta com a perda ou redução da qualidade das sementes durante a colheita, secagem, processamento, transporte e armazenamento. Vários fatores afetam o desempenho final das sementes de soja e, segundo YAKLICH et al.(1979), o conceito de vigor foi introduzido com a finalidade de identificar outros fatores, além da viabilidade, que interferem no estabelecimento e crescimento das plântulas em campo. É importante ressaltar que a ausência de uma estreita relação entre a germinação, obtida em laboratório, e a emergência de plântulas em campo foi o principal fator responsável pelo desenvolvimento do conceito de vigor (CARVALHO \& NAKAGAWA, 1988). Esta constatação conduziu, então, à necessidade de se avaliar o estádio de deterioração dos lotes de sementes, ou seja, o vigor, mediante a condução de testes específicos para este fim.

\subsection{Avaliação do vigor das sementes}

De acordo com MARCOS FILHO et al. (1987), o objetivo básico de se avaliar o vigor das sementes é identificar possiveis diferenças sıgnificativas na qualidade fisiológica de lotes que apresentem poder germinativo semelhante. Frequentemente, observa-se que lotes de sementes apresentando germinação semelhante exibem comportamentos distintos no campo e/ou no armazenamento.

Para DELOUCHE \& BASKIN (1973) tais diferenças no comportamento de lotes com germinação semelhante, podem ser explicadas pelo fato de que as primeiras alterações nos processos bioquímicos associados à deterioração, geralmente, ocorrem antes que o declínio na capacidade germinativa seja verificado. A perda de germinação, segundo HEYDECKER (1972), é um indicativo importante da perda de qualidade, mas é a última consequêencia, ou seja, o evento final. Desta forma, o uso de testes de vigor é de grande utilidade no monitoramento da qualidade das 
sementes a partir da maturidade, durante a colheita, processamento e armazenamento, pois a queda do vigor precede a perda de viabilidade.

Portanto, o principal desafio das pesquisas sobre testes de vigor está na identificação de parâmetros adequados, comuns à deterioração das sementes, de forma que, quanto mais distante da perda da capacidade de germinação estiver o parâmetro empregado, mais promissor será o teste, fornecendo, assim, informações complementares àquelas obtidas através do teste padrão de germinação (AOSA, 1983).

Como a deterioração de sementes, e a conseqüente queda de vigor, manifesta-se de diferentes formas, vários testes de vigor têm sido propostos, já que um único teste não consegue avaliar, simultaneamente, todos os aspectos de vigor que podem afetar o estabelecimento das plântulas em campo.

Várias classificações para os testes de vigor têm sido propostas, com finalidade principalmente didática ISELY (1957); POLLOCK \& ROSS (1972); WOODSTOCK (1973) e McDONALD Jr. (1975).

Independentemente da classificação adotada, o teste de vigor, para possuir boa receptividade entre os tecnologistas de sementes, deve ser reproduzível e correlacionado com a emergência de plântulas em campo, além de rápido, não oneroso, objetivo e de fácil execução, conforme McDONALD Jr. (1975) e MATTHEWS (1981).

Diante destas considerações, de acordo com CARVALHO (1986), apenas alguns testes foram considerados mais adequados pela AOSA (1983), sendo eles: teste de crescimento de plântulas, teste de classificação do vigor de plântulas, teste de envelhecimento acelerado, teste de frio, teste de tetrazólio e teste de condutividade elétrica. Embora as informações fornecidas por estes testes sejam de grande utilidade nos programas de controle de qualidade interno, o seu emprego em laboratório de rotina depende, principalmente, de sua padronização, já que os resultados obtidos devem ser reproduziveis entre laboratórios (MCDONALD Jr., 1980). Sabe-se que vários fatores contribuem para dificultar a padronização dos testes de vigor $\mathrm{e}$ CARVALHO (1986) relacionou dentre os principais a precisão dos procedimentos, a apresentação dos resultados e o estabelecimento de níveis aceitáveis de vigor.

Através do exame de literatura, nota-se que a evolução dos conhecimentos sobre este assunto tem demonstrado que, em função das características que determinam o vigor e dos inúmeros fatores que o influenciam, a sua avaliação deve envolver a condução de vários testes com a utilização conjunta dos resultados. 
Um fator relevante a ser considerado na avaliação do vigor das sementes, é o periodo de tempo necessário para a realização do teste. A rapidez na obtenção dos resultados proporciona expressivas vantagens nos diversos segmentos da produção de sementes, especialmente nas etapas de pré-colheita, recepção e processamento, permitindo agilização nas tomadas de decisões.

De acordo com POLLOCK \& ROSS (1972) e ABDULBAKI \& ANDERSON (1973), os testes que demandam um período de tempo relativamente curto são os relacionados com os processos fisiológicos e bioquimicos da deterioração das sementes, especialmente as atividades enzimáticas e respiratórias e a integridade das membranas celulares das sementes. Os referidos autores destacaram que as pesquisas realizadas com testes baseados nestes processos devem incluir, como referencial, a emergência das plântulas em campo. Tais testes, geralmente, se baseiam na coloração dos tecidos vivos das sementes, em função de alterações na atividade respiratória, caso especifico do teste de tetrazólio, ou nas reações bioquimicas (testes de respiração e de conteúdo de ATP) ou, então, na permeabilidade das membranas, como as alterações do $\mathrm{pH}$ do exsudato das sementes, a condutividade elétrica do meio de embebição e a quantidade de íons lixiviados.

Apesar das pesquisas com estes testes serem relativamente recentes, alguns deles já . estão sendo utilizados com sucesso em muitos laboratórios. Em levantamento realizado por TEKRONY (1983), em 102 laboratórios de análise de sementes dos EUA, foi possivel constatar que entre os testes de vigor mais utilizados, destacaram-se o teste de tetrazólio (66\% dos laboratórios) e o de condutividade elétrica (31\%), tomando como base o ano de 1982.

Portanto, testes de vigor baseados na integridade dos sistemas de membranas da semente devem merecer atenção especial por parte da pesquisa, em virtude de permitirem que o processo de deterioração seja detectado em sua fase inicial e, conseqüentemente, que medidas cabiveis sejam tomadas, no sentido de reduzir ou minimizar o seu efeito na qualidade fisiológica da semente.

\subsubsection{Testes de vigor baseados na permeabilidade das membranas}

Estruturalmente, as membranas biológicas são constituidas por uma dupla camada lipídica contendo proteinas intrínsecas e extrínsecas. Os principais constituintes da camada lipídica são lipidios polares, representados pelos fosfolipídios, moléculas complexas derivadas do glicerol e de ácidos graxos, sendo mais abundantes os do tipo fosfatidil colina, etanolamina e inositol; têm natureza anfipática, 
apresentando um grupo hidrofilico em uma extremidade da molécula e na outra, dois ácidos graxos de longa cadeia hidrofóbica (SIMON, 1974). Por esta razão, são denominados polares, uma vez que as extremidades de suas moléculas exibem comportamentos opostos em relação à água.

Conforme teoria proposta por BRANTON (1969), os fosfolipídios estão arranjados em camada dupla, contínua, com as moléculas alinhadas lado a lado, perpendicularmente à superficie da parede celular; a continuidade só é interrompida por proteinas intrínsecas que atravessam o complexo fosfolipidico. Em meio aquoso, as moléculas integrantes da membrana celular formam um arranjo denominado "mosaico fluído" (SINGER \& NICOLSON, 1972) devido às suas propriedades fisicas. Assim, as extremidades hidrofóbicas (ácidos graxos de cadeia longa) apresentam-se voltadas para $o$ interior enquanto as hidrofilicas, representadas pelos grupos polares, se arranjam em direção ao exterior aquoso. Dessa forma, os lipídios constituintes da membrana celular exibem uma configuração laminar (BRANTON, 1969).

SINGER \& NICOLSON (1972) propuseram um modelo para a estrutura das membranas onde tanto fosfolipidios como proteinas contribuem para regular a difusão de solutos celulares. Este modelo sugere que, proteinas globulares se associam interna e externamente à camada dupla lipídica sendo denominadas, respectivamente, intrínsecas e extrinsecas (periféricas). As primeiras, segundo CARVALHO (1994), permitem o transporte de solutos através da camada lipídica, sendo abundantes quando o fluxo de substâncias é intenso. Por sua vez, as proteinas extrinsecas, nas quais predominam sequências de aminoácidos hidrofilicos, mostram-se incapazes de atravessar o interior da membrana. A principal função deste grupo é, portanto, capturar ions próximos à membrana celular que, posteriormente, seriam transportados para o interior da célula.

Estudos sobre a estrutura da dupla camada lipidica em vários sistemas aquosos, usando técnicas de difração de raio-X, têm demonstrado que a estrutura das membranas não permanece sempre na fase lamelar, conforme LUZZATI \& HUSSON (1962). Em sistemas cujo conteúdo de água está abaixo de $20 \%$, os fosfolipídios exibiriam, segundo estes autores, um arranjo hexagonal, desenvolvido em função dos grupos polares destas moléculas tornarem-se alinhados formando cilindros. A existência desta fase hexagonal também foi demonstrada por STOECKENIUS (1962) em sistemas contendo de 2,5 a 3,5\% de água, enquanto a fase lamelar foi observada quando a umidade era de 30\%. Finean (1969)1, citado por LOEFFLER

\footnotetext{
${ }^{1}$ FINEAN, J.B. Biophysical contribuitions to membrane structure. Q. Rev. Biophys., 2: 1- 22, 1969.
} 
(1981) concluiu que foi necessário um grau de umidade de pelo menos 20 a $30 \%$ para manter a associação da dupla camada de lipídios; entretanto, alterações na configuração das membranas ocorrem quando o conteúdo de água decresce, com conseqüente aumento da permeabilidade.

Diante dessas considerações, pode-se inferir que durante a maturação da semente seu sistema de membranas está sujeito às referidas transformações, em função das alterações do grau de umidade. De acordo com ABDUL-BAKI (1980), a organização das membranas é máxima na maturidade fisiológica. Entretanto, a partir deste momento, as organelas perdem sua organização estrutural a níveis variáveis, tornando-se menos ativas metabolicamente em sementes secas (12 a $14 \%$ de água). Assim, à medida em que as sementes perdem água, seja naturalmente ou através do processo de secagem artificial, ocorre uma desorganização das membranas celulares, com as camadas lipídicas exibindo configuração hexagonal (SIMON, 1974). De acordo com este autor, níveis de água inferiores a $20 \%$ são considerados insuficientes para manter a configuração típica da camada dupla das membranas e, conseqüentemente, os fosfolipídeos arranjam-se em forma hexagonal. Entretanto, estudos realizados por McKERSIE \& STINSON (1980) indicaram que a configuração lamelar persiste em sementes com $5 \%$ de água.

Tem sido observado que quando sementes secas são colocadas em contacto com substrato úmido, ocorre uma rápida e intensa liberação de eletrólitos, que normalmente é seguida por uma fase em que a quantidade de solutos vai decrescendo a medida que os tecidos são reidratados, até atingir um estado de equilíbrio (SIMON \& RAJA-HARUN, 1972). Duas teorias foram propostas para explicar tal comportamento. A primeira, proposta por LARSON (1968), sugere a ocorrência de ruptura física e morte de algumas células da superficie cotiledonar no início do processo de entrada de água na semente. Este autor observou alta lixiviação inicial de embriões de ervilha, devido à ruptura de membranas celulares durante a rápida embebição. Esta teoria foi acatada por POWELL \& MATTHEWS (1978), que constataram maior liberação de eletrólitos, após 24 horas de embebição, em sementes de ervilha desprovidas de tegumento em relação a sementes intactas. Após a embebição, as sementes foram imersas em solução de tetrazólio, revelando que as células externas e as adjacentes do embrião das sementes sem tegumento não se coloriram. Outros trabalhos de POWELL \& MATTHEWS (1979, 1981) contribuíram para a confirmação desta teoria. A segunda teoria refere-se à reorganização do sistema de membranas das sementes secas durante a embebição (SIMON \& RAJA-HARUN,1972). 
Várias pesquisas têm sido conduzidas buscando esclarecer os principais aspectos envolvidos no processo de liberação de exsudatos pelas sementes durante a embebição. SIMON \& RAJA-HARUN (1972) observaram em embriões de ervilha, que a liberação de eletrólitos foi mais rápida durante os primeiros minutos de embebição, seguida por um lento declínio nos 30 minutos iniciais. Após 8 horas, a velocidade de lixiviação decresceu ocorrendo a completa embebição dos tecidos. Estes resultados permitiram inferir que, o plasmalema e tonoplasto das células perderam sua integridade quando as sementes foram secas $\mathrm{e}$ se reorganizaram durante o periodo de rápida liberação de exsudatos. Foi proposto, ainda, que as camadas de células externas contribuem mais para o total de material lixiviado do que as células de tecidos internos; assim, a maior distância necessária à difusão de materiais destas células contribui para evitar que a fase de rápida lixiviação seja continua.

Em trabalho com amendoim, ABDEL-SAMAD \& PEARCE (1978) verificaram que sementes com tegumento danificado liberaram mais eletrólitos totais, após 24 horas de imersão em água, do que sementes intactas; entretanto, a velocidade de absorção de água foi a mesma para ambas. Observaram ainda, que durante os primeiros 20 minutos de imersão, sementes sem tegumento liberaram 2,8 vezes mais solutos do que sementes intactas. Eles sugeriram, então, que este aumento na lixiviação não foi relacionado à velocidade de absorção de água, contrariando a proposta de LARSON (1968).

Por sua vez, CHING \& SCHOOLCRAFT (1968) em pesquisa com trevo carmezim e azevém perene confirmaram que o aumento no teor de eletrólitos na água de embebição estava diretamente relacionado com a degradação das membranas e perda do controle da permeabilidade. Esta teoria também tem sido aplicada às espécies de sementes sensiveis à desidratação, conforme dados de BECWAR et al. (1982). LIN (1990) em trabalho com sementes de soja, observou que o decréscimo na germinação e vigor foi diretamente proporcional ao aumento da lixiviação de solutos celulares, e que a degradação da membrana estava relacionada à redução dos fosfolipideos totais.

Dados obtidos por DUKE et al. (1983), sugeriram que a liberação de eletrólitos pelas sementes de soja em embebição é devida, em primeira instância, à difusão passiva, enquanto a difusão de macromoléculas intracelulares é dependente, fundamentalmente, de um fenômeno fisiológico afetando a integridade das membranas.

De acordo com ABDUL-BAKI (1980), durante a embebição, o sistema de membranas das sementes se reorganiza, readquirindo sua permeabilidade, e o ideal é que este processo ocorra no menor periodo possivel, para reduzir a ocorrência 
de misturas indesejáveis do conteúdo celular e a lixiviação comprometedora de eletrólitos. Portanto, é essa velocidade de reorganização do sistema de membranas que reflete o vigor da semente. WOODSTOCK (1973) considerou que a exsudação de constituintes celulares mostrou-se inversamente associada ao vigor, com base em três fatores: reflete a perda da integridade das membranas, representa a conseqüente perda de compartimentalização dos constituintes celulares e constitui excelente substrato para o desenvolvimento de microorganismos, acelerando o processo de deterioração.

Portanto, tem sido aceito que a integridade das membranas é incompleta durante, no mínimo, alguns minutos após a embebição; contudo, com o decorrer do tempo essa situação se altera, com a retomada natural de sua configuração mais estável ou através da restauração por algum mecanismo enzimático ainda não identificado perfeitamente. Em sementes mais deterioradas ou não viáveis, esses mecanismos de reparo estariam ausentes ou seriam ineficientes; ou ainda, as membranas estariam tão profundamente danificadas, que o reparo seria impossivel (BEWLEY \& BLACK, 1985).

Desse modo, a desestruturação e perda de integridade do sistema de membranas celulares, causadas principalmente pela oxidação de lipídios, promove o descontrole do metabolismo e das trocas de água e solutos entre as células e o meio exterior, com reflexos diretos sobre a qualidade fisiológica das sementes.

Tem sido observado que, por ocasião da embebição, as sementes liberam grande variedade de substâncias, tais como íons inorgânicos, açúcares, aminoácidos, enzimas, nucleosídeos e ácidos graxos (MATTHEWS \& BRADNOCK, 1967; CHING \& SCHOOLCRAFT, 1968; ABDUL-BAKI \& ANDERSON, 1972; HALLOIN, 1975; ABDEL SAMAD \& PEARCE, 1978; SUBRAHMANYAM et al., 1983 e WOODSTOCK, 1988). A quantidade e intensidade de material lixiviado estão diretamente relacionadas à permeabilidade das membranas e, conseqüentemente, são influenciadas pela idade da semente, pela sua condição fisiológica e também pela incidência de danificações (POWELL, 1986). Estes solutos com propriedades eletrolíticas apresentam carga elétrica podendo, então, ser detectados por um medidor de condutividade (condutivímetro).

Com base nestas considerações, a quantidade de eletrólitos liberados pelas sementes tem sido avaliada através da condutividade elétrica da solução de embebição, constituindo-se em importante método para avaliação da qualidade fisiológica das sementes (MAGUIRE, 1977; YAKLICH et al., 1979 e POWELL, 1986).

Alguns trabalhos têm relacionado condutividade elétrica e quantidade de carboidratos ou açúcares lixiviados durante a embebição das se- 
mentes (MATTHEWS \& WHITBREAD, 1968; TAKAYANAGI \& MURAKAMI, 1968 e YAKLICH \& ABDUL-BAKI, 1975). MATTHEWS \& CARVER (1971) mostraram regressão altamente significativa entre condutividade elétrica total e conteúdo de carboidratos solúveis e entre condutividade e conteúdo de aminoácidos na solução de embebição de sementes de ervilha. Entretanto, ABDUL-BAKI \& ANDERSON (1972) verificaram que a determinação da quantidade de açúcares liberados por sementes de cevada não foi um bom indicador da viabilidade das sementes.

\subsubsection{Teste de condutividade elétrica}

\section{a) Condutividade elétrica de massa}

$\mathrm{O}$ uso da condutividade elétrica para determinar a viabilidade das sementes, baseia-se no trabalho pioneiro de Osterhout $(1922)^{2}$ citado por ROSS (1986). Usando esta técnica, Fick \& Hibbard $(1925)^{3}$, citados por POWELL (1986), estudaram a relação entre viabilidade e condutividade elétrica em sementes de forrageiras; no entanto, o maior numero de pesquisas sobre o referido teste é relativamente recente.

Neste teste, a qualidade das sementes é avaliada através da sua imersão em água e medição da condutividade da solução de embebição, que indicará o nivel de qualidade do lote avaliado. Assim, baixos valores de condutividade (baixa lixiviação) indicam que as sementes apresentam alta qualidade, enquanto valores elevados, estão relacionados a sementes de qualidade inferior (WOODSTOCK, 1973).

Trata-se de um teste de vigor bastante promissor em termos de padronização, pois preenche alguns requisitos básicos relacionados por MATTHEWS \& POWELL (1981), dentre os quais destacam-se: fundamentar-se em base teórica consistente, proporcionar resultados reproduziveis e, muitas vezes, correlacionados com a emergência em campo além de envolver procedimento simples, de baixo custo e fornecer resultados com rapidez.

Segundo HEYDECKER (1969) e HEPBURN et al. (1984) o teste de condutividade tem se mostrado promissor para espécies de sementes graúdas como ervilha, feijão e soja, em várias partes do mundo. Pesquisas realizadas com diferentes espécies têm mostrado que o decréscimo na germinação e no vigor é

2 OSTERHOUT, W.J.V. Injury, recovery, and death, in relation to conductivity and permeability. J.B. Lippincott Co. at the Washington Square Press, Philadelphia, PA., 1922.

${ }^{3}$ FICK, G.L. \& HIBBARD, R.P. A method for determining seed viability by electrical conductivity measurements. Michigan Acad. Sci., Arts and Letters, 5: 95-103, 1925. 
diretamente proporcional ao aumento da lixiviação de solutos, indicando que a condutividade elétrica é um método eficiente para a avaliação do vigor. Dentre os trabalhos mais recentes destacam-se os de SCHOETTLE \& LEOPOLD (1984) com soja, GORECKI et al. (1985) com ervilha, MARCOS FILHO et al. $(1985,1990)$ e LOEFFLER et al. (1988) com soja, WOODSTOCK et al. (1985), FRAGA (1988), BRIGANTE (1988) e SANTOS (1993) com algodão e BRUGGINK et al. (1991) com milho.

Pelo exame da literatura, constatou-se que a maioria das pesquisas foi conduzida, inicialmente, com sementes de ervilha e, posteriormente, com soja, de forma que a metodologia desenvolvida para a obtenção de resultados consistentes foi proveniente de experimentos com estas duas espécies. Com o aumento do emprego deste teste a metodologia inicial, proposta por MATTHEWS \& BRADNOCK (1967) para sementes de ervilha, sofreu algumas modificações e foi posteriormente recomendada e publicada pela INTERNATIONAL SEED TESTING ASSOCIATION- ISTA (MATTHEWS \& POWELL, 1981) e pela ASSOCIATION OF OFFICIAL SEEDS ANALYSTS - AOSA (1983), cujos métodos diferem quanto ao número de sementes e volume de água utilizados.

O teste de condutividade elétrica é considerado promissor e interessante em termos de padronização. Contudo, estudos conduzidos pelo Comitê de Vigor da ISTA constataram variações nos resultados entre laboratórios devido a problemas de metodologia (PERRY, 1981). De fato, a pesquisa tem demonstrado que vários fatores podem afetar os resultados do teste, tais como: qualidade da água, temperatura e duração do período de embebição, grau de umidade e número de sementes testadas (BRADNOCK \& MATTHEWS, 1970; YAKLICH \& ABDUL-BAKI, 1975; TAO, 1978). BEDFORD (1974) acrescentou a estes fatores, o genótipo. Para ROWLAND \& GUSTA (1977), a liberação de eletrólitos de sementes de leguminosas resulta da interação de três fatores principais: cultivar, grau de umidade da semente e temperatura de embebição.

Este último parâmetro vem merecendo atenção especial por parte de alguns pesquisadores. Para MURPHY \& NOLAND (1982) o efeito da temperatura sobre a embebição e lixiviação pode estar relacionado com alterações na viscosidade da água interferindo tanto na quantidade como na velocidade de liberação dos exsudatos.

Muitas pesquisas têm sido conduzidas empregando o teste de condutividade para avaliação de injúria por embebição à baixa temperatura. Assim, SWAMY \& NARASIMHA REDDY (1977) constataram em sementes de amendoim 
embebidas a $10,20,30$ e $40^{\circ} \mathrm{C}$, um aumento na perda de solutos em temperaturas mais baixas, o que provavelmente está relacionado ao referido dano. Resultados semelhantes foram demonstrados por PERRY \& HARRISON (1970), SENARATNA \& McKERSIE (1983) e POWELL et al. (1986).

Por outro lado, tal relação não foi confirmada por BOCHICCHIO et al. (1991) com sementes de milho embebidas a $5^{\circ} \mathrm{C}$ e a $25^{\circ} \mathrm{C}$. MARBACH \& MAYER (1985) estudando o efeito destas temperaturas na condutividade de sementes de ervilha, obtiveram valores mais altos a $25^{\circ} \mathrm{C}$, embora a duração da lixiviação tenha sido maior a $5^{\circ} \mathrm{C}$. Por sua vez, GIVELBERG et al. (1984) em pesquisa com sementes de Maria pretinha (Solamum nigrum) observaram que a condutividade inicial, após 5 minutos de embebição, foi semelhante para todas as temperaturas estudadas; após uma hora, os efeitos das temperaturas começaram a se evidenciar e a condutividade total aumentou acentuadamente com a elevação da temperatura.

Dados obtidos por LOEFFLER et al. (1988) utilizando três temperaturas de embebição em soja $\left(15,20\right.$ e $\left.25^{\circ} \mathrm{C}\right)$ indicaram que quantidades semelhantes de eletrólitos foram liberados nas três temperaturas; no entanto, $5^{\circ} \mathrm{C}$ de alteração na temperatura da solução antes da avaliação, pode interferir significativamente nos resultados de condutividade elétrica. Dessa forma, recomendaram que a avaliação deve ser efetuada imediatamente após a retirada das amostras da câmara, o que pode ser obtido mediante a remoção gradual das amostras (8 a 10 recipientes de cada vez).

A duração do periodo de embebição das sementes tem efeito marcante na capacidade do teste distinguir diferenças de qualidade entre lotes. Neste sentido, MATTHEWS \& BRADNOCK (1968), avaliando a condutividade elétrica de sementes de ervilha, verificaram que periodos de embebição superiores a 24 horas não promoveram uma separação eficiente dos lotes quanto ao vigor, permitindo concluir que este periodo foi adequado para a avaliação da qualidade fisiológica das sementes. Os dados de LOEFFLER et al. (1988) também sugerem que, reduções no periodo de embebição podem ser associadas ao aumento da temperatura, em substituição ao periodo de 24 horas a $25^{\circ} \mathrm{C}$. Entretando, a duração do período de condicionamento deve ser precisa e as leituras devem ser efetuadas em curto intervalo de tempo, evitando-se alterações em função da variação da temperatura das amostras durante a avaliação.

A progressão da condutividade elétrica de embriões de ervilha durante 24 horas foi acompanhada por SIMON \& RAJA HARUN (1972). Os autores observaram que após 10 horas de embebição houve um declinio na condutividade que 
permaneceu constante até 24 horas. Em trabalho mais recente, BRUGGINK et al. (1991) avaliaram a liberação de exsudatos por sementes de milho envelhecidas artificialmente e observaram que o efeito do envelhecimento tornou-se aparente apenas 10-20 horas após o início da embebição. EDJE \& BURRIS (1970) foram capazes de distinguir diferentes níveis de qualidade através da condutividade avaliada após 4 horas de embebição a $25^{\circ} \mathrm{C}$, em sementes de soja envelhecidas artificialmente. Também YAKLICH et al. (1979) obtiveram sucesso na classificação de lotes de sementes de soja empregando este periodo de embebição.

LOEFFLER et al. (1988) estudaram o efeito de vários períodos de embebição na condutividade elétrica de sementes de soja e constataram que lotes com niveis extremos de vigor podem ser separados usando condutividade após 6 horas; entretanto, um período mais longo ( 18 a 24 horas) foi necessário para detectar diferenças menos acentuadas entre todos os lotes estudados, concordando, então, com as recomendações da ISTA (MATTHEWS \& POWELL, 1981) e da AOSA (1983). Também MARCOS FILHO et al. (1990) obtiveram resultados semelhantes com sementes de soja.

Assim, tradicionalmente, o teste de condutividade elétrica tem sido realizado com 24 horas de imersão, embora outros períodos de tempo tenham sido testados: 15 a 45 minutos (HALLOIN, 1975), 60 minutos (THOMAS, 1960), 4 horas (EDJE \& BURRIS, 1970 e YAKLICH et al., 1979). No caso especifico de sementes de amendoim, KEYS (1982) observou que a liberação de solutos ocorreu linearmente até as 16 horas de embebição, havendo um aumento acentuado a partir deste ponto, o que foi atribuído a possíveis fraturas na semente ou, até mesmo, morte de células. $\mathrm{O}$ autor considerou que o periodo de 24 horas foi muito longo para amendoim, sugerindo que avaliações de condutividade elétrica para esta espécie podem ser feitas após 60 a 180 minutos de embebição. Ao comparar estes resultados com os obtidos com soja e milho, verificou que sementes de soja liberaram maior quantidade exsudatos. Tal caracteristica é importante na definição do tamanho ideal da amostra, sendo sugerido para soja, 100 gramas por repetição e, para milho e amendoim, 200 gramas.

Resultados obtidos com sementes de feijão por BROUWER \& MULDER (1982) indicaram coeficientes de correlação de 0,78 entre condutividade avaliada após 24 horas e após 30 minutos de embebição e de 0,96 entre os períodos de 24 e 9 horas de embebição.

Diante destes resultados, torna-se interessante a condução de estudos mais conclusivos referentes à redução do periodo de duração 
do teste de condutividade elétrica, uma vez que a rapidez na obtenção das informações tem sido preconizada como fator fundamental para a dinamização dos programas de controle de qualidade interno exercidos pelas empresas de sementes.

Neste sentido, é importante considerar que a embebição das sementes obedece a um padrão trifásico (BEWLEY \& BLACK, 1985), onde a fase inicial do processo (fase I) constitui um fenômeno essencialmente fisico, podendo ser completada em uma ou duas horas nas sementes que armazenam reservas nos cotilédones, independentemente de sua condição fisiológica. A segunda etapa (fase II), 8 a 10 vezes mais longa que a anterior, envolve uma série de eventos metabólicos preparatórios para a emissão da raiz primária, marco do estabelecimento da fase III, representada pelo início visivel da germinação (CARVALHO \& NAKAGAWA, 1988). Portanto, considerando que a integridade de membranas tem reflexos diretos sobre a eficiência metabólica da fase II, o referido modelo representa um suporte para a busca de informações sobre a qualidade fisiológica das sementes durante as fases iniciais de embebição.

Por outro lado, o grau de umidade das sementes tem mostrado uma relação inversa com a condutividade (SIMON \& WIEBE, 1975; PARRISH \& LEOPOLD, 1977; TAO, 1978; HAMPTON et al., 1992). Sementes de soja com umidade inicial de 13, 15 e 19,5\% apresentaram valores semelhantes de condutividade; entretanto, houve aumento significativo nas leituras quando o conteúdo de água das sementes foi inferior a 8,8\%, o que levou TAO (1978) a sugerir a condução do teste com sementes com umidade superior a $13 \%$. Resultados semelhantes foram obtidos por LOEFLLER et al. (1988) também com soja, indicando que umidade inicial inferior a $11 \%$ contribuiu para o aumento da condutividade, enquanto pequenas diferenças ocorreram quando os niveis de umidade permaneceram entre 11 e $18 \%$. Estes autores mencionam que tal problema pode ser minimizado mediante a uniformização do conteúdo inicial de água das sementes, antes do início do teste, ou através do desenvolvimento de um fator de correção, que permita o ajuste das medidas de condutividade a um grau de umidade padrão.

A interferência do genótipo nas leituras de condutividade tem sido destacada por BEDFORD (1974) e CALIARI \& MARCOS FILHO (1990) em ervilha, TAO (1980) e FRATIN (1987) em milho, MAITI et al. (1985) em sorgo e KUO (1989) em soja. Este último autor, observou que o teste de condutividade se mostrou eficiente no monitoramento da permeabilidade do tegumento das sementes; tratase portanto, de um teste que pode ser empregado nos programas de melhoramento genético voltados para qualidade de semente. 
Com relação à qualidade da água empregada no teste TAO (1978) e LOEFFLER (1981), trabalhando com sementes de soja, verificaram que não houve diferenças significativas nas avaliações de condutividade tanto utilizando-se água deionizada como destilada.

Embora pouco estudados, a presença de patógenos associados às sementes e de tratamento fungicida também têm sido relacionados como parâmetros que podem interferir nos resultados de condutividade elétrica. LOEFFLER et al. (1988) não constataram aumento na condutividade de sementes de soja intactas com elevados níveis de Phomopsis sp. ou Cercospora kikuchii; entretanto, sementes danificadas e doentes exibiram alta liberação de eletrólitos. Com relação ao tratamento fungicida, os referidos autores concluíram que Captan-80, Arasan-50 e Vitavax 200 tiveram pequeno efeito nos resultados de condutividade, permitindo sugerir que a remoção do tratamento das sementes através de lavagens com metanol antes do teste, conforme recomendações da AOSA (1983) pode ser desnecessária, especialmente, para estes fungicidas testados. TAO (1980) após utilizar este procedimento para remover fungicidas em sementes de milho constatou alterações na classificação dos lotes quanto ao vigor.

Outro fator importante que pode afetar os resultados do teste de condutividade elétrica é o tamanho das sementes. Acréscimos significativos na condutividade (umhos) foram observados por TAO (1978), em sementes de soja, em função do aumento no tamanho das sementes. Porém, quando os resultados foram expressos com base no peso das sementes (umhos/cm/g) o efeito do tamanho praticamente desapareceu. LOEFFLER (1981) e HEPBURN et al. (1984) propuseram que os resultados do teste fossem expressos por unidade de peso das sementes contribuindo, assim, para a padronização e a comparação entre resultados obtidos em diferentes laboratórios. Recentemente, DESWAL \& SHEORAN (1993), considerando que a maioria dos estudos de condutividade elétrica têm sido realizados com espécies de sementes grandes, conduziram testes com sementes pequenas e observaram que a liberação de eletrólitos foi pouco expresiva. Os resultados indicaram claramente, que em exsudatos muito dilú́dos o sistema de massa não mostrou sensibilidade em termos de avaliação da qualidade fisiológica das sementes.

Por sua vez, HOY \& GAMBLE (1985) não constataram diferenças entre a condutividade de sementes de soja com alta e baixa densidade, embora tenham observado um aumento nas leituras de sementes de maior tamanho.

$O$ efeito do tamanho da amostra nas leituras de condutividade após 24 horas de embebição à $25^{\circ} \mathrm{C}$ foi avaliado por LOEFFLER (1981) em uma série de 
ensaios. $\mathrm{O}$ autor constatou que a condutividade aumentou de 16 para $1870 \mathrm{umhos} / \mathrm{cm}$ quando o número de sementes aumentou de 1 para $150 \mathrm{em} 75 \mathrm{ml}$ de água. Entretanto, quando a condutividade foi expressa em umhos/cm/g houve apenas uma pequena tendência de alterações nas leituras obtidas nas amostras, sugerindo que semelhantes concentrações de eletrólitos lixiviam de cada grama de semente, em um volume constante de água, independentemente do número de sementes presentes.

Experimentos conduzidos por LOEFFLER et al. (1988) para avaliar o efeito de diferentes níveis de vigor nos resultados de condutividade em amostras de 25, 50 e 100 sementes de soja indicaram menor variação entre as leituras quando foram empregadas 4 repetições de 50 ou mais sementes, em todos os niveis de vigor, especialmente para lotes de menor qualidade fisiológica.

Para HEYDECKER (1969) e HEPBURN et al. (1984) o teste de condutividade elétrica, por ser baseado na avaliação simultânea de uma amostra de sementes representativa de uma população, apresenta a desvantagem de não distinguir uma amostra contendo muitas sementes de alta qualidade e algumas mortas, de outra, apresentando apenas sementes de qualidade regular. Além disso, a presença de sementes danificadas pode originar avaliações incorretas. Para minimizar este problema, recomenda-se a escolha das sementes excluindo-se aquelas danificadas (BEDFORD, 1974; TAO, 1978 e 1980; AOSA, 1983 e MARCOS FILHO et al., 1987). De acordo com TAO (1978), a presença de duas sementes de soja apresentando danificações visuais em uma amostra de 25 sementes, promoveu aumentos significativos nas leituras de condutividade elétrica. Este fato levou o autor a sugerir a eliminação de sementes danificadas da amostra se sua proporção não for superior a 10\%. Tal procedimento, no entanto, é criticado por alguns pesquisadores. OLIVEIRA et al. (1984) afirmaram que, a remoção destas sementes, exclui do teste uma das principais causas de redução da emergência em campo e, para que o teste tenha valor prático e possa ser utilizado rotineiramente, elas deveriam ser incluídas na avaliação. Também LOEFFLER et al. (1988) consideraram impraticável e subjetivo identificar visualmente as sementes danificadas ou doentes e sugeriram a realização do teste a partir de sementes fisicamente puras. Neste caso, o tamanho da amostra deve ser maior, de forma a diluir os efeitos de eventuais sementes danificadas. Os referidos autores, em ensaio com 20 lotes de sementes de soja, constataram que com o aumento do número de sementes testadas de 25 para 50 por repetição houve redução nos coeficientes de variação do teste, de 19,0 para $9,8 \%$, respectivamente, mesmo sem a escolha prévia.

Por outro lado, FRATIN (1987) trabalhando com sementes de milho observou que a única vantagem da eliminação de sementes danificadas do teste, 
conforme sugestão de TAO (1980), deveu-se à redução dos coeficientes de variação, indicando menor variabilidade entre repetições, pois todos os tratamentos com ou sem escolha de sementes apresentaram concordância quanto à ordenação dos lotes em níveis de vigor.

Através do exame da literatura, observa-se que persistem algumas dificuldades quanto à padronização das variáveis envolvidas no teste de condutividade elétrica e que podem interferir na precisão dos resultados obtidos. Entretanto, nenhuma destas variáveis é incontrolável, permitindo assim, a possibilidade de se alcançar elevada padronização e uniformidade de resultados no referido teste. DIAS \& BARROS (1992), em trabalho de aferição de testes de vigor para sementes de feijão, afirmaram ser de grande importância o aperfeiçoamento da metodologia do teste de condutividade. As principais fontes de variação constatadas pelos autores foram: dificuldades na seleção das sementes íntegras, diferenças na condutividade elétrica da água utilizada para embebição das sementes, diferenças na temperatura da solução durante as avaliações e variações no diâmetro dos recipientes.

Considerando estes aspectos, a avaliação da condutividade elétrica das sementes pode ser realizada em sementes individuais, com o auxílio de aparelhos específicos para este fim.

\section{b) Condutividade elétrica individual}

Sabe-se que quando as sementes são imersas em água, ocorre a liberação de eletrólitos, criando uma solução capaz de conduzir corrente elétrica, proporcionalmente à sua concentração eletrolítica. Assim, de acordo com ABDUL-BAKI \& ANDERSON (1972), exsudatos altamente concentrados indicam desintegridade das membranas estando associados, portanto, com baixa viabilidade e vigor.

Com base nestas considerações foram desenvolvidos aparelhos capazes de monitorar o exsutado de sementes individuais, através da quantificação da intensidade de corrente elétrica (uA) que passa entre dois eletrodos imersos em cada exsudato (McDONALD Jr. \& WILSON, 1979).

Algumas pesquisas têm mostrado ser conveniente a utilização de aparelhos que analisam individualmente as sementes, particularmente o ASA-610, o ASA-220 e o ASAC-1000 (MCDONALD Jr. \& WILSON, 1979, 1980; MULLET \& WILKINSON, 1979; MIRANDA, 1981; STEERE, et al., 1981; RACHIDIAN \& LE DEUNFF, 1986; WANN, 1986; FURMAN et al., 1987; WILSON \& TRAWATHA, 1991; TYAGI, 1992 e WILSON et al. , 1992). 
MULLET \& WILKINSON (1979) avaliando a condutividade elétrica individual de sementes de ervilha e relacionando-a com germinação e crescimento de plântulas e de plantas, obtiveram resultados que permitiram a identificação de lotes de melhor desempenho quanto à velocidade de emergência e ao crescimento inicial de plântulas.

A distribuição das avaliações de condutividade também tem sido utilizada para selecionar um valor limite capaz de distinguir sementes viáveis das não viáveis e que possa ser utilizado para estimar a viabilidade de diferentes lotes. Neste sentido, McDONALD Jr. \& WILSON (1979) estudaram as principais variáveis que interferem nos resultados fornecidos pelo ASA-610, constatando que o desempenho do aparelho pode ser influenciado pela temperatura da água de embebição, pelo tamanho e grau de umidade das sementes, não sendo afetado pelo tratamento fungicida nas sementes. Observaram ainda, que o aparelho só foi eficiente para estimar a viabilidade de lotes apresentando mais de $80 \%$ e menos de $20 \%$ de germinação. Segundo estes autores, este fato pode ser atribuido ao valor do limite referencial entre sementes germináveis e não germináveis, estabelecido em $90 \mathrm{uA} / \mathrm{semente}$, conforme recomendações do fabricante. Assim, apesar de os resultados obtidos com o ASA-610 terem mostrado coeficiente de correlação positivo $(+0,96)$ com os de condutividade elétrica de massa, indicando que o aparelho foi eficiente no monitoramento dos eletrólitos liberados pelas sementes, os dados evidenciaram a necessidade de maiores estudos referentes à padronização de algumas variáveis, especialmente das intensidades de corrente elétrica (valores limite) mais adequadas para a determinação da viabilidade e vigor.

Neste sentido, SMITH \& VARVIL (1985) avaliaram o efeito de tratamento fungicida, de quatro valores limites e de temperaturas de embebição em sementes de algodão testadas através do ASA-610. Os resultados indicaram que, dos 25 fungicidas estudados, 20 não interferiram nas leituras realizadas após 19 horas de embebição e utilizando valor de partição de 55 uA; no caso de sementes deslintadas com ácido, as informações fornecidas pelo ASA não se correlacionaram com germinação.

Em trabalho com soja, McDONALD Jr. \& WILSON (1980) utilizaram sementes com diferentes niveis de danificação mecânica e envelhecidas artificialmente, mostrando que o ASA-610 detectou, de um modo geral, todas as alterações de viabilidade das sementes, quando comparadas ao teste de germinação, podendo ser útil em programas de controle de qualidade das empresas de sementes. Resultados semelhantes foram obtidos por STEERE et al. (1981) com sementes de soja, 
feijão e algodão. Por sua vez, RACHIDIAN \& LE DEUNFF (1986) avaliaram a germinação de sementes de ervilha com o ASA-610, observando maior lixiviação em sementes imaturas.

Para HERTER \& BURRIS (1989) a germinação de sementes de milho pode ser estimada através do ASA-610, embora os resultados tenham indicado que a avaliação é mais segura nos lotes de baixa qualidade do que naqueles de qualidade alta ou intermediária. Portanto, o método pode ser útil para o descarte de lotes de qualidade inferior.

Entretanto, HEPBURN et al. (1984) avaliando os possíveis problemas com a utilização rotineira do teste de condutividade individual, com sementes de soja e de ervilha, enfatizaram a necessidade da intensificação da pesquisa, uma vez que os resultados não possibilitaram uma separação eficiente dos lotes em diferentes níveis de vigor. Os autores observaram ainda, que cultivares de ervilha apresentando sementes grandes exibiram maiores valores de condutividade do que aqueles de sementes pequenas, sugerindo que a utilização de um único valor limite para diferentes cultivares pode não ser apropriado. Também HOPPER \& HINTON (1987) em dois ensaios com sementes de algodão, testadas através do ASA-610, obtiveram resultados pouco consistentes para a seleção de um único valor limite de separação indicando assim, dificuldades na avaliação da qualidade destas sementes através deste método.

Recentemente, o Comitê de Vigor da Associação Brasileira de Tecnologia de Sementes, no programa de aferição de testes de vigor para sementes de soja, em 1990, concluiu que o teste de condutividade elétrica (ASA), para viabilidade , com leitura em 90uA, apresentou reprodutibilidade, indicando a possibilidade de ser utilizado rotineiramente na avaliação da qualidade de sementes de soja (KRZYZANOWSKI \& MIRANDA, 1990).

Cabe ressaltar que, o sucesso no emprego dos testes de condutividade elétrica, tanto pelo sistema de massa como pelo individual depende, dentre outros fatores, das relações entre as informações provenientes do laboratório e o desempenho das sementes em campo, além da capacidade de diferenciar lotes quanto ao nível de vigor.

\section{c) Relações entre condutividade elétrica e emergência das plântulas em campo}

$\mathrm{O}$ teste de condutividade elétrica tem sido considerado por diversos pesquisadores como um eficiente indicador da emergência das plântulas em campo (MATTHEWS \& BRADNOCK, 1967; BRADNOCK , 1968 e MATTHEWS \& CARVER, 1971). 
BEDFORD (1974) analisou a condutividade de lotes comerciais de ervilha e de lotes colhidos manualmente e obteve diferenças acentuadas entre as amostras, além de uma separação eficiente em termos de niveis de vigor. Por sua vez, SCOTT \& CLOSE (1976) avaliaram 98 lotes de três cultivares de ervilha e chegaram a uma equação de "estimativa de emergência", composta pelos resultados de três testes de laboratório, sendo um deles o de condutividade elétrica. Por sua vez, MATTHEWS \& ROGERSON (1976), trabalhando com dois cultivares de sementes de ervilha, mostraram que os resultados de condutividade de apenas um cultivar foram correlacionados com a emergência das plântulas em campo.

A partir destes estudos iniciais com ervilha, vários trabalhos envolvendo condutividade elétrica têm sido realizados com diferentes espécies, buscando informações a respeito do vigor das sementes.

Para McDONALD Jr. et al. (1978) o teste de condutividade para soja e milho não foi eficiente na separação de lotes com diferenças de vigor. Entretanto, TAO (1980) obteve informações consistentes com o referido teste para estas duas espécies, salientando que para soja houve correlação com a emergência das plântulas em campo. Resultados semelhantes foram obtidos por YAKLICH et al. (1979) também com sementes de soja.

Por sua vez, OLIVEIRA et al. (1984) constataram que o teste de condutividade elétrica em sementes de soja foi um indicador mais eficiente da emergência das plântulas em campo do que o teste de germinação.

MARCOS FILHO et al. (1985) em pesquisa com sementes de soja colhidas em diferentes épocas e armazenadas em ambientes distintos, concluiram que o conjunto de informações proporcionadas pelos testes de germinação, envelhecimento artificial e condutividade elétrica foi eficiente para diferenciar niveis de qualidade fisiológica das sementes e estimar o potencial de emergência das plântulas em campo, com destaque para o teste de condutividade que permitiu a obtenção de informações mais precisas. Também BARROS (1988) realizando um estudo comparativo entre testes para avaliação da viabilidade e vigor de sementes de soja, ressaltou a eficiência da condutividade na identificação de lotes com diferentes niveis de qualidade e potencial de emergência em campo. Por sua vez, NASCIMENTO \& CICERO (1991), avaliando a qualidade fisiológica de sementes de ervilha submetidas a diferentes tratamentos fungicidas, constataram alterações no vigor durante o armazenamento através da condutividade.

WATERS Jr.\& BLANCHETTE (1983) trabalhando com sementes de milho doce revelaram que, os testes de condutividade de massa e individual 
apresentaram correlação com a emergência em campo, com certo destaque para a condutividade individual. Também com sementes de milho doce, TRACY \& JUVIK (1988) relataram que a condutividade elétrica foi negativamente correlacionada com porcentagem de emergência, peso de planta e uniformidade de estande. A combinação dos resultados dos testes de envelhecimento artificial e condutividade individual (ASA-610) foi eficiente para estimar o estado final de sementes desta espécie, conforme WILSON \& TRAWATHA (1991) e WILSON et al. (1992).

$\mathrm{O}$ teste de condutividade elétrica tem sido usado ainda para estudar a influência de outros fatores que afetam o desempenho das sementes. HADAVIZADEH \& GEORGE (1988) utilizaram o teste para determinar o efeito da adubação sobre o vigor de sementes de ervilha, enquanto VIEIRA et al. (1991; 1992) avaliaram o efeito do estresse hídrico na germinação e no vigor de sementes de soja.

Sementes de soja produzidas em quatro diferentes épocas de semeadura foram avaliadas através do teste de germinação, envelhecimento artificial e condutividade elétrica. Os resultados indicaram que sementes provenientes de semeaduras precoces apresentaram maior condutividade. Associando-se estes dados com aqueles obtidos no teste de germinação, verificou-se que valores abaixo de 70 umhos $/ \mathrm{cm} / \mathrm{g}$ foram relacionados com alta capacidade germinativa e de 80 umhos $/ \mathrm{cm} / \mathrm{g}$, com baixa germinação (BHÉRING et al., 1991). Resultados semelhantes foram obtidos por COSTA (1986). VIEIRA et al. (1991) encontraram valores de 48 a 52 umhos $/ \mathrm{cm} / \mathrm{g}$ para lotes de soja com alto vigor.

HEPBURN et al. (1984), utilizando avaliações da condutividade individual e de massa em sementes de soja e ervilha, evidenciaram que ocorreu uma sobreposição entre a condutividade de lotes de sementes com diferentes níveis de vigor, não possibilitando uma separação eficiente entre os mesmos. Verificaram ainda, que esta sobreposição foi menor nos estudos com sementes individuais.

Resultados obtidos por CALIARI \& MARCOS FILHO (1990) com sementes de ervilha, indicaram que o teste de condutividade apresentou eficiência variável com o cultivar avaliado, tanto na separação dos lotes quanto ao vigor como na relação com a emergência em campo. Por sua vez, DIAS \& BARROS (1992) em trabalho de aferição de testes de vigor em feijão verificaram que, o teste de condutividade pelo sistema de massa não conseguiu identificar os lotes de sementes de feijão com diferentes níveis de vigor, sendo necessários estudos específicos para esta espécie. 
Verifica-se, pelo exame da literatura, que os resultados até então obtidos com os testes de condutividade elétrica, pelo sistema de massa e individual, indicam a necessidade de estudos buscando o aperfeiçoamento de suas metodologias.

\subsubsection{Teste de lixiviação de potássio}

A concentração total de eletrólitos liberados pelas sementes durante a embebição tem sido avaliada indiretamente, principalmente através do teste de condutividade elétrica. Considerando que porção significativa desses eletrólitos é representada por vários ions inorgânicos, alguns estudos têm sido conduzidos visando determinar a liberação de cátions especificos pelas sementes, durante a embebição.

Assim, ABDEL SAMAD \& PEARCE (1978) constataram rápida liberação de $\mathrm{K}^{+} \mathrm{e}$ outros compostos na primeira hora de embebição de sementes de amendoim. Perdas de $\mathrm{Ca}^{++}, \mathrm{Mg}^{++}, \mathrm{Mn}^{++}, \mathrm{K}^{+}$e $\mathrm{Cl}^{-}$durante a embebição de sementes de repolho envelhecidas artificialmente foram medidas por LOOMIS \& SMITH (1980) enquanto outros estudos mediram $\mathrm{K}^{+}$e Na ${ }^{+}$liberados (McKERSIE \& STINSON, 1980). A quantidade de ions $\mathrm{Na}, \mathrm{K}, \mathrm{Ca}$ e $\mathrm{Mg}$ perdidos por sementes de Solanum nigrum expostas à alta temperatura durante a embebição foi determinada por GIVELBERG et al. (1984). GRANQVIST (1987) observaram lixiviação de $\mathrm{K}^{+}$, $\mathrm{Ca}^{++}, \mathrm{Mg}^{++}$e $\mathrm{Na}^{+}$em sementes de cenoura, com destaque para o $\mathrm{K}^{+}$.

OLIVEIRA (1990) constatou que alguns cultivares de soja apresentaram correlação significativa entre a perda de germinação e o efluxo de ions por sementes embebidas, com exceção do ion sódio. $\mathrm{O}$ autor quantificou a presença de $\mathrm{Ca}^{++}$, $\mathrm{Mg}^{++}, \mathrm{Na}^{+} \mathrm{e} \mathrm{K}^{+}$medidos no exsudato de sementes após 90 minutos de imersão em água deionizada a $28^{\circ} \mathrm{C}$.

Recentemente, LOTT et al. (1991) quantificaram o total de ions $\mathrm{K}, \mathrm{Mg}, \mathrm{Cl}, \mathrm{Ca}$ e $\mathrm{Mn}$ na água de embebição de sementes intactas ou em partes isoladas destas, em diversas espécies, dentre as quais, soja e ervilha. Os resultados indicaram que o potássio foi, de modo geral, o elemento liberado em maior quantidade enquanto o Mn foi o menos lixiviado.

Desse modo, dentre os ions estudados, o potássio tem merecido especial atenção por se tratar, segundo o exame da literatura, do principal íon em termos de quantidade lixiviada.

A quantidade de potássio liberado por sementes embebidas tem sido utiilizada como um indicador da integridade do sistema de membranas celu- 
lares, conforme trabalhos realizados por HALLOIN (1975), McKERSIE \& STINSON (1980), WOODSTOCK et al. (1985) e WEBES \& KARSSEN (1990).

Além disso, pesquisas têm sido conduzidas no sentido de obter informações sobre as principais mudanças que ocorrem durante a deterioração. LOOMIS \& SMITH (1980) observaram que, com o aumento do período de envelhecimento as sementes perderam maiores quantidades de $\mathrm{K}^{+}$e $\mathrm{Cl}^{-}$, destacando -se o primeiro elemento. A deterioração de sementes de algodão foi relacionada à liberação de íons, especialmente $\mathrm{K}, \mathrm{Mn}, \mathrm{Mg}$ e Ca, por WOODSTOCK et al. (1985). Por outro lado, a quantidade de potássio liberado foi utilizada para avaliar a eficiência do tratamento de condicionamento fisiológico ("priming") em sementes de feijão (PANDEY, 1989) e de alface (WEBES \& KARSSEN, 1990).

Neste contexto, a determinação da quantidade de potássio liberado pelas sementes após certo período de embebição, também vem sendo pesquisada como um índice rápido de avaliação do vigor de sementes de algumas espécies.

SIMON \& RAJA-HARUN (1972) em pesquisa com sementes de ervilha encontraram uma estreita relação entre os resultados de condutividade elétrica e quantidade de potássio liberado após 24 horas de embebição. Também HALLOIN (1975) verificando a perda de solutos em sementes de algodão, em função da permeabilidade de membranas, observou que a concentração de íons potássio liberados, determinada aos 60 minutos de embebição, também correspondeu à condutividade avaliada com 15 e 45 minutos. Por sua vez, MOSS \& MULLETT (1982) utilizaram a quantidade de potássio lixiviado por sementes de feijão, após embebição por 72 horas, como parâmetro indicativo do vigor. Já SREERAMULU (1983) trabalhando com sementes de Voandzeia subterranea (L.) Thouars encontrou alta correlação positiva entre perda de germinação e conteúdo de potássio nos exsudatos das sementes após 20 horas de embebição.

Com relação as sementes de soja, MARCOS FLHO et al. (1982) estudando as relações entre germinação, vigor e permeabilidade das membranas celulares durante a maturação das sementes, verificaram índices de correlação negativos e altamente significativos entre os dados de lixiviação de potássio e os de germinação e primeira contagem do teste de gerninação e envelhecimento artificial. Constataram ainda que, sementes colhidas em épocas subsequentes à da maturidade, exibiram acréscimos na taxa de lixiviação de potássio e reduções da qualidade fisiológica; a determinação do potássio liberado pelas sementes foi realizada após 90 minutos de embebição. Dessa forma, este teste de simples execução, forneceu informações suficientes para caracterizar a maturidade fisiológica das sementes. 
Por outro lado, MARCOS FILHO et al. (1984) relacionando os resultados obtidos de diferentes testes de vigor com a emergência das plântulas em campo, constataram que o teste de lixiviação de potássio não foi eficiente para detectar as diferenças de qualidade existentes entre os lotes estudados. Resultados semelhantes foram obtidos por BARROS (1988) que sugeriu, apesar da menor precisão das informações geradas pelo referido teste, a realização de pesquisas buscando estabelecer relações mais consistentes entre quantidade de potássio lixiviado e o grau de deterioração de sementes de soja.

Em pesquisa com sementes de algodão, WOODSTOCK et al. (1985) avaliando o processo de deterioração a que as sementes estão sujeitas no campo, antes da colheita, concluíram que as quantidades de elementos liberados durante a embebição das sementes, especialmente $\mathrm{K}^{+}$e $\mathrm{Ca}^{++}$, se constituiram em promissores indices para avaliação do vigor suplantando a concentração de eletrólitos totais.

Portanto, com base nos trabalhos discutidos nesta revisão, pode se considerar que a determinação do potássio lixiviado durante a embebição das sementes tem se mostrado como uma alternativa promissora para a obtenção de informações rápidas sobre a qualidade fisiológica das sementes. Contudo, é importante o desenvolvimento de uma metodologia definida e padronizada que permita a reprodutibilidade dos resultados.

A quantidade de ions $\mathrm{K}$ liberados por sementes embebidas tem sido determinada, principalmente, através de análises de ativação de neutrons (LOOMIS \& SMITH, 1980 e LOTT et al., 1991), de espectofotômetro de absorção atômica (GRANQVIST, 1987 e WOODSTOCK et al., 1985) e por meio do fotômetro de chama (ABDEL SAMAD \& PEARCE, 1978; SREERAMULU, 1983; GIVELBERG et al., 1984; MARCOS FILHO et al., 1982; 1984; BARROS, 1988 e PANDEY, 1989).

No entanto, as relações entre quantidade de sementes avaliadas e volume de água para embebição, temperatura e periodo de embebição têm sido variáveis, não havendo uma definição clara de metodologia, especialmente para sementes de feijão, ervilha e soja. MARCOS FILHO et al. (1984), em pesquisa com sementes de soja, propôs uma adaptação para o método desenvolvido por AMORIM (1978). Tal adaptação envolveu a utilização de amostras de $10 \mathrm{~g}$ de sementes imersas em $75 \mathrm{ml}$ de água destilada a $30^{\circ} \mathrm{C}$ por 90 minutos, de onde eram retiradas aliquotas para a determinação do $\mathrm{K}^{+}$liberado. BARROS (1988), por sua vez, basicamente utilizou este mesmo método, só que avaliando 100 sementes/repetição, pesadas com precisão de $0,01 \mathrm{~g}$. 
A falta de consistência nos resultados obtidos experimentalmente, mediante a adoção destas metodologias, abriu então, a possibilidade de serem conduzidos alguns estudos preliminares referentes as principais variáveis envolvidas no referido teste.

O desenvolvimento de testes de vigor capazes de fornecer resultados com rapidez e precisão é fator fundamental para a evolução da indústria brasileira de sementes e, neste contexto, o teste de lixiviação de potássio bem como os de condutividade elétrica (de massa e individual) apresentam grandes potencialidades. 


\section{MATERIAL E MÉTODOS}

O presente trabalho foi conduzido no Laboratório de Análise de Sementes e no campo experimental do Departamento de Agricultura da ESALQ/USP, em Piracicaba, SP, tendo sido realizado em duas etapas. A primeira etapa foi conduzida de abril a setembro de 1991, compreendendo quatro épocas de avaliações, exceto para os testes de lixiviação de potássio, que foram realizados em três épocas. A segunda etapa teve início em agosto de 1992, estendendo-se até dezembro do mesmo ano, compreendendo três épocas de avaliações.

\subsection{Sementes e cultivares}

Para a realização da pesquisa foram utilizadas sementes básicas de soja, dos cultivares IAC-8 e IAC-15, cada um representado por quatro lotes. Para a primeira etapa do experimento, trabalhou-se com sementes produzidas no ano agrícola de 1990/1991 pela empresa Comércio e Indústria de Sementes Brejeiro e pelo Instituto Agronômico de Campinas. As sementes utilizadas na segunda etapa da pesquisa foram provenientes da Coordenadoria de Assistência Técnica Integral (CATI), produzidas no ano agrícola de 1991/1992.

Após a recepção, os lotes foram homogeneizados utilizando-se divisor cônico (tipo Boerner) e, em seguida, foi realizada a avaliação do tamanho das sementes, com base na retenção em peneiras. Para tanto, foram tomadas duas amostras de $200 \mathrm{~g}$ de cada lote que foram submetidas a uma sequência de peneiras de chapas metálicas perfuradas com crivos oblongos, variando de $18 \times 3 / 4 "(7,14 \times 19,05 \mathrm{~mm})$ a $11 \times 3 / 4 "(4,37 \times 19,05 \mathrm{~mm})$, com intervalos de $1 \times 3 / 4 "(0,40 \times 19,05 \mathrm{~mm})$. Essa avaliação permitiu verificar a uniformidade dos lotes com relação ao tamanho das sementes. Foram utilizadas no experimento sementes de tamanho médio, com retenção entre as peneiras $16 \times 3 / 4 "(6,35 \times 19,05 \mathrm{~mm})$ e $12 \times 3 / 4 "(4,76 \times 19,05 \mathrm{~mm})$.

Em seguida, cada lote foi devidamente amostrado com a finali-

dade de se realizarem determinações preliminares que forneceram informações a respeito 
da qualidade inicial das sementes. Os resultados destas determinações encontram-se nas Tabelas 1 (etapa 1) e 2 (etapa 2). Examinado-se a Tabela 1, verifica-se que todos os lotes do cultivar IAC-8 apresentavam, por ocasião do início do experimento, elevada qualidade fisiológica. Entre os lotes do cultivar IAC-15, houve uma tendência para os lotes 1, 2 e 3 exibirem comportamento semelhante, sendo superiores ao lote 4 , em todos os testes conduzidos.

Pela Tabela 2 observa-se que, apesar das pequenas diferenças entre os lotes do cultivar IAC-8, houve uma leve tendência de superioridade do lote 1 enquanto o lote 3 mostrou desempenho inferior. Para o cultivar IAC-15, embora todos os lotes apresentassem elevada qualidade inicial, o teste de envelhecimento artificial indicou uma tendência de menor qualidade para o lote 3.

Após a realização dos testes iniciais, os lotes foram então divididos em divisor cônico, obtendo-se quatro subdivisões de cada lote, que colocadas individualmente em embalagens permeáveis (sacos de papel), constituíram as repetições.

Durante o período experimental, as sementes permaneceram armazenadas em condições normais de ambiente do Laboratório de Sementes da ESALQ/USP. A umidade das sementes variou entre 10,0 e $11,5 \%$ no decorrer do experimento.

Tabela 1. Dados médios da qualidade fisiológica inicial dos lotes de sementes dos cultivares IAC- 8 e IAC-15 empregados nas etapas 1 e 2. Piracicaba, 1991.

\begin{tabular}{lccccc}
\hline Cultivares & Lotes & $\begin{array}{c}\text { Germinação } \\
(\%)\end{array}$ & $\begin{array}{c}\text { a Contagem } \\
(\%)\end{array}$ & $\begin{array}{c}\text { Env. Artificial } \\
(\%)\end{array}$ & $\begin{array}{c}\text { Grau de } \\
\text { Umidade (\%) }\end{array}$ \\
\hline IAC-8 & 1 & 99 & 96 & 94 & 11,0 \\
& 2 & 95 & 92 & 94 & 10,7 \\
& 3 & 98 & 98 & 95 & 11,1 \\
& 4 & 98 & 92 & 94 & 10,8 \\
& & & & & \\
IAC-15 & 1 & 96 & 92 & 84 & 11,2 \\
& 2 & 94 & 91 & 85 & 10,9 \\
& 3 & 95 & 92 & 89 & 11,0 \\
& 4 & 88 & 83 & 79 & 10,7 \\
\hline
\end{tabular}


Tabela 3. Dados médios da qualidade fisiológica inicial dos lotes de sementes dos cultivares IAC-8 e IAC-15 empregados na etapa 2. Piracicaba, 1992.

\begin{tabular}{|c|c|c|c|c|c|c|c|}
\hline \multirow[b]{2}{*}{$\begin{array}{l}\text { Culti- } \\
\text { vares }\end{array}$} & \multirow[b]{2}{*}{ Lotes } & \multicolumn{6}{|c|}{ Parâmetros } \\
\hline & & $\begin{array}{l}\text { TG } 1 \\
(\%) \\
\end{array}$ & $\begin{array}{l}\mathrm{PC}^{2} \\
(\%)\end{array}$ & $\begin{array}{l}\mathrm{EA}^{3} \\
(\%)\end{array}$ & $\begin{array}{c}\mathrm{CE}^{4} \\
(\text { umhos } / \mathrm{cm} / \mathrm{g})\end{array}$ & $\begin{array}{l}E C^{5} \\
(\%) \\
\end{array}$ & $\begin{array}{r}\text { GU } \\
(\%) \\
\end{array}$ \\
\hline \multirow[t]{4}{*}{ IAC- 8} & 1 & 93 & 87 & 90 & 63,33 & 92 & 10,7 \\
\hline & 2 & 95 & 88 & 86 & 68,84 & 87 & 10,6 \\
\hline & 3 & 91 & 87 & 84 & 75,02 & 86 & 10,6 \\
\hline & 4 & 93 & 89 & 88 & 62,57 & 86 & 10,8 \\
\hline \multirow[t]{4}{*}{ IAC- 15} & 1 & 93 & 89 & 92 & 57,67 & 90 & 10,6 \\
\hline & 2 & 97 & 92 & 94 & 58,66 & 92 & 10,7 \\
\hline & 3 & 94 & 89 & 86 & 60,12 & 89 & 11,3 \\
\hline & 4 & 97 & 94 & 93 & 54,20 & 91 & 11,2 \\
\hline
\end{tabular}

1. Germinação

2. Primeira contagem de germinação

3. Envelhecimento artificial

4. Condutividade elétrica

5. Emergência das plântulas em campo

6. Grau de umidade 


\subsection{Estudo dos testes de condutividade elétrica e de lixiviação de potássio} (Etapa 1)

Foram conduzidos estudos específicos de condutividade elétrica, em quatro épocas de testes e de lixiviação de potássio, em três épocas, procurando-se verificar sua eficiência quanto à identificação de diferentes níveis de vigor dos lotes estudados. Durante esta etapa foram efetuados os testes descritos a seguir.

\subsubsection{Determinação do grau de umidade}

Efetuada em estufa a $105 \pm 3^{\circ} \mathrm{C}$ durante 24 horas, utilizando-se duas amostras para cada lote, segundo as prescrições das Regras para Análise de Sementes (BRASIL, 1980). Os resultados foram expressos em porcentagem média para cada lote.

\subsubsection{Germinação}

Realizado com 200 sementes (quatro sub-amostras de 50) para cada lote, semeadas em rolo de papel toalha tipo Germitest, umedecido com quantidade de água equivalente a 2,5 vezes o peso do substrato seco, e colocadas para germinar à temperatura de $30^{\circ} \mathrm{C}$. As contagens foram realizadas aos quatro e sete dias após a semeadura e, as avaliações, efetuadas segundo os critérios estabelecidos pelas Regras para Análise de Sementes (BRASIL, 1980). Os resultados foram expressos em porcentagem, com base no número médio de plântulas normais para cada lote.

\subsubsection{Primeira contagem de germinação}

Foi conduzido conjuntamente com o teste de germinação, consistindo do registro das porcentagens de plântulas normais encontradas na primeira contagem do referido teste, feita no quarto dia após a semeadura. Os resultados foram expressos em porcentagem média de plântulas normais por lote.

\subsubsection{Envelhecimento artificial}

Adotou-se a metodologia recomendada pelo Comitê de Vigor da ASSOCIATION OF OFFICIAL SEED ANALYSTS (AOSA, 1983) e complementada em MARCOS FILHO et al. (1987). 
As sementes foram colocadas em "gerbox" adaptado funcionando como compartimento individual (mini-câmara). Cada gerbox possui em seu interior uma bandeja de tela de alumínio, onde foi distribuida quantidade de sementes suficiente para formar uma única camada; no fundo de cada mini-câmara foram colocados $40 \mathrm{ml}$ de água $\mathrm{e}$, a seguir, as caixas gerbox foram mantidas em incubadora tipo BOD regulada a $41^{\circ} \mathrm{C}$ por 48 horas. Decorrido este periodo, 200 sementes /lote, em quatro sub-amostras de 50 sementes, foram colocadas para germinar conforme método descrito em 3.2.2. A avaliação foi realizada aos quatro dias após a semeadura, computando-se a porcentagem média de plântulas normais por lote.

\subsubsection{Condutividade elétrica de massa - CE I}

Para esta avaliação foi adotada a metodologia proposta pelo Comitê de Vigor da AOSA (AOSA, 1983) e relatada por MARCOS FILHO et al. (1987). Quatro sub-amostras de 25 sementes para cada lote, previamente escolhidas para remoção daquelas com tegumento danificado, foram pesadas com precisão de $0,01 \mathrm{~g}$ e colocadas em copos plásticos ( $6 \mathrm{~cm}$ de base) contendo $75 \mathrm{ml}$ de água destilada. Em seguida, foram levadas para um germinador regulado à temperatura constante de $20^{\circ} \mathrm{C}$, onde permaneceram por diferentes períodos de embebição, a saber: 4, 8, 12, 16, 20 e 24 horas. Decorridos cada um desses periodos, a condutividade elétrica da solução foi determinada através de leitura em condutivimetro Digimed CD-20 e os valores médios obtidos para cada lote foram expressos em umhos $/ \mathrm{cm} / \mathrm{g}$ de semente.

\subsubsection{Condutividade elétrica de massa - CE 11}

Seguiu-se o procedimento alternativo ao método sugerido pela AOSA (AOSA, 1983) descrito por LOEFFLER et al. (1988). Quatro sub-amostras de 50 sementes, provenientes da porção de sementes fisicamente puras e pesadas com precisão de $0,01 \mathrm{~g}$ foram colocadas em copos plásticos ( $6 \mathrm{~cm}$ de base) contendo $75 \mathrm{ml}$ de água destilada; as amostras permaneceram em germinador a $25^{\circ} \mathrm{C}$ por periodos de tempo de 4 , $8,12,16,20$ e 24 horas. Decorridos cada um destes períodos, a condutividade elétrica das soluções foi determinada conforme descrito no item anterior (3.2.5.).

\subsubsection{Condutividade elétrica individual}

Para este teste foi utilizado um analisador de sementes automático-eletrônico, modelo ASA-610, que mede a condutividade elétrica do exsudato de cada semente, estimando indiretamente a sua qualidade fisiológica. Adotaram-se os 
procedimentos recomendados pelo manual do equipamento (AGROSCIENCES, 1979) e a metodologia descrita por McDONALD Jr. \& WILSON (1979).

Foram utilizadas quatro sub-amostras de 100 sementes para cada lote, oriundas da porção de sementes puras, colocando-se uma semente em cada uma das 100 células da bandeja plástica que acompanha o equipamento, adicionando-se água destilada até equalização com o prato nivelador. Em seguida, as bandejas foram colocadas em germinador a $20^{\circ} \mathrm{C}$ por período de $4,8,12,16,20$ e 24 horas. Decorridos estes períodos, avaliou-se a condutividade individual empregando-se o ASA-610. Para tanto, uma placa contendo 100 pares de eletrodos foi colocada sobre a bandeja de embebição, de forma que cada par permanecesse imerso no exsudato de cada semente. Foram testadas então, intensidades de corrente elétrica (valores limites) de 95 a 45uA/semente, em intervalos de 5uA. Os valores limites são pontos teóricos arbitrários que classificam cada semente, em função do nível de corrente elétrica apresentado pelo seu exsudato, nas categorias viável ou não viável e vigorosa ou não vigorosa.

O potencial fisiológico de cada lote foi representado, portanto, pelo número de sementes cujos exsudatos apresentaram corrente elétrica inferior aos valores limite pré-estabelecidos. Tal informação foi obtida através da leitura feita diretamente no painel digital do analisador, cuja escala de seleção (sensibilidade), siutada na parte traseira do equipamento, foi mantida na posição 1 . Os resultados médios de cada lote foram expressos em porcentagem.

\subsubsection{Lixiviação de potássio - Kl e KII}

Foi adotada a metodologia desenvolvida por AMORIM (1978) e adaptada por MARCOS FILHO et al. $(1982,1984)$ com a finalidade de averiguar a quantidade de potássio liberado pelas sementes durante o processo de embebição.

Foram utilizadas amostras de 200 sementes de cada lote, sendo quatro sub-amostras de 25 sementes previamente escolhidas para remoção daquelas danificadas (KI) e quatro sub-amostras de 25 , oriundas da porção de sementes puras (KII), pesadas com precisão de $0,01 \mathrm{~g}$. As sementes foram colocadas em copos plásticos ( $6 \mathrm{~cm}$ de base) contendo $75 \mathrm{ml}$ de água destilada e mantidas à temperatura constante de $30^{\circ} \mathrm{C}$, em germinador, por períodos de $60,90,120$ e 150 minutos, sendo os copos agitados no início e no final destes períodos. Após cada período, foram retiradas alíquotas de $5 \mathrm{ml}$ para a determinação do potássio lixiviado em fotômetro de chama, marca Digimed NK-2004.

Os resultados obtidos foram expressos em ppm de potássio/g de semente, correspondendo a valores médios/lote. 


\subsection{Comparação entre métodos para avaliação da qualidade fisiológica das sementes (Etapa 2)}

Os resultados considerados promissores referentes aos estudos de condutividade elétrica e de lixiviação de potássio obtidos na primeira etapa, ou seja, os procedimentos que forneceram indicações precisas a respeito do vigor das sementes foram, então, avaliados comparativamente em relação a outros testes de vigor, constituindo a segunda etapa do experimento.

As avaliações foram conduzidas em três épocas de testes ( de agosto a dezembro de 1992) que encontram-se relacionados a seguir.

\subsubsection{Determinação do grau de umidade}

Foi realizado de acordo com o procedimento descrito no item 3.2.1.

\subsubsection{Identificação de sementes com danos mecânicos}

Duas amostras de 100 sementes de cada lote foram colocadas em copos plásticos e cobertas com água, permanecendo em embebição por cinco minutos. Em seguida, eliminou-se o excesso de água, sendo cada amostra distribuida sobre folha de papel toalha para a contagem do numero de sementes intumescidas (danificadas), conforme metodologia descrita por MARCOS FILHO et al. (1987). Os resultados foram expressos em porcentagem média por lote.

\subsubsection{Germinação}

Os testes de germinação foram conduzidos conforme a metodologia descrita no item 3.2.2.

\subsubsection{Primeira contagem do teste de germinação}

Realizado conforme descrição feita em 3.2.3.

\subsubsection{Envelhecimento artificial}

Adotou-se procedimento idêntico ao descrito no ítem 3.2.4.

\subsubsection{Tetrazólio}

Para este teste foram utilizadas quatro repetições de 50 sementes por lote, as quais foram précondicionadas em papel toalha suficientemente umedecido, em germinador a $30^{\circ} \mathrm{C}$ por 16 horas. Decorrido este periodo, as sementes foram 
transferidas para copinhos plásticos, imersas em solução $0,075 \%$ de sal de tetrazólio (cloreto 2, 3, 5 - trifenil tetrazólio) e mantidas durante quatro horas no interior de uma estufa a $40^{\circ} \mathrm{C}$.

Após o desenvolvimento da coloração, as sementes foram então lavadas em água corrente e avaliadas individualmente segundo os critérios de interpretação propostos por FRANÇA NETO et al. (1988). Foram computadas as porcentagens de sementes viáveis (TZ 1-5) e de sementes vigorosas (TZ 1-3) para cada amostra e os resultados expressos em porcentagem média por lote.

\subsubsection{Condutividade elétrica de massa - CE I}

Seguiu-se a metodologia descrita no item 3.2.5. alterando-se apenas a duração dos períodos de embebição para 8, 12, 16, 20 e 24 horas.

\subsubsection{Condutividade elétrica de massa - CE II}

Adotou-se o mesmo procedimento descrito em 3.2.6. testando-se os seguintes periodos de embebição: $8,12,16,20$ e 24 horas.

\subsubsection{Condutividade elétrica individual}

Esta avaliação foi realizada conforme o método descrito no item 3.2.7., embora com algumas alterações. Em função dos resultados obtidos na primeira etapa, foram testados os valores limite de $90,80,70,60,55,50$ e $45 \mathrm{uA}$ e os períodos de embebição de 8, 12, 16, 20 e 24 horas.

\subsubsection{Lixiviação de potássio - KI e KII}

Os procedimentos empregados neste teste encontram-se descritos em 3.2.8. Entretanto, nesta segunda etapa, as sementes permaneceram em embebição durante 60,90 e 120 minutos.

\subsubsection{Classificação do vigor de plântulas}

A metodologia adotada para este teste foi recomendada pelo Comitê de Vigor da AOSA (1983) e relatada por MARCOS FILHO et al. (1987). Esta avaliação foi conduzida conjuntamente com o teste de germinação descrito em 3.2.2., classificando-se as plântulas em "normais fortes" e "normais fracas"; na data prevista para a primeira contagem foram removidas todas as plântulas que se apresentaram desenvolvidas e morfologicamente perfeitas, sem rachaduras ou lesões, computadas como "normais fortes". Na contagem final, todas as plântulas normais remanescentes foram 
classificadas como "fortes" ou "fracas", sendo estas as que apresentaram qualquer problema referente à sua estrutura ou lesões que não caracterizassem anormalidade da plântula. Os resultados foram expressos em de porcentagem média de plântulas "normais fortes" por lote.

\subsubsection{Emergência das plântulas em campo}

A avaliação da emergência das plântulas em campo foi realizada com 200 sementes por lote. Cada repetição de 50 sementes foi distribuída em um sulco de $2,0 \mathrm{~m}$ de comprimento, com $0,05 \mathrm{~m}$ de profundidade e cobertas com, aproximadamente, $0,02 \mathrm{~m}$ de solo. A distância entre sulcos foi de $0,30 \mathrm{~m}$ e a semeadura realizada em solo considerado suficientemente úmido.

As contagens foram efetuadas aos 21 dias após a semeadura, determinando-se a porcentagem de plântulas emersas; foram computadas as plântulas que atingiram o estádio VC, ou seja, com os cotilédones acima da superficie do solo e com folhas unifoliadas com as margens não mais se tocando, de acordo com a caracterização realizada por COSTA \& MARCHEZAN (1982). As datas de semeadura foram as seguintes: 02/09/92, 05/1 1/92 e 14/12/92.

\subsection{Procedimento estatístico}

Os dados provenientes dos testes de germinação, primeira contagem de germinação, envelhecimento artificial, tetrazólio, classificação do vigor de plântulas, emergência em campo e condutividade elétrica individual foram transformados em $\operatorname{arcsen} \sqrt{x / 100}$, enquanto os de condutividade elétrica de massa e de lixiviação de potássio não sofreram transformações. Os dados correspondentes à identificação de danos mecânicos e determinação do grau de umidade das sementes não foram analisados estatisticamente; sua interpretação foi relacionada apenas aos aspectos biológicos.

As análises de variância foram realizadas separadamente para cada cultivar e teste conduzido, nas duas etapas; os testes de germinação, primeira contagem, tetrazólio, envelhecimento artificial, classificação do vigor de plântulas e emergência em campo foram analisados segundo delineamento em blocos inteiramente casualizados, sendo que as épocas constituíram os blocos, com quatro repetições. Os testes de condutividade elétrica e lixiviaçào de potássio seguiram o mesmo delineamento anterior, sendo cada período de embebição analisado separadamente. Especificamente para os testes com o ASA-610, foram realizadas análises de variância para cada valor limite testado. 
Os esquemas das análises de variância são apresentados nas Tabelas 3 e 4 . A comparação múltipla de médias foi realizada através do teste de Tukey ao nível de $5 \%$ de probabilidade. Posteriormente, foram calculados os coeficientes de correlação simples (r) para todas as combinações entre os testes estudados na segunda etapa; a significância dos valores de $r$ foi determinada pelo teste $t$, aos níveis de 5 e $1 \%$ de probabilidade.

Os cálculos estatísticos foram realizados através do Sistema de Análise Estatística - SANEST para micro-computadores (ZONTA et al., 1984).

Tabela 3. Esquema da análise de variância dos dados obtidos nos testes de laboratório, para cada cultivar, período de embebição e valor limite estudados na etapa 1 . Piracicaba, 1991.

\begin{tabular}{lc}
\hline Causas de Variação & Graus de Liberdade \\
\hline Lotes (L) & 3 \\
Épocas (E) & 3 \\
Interação (LxE) & 9 \\
Resíduo & 48 \\
\hline Total & 63 \\
\hline
\end{tabular}

Tabela 4. Esquema da análise de variância dos dados obtidos nos testes de laboratório e de campo, para cada cultivar, período de embebição e valor limite estudados na etapa 2, e para os testes de lixiviação de potássio, na etapa 1. Piracicaba, 1991.

\begin{tabular}{lc}
\hline Causas de Variação & Graus de Liberdade \\
\hline Lotes (L) & 3 \\
Épocas (E) & 2 \\
Interação (LxE) & 6 \\
Resíduo & 36 \\
\hline Total & 47 \\
\hline
\end{tabular}




\section{RESULTADOS E DISCUSSÃO}

No presente capítulo serão discutidos os resultados referentes aos testes empregados para a avalią̧ão da qualidade fisiológica de sementes de soja, para cada etapa e cultivar.

\subsection{Etapa 1}

\subsubsection{Cultivar IAC-8}

Examinando-se os valores de $\mathrm{F}$ obtidos nas análises de variância (Tabela 5), verifica-se que ocorreram efeitos significativos para lotes e épocas para praticamente todos os parâmetros estudados, ao contrário da interação lotes $\mathrm{x}$ épocas que mostrou-se altamente significativa apenas nos testes de condutividade elétrica de massa (CE I) no periodo de 24 horas e de lixiviação de potássio (KI) realizados aos $60 \mathrm{e}$ 90 minutos de embebição.

Para o teste de condutividade individual (Tabela 6), de modo geral, os efeitos significativos de lotes, épocas e da interação lotes $x$ épocas ocorreram principalmente nos limites inferiores à $90 \mathrm{uA}$, para a maioria dos períodos de embebição estudados. Assim, a redução das intensidades de corrente elétrica contribuiu para uma maior sensibilidade do teste em termos de identificação de diferenças entre a qualidade fisiológica dos lotes e entre as épocas de avaliação.

Com relação as análises estatísticas dos dados referentes aos testes para avaliação da qualidade fisiológica das sementes (Tabela 7), observou-se valores de $\mathrm{F}$ altamente significativos para efeitos de lotes e épocas em todos os parâmetros, enquanto a interação lotes $x$ épocas revelou significância apenas no teste de primeira contagem de germinação. 
Tabela 5. Valores de F obtidos nas análises de variância dos dados referentes aos testes de condutividade elétrica (CE I e CE II) e de lixiviação de potássio (KI e KII), para os lotes de sementes de soja, cultivar IAC- 8. Piracicaba, 1991.

\begin{tabular}{lrcc}
\hline \multirow{2}{*}{ Testes } & \multicolumn{3}{c}{ Valores de F } \\
\cline { 2 - 4 } & Lotes (L) & Épocas (E) & Interação (L x E) \\
\hline CE I - 4 h & $20,23^{* *}$ & $7,37^{* *}$ & $0,84^{\mathrm{ns}}$ \\
CE I - 8 h & $11,51^{* *}$ & $4,24^{* *}$ & $0,59^{\mathrm{ns}}$ \\
CE I - 12 h & $7,82^{* *}$ & $12,68^{* *}$ & $0,75^{\mathrm{ns}}$ \\
CE I - 16 h & $6,38^{* *}$ & $18,63^{* *}$ & $0,80^{\mathrm{ns}}$ \\
CE I - 20 h & $5,38^{* *}$ & $13,82^{* *}$ & $0,81^{\mathrm{ns}}$ \\
CE I - 24 h & $6,01^{* *}$ & $14,03^{* *}$ & $2,33^{*}$ \\
CE II - 4 h & $5,96^{* *}$ & $3,97^{*}$ & $1,54^{\mathrm{ns}}$ \\
CE II - 8 h & $5,77^{* *}$ & $3,19^{*}$ & $1,84^{\mathrm{ns}}$ \\
CE II - 12 h & $20,32^{* *}$ & $1,46^{\mathrm{ns}}$ & $1,62^{\mathrm{ns}}$ \\
CE II - 16 h & $16,27^{* *}$ & $6,63^{* *}$ & $1,76^{\mathrm{ns}}$ \\
CE II - 20 h & $18,85^{* *}$ & $0,68^{\mathrm{ns}}$ & $1,05^{\mathrm{ns}}$ \\
CE II - 24 h & $10,84^{* *}$ & $6,50^{* *}$ & $1,66^{\mathrm{ns}}$ \\
K I - 60 minutos & $5,25^{* *}$ & $36,47^{* *}$ & $2,86^{*}$ \\
K I - 90 minutos & $29,67^{* *}$ & $52,31^{* *}$ & $3,92^{* *}$ \\
K I - 120 minutos & $20,69^{* *}$ & $42,08^{* *}$ & $0,93^{\mathrm{ns}}$ \\
K I - 150 minutos & $18,88^{* *}$ & $37,52^{* *}$ & $1,45^{\mathrm{ns}}$ \\
K II - 60 minutos & $8,82^{* *}$ & $160,15^{* *}$ & $0,90^{\mathrm{ns}}$ \\
K II - 90 minutos & $26,10^{* *}$ & $111,94^{* *}$ & $0,88^{\mathrm{ns}}$ \\
K II - 120 minutos & $27,13^{* *}$ & $98,71^{* *}$ & $0,74^{\mathrm{ns}}$ \\
K II - 150 minutos & $30,86^{* *}$ & $118,60^{* *}$ & $0,19^{\mathrm{ns}}$ \\
\hline & & &
\end{tabular}

* - significativo ao nível de $5 \%$ de probabilidade.

** - significativo ao nível de $1 \%$ de probabilidade.

ns - não significativo. 
Tabela 6- Valores de F obtidos nas análises de variância dos dados referentes aos testes de condutividade elétrica individual (ASA-610), para os lotes do cultivar IAC8. Piracicaba, 1992.

\begin{tabular}{|c|c|c|c|}
\hline \multirow[t]{2}{*}{ Testes } & \multicolumn{3}{|c|}{ Valores de F } \\
\hline & Lotes (L) & Epocas (E) & Interação $(\mathrm{L} \times \mathrm{E})$ \\
\hline ASA $95-4 h$ & $1,89^{n s}$ & $0,54^{\mathrm{ns}}$ & $1,44^{\mathrm{ns}}$ \\
\hline ASA $95-8 h$ & $2,83^{*}$ & $1,58^{\mathrm{ns}}$ & $0,88^{n s}$ \\
\hline ASA $95-12 \mathrm{~h}$ & $0,64^{\mathrm{ns}}$ & $0,78^{\mathrm{ns}}$ & $3,00^{\mathrm{ns}}$ \\
\hline ASA $95-16 \mathrm{~h}$ & $1,74^{\mathrm{ns}}$ & $1,86^{\mathrm{nS}}$ & $4,09^{n s}$ \\
\hline ASA $95-20 \mathrm{~h}$ & $1,31^{\mathrm{ns}}$ & $1,30^{\mathrm{ns}}$ & $4,52^{\mathrm{ns}}$ \\
\hline ASA $95-24 \mathrm{~h}$ & $3,34 *$ & $8,29 * *$ & $6,96 * *$ \\
\hline ASA $90-4 h$ & $4,71 * *$ & $0,82^{\mathrm{ns}}$ & $0,38^{\mathrm{nS}}$ \\
\hline ASA $90-8 h$ & $3,90 *$ & $1,68^{n s}$ & $0,79^{\mathrm{ns}}$ \\
\hline ASA $90-12 \mathrm{~h}$ & $1,13^{\mathrm{ns}}$ & $1,44^{\text {ns }}$ & $1,53^{\mathrm{ns}}$ \\
\hline ASA $90-16 \mathrm{~h}$ & $1,27^{\mathrm{ns}}$ & $2,12^{\mathrm{nS}}$ & $3,71 * *$ \\
\hline ASA $90-20 \mathrm{~h}$ & $1,90^{\mathrm{ns}}$ & $2,26^{\mathrm{ns}}$ & $5,70^{* *}$ \\
\hline ASA $90-24 h$ & $3,06 *$ & $8,01^{* *}$ & $6,90 * *$ \\
\hline ASA $85-4 h$ & $6,18^{* *}$ & $0,54^{\mathrm{ns}}$ & $1,30^{\mathrm{ns}}$ \\
\hline ASA $85-\quad 8 h$ & $3,15^{*}$ & $1,76^{\mathrm{ns}}$ & $0,51^{\text {ns }}$ \\
\hline ASA $85-12 \mathrm{~h}$ & $1,97^{\mathrm{ns}}$ & $2,87^{*}$ & $3,70 * *$ \\
\hline ASA $85-16 h$ & $3,25^{*}$ & $5,00 * *$ & $5,45^{* *}$ \\
\hline ASA $85-20 h$ & $3,97 *$ & $4,55^{* *}$ & $6,74^{* *}$ \\
\hline A SA $85-24 h$ & $4,35^{* *}$ & $7,85 * *$ & $7,23 * *$ \\
\hline ASA $80-4 h$ & $4,24^{* *}$ & $0,78^{\mathrm{ns}}$ & $1,30^{\text {ns }}$ \\
\hline ASA $80-\quad 8 h$ & $3,29 *$ & $2,04^{\mathrm{nS}}$ & $0,91^{\text {ns }}$ \\
\hline ASA $80-12 h$ & $2,80^{*}$ & $3,78^{*}$ & $3,46 * *$ \\
\hline ASA $80-16 h$ & $5,19 * *$ & $6,75 * *$ & $5,34 * *$ \\
\hline ASA $80-20 \mathrm{~h}$ & $4,24 * *$ & $6,47 * *$ & $6,66 * *$ \\
\hline ASA $80-24 h$ & $6,10^{* *}$ & $18,87^{* *}$ & $8,03 * *$ \\
\hline ASA $75-4 h$ & $2,83^{*}$ & $0,27^{\text {ns }}$ & $183^{\mathrm{ns}}$ \\
\hline ASA $75-8 h$ & $2,31^{\text {ns }}$ & $0,97^{\mathrm{ns}}$ & $1,25^{\mathrm{ns}}$ \\
\hline ASA $75-12 \mathrm{~h}$ & $3,58^{*}$ & $4,26 * *$ & $5,24 * *$ \\
\hline ASA $75-16 h$ & $7,41^{* *}$ & $11,90 * *$ & $6,40^{* *}$ \\
\hline ASA $75-20 \mathrm{~h}$ & $5,52 * *$ & $6,70 * *$ & $\begin{array}{l}6,40^{* *} \\
5,14^{* *}\end{array}$ \\
\hline ASA $75-24 h$ & $5,26 * *$ & $15,34 * *$ & $\begin{array}{l}5,14 * * \\
5,08 * *\end{array}$ \\
\hline ASA $70-4 h$ & $349 *$ & $0,41^{n S}$ & $\begin{array}{l}5,08 * * \\
197 \mathrm{~ns}\end{array}$ \\
\hline ASA $70-8 h$ & $\begin{array}{l}3,49^{*} \\
2,70^{n s}\end{array}$ & $0,64^{\mathrm{ns}}$ & $1,92^{\mathrm{ns}}$ \\
\hline ASA $70-12 \mathrm{~h}$ & $2,70^{\text {ns }}$ & $6,32 * *$ & $2,37^{*}$ \\
\hline ASA $70-16 h$ & $4,95 * *$ & & $4,34 * *$ \\
\hline ASA $70-20 h$ & $9,47 * *$ & $\begin{array}{l}18,59 * * \\
10,70 * *\end{array}$ & $7,42 * *$ \\
\hline ASA $70-24 h$ & $5,05^{* *}$ & $10,70^{* *}$ & $7,05^{* *}$ \\
\hline ASA $65-4 h$ & $6,34^{* *}$ & $24,26 * *$ & $5,52 * *$ \\
\hline ASA $65-8 h$ & $5,56^{* *}$ & $0,40^{\mathrm{ns}}$ & $2,49 * *$ \\
\hline ASA $65-12 \mathrm{~h}$ & $4,89^{* *}$ & $1,87^{\text {ns }}$ & $3,17^{* *}$ \\
\hline $\begin{array}{l}\text { ASA 65-12h } \\
\text { ASA } 65-16 h\end{array}$ & $5,85^{* *}$ & $10,30^{* *}$ & $5,14 * *$ \\
\hline $\begin{array}{l}\text { ASA } 65-16 \mathrm{~h} \\
\text { ASA } 65-20 \mathrm{~h}\end{array}$ & $11,52 * *$ & $25,83^{* *}$ & $8,79 * *$ \\
\hline $\begin{array}{l}\text { ASA } 65-20 h \\
\text { ASA } 65-24 h\end{array}$ & $6,23 * *$ & $8,59 * *$ & $4,75^{* *}$ \\
\hline ASA $65-24 h$ & $10,35^{* *}$ & $23,55 * *$ & $4,74 * *$ \\
\hline
\end{tabular}


continuação

Tabela 6- Valores de F obtidos nas análises de variância dos dados referentes aos testes de condutividade elétrica individual (ASA-610), para os lotes do cultivar IAC8. Piracicaba, 1992.

\begin{tabular}{|c|c|c|c|}
\hline \multirow[t]{2}{*}{ Testes } & \multicolumn{3}{|c|}{ Valores de F } \\
\hline & Lotes $(\mathrm{L})$ & Épocas (E) & Interação (LX E) \\
\hline ASA $60-4 h$ & $4,89 * *$ & $0,80^{\text {ns }}$ & $3,15^{* *}$ \\
\hline ASA $60-\quad 8 h$ & $3,97 * *$ & $3,30^{*}$ & $1,39 \mathrm{~ns}$ \\
\hline ASA $60-12 \mathrm{~h}$ & $7,58^{* *}$ & $10,54 * *$ & $5,66 * *$ \\
\hline ASA $60-16 \mathrm{~h}$ & $11,45^{* *}$ & $23,57 * *$ & $7,29 * *$ \\
\hline ASA $60-20 \mathrm{~h}$ & $11,68^{* *}$ & $3,56^{*}$ & $1,28^{\mathrm{ns}}$ \\
\hline ASA $60-24 \mathrm{~h}$ & $22,97 * *$ & $25,95^{* *}$ & $6,71 * *$ \\
\hline ASA $55-4 \mathrm{~h}$ & $2,79^{*}$ & $1,59^{\mathrm{ns}}$ & $2,32^{*}$ \\
\hline ASA $55-\quad 8 \mathrm{~h}$ & $3,71^{*}$ & $2,80 *$ & $1,03^{\mathrm{nS}}$ \\
\hline ASA $55-12 h$ & $18,04^{* *}$ & $11,26 * *$ & $6,55 * *$ \\
\hline ASA $55-16 \mathrm{~h}$ & $45,05^{* *}$ & $22,91 * *$ & $10,56 * *$ \\
\hline ASA $55-20 h$ & $44,39 * *$ & $2,08^{\text {nS }}$ & $4,74 * *$ \\
\hline ASA $55-24 h$ & $47,37^{* *}$ & $25,63 * *$ & $8,76 * *$ \\
\hline ASA $50-4 h$ & $5,73 * *$ & $1,43^{\text {nS }}$ & $2,04^{n s}$ \\
\hline ASA $50-8 \mathrm{~h}$ & $2,78^{*}$ & $1,86^{\mathrm{nS}}$ & $1,27^{n S}$ \\
\hline ASA $50-12 \mathrm{~h}$ & $36,42^{* *}$ & $16,35^{* *}$ & $8,38^{* *}$ \\
\hline ASA $50-16 \mathrm{~h}$ & $63,27^{* *}$ & $24,17 * *$ & $17,74 * *$ \\
\hline ASA $50-20 \mathrm{~h}$ & $51,60 * *$ & $2,56^{\mathrm{ns}}$ & $6,47 * *$ \\
\hline ASA $50-24 \mathrm{~h}$ & $79,67 * *$ & $32,37 * *$ & $6,71 * *$ \\
\hline ASA $45-4 h$ & $9,48 * *$ & $1,52^{\mathrm{ns}}$ & $0,57^{\mathrm{ns}}$ \\
\hline ASA $45-8 h$ & $12,28^{* *}$ & $12,07 * *$ & $7,04 * *$ \\
\hline ASA $45-12 h$ & $29,84 * *$ & $13,30 * *$ & $12,44 * *$ \\
\hline ASA $45-16 h$ & $78,04^{* *}$ & $51,00 * *$ & $28,04 * *$ \\
\hline ASA $45-20 h$ & $90,84 * *$ & $19,48^{* *}$ & $14,23^{* *}$ \\
\hline ASA $45-24 h$ & $54,07 * *$ & $31,93 * *$ & $7,55^{* *}$ \\
\hline
\end{tabular}

* - significativo ao nível de $5 \%$ de probabilidade

** - significativo ao nível de $1 \%$ de probabilidade

ns - não significativo 
Tabela 7. Valores de $\mathrm{F}$ obtidos nas análises de variância dos dados referentes aos testes de germinação (TG), primeira contagem de germinação (PC) e envelhecimento artificial (EA), para os lotes do cultivar IAC-8. Piracicaba, 1991.

\begin{tabular}{lccc}
\hline Causas de Variação & \multicolumn{3}{c}{ Valores de $\mathrm{F}$} \\
\cline { 2 - 4 } & \multicolumn{1}{c}{ TG } & PC & EA \\
\hline Lotes $(\mathrm{L})$ & $6,16^{* *}$ & $10,91^{* *}$ & $5,12^{* *}$ \\
Épocas $(\mathrm{E})$ & $32,51^{* *}$ & $46,52^{* *}$ & $88,69^{* *}$ \\
Interação $(\mathrm{L} \times \mathrm{E})$ & $1,10^{\mathrm{ns}}$ & $4,97^{* *}$ & $2,03^{\mathrm{ns}}$ \\
\hline
\end{tabular}

**- significativo ao nível de $1 \%$ de probabilidade.

ns - não signifitativo.

Apesar dos efeitos significativos do fator época, na maioria dos parâmetros, optou-se pela não apresentação dos resultados referentes a tais efeitos, uma vez que as variações entre épocas não foram consideradas relevantes para a interpretação dos resultados; tais épocas, na realidade, representam blocos utilizados como repetições distribuídas no tempo. Portanto, foram apresentadas as médias originais dos dados obtidos nas quatro épocas de avaliações.

\subsubsection{Condutividade elétrica de massa - CE I e CE II}

Pela Tabela 8, observa-se, em ambos os estudos, um aumento na quantidade de eletrólitos liberados pelas sementes com o decorrer da embebição, fato também constatado por diversos autores (SIMON \& RAJA-HARUM, 1972; KEYS, 1982; LOEFFLER et al., 1988; MARCOS FILHO et al., 1990 e BRUGGINK et al., 1991). No entanto, é importante observar que liberação mais intensa ocorreu no estudo II, provavelmente, em função da temperatura de condicionamento de $25^{\circ} \mathrm{C}$ e da condução do teste sem a eliminação das sementes danificadas. Nota-se ainda, que os dois estudos apresentaram tendência semelhante de aumento da condutividade, ou seja, os valores obtidos com 24 horas representavam, aproximadamente, o dobro daqueles observados com 4 horas de embebição . 
Tabela 8- Condutividade elétrica (CE I e II): valores médios (umhos/cm/g) para os lotes de sementes de soja, cultivar IAC-8, em cada período de embebição (médias de 4 épocas) e coeficientes de variação. Piracicaba, 1991.

\begin{tabular}{|c|c|c|c|c|c|c|c|}
\hline \multirow[t]{2}{*}{ Lotes } & \multicolumn{6}{|c|}{ CE I - Períodos (h) } & \multirow[t]{2}{*}{ Médias } \\
\hline & 4 & 8 & 12 & 16 & 20 & 24 & \\
\hline 1 & $31,96 \mathrm{~b}$ & $42,07 \mathrm{ab}$ & $46,41 \mathrm{a}$ & $55,30 \mathrm{a}$ & $60,21 \mathrm{a}$ & $63,83 \mathrm{ab}$ & 49,96 \\
\hline 2 & $34,81 \mathrm{c}$ & $46,43 \mathrm{c}$ & $50,46 b$ & $59,43 \mathrm{c}$ & $64,94 \mathrm{c}$ & $67,50 \mathrm{~b}$ & 53,93 \\
\hline 3 & $32,89 b$ & $43,64 \mathrm{bc}$ & $50,01 \mathrm{~b}$ & 58,55 bc & $64,19 b c$ & $65,58 b$ & 52,48 \\
\hline 4 & $29,71 \mathrm{a}$ & $40,55 \mathrm{a}$ & $46,75 \mathrm{a}$ & $55,93 \mathrm{ab}$ & $60,91 \mathrm{ab}$ & $61,66 \mathrm{a}$ & 49,25 \\
\hline Médias & 32,34 & 43,17 & 48,41 & 57,30 & 62,56 & 64,64 & \\
\hline CV $(\%)$ & 5,83 & 6,86 & 6,27 & 5,52 & 6,47 & 6,29 & \\
\hline \multirow[t]{2}{*}{ Lotes } & \multicolumn{6}{|c|}{ CE II - Períodos (h) } & Médias \\
\hline & 4 & 8 & 12 & 16 & 20 & 24 & \\
\hline 1 & $36,01 \mathrm{a}$ & $51,43 b$ & $54,88 \mathrm{a}$ & $62,74 \mathrm{a}$ & $67,83 \mathrm{a}$ & $73,00 \mathrm{ab}$ & 57,65 \\
\hline 2 & $38,68 \mathrm{~b}$ & $55,60 \mathrm{c}$ & $62,56 \mathrm{c}$ & $71,99 \mathrm{c}$ & $77,45 \mathrm{c}$ & $76,99 \mathrm{~b}$ & 63,88 \\
\hline 3 & $36,73 a b$ & 53,05 bc & $58,76 \mathrm{~b}$ & $66,81 \mathrm{~b}$ & $72,94 \mathrm{~b}$ & $75,72 b$ & 60,67 \\
\hline 4 & $34,96 \mathrm{a}$ & $48,07 \mathrm{a}$ & $54,80 \mathrm{a}$ & $63,02 \mathrm{a}$ & $68,49 \mathrm{a}$ & $68,90 \mathrm{a}$ & 56,37 \\
\hline Médias & 36,59 & 52,04 & 57,75 & 66,14 & 71,68 & 73,65 & \\
\hline CV (\%) & 7,03 & 5,25 & 5,69 & 5,98 & 5,74 & 5,91 & \\
\hline
\end{tabular}

em cada coluna, médias seguidas pela mesma letra não diferiram entre si, pelo teste de Tukey, ao nível de $5 \%$ de probabilidade. 
Examinando os resultados obtidos com o método CE I (Tabela 8) verificou-se que os períodos de 4 e 8 horas de embebição forneceram informações semelhantes, indicando a superioridade do lote 4 e a inferioridade do lote 2 . Já as leituras feitas com 12 horas de condicionamento mostraram uma tendência de agrupamento das médias, classificando os lotes 1 e 4 como superiores e os lotes 2 e 3 como inferiores. Por sua vez, os periodos de 16 e 20 horas mostraram-se estatisticamente semelhantes, revelando melhor e pior desempenho repectivamente, para os lotes 1 e 2. O período de embebição mais longo, ou seja, 24 horas, indicou alta qualidade fisiológica para o lote $4 \mathrm{e}$ baixo potencial para os lotes 2 e 3 . Portanto, observou-se que apesar das alterações na classificação dos melhores lotes em função da duração do período de embebição, houve, de um modo geral, concordância quanto à indicação da inferioridade do lote 2 em todas as avaliações.

Ainda na Tabela 8, observou-se que através do método CE II (sementes fisicamente puras) foi possivel a ordenação dos lotes em níveis de qualidade fisiológica, embora tenham ocorrido alterações na classificação em função do período de tempo que as sementes pemaneceram embebidas. A alta qualidade do lote 4 foi indicada em todos os estudos, embora acompanhado pelo lote 1 nas avaliações feitas com 4, 12, 1620 e 24 horas de embebição. Com relação ao lote deficiente, observou-se, de maneira geral, que a maioria das leituras indicou o lote 2 .

Diante dos resultados da Tabela 8, constatou-se que ambas as metodologias de condutividade de massa (CE I e II) foram eficientes na classificação dos diferentes lotes quanto ao vigor, ocorrendo algumas variações de acordo com o período de embebição adotado. Além disso, os métodos revelaram sensibilidade já no início do processo de embebição, concordando com EDGE \& BURRIS (1970) que obtiveram uma ordenação adequada de lotes de sementes de soja em níveis de vigor, através da condutividade elétrica realizada com 4 horas de embebição à $25^{\circ} \mathrm{C}$. Por outro lado, LOEFFLER et al. (1988) e MARCOS FILHO et al. (1990) verificaram que períodos de embebição mais curtos não permitiram diferenciação marcante entre os lotes.

Portanto, a condução do teste com sementes fisicamente puras forneceu resultados satisfatórios, em termos de separação de lotes, o que indica a possibilidade de adoção de uma metodologia menos subjetiva e mais rápida. 


\subsubsection{Condutividade elétrica individual}

O exame da Tabela 9 revela que a intensidade de corrente elétrica de 95 uA permitiu a separação dos lotes em niveis de qualidade fisiológica somente após 24 horas de embebição, indicando melhor e pior desempenho para os lotes 4 e 1 , respectivamente. Resultados semelhantes foram obtidos neste mesmo período com os valores limites de 90 e 85 uA. Com o limite de 90 uA, os periodos de embebição de 4 e 8 horas também mostraram diferenças significativas entre os lotes; no entanto, tais diferenças foram mais perceptíveis quando as leituras foram feitas com 24 horas.

Observando-se o limite de 80 uA (Tabela 9), verifica-se que os períodos de 4 e 12 horas não promoveram a separação dos lotes. As leituras realizadas com 8 horas indicaram a superioridade do lote 1 e inferioridade do lote 3 , enquanto as de 16, 20 e 24 horas, apesar de algumas variações, destacaram, de um modo geral, os lotes 1 e 2 como de pior e melhor desempenho, respectivamente. Os resultados obtidos com os limites de 75 e 70 uA mostraram semelhança para todos os períodos, identificando o lote 2 como de elevada qualidade fisiológica, não revelando coerência quanto aos lotes de médio e fraco desempenho.

As leituras realizadas com a regulagem de 65 uA (Tabela 9) mostraram, de modo geral, a superioridade do lote 2 em relação aos demais, principalmente com base nos períodos de embebição de $8,12,16$ e 20 horas, classificando o lote 3 como inferior. Resultados semelhantes foram obtidos com 60 uA, embora não tenham sido detectadas diferenças significativas entre os lotes na leitura de 8 horas. Por sua vez, com a intensidade de corrente elétrica de $55 \mathrm{uA}$ a partir de 12 horas de condicionamento, foi possivel se destacar a superioridade do lote 2 e o comportamento inferior do lote 3 .

Conforme mostra ainda a Tabela 9 , no valor limite de 50 uA, a maioria dos períodos estudados indicou o melhor potencial fisiológico do lote 2 , embora nas avaliações de 4 e 24 horas este lote tenha sido acompanhado também pelo lote 4. Já a inferioridade do lote 3 foi indicada a partir de 12 horas de embebição.

Finalmente, o exame dos resultados obtidos com a intensidade de corrente elétrica de 45 uA revelou a elevada qualidade dos lotes 2 e 4 , dependendo do período de tempo considerado. Assim, as leituras de 8, 12 e 24 horas destacaram o desempenho superior do lote 2 enquanto o lote 4 foi também incluído nesta categoria nas avaliações realizadas após 16 e 20 horas. Com relação ao lote de pior desempenho, verificou-se, em todos os períodos de embebição, que houve concordância quanto à indicação do lote 3 . 
Tabela 9. Condutividade elétrica individual (ASA-610): dados médios (\%) obtidos para os valores limites (VL) e períodos de embebição para os lotes de sementes de soja, cultivar IAC-8 e coeficientes de variação (médias de 4 épocas). Piracicaba, 1991.

\begin{tabular}{|c|c|c|c|c|c|c|c|c|}
\hline \multirow{2}{*}{$\begin{array}{l}\text { VL } \\
(\mathrm{uA})\end{array}$} & \multirow[t]{2}{*}{ Lotes } & \multicolumn{6}{|c|}{ Períodos (h) } & \multirow[t]{2}{*}{ Médias } \\
\hline & & 4 & 8 & 12 & 16 & 20 & 24 & \\
\hline & 1 & $100 a$ & $100 a$ & $100 \mathrm{a}$ & $98 \mathrm{a}$ & $96 a$ & $94 \mathrm{~b}$ & 99 \\
\hline & 2 & $100 \mathrm{a}$ & $100 \mathrm{a}$ & $100 \mathrm{a}$ & $98 \mathrm{a}$ & $97 \mathrm{a}$ & $96 \mathrm{ab}$ & 99 \\
\hline & 3 & $100 \mathrm{a}$ & $100 a$ & $100 \mathrm{a}$ & $98 \mathrm{a}$ & 97 a & $96 \mathrm{ab}$ & 99 \\
\hline & 4 & $100 \mathrm{a}$ & $100 \mathrm{a}$ & $99 \mathrm{a}$ & $98 \mathrm{a}$ & $97 \mathrm{a}$ & $97 \mathrm{a}$ & 99 \\
\hline & Médias & 100 & 100 & 100 & 98 & 96 & 96 & \\
\hline & $\mathrm{CV}(\%)$ & 2,38 & 3,17 & 4,16 & 4,54 & 4,36 & 3,56 & \\
\hline \multirow[t]{6}{*}{90} & 1 & $100 \mathrm{a}$ & $100 a$ & $99 a$ & $97 a$ & $94 \mathrm{a}$ & $93 \mathrm{~b}$ & 97 \\
\hline & 2 & $100 a$ & $100 a b$ & $99 a$ & $98 \mathrm{a}$ & $96 \mathrm{a}$ & $94 \mathrm{ab}$ & 98 \\
\hline & 3 & $100 \mathrm{a}$ & $99 \mathrm{~b}$ & $99 a$ & 97 a & $95 \mathrm{a}$ & $94 \mathrm{ab}$ & 97 \\
\hline & 4 & $100 a$ & $100 \mathrm{ab}$ & $98 \mathrm{a}$ & $97 a$ & $95 \mathrm{a}$ & $96 \mathrm{a}$ & 98 \\
\hline & Médias & 100 & 100 & 99 & 97 & 95 & 95 & \\
\hline & CV(\%) & 2,90 & 3,56 & 4,89 & 4,60 & 4,38 & 3,81 & \\
\hline \multirow[t]{6}{*}{85} & 1 & $100 a$ & $100 a$ & $97 \mathrm{a}$ & $95 \mathrm{~b}$ & $91 \mathrm{~b}$ & $90 \mathrm{~b}$ & 96 \\
\hline & 2 & $100 a$ & $99 \mathrm{ab}$ & 99 a & $97 a$ & $93 \mathrm{ab}$ & $92 \mathrm{ab}$ & 97 \\
\hline & 3 & $99 a$ & $99 \mathrm{~b}$ & $97 \mathrm{a}$ & $96 \mathrm{ab}$ & $93 \mathrm{ab}$ & $92 \mathrm{ab}$ & 96 \\
\hline & 4 & $100 \mathrm{a}$ & $100 \mathrm{ab}$ & $97 \mathrm{a}$ & $95 \mathrm{ab}$ & $94 \mathrm{a}$ & $93 a$ & 96 \\
\hline & Médias & 100 & 99 & 98 & 96 & 93 & 92 & \\
\hline & CV(\%) & 3,82 & 3,98 & 3,75 & 4,35 & 4,23 & 3,32 & \\
\hline \multirow[t]{6}{*}{80} & 1 & $100 a$ & $99 a$ & $96 a$ & $92 \mathrm{~b}$ & $88 \mathrm{~b}$ & $87 \mathrm{~b}$ & 94 \\
\hline & 2 & $100 a$ & $99 \mathrm{ab}$ & $97 \mathrm{a}$ & $96 \mathrm{a}$ & $92 a$ & $90 \mathrm{a}$ & 96 \\
\hline & 3 & $99 \mathrm{a}$ & $98 \mathrm{~b}$ & $96 a$ & $93 \mathrm{~b}$ & $90 \mathrm{ab}$ & $89 \mathrm{ab}$ & 94 \\
\hline & 4 & $100 \mathrm{a}$ & $99 \mathrm{ab}$ & $96 \mathrm{a}$ & $93 \mathrm{~b}$ & $91 \mathrm{ab}$ & 91 a & 95 \\
\hline & Médias & 100 & 99 & 96 & 94 & 90 & 89 & \\
\hline & CV(\%) & 3,55 & 3,72 & 4,00 & 4,08 & 4,00 & 3,19 & \\
\hline \multirow[t]{6}{*}{75} & 1 & $100 a$ & $98 \mathrm{a}$ & $94 \mathrm{~b}$ & $89 \mathrm{~b}$ & $84 \mathrm{~b}$ & $84 \mathrm{~b}$ & 93 \\
\hline & 2 & $99 \mathrm{ab}$ & 99 a & $96 a$ & $94 \mathrm{a}$ & $89 a$ & $88 \mathrm{a}$ & 95 \\
\hline & 3 & $98 \mathrm{~b}$ & 97 a & $94 \mathrm{ab}$ & $90 \mathrm{~b}$ & $88 \mathrm{a}$ & $85 \mathrm{~b}$ & 93 \\
\hline & 4 & $99 \mathrm{ab}$ & 99 a & $94 \mathrm{a}$ & $91 \mathrm{ab}$ & $87 \mathrm{ab}$ & $88 \mathrm{a}$ & 94 \\
\hline & Médias & 99 & 98 & 95 & 91 & 87 & 86 & \\
\hline & $\mathrm{CV}(\%)$ & 3,84 & 3,45 & 3,91 & 4,52 & 4,21 & 3,84 & \\
\hline \multirow[t]{6}{*}{70} & 1 & $100 a$ & $97 \mathrm{a}$ & $91 \mathrm{~b}$ & $85 \mathrm{~b}$ & $81 \mathrm{~b}$ & $81 \mathrm{ab}$ & 91 \\
\hline & 2 & $99 \mathrm{ab}$ & $98 \mathrm{a}$ & 95 a & $92 \mathrm{a}$ & $87 a$ & $85 \mathrm{a}$ & 93 \\
\hline & 3 & $98 \mathrm{~b}$ & $96 \mathrm{a}$ & $92 \mathrm{~b}$ & $88 \mathrm{~b}$ & $82 \mathrm{~b}$ & $80 \mathrm{~b}$ & 91 \\
\hline & 4 & $99 \mathrm{ab}$ & $98 \mathrm{a}$ & $92 \mathrm{ab}$ & $88 \mathrm{~b}$ & $83 \mathrm{ab}$ & $84 a$ & 92 \\
\hline & Médias & 99 & 97 & 92 & 88 & 83 & 82 & \\
\hline & $\mathrm{CV}(\%)$ & 3,90 & 3,57 & 4,16 & 4,64 & 4,33 & 4,10 & \\
\hline
\end{tabular}


Continuação

Tabela 9. Condutividade elétrica individual (ASA-610), dados médios (\%) obtidos para os valores limites (VL) e períodos de embebição para os lotes de sementes de soja, cultivar IAC-8 e coeficientes de variação (médias de 4 épocas). Piracicaba, 1991.

\begin{tabular}{|c|c|c|c|c|c|c|c|c|}
\hline \multirow[t]{2}{*}{$\mathrm{VL}(\mathbf{u A})$} & \multirow[t]{2}{*}{ Lotes } & \multicolumn{6}{|c|}{ Períodos (h) } & \multirow[b]{2}{*}{ Médias } \\
\hline & & 4 & 8 & 12 & 16 & 20 & 24 & \\
\hline \multirow[t]{6}{*}{65} & 1 & $99 a$ & $96 \mathrm{ab}$ & $89 \mathrm{~b}$ & $83 \mathrm{~b}$ & $76 b$ & $77 a$ & 88 \\
\hline & 2 & $99 a b$ & 97 a & $92 \mathrm{a}$ & $88 a$ & $82 a$ & $80 a$ & 91 \\
\hline & 3 & $97 \mathrm{~b}$ & $95 \mathrm{~b}$ & $89 \mathrm{~b}$ & $83 \mathrm{~b}$ & $75 b$ & $72 \mathrm{~b}$ & 86 \\
\hline & 4 & $98 \mathrm{a}$ & $96 \mathrm{ab}$ & $89 \mathrm{~b}$ & $84 \mathrm{~b}$ & $78 \mathrm{ab}$ & $79 a$ & 89 \\
\hline & Médias & 98 & 96 & 90 & 85 & 78 & 76 & \\
\hline & CV $(\%)$ & 3,40 & 3,62 & 4,41 & 4,63 & 5,60 & 4,85 & \\
\hline \multirow[t]{6}{*}{60} & 1 & $98 \mathrm{a}$ & $94 \mathrm{a}$ & $86 b$ & $80 b$ & $71 \mathrm{~b}$ & $70 a$ & 85 \\
\hline & 2 & $99 a$ & $97 \mathrm{a}$ & $90 a$ & $86 a$ & $79 a$ & $74 a$ & 91 \\
\hline & 3 & $97 \mathrm{~b}$ & $94 a$ & $85 \mathrm{~b}$ & $76 \mathrm{~b}$ & $62 \mathrm{c}$ & $60 \mathrm{~b}$ & 81 \\
\hline & 4 & $98 \mathrm{a}$ & $96 \mathrm{a}$ & $85 \mathrm{~b}$ & $80 \mathrm{~b}$ & $73 \mathrm{ab}$ & $72 a$ & 86 \\
\hline & Médias & 98 & 95 & 87 & 81 & 72 & 71 & \\
\hline & $\operatorname{CV}(\%)$ & 2,89 & 3,86 & 4,85 & 5,85 & 9,48 & 5,69 & \\
\hline \multirow[t]{6}{*}{55} & 1 & $96 a$ & $92 \mathrm{~b}$ & $82 b$ & $76 b$ & $61 \mathrm{~b}$ & $58 \mathrm{~b}$ & 79 \\
\hline & 2 & $97 \mathrm{a}$ & $94 \mathrm{a}$ & $88 a$ & $83 a$ & $70 a$ & $67 a$ & 85 \\
\hline & 3 & $96 a$ & $92 \mathrm{ab}$ & $76 \mathrm{~b}$ & $60 c$ & $42 \mathrm{c}$ & $42 c$ & 71 \\
\hline & 4 & $97 \mathrm{a}$ & $94 \mathrm{ab}$ & $81 \mathrm{bc}$ & $74 \mathrm{~b}$ & $65 \mathrm{ab}$ & $63 \mathrm{ab}$ & 81 \\
\hline & Médias & 97 & 93 & 82 & 72 & 60 & 58 & \\
\hline & $\mathrm{CV}(\%)$ & 3,14 & 4,15 & 5,33 & 6,23 & 8,57 & 7.51 & \\
\hline \multirow[t]{6}{*}{50} & 1 & $95 \mathrm{ab}$ & $89 a$ & $76 b$ & $65 b$ & $46 b$ & $42 b$ & 69 \\
\hline & 2 & $96 \mathrm{a}$ & $92 a$ & $83 a$ & $71 \mathrm{a}$ & $57 \mathrm{a}$ & $55 \mathrm{a}$ & 76 \\
\hline & 3 & $94 \mathrm{~b}$ & $89 a$ & $64 \mathrm{c}$ & $42 \mathrm{c}$ & $22 \mathrm{c}$ & $21 \mathrm{c}$ & 55 \\
\hline & 4 & $96 \mathrm{a}$ & $91 \mathrm{a}$ & $74 \mathrm{~b}$ & $65 \mathrm{~b}$ & $53 \mathrm{ab}$ & $50 a$ & 72 \\
\hline & Médias & 95 & 90 & 74 & 62 & 45 & 42 & \\
\hline & $\operatorname{CV}(\%)$ & 3,43 & 5,01 & 5,85 & 7,84 & 12,51 & 10,31 & \\
\hline \multirow[t]{6}{*}{45} & 1 & $93 \mathrm{bc}$ & $85 \mathrm{bc}$ & $60 \mathrm{~b}$ & $46 b$ & $27 b$ & $19 c$ & 55 \\
\hline & 2 & $93 \mathrm{ab}$ & $89 a$ & $71 \mathrm{a}$ & $56 \mathrm{a}$ & $38 \mathrm{a}$ & $37 \mathrm{a}$ & 64 \\
\hline & 3 & $90 \mathrm{c}$ & $81 \mathrm{c}$ & $42 \mathrm{c}$ & $20 \mathrm{c}$ & $09 \mathrm{c}$ & $09 \mathrm{~d}$ & 42 \\
\hline & 4 & $95 \mathrm{a}$ & $88 \mathrm{ab}$ & $66 \mathrm{ab}$ & $54 \mathrm{a}$ & $40 \mathrm{a}$ & $29 b$ & 62 \\
\hline & Médias & 93 & 86 & 60 & 44 & 29 & 24 & \\
\hline & $\mathrm{CV}(\%)$ & 3,76 & 5,20 & 10,66 & 10,87 & 13,69 & 16,59 & \\
\hline
\end{tabular}

em cada coluna, médias seguidas pela mesma letra não diferiram entre si, pelo teste de Tukey, ao nivel de $5 \%$ de probabilidade. 
É importante observar que os coeficientes de variação obtidos com 50 e 45 uA foram mais elevados em relação aos demais limites, principalmente, com o aumento do período de embebição, indicando variabilidade entre os dados e cons qüentemente, menor precisão das informações obtidas.

A análise global dos resultados fornecidos pelo ASA-610 indicou para as intensidades de corrente mais altas, ou seja, acima de 80 uA qualidade fisiológica superior para os lotes 2 e 4 , situando o lote 1 como inferior aos demais, no período de 24 horas de embebição. No entanto, com a redução dos valores de corrente elétrica ocorreram modificações no comportamento dos lotes; assim, os limites de 75 e $70 \mathrm{uA}$, mantiveram, geralmente, os lotes 2 e 4 em posição de destaque classificando os lotes 1 e 3 como inferiores. Já nas regulagens inferiores à 60 uA o lote 2 assumiu condição de superioridade enquanto o lote 3 exibiu desempenho fisiológico inferior.

Portanto, em função do nível de corrente elétrica adotado, foram observadas variações na ordenação dos lotes quanto ao vigor, dificultando indicações mais precisas sobre o potencial relativo de cada lote. Também HEPBURN et al. (1984) não obtiveram informações consistentes com o referido método. Por outro lado, para McDONALD Jr. \& WILSON $(1979,1980)$ a condutividade individual mostrou-se promissora para a avaliaçao da qualidade fisiológica de sementes de soja.

Cumpre ressaltar, contudo, que os valores limites acima de 80uA indicaram elevadas porcentagens de exsudatos apresentando leituras de corrente elétrica inferiores ao valor limite testado foram relativamente altas, de forma que as diferenças entre as médias dos lotes, apesar de significativas, mostraram-se pouco acentuadas, especialmente nos períodos de condicionamento mais curtos, devido a pequena concentração dos exsudatos. Desse modo, para a utilização do analisador automático (ASA -610) em laboratórios de análise de sementes, os resultados indicaram que limites mais baixos e períodos mais longos demonstraram maior sensibilidade, ou seja, as diferenças entre as médias de cada lote foram mais perceptíveis.

Comparando-se os resultados do ASA-610 (Tabela 9) com os de condutividade elétrica de massa (Tabela 8), observou-se, de um modo geral, concordância apenas quanto à superioridade do lote 4 , revelada pela maioria dos estudos pelo sistema de massa e somente não indicada no limite de 55uA. Com relação aos lotes de pior desempenho, enquanto o método de massa identificou o lote 2 em todos os períodos, acompanhado eventualmente pelo lote 3, o sistema individual indicou os lotes 1 e 3, respectivamente, nos limites acima e abaixo de 75 uA. 
Portanto, os testes de condutividade elétrica de massa e individual não forneceram informações totalmente compativeis quanto à classificação dos lotes em niveis de vigor, mostrando divergências acentuadas. REUSCHE (1987) também não encontrou correspondência entre estes dois sistemas.

\subsubsection{Lixiviação de potássio - K I e K II}

Analisando os resultados dos testes de lixiviação de potássio (Tabela 10) observou-se que ambas as metodologias (K I e K II) identificaram o lote 4 como superior aos demais, em todos os períodos de embebição estudados. O lote 2, por sua vez, foi classificado como de pior desempenho na maioria dos estudos, exceto nas avaliações feitas com 90 minutos de embebição, que incluiram nesta categoria também os lotes 1 e 3 . No entanto, os valores absolutos indicam que maior quantidade de potássio foi liberado pelas sementes do lote 2 em relação aos lotes 1 e 3, apesar da análise estatística não ter acusado diferenças significativas entre estes três lotes, após 90 minutos de condicionamento, tanto em KI como em KII.

A semelhança na classificação das médias fornecida pelos dois sistemas permitiu observar que a remoção de sementes danificadas (Kl) não mostrou-se vantajosa, pois além de ser um procedimento subjetivo, requer maior tempo para o preparo das amostras. Portanto, a condução do teste com sementes fisicamente puras revelou sensibilidade para classificar, com rapidez, os lotes em níveis de vigor.

Com referência aos periodos de embebição empregados, notou-se um aumento gradativo da quantidade de potássio lixiviado com o decorrer do tempo, em ambas as metodologias. Observou-se ainda, que coeficientes de variação mais altos foram obtidos nas leituras realizadas aos 60 minutos, tanto em KI como em KII. Este fato pode ser atribuido, possivelmente, ao periodo de condicionamento relativamente curto para a liberação expressiva de ions potássio; assim, a elevada diluição dos exsudatos nesta ocasião pode ter contibuído para a variabilidade das leituras.

Estes resultados indicam ainda, que as avaliações do potássio lixiviado (Tabela 10) mostraram a mesma tendência do teste de condutividade de massa (Tabela 8), ou seja, permitiram a ordenação dos lotes, contrariando informações obtidas por MARCOS FILHO et al. (1984) e BARROS (1988). Por outro lado, WEBES \& KARSSEN (1990) constataram que a quantidade de potássio lixiviado foi um eficiente indicador da integridade das membranas; observa-se portanto, que o referido teste pode ser considerado promissor para a avaliação do estádio de deterioração das sementes. 
Tabela 10. Lixiviação de potássio (KI e KII): valores médios (ppm/g) obtidos para os lotes de sementes de soja, cultivar IAC-8, em cada período de embebição (média de 3 épocas) e coeficientes de variação. Piracicaba, 1991.

\begin{tabular}{|c|c|c|c|c|c|}
\hline \multirow[t]{2}{*}{ Lotes } & \multicolumn{4}{|c|}{ K I - Períodos (min.) } & \multirow[t]{2}{*}{ Médias } \\
\hline & 60 & 90 & 120 & 150 & \\
\hline 1 & $595 \mathrm{~b}$ & $649 \mathrm{~b}$ & $691 \mathrm{bc}$ & $719 b c$ & 664 \\
\hline 2 & $618 \mathrm{~b}$ & $679 \mathrm{~b}$ & $726 c$ & $748 \mathrm{c}$ & 693 \\
\hline 3 & $565 \mathrm{ab}$ & $624 \mathrm{~b}$ & $661 \mathrm{~b}$ & $694 \mathrm{~b}$ & 636 \\
\hline 4 & $463 \mathrm{a}$ & $491 \mathrm{a}$ & $578 \mathrm{a}$ & $613 \mathrm{a}$ & 536 \\
\hline Médias & 560 & 611 & 664 & 693 & \\
\hline CV (\%) & 18,46 & 8,66 & 7,27 & 6,64 & \\
\hline \multirow[t]{2}{*}{ Lotes } & \multicolumn{4}{|c|}{ K II - Periodos (min.) } & Médias \\
\hline & 60 & 90 & 120 & 150 & \\
\hline 1 & $684 \mathrm{bc}$ & $751 \mathrm{~b}$ & $784 \mathrm{~b}$ & $825 \mathrm{~b}$ & 761 \\
\hline 2 & $720 \mathrm{c}$ & $822 \mathrm{~b}$ & $891 \mathrm{c}$ & $955 \mathrm{c}$ & 847 \\
\hline 3 & $607 \mathrm{ab}$ & $763 b$ & $836 \mathrm{bc}$ & $884 \mathrm{~b}$ & 773 \\
\hline 4 & $554 \mathrm{a}$ & $597 \mathrm{a}$ & $677 \mathrm{a}$ & $729 \mathrm{a}$ & 639 \\
\hline Médias & 641 & 733 & 797 & 848 & \\
\hline CV (\%) & 13,61 & 8,85 & 7,61 & 7,02 & \\
\hline
\end{tabular}

em cada coluna, médias seguidas pela mesma letra não diferiram entre si, pelo teste de Tukey, ao nível de $5 \%$ de probabilidade. 
Ainda de forma comparativa, verificou-se que, de mancira geral, o teste de lixiviação de potássio (Tabela 10) apresentou resultados semelhantes aos de condutividade individual (Tabela 9) apenas com relação ao melhor desempenho do lote 4 , nos valores limites de 95 e 70 uA. Nos demais limites, as informações obtidas com os dois testes mostraram-se divergentes.

\subsubsection{Análise comparativa entre os testes para avaliação da qua- lidade fisiológica}

Examinando-se a Tabela 11, observa-se que houve uma separação dos lotes em diferentes níveis de qualidade fisiológica. Pelos resultados de germinação nota-se que o lote 1 foi superior aos demais embora não tenha sido estatisticamente diferente do lote 4; em contrapartida, o lote 2 apresentou menor porcentagem de germinação, não diferindo significativamente do lote 3 . O teste de primeira contagem de germinação revelou o melhor desempenho do lote 1 em relação aos lotes 2 e 3 mostrando concordância com os resultados de germinação. Esta semelhança pode ser atribuida principalmente, ao fato de que as avaliações foram realizadas com a mesma amostra. Já o teste de envelhecimento artificial apontou o lote 4 como superior, embora não tenha diferido dos lotes 1 e 2 , enquanto o lote 3 foi identificado como o de pior qualidade fisiológica. Assim, de modo geral, os dados da Tabela 11 indicaram uma tendência dos testes em destacar os lotes 1 e 4 como superiores; uma separação mais eficiente não foi possivel, provavelmente, pelos lotes apresentarem pequenas diferenças de qualidade.

Comparando os resultados da Tabela $11 \mathrm{com}$ os de condutividade de massa (Tabela 8) pode-se constatar que, de modo geral, houve eficiência semelhante quanto à identificação dos lotes de melhor qualidade fisiológica ( 1 e 4). Com relação aos lotes de pior desempenho, notou-se que o lote 3 exibiu maior sensibilidade às condições adversas do teste de envelhecimento artificial, revelando-se inferior aos demais; tal inferioridade só foi observada nos testes de condutividade elétrica quando foram empregados os periodos de embebição de 12 e 24 horas no sistema II e 24 horas no método CE I. Sabe-se que o histórico de cada lote interfere na sua maior ou menor sensibilidade às diferentes condições a que é submetido em cada teste. Neste caso, tem sido relatada na literatura a dificuldade de se detectar diferenças entre lotes com niveis médios de vigor (KULIK \& YAKLICH, 1982).

Ainda de forma comparativa, analisando-se as Tabelas 8 e 11, verificou-se que houve concordância entre envelhecimento artificial e condutividade indi- 
vidual nos limites superiores a 70 uA somente com relação à caracterização do lote de alto vigor (lote 4). Em contrapartida, a inferioridade do lote 3, indicada no teste de envelhecimento e primeira contagem só foi observada nas intensidades de corrente elétrica mais baixas, ou seja, inferiores a $60 \mathrm{uA}$, que por sua vez, mostraram-se, de modo geral, ineficientes quanto à identificação do lote mais vigoroso. Portanto, as informações proporcionadas pelo ASA-610 exibiram variações na classificação dos lotes em função do limite adotado. Assim, houve dificuldade em se selecionar um único valor referência que possibilitasse a identificação precisa tanto de lotes de alta qualidade como de fraco desempenho.

Comparando-se as Tabelas 10 e 11, verificou-se que o teste de lixiviação de potássio proporcionou informações semelhantes ao teste de envelhecimento artificial, uma vez que ambos indicaram o lote 4 como superior aos demais. No entanto, no que diz respeito a lotes de pior qualidade não houve coerência entre os resultados dos dois testes; neste caso, houve maior semelhança entre os resultados de lixiviação de potássio, germinação e primeira contagem, conforme também observado na avaliação da condutividade elétrica pelo sistema de massa.

Os dados referentes ao grau de umidade das sementes (Tabela 11), embora não tenham sido analisados estatisticamente, foram, de um modo geral, semelhantes para os 4 lotes estudados; este fato é importante na execução dos testes, considerando-se que a uniformização da umidade das sementes é imprescindível para a padronização das avaliações e obtenção de resultados consistentes (MATTHEWS, 1981; MARCOS FLLHO et al., 1987 e LOEFFLER et al., 1988).

Tabela 11. Valores médios (\%) de germinação (TG), primeira contagem de germinação (PC), envelhecimento artificial (EA) e grau de umidade (GU) dos lotes de sementes de soja, cultivar IAC-8 e coeficientes de variação. Piracicaba, 1991.

\begin{tabular}{lcccc}
\hline Lotes & TG $(\%)$ & PC $(\%)$ & EA $(\%)$ & GU (\%) \\
\hline 1 & $95 \mathrm{a}$ & $92 \mathrm{a}$ & $85 \mathrm{ab}$ & 10,6 \\
2 & $91 \mathrm{c}$ & $87 \mathrm{~b}$ & $85 \mathrm{ab}$ & 11,0 \\
3 & $92 \mathrm{bc}$ & $88 \mathrm{~b}$ & $81 \mathrm{~b}$ & 10,8 \\
4 & $94 \mathrm{ab}$ & $90 \mathrm{ab}$ & $86 \mathrm{a}$ & 10,9 \\
\hline $\mathrm{CV}(\%)$ & 4,79 & 4,48 & 4,50 & - \\
\hline
\end{tabular}

em cada coluna, médias seguidas pela mesma letra não diferiram entre si, pelo teste de Tukey, ao nível de $5 \%$ de probabilidade. 


\subsubsection{Cultivar IAC-15}

$\mathrm{O}$ exame dos valores de $\mathrm{F}$ obtidos nas análises de variância e apresentados na Tabela 12 permite constatar que ocorreram efeitos significativos para lotes e épocas para quase todos os parâmetros estudados, exceto para os efeitos de épocas no método CE I com 8 horas e CE 11 com 4 horas de embebição. Por outro lado, a interação lotes $\mathrm{x}$ épocas foi significativa, apenas nas avaliações de 20 horas no sistema CE I e nos estudos de lixiviação de potássio (KII), em todos os períodos de condicionamento.

Pela Tabela 13, observaram-se efeitos significativos de lotes e épocas na maioria dos estudos realizados com o ASA-610. De modo geral, os limites de 65, 60 e 55 uA não mostraram efeitos significativos para o fator lote nos períodos de embebição mais curtos, ou seja, 4 e 8 horas, enquanto os limites de 50 e 45 uA revelaram significância para lotes e épocas em todas as avaliações. Já a interação lotes $\mathrm{x}$ épocas mostrou-se altamente significativa nos periodos de condicionamento mais longos (20 e/ou 24 horas) em todos os limites testados.

Com referência aos valores de $\mathrm{F}$ obtidos nas análises de variância dos dados relativos aos testes para avaliação da qualidade fisiológica das sementes (Tabela 14), constataram-se efeitos altamente significativos de lotes e de épocas para todos os parâmetros. A interação lotes $x$ épocas, por sua vez, só não foi significativa no teste de primeira contagem de germinação.

\subsubsection{Condutividade elétrica CE I e II}

Os dados obtidos para os lotes do cultivar IAC-15 nos testes de condutividade elétrica de massa (Tabela 15) permitiram destacar o lote 1 em relação aos demais, nas avaliações feitas com 4 horas de embebição; no entanto, os números absolutos indicaram uma ligeira inferioridade para o lote 4, que também foi confirmada nos estudos realizados com 8 horas de embebição, que destacaram a superioridade do lote 3. Os resultados obtidos com 12, 16 e 20 horas foram semelhantes no sentido de agrupar os lotes 1 e 3 como de alta qualidade e os demais (2 e 4) numa condição inferior. Com 24 horas de condicionamento, as informações obtidas foram semelhantes àquelas fornecidas com 8 horas, principalmente, com relação à superioridade do lote 3 . Assim, de modo geral, os lotes 1 e 3 ocuparam posição de destaque em relação aos lotes 2 e 4 , ocorrendo pequenas variações em função do periodo de embebição considerado. 
Tabela 12. Valores de $\mathrm{F}$ obtidos nas análises de variância dos dados referentes aos testes de condutividade elétrica CE I e II e de lixiviação de potássio (KI e KII), para os lotes de sementes de soja, cultivar IAC-15. Piracicaba, 1991.

\begin{tabular}{lccc}
\hline Testes & \multicolumn{3}{c}{ Valores de F } \\
\hline & Lotes (L) & Épocas (E) & Interação (L x E) \\
\hline CE I - 4 h & $6,90^{* *}$ & $12,33^{* *}$ & $0,95^{\mathrm{ns}}$ \\
CE I - 8 h & $6,58^{* *}$ & $0,13^{\mathrm{ns}}$ & $1,86^{\mathrm{ns}}$ \\
CE I - 12 h & $14,71^{* *}$ & $3,30^{*}$ & $1,73^{\mathrm{ns}}$ \\
CE I - 16 h & $22,40^{* *}$ & $9,46^{* *}$ & $1,74^{\mathrm{ns}}$ \\
CE I - 20 h & $24,96^{* *}$ & $6,46^{* *}$ & $2,40^{*}$ \\
CE I - 24 h & $28,39^{* *}$ & $6,02^{* *}$ & $0,81^{\mathrm{ns}}$ \\
CE II - 4 h & $10,02^{* *}$ & $9,95^{* *}$ & $1,61^{\mathrm{ns}}$ \\
CE II - 8 h & $10,35^{* *}$ & $2,26^{\mathrm{ns}}$ & $0,90^{\mathrm{ns}}$ \\
CE II - 12 h & $37,65^{* *}$ & $11,57^{* *}$ & $1,41^{\mathrm{ns}}$ \\
CE II - 16 h & $37,45^{* *}$ & $21,14^{* *}$ & $1,66^{\mathrm{ns}}$ \\
CE II - 20 h & $50,09^{* *}$ & $16,85^{* *}$ & $2,03^{\mathrm{ns}}$ \\
CE II - 24 h & $21,08^{* *}$ & $5,83^{* *}$ & $0,62^{\mathrm{ns}}$ \\
K I - 60 minutos & $12,11^{* *}$ & $45,03^{* *}$ & $1,05^{\mathrm{ns}}$ \\
K I - 90 minutos & $19,48^{* *}$ & $118,19^{* *}$ & $2,15^{\mathrm{ns}}$ \\
K I - 120 minutos & $24,12^{* *}$ & $3,24^{* *}$ & $2,23^{\mathrm{ns}}$ \\
K I - 150 minutos & $38,96^{* *}$ & $34,73^{* *}$ & $2,33^{\mathrm{ns}}$ \\
K II - 60 minutos & $13,56^{* *}$ & $116,59^{* *}$ & $3,43^{* *}$ \\
K II - 90 minutos & $9,21^{* *}$ & $64,90^{* *}$ & $2,68^{*}$ \\
K II - 120 minutos & $14,63^{* *}$ & $34,24^{* *}$ & $2,66^{*}$ \\
K II - 150 minutos & $6,59^{* *}$ & $49,22^{* *}$ & $3,03^{*}$ \\
\hline
\end{tabular}

* - significativo ao nível de $5 \%$ de probabilidade.

** - significativo ao nível de $1 \%$ de probabilidade.

ns - não significativo. 
Tabela 13-Valores de F obtidos nas análises de variância dos dados referentes aos testes de condutividade elétrica individual (ASA-610), para os lotes do cultivar IAC15. Piracicaba, 1991.

\begin{tabular}{|c|c|c|c|}
\hline \multirow[t]{2}{*}{ Testes } & \multicolumn{3}{|c|}{ Valores de F } \\
\hline & Lotes $(\mathrm{L})$ & Épocas (E) & Interafão $(L \times E)$ \\
\hline ASA 95- $4 \mathrm{~h}$ & $1,46^{\mathrm{nS}}$ & $1,46^{\mathrm{ns}}$ & $1,26^{\mathrm{nS}}$ \\
\hline ASA $95-8 h$ & $1,68^{n S}$ & $3,90^{*}$ & $1,41^{\mathrm{ns}}$ \\
\hline ASA $95-12 \mathrm{~h}$ & $3,96^{*}$ & $12,50 * *$ & $2,68^{*}$ \\
\hline ASA $95-16 h$ & $5,24 * *$ & $13,50 * *$ & $2,08^{*}$ \\
\hline ASA $95-20 h$ & $6,35^{* *}$ & $16,80^{* *}$ & $2,96^{* *}$ \\
\hline ASA $95-24 h$ & $0,19^{n s}$ & $1,48^{\mathrm{ns}}$ & $5,06^{* *}$ \\
\hline ASA $90-4 h$ & $2,42^{n S}$ & $0,10^{\text {ns }}$ & $0,96^{\mathrm{ns}}$ \\
\hline ASA $90-8 h$ & $0,61^{\mathrm{ns}}$ & $1,47^{\mathrm{ns}}$ & $0,85^{\mathrm{nS}}$ \\
\hline ASA $90-12 h$ & $2,80^{*}$ & $9,46^{* *}$ & $1,24^{\mathrm{ns}}$ \\
\hline ASA $90-16 h$ & $5,82 * *$ & $20,84 * *$ & $1,71^{\mathrm{ns}}$ \\
\hline ASA $90-20 h$ & $6,75^{* *}$ & $21,12^{* *}$ & $2,75^{*}$ \\
\hline ASA $90-24 \mathrm{~h}$ & $0,38^{n s}$ & $8,52^{* *}$ & $3,08^{* *}$ \\
\hline ASA $85-4 h$ & $1,17^{\mathrm{ns}}$ & $0,07^{\mathrm{ns}}$ & $1,15^{\mathrm{ns}}$ \\
\hline ASA $85-8 h$ & $1,33^{\mathrm{ns}}$ & $1,75^{\mathrm{ns}}$ & $0,98^{\mathrm{ns}}$ \\
\hline ASA $85-12 \mathrm{~h}$ & $5,88^{* *}$ & $10,95 * *$ & $2,50^{*}$ \\
\hline ASA $85-16 h$ & $5,62 * *$ & $24,06 * *$ & $2,38^{*}$ \\
\hline ASA $85-20 h$ & $3,98^{*}$ & $15,58 * *$ & $1,72^{\mathrm{ns}}$ \\
\hline ASA $85-24 h$ & $1,03^{\mathrm{ns}}$ & $17,36 * *$ & $4,33^{* *}$ \\
\hline ASA $80-4 h$ & $1,93^{\mathrm{ns}}$ & $0,56^{\mathrm{ns}}$ & $0,65^{\text {ns }}$ \\
\hline ASA $80-\quad 8 \mathrm{~h}$ & $3,07^{*}$ & $1,07^{\mathrm{ns}}$ & $1,37^{\mathrm{ns}}$ \\
\hline ASA $80-12 \mathrm{~h}$ & $8,23^{* *}$ & $16,37^{* *}$ & $2,43^{*}$ \\
\hline ASA $80-16 h$ & $4,18^{*}$ & $27,11^{* *}$ & $1,58^{\mathrm{ns}}$ \\
\hline ASA $80-20 h$ & $3,05^{*}$ & $17,52 * *$ & $2,32^{*}$ \\
\hline ASA $80-24 h$ & $1,56^{\mathrm{ns}}$ & $12,76^{* *}$ & $2,24^{*}$ \\
\hline ASA $75-4 h$ & $1,44^{\mathrm{ns}}$ & $0,95^{\mathrm{ns}}$ & $0,72^{n s}$ \\
\hline ASA $75-8 h$ & $2,34^{n s}$ & $0,85^{n s}$ & $1,36^{\mathrm{ns}}$ \\
\hline ASA $75-12 \mathrm{~h}$ & $7,51^{* *}$ & $14,27^{* *}$ & $2,30^{*}$ \\
\hline ASA $75-16 h$ & $4,81 * *$ & $23,70 * *$ & $1,25^{\mathrm{ns}}$ \\
\hline ASA $75-20 h$ & $5,80^{* *}$ & $19,03^{* *}$ & $2,57^{*}$ \\
\hline ASA $75-24 h$ & $3.21^{*}$ & $29,98 * *$ & $4,50^{* *}$ \\
\hline ASA $70-4 h$ & $0,64^{\mathrm{ns}}$ & $1,33^{\mathrm{ns}}$ & $1,73^{\mathrm{ns}}$ \\
\hline ASA $70-8 h$ & $1,47^{\mathrm{ns}}$ & $1,90^{\mathrm{ns}}$ & $1,24^{\mathrm{ns}}$ \\
\hline ASA $70-12 \mathrm{~h}$ & $5,05^{* *}$ & $16,28 * *$ & $1,42^{\mathrm{ns}}$ \\
\hline ASA $70-16 h$ & $4,10^{*}$ & $20,30 * *$ & $0.94^{\mathrm{ns}}$ \\
\hline ASA $70-20 h$ & $2,92 *$ & $5,75^{* *}$ & $0,60^{\mathrm{ns}}$ \\
\hline ASA $70-24 h$ & $5,25^{* *}$ & $37,88 * *$ & $5,42 * *$ \\
\hline ASA $65-4 h$ & $1,38^{\mathrm{nS}}$ & $0,64^{\mathrm{ns}}$ & $1,71^{\mathrm{ns}}$ \\
\hline ASA $65-8 \mathrm{~h}$ & $0,76^{\mathrm{ns}}$ & $3,03^{n s}$ & $1,23^{\mathrm{ns}}$ \\
\hline ASA $65 .-12 \mathrm{~h}$ & $4,31^{* *}$ & $11,07^{* *}$ & $1,29^{\mathrm{ns}}$ \\
\hline ASA $65-16 \mathrm{~h}$ & $5,73^{* *}$ & $24,71 * *$ & $1,38^{\mathrm{ns}}$ \\
\hline ASA $65-20 h$ & $9,37^{* *}$ & $20,06 * *$ & $3,55^{* *}$ \\
\hline ASA $65-24 h$ & $9,87^{* *}$ & $32,31^{* *}$ & $4,68^{* *}$ \\
\hline
\end{tabular}


continuação

Tabela 13. Valores de $\mathrm{F}$ obtidos nas análises de variância dos dados referentes aos testes de condutividade elétrica individual (ASA-610), para os lotes do cultivar IAC15. Piracicaba, 1991.

\begin{tabular}{|c|c|c|c|}
\hline \multirow[t]{2}{*}{ Testes } & \multicolumn{3}{|c|}{ Valores de F } \\
\hline & Lotes (L) & Epocas (E) & Interação (L $\times \mathrm{E})$ \\
\hline ASA $60-4 h$ & $1,84^{\mathrm{ns}}$ & $1,46^{\text {ns }}$ & $3,15^{* *}$ \\
\hline ASA $60-8 h$ & $1,18^{n s}$ & $4,43^{*}$ & $1,39 \mathrm{~ns}$ \\
\hline ASA $60-12 \mathrm{~h}$ & $6,77^{* *}$ & $15,42 * *$ & $5,66 * *$ \\
\hline ASA $60-16 h$ & $9,39 * *$ & $28,58^{* *}$ & $7,29 * *$ \\
\hline ASA $60-20 h$ & $15,73 * *$ & $19,15^{* *}$ & $1,28^{\mathrm{ns}}$ \\
\hline ASA $60-24 \mathrm{~h}$ & $16,16^{* *}$ & $33,13 * *$ & $6,71^{* *}$ \\
\hline ASA $55-4 h$ & $2,24^{\mathrm{ns}}$ & $2,11^{\mathrm{ns}}$ & $2,32^{*}$ \\
\hline ASA 55- $8 \mathrm{~h}$ & $1,16^{\mathrm{ns}}$ & $8,47 * *$ & $1,03^{\mathrm{ns}}$ \\
\hline ASA $55-12 \mathrm{~h}$ & $8,67 * *$ & $17,77 * *$ & $6,55^{* *}$ \\
\hline ASA $55-16 h$ & $16,77 * *$ & $28,10^{* *}$ & $10,56 * *$ \\
\hline ASA $55-20 h$ & $30,16 * *$ & $19,33^{* *}$ & $4,74 * *$ \\
\hline ASA $55-24 h$ & $33,48 * *$ & $34,79 * *$ & $8,76^{* *}$ \\
\hline ASA $50-4 h$ & $4,30 * *$ & $4,15^{*}$ & $2,04^{\mathrm{ns}}$ \\
\hline ASA $50-8 h$ & $3,78^{*}$ & $19,39 * *$ & $1,27^{\mathrm{ns}}$ \\
\hline ASA $50-12 \mathrm{~h}$ & $13,19 * *$ & $15,91 * *$ & $8,38 * *$ \\
\hline ASA $50-16 h$ & $27,86 * *$ & $33,29 * *$ & $17,74 * *$ \\
\hline ASA $50-20 h$ & $30,16^{* *}$ & $17,46^{* *}$ & $6,47 * *$ \\
\hline ASA $50-24 h$ & $54,94 * *$ & $33,46 * *$ & $6,71 * *$ \\
\hline ASA $45-4 h$ & $7,02 * *$ & $6,49 * *$ & $0,57^{\mathrm{ns}}$ \\
\hline ASA $45-8 h$ & $6,35 * *$ & $30,30 * *$ & $7,04 * *$ \\
\hline ASA $45-12 \mathrm{~h}$ & $27,68 * *$ & $24,37 * *$ & $12,44 * *$ \\
\hline ASA $45-16 h$ & $44,01 * *$ & $59,00 * *$ & $28,04 * *$ \\
\hline ASA $45-20 h$ & $56,13 * *$ & $29,13 * *$ & $14,23 * *$ \\
\hline ASA $45-24 \mathrm{~h}$ & $71,02 * *$ & $32,70 * *$ & $7,55^{* *}$ \\
\hline
\end{tabular}

* - significativo ao nivel de $5 \%$ de probabilidade

** - significativo ao nível de $1 \%$ de probabilidade

ns - não significativo 
Tabela 14. Valores de F obtidos nas análises de variância dos dados referentes aos testes de germinação (TG), primeira contagem de germinação (PC) e envelhecimento artificial (EA), para os lotes do cultivar IAC-15. Piracicaba, 1991.

\begin{tabular}{lccc}
\hline Causas de Variação & \multicolumn{3}{c}{ Valores de $\mathrm{F}$} \\
\cline { 2 - 4 } & TG & PC & EA \\
\hline Lotes $(\mathrm{L})$ & $9,03^{* *}$ & $6,13^{* *}$ & $74,96^{* *}$ \\
Épocas $(\mathrm{E})$ & $34,43^{* *}$ & $43,67^{* *}$ & $68,47^{* *}$ \\
Interação $(\mathrm{L} \times \mathrm{E})$ & $22,27^{* *}$ & $1,57^{\mathrm{ns}}$ & $3,55^{* *}$ \\
\hline
\end{tabular}

**- significativo ao nível de $1 \%$ de probabilidade.

ns - não significativo.

Cabe ressaltar que o período de 4 horas mostrou-se menos sensível às diferenças de qualidade entre os lotes, o que também foi constatado por MARCOS FILHO et al. (1990), empregando a mesma metodologia em sementes de soja.

Por sua vez, o teste envolvendo sementes fisicamente puras (CE II) revelou tendências semelhantes ao sistema I, indicando qualidade fisiológica elevada para os lotes 1 e 3 e inferior para os lotes 2 e 4 nos estudos realizados a partir da $8 \underline{a}$ hora de embebição. Nota-se, contudo, que as leituras feitas com 4 horas de condicionamento identificaram os lotes 1 e 2 como apresentando, respectivamente, melhor e pior desempenho, mostrando-se mais sensíveis que o mesmo período no sistema I (Tabela 15). LOEFFLER et al. (1988) também empregando o sistema II, obtiveram uma separação mais eficiente dos lotes nos períodos de embebição mais longos.

Examinando ainda a Tabela 15, verificou-se um aumento gradativo dos valores de condutividade com o decorrer da embebição, sendo que leituras mais altas foram obtidas no método II, conforme também observado para os lotes do cultivar IAC-8. 
Tabela 15. Condutividade elétrica (CE I e II): valores médios (umhos/cm/g) para os lotes de sementes de soja, cultivar IAC-15, em cada período de embebição (médias de 4 épocas) e coeficientes de variação. Piracicaba, 1991.

\begin{tabular}{|c|c|c|c|c|c|c|c|}
\hline \multirow[t]{2}{*}{ Lotes } & \multicolumn{6}{|c|}{ CE I - Períodos (h) } & \multirow[t]{2}{*}{ Médias } \\
\hline & 4 & 8 & 12 & 16 & 20 & 24 & \\
\hline 1 & $37,21 \mathrm{a}$ & $52,73 \mathrm{ab}$ & 58,15 a & $67,95 \mathrm{a}$ & 77,49 a & $86,62 \mathrm{~b}$ & 63,36 \\
\hline 2 & $41,31 \mathrm{~b}$ & $55,31 \mathrm{bc}$ & $67,31 b$ & $81,64 \mathrm{~b}$ & $92,98 \mathrm{~b}$ & $95,65 \mathrm{~b}$ & 72,37 \\
\hline 3 & $40,56 \mathrm{~b}$ & $51,01 \mathrm{a}$ & $60,12 \mathrm{a}$ & $69,84 \mathrm{a}$ & $75,85 \mathrm{a}$ & $77,55 \mathrm{a}$ & 62,49 \\
\hline 4 & $42,36 \mathrm{~b}$ & $56,51 \mathrm{c}$ & $68,93 \mathrm{~b}$ & $82,90 \mathrm{~b}$ & $92,82 \mathrm{~b}$ & $99,59 \mathrm{c}$ & 73,85 \\
\hline Médias & 40,36 & 53,89 & 63,58 & 75,58 & 84,79 & 89,85 & \\
\hline $\operatorname{CV}(\%)$ & 8,41 & 7,19 & 8,67 & 8,70 & 8,87 & 8,22 & \\
\hline \multirow[t]{2}{*}{ Lotes } & \multicolumn{6}{|c|}{ CE II - Períodos (h) } & \multirow[t]{2}{*}{ Médias } \\
\hline & 4 & 8 & 12 & 16 & 20 & 24 & \\
\hline 1 & $41,94 \mathrm{a}$ & $61,44 \mathrm{a}$ & $65,60 \mathrm{a}$ & $81,21 \mathrm{a}$ & $88,27 \mathrm{a}$ & $95,51 \mathrm{a}$ & 72,16 \\
\hline 2 & $48,18 \mathrm{c}$ & $69,18 b$ & $79,12 b$ & $95,59 \mathrm{~b}$ & $106,04 \mathrm{~b}$ & $110,49 b$ & 84,77 \\
\hline 3 & $44,63 \mathrm{ab}$ & $62,10 \mathrm{a}$ & $69,24 \mathrm{a}$ & $82,29 \mathrm{a}$ & $90,03 \mathrm{a}$ & $94,50 \mathrm{a}$ & 73,80 \\
\hline 4 & 47,32 bc & $67,36 \mathrm{~b}$ & $81,88 \mathrm{~b}$ & $98,31 \mathrm{~b}$ & $109,17 \mathrm{~b}$ & $109,65 \mathrm{~b}$ & 85,62 \\
\hline Médias & 45,52 & 65,02 & 73,96 & 89,10 & 98,38 & 102,54 & \\
\hline $\mathrm{CV}(\%)$ & 7,84 & 7,33 & 6,86 & 6,73 & 6,18 & 7,40 & \\
\hline
\end{tabular}

em cada coluna, médias seguidas pela mesma letra não diferiram entre si, pelo teste de Tukey, ao nível de $5 \%$ de probabilidade. 


\subsubsection{Condutividade elétrica individual}

Pela Tabela 16 observa-se, de modo geral, que as intensidades de corrente elétrica maiores que 75 uA forneceram informações menos detalhadas sobre a qualidade fisiológica dos lotes, destacando a superioridade do lote 3 em relação aos demais. Tal classificação não foi constatada em todos os períodos de tempo estudados, ocorrendo variações de acordo com o valor limite considerado. Assim, nos limites de 95 e $85 \mathrm{uA}$, os períodos mais sensíveis foram os de 12,16 e 20 horas, enquanto que com $90 \mathrm{uA}$ foram os de 16 e 20 horas. Por sua vez, no limite de $80 \mathrm{uA}$, diferenças significativas entre os lotes foram obtidas com 8, 12 e 16 horas de embebição.

Observou-se ainda na Tabela 16, nos limites situados entre 75 e 55 uA, que não houve diferenças significativas entre os lotes quando foram adotados períodos de condicionamento mais curtos ( 4 e 8 horas). Tais períodos só exibiram sensibilidade nas intensidades de corrente mais baixas como, por exemplo, 50 e 45 uA. O melhor desempenho do lote 3 também foi constatado nas intensidades de corrente elétrica abaixo de $75 \mathrm{uA}$, exceto no período de 24 horas, que destacou o lote 1 como superior. Com referência ao lote de qualidade inferior, ocorreram algumas variações, embora á maioria dos estudos tenha indicado os lotes 2 e 4 .

As regulagens de 50 e 45 uA (Tabela 16), de modo geral, classificaram os lotes 1 e 3 como superiores aos lotes 2 e 4 , já no início da embebição mostrando que com a redução da intensidade de corrente elétrica (uA) foi possível a obtenção de resultados consistentes num período de tempo mais curto ( 4 e 8 horas). Tais períodos exibiram coeficientes de variação inferiores àqueles obtidos nas avaliações de 16, 20 e 24 horas, considerados relativamente altos para experimentos conduzidos sob condições controladas.

A análise global dos resultados obtidos com o ASA-610 (Tabela 16) mostrou, de uma maneira geral, que todos os valores de corrente elétrica testados identificaram o lote 3 como de elevada qualidade fisiológica, embora acompanhado pelo lote 1 em algumas avaliações, agrupando os lotes 2 e 4 como inferiores. Este aparelho foi considerado por STEERE et al. (1981) como promissor para a indicação rápida da qualidade de sementes de soja, feijão e algodão.

Os resultados da Tabela 16 mostraram-se concordantes com aqueles obtidos no método de massa (Tabela 15) quanto à separação dos lotes em níveis de vigor. McDONALD Jr. \& WILSON (1979) observaram alta correlação entre valores de corrente elétrica ( $\mathrm{uA} /$ semente) e de condutividade (umhos/semente), indicando 
Tabela 16. Condutividade elétrica individual (ASA-610): dados médios (\%) obtidos para os valores limites (VL) e períodos de embebição para os lotes de sementes de soja, cultivar IAC-15 e coeficientes de variação (médias de 4 épocas ). Piracicaba, 1991.

\begin{tabular}{|c|c|c|c|c|c|c|c|c|}
\hline \multirow[t]{2}{*}{$\operatorname{VL}(\mathbf{u A})$} & \multirow[t]{2}{*}{ Lotes } & \multicolumn{7}{|c|}{ Períodos (h) } \\
\hline & & 4 & 8 & 12 & 16 & 20 & 24 & Médias \\
\hline \multirow[t]{6}{*}{95} & 1 & $100 a$ & $100 a$ & 996 & $97 \mathrm{~b}$ & $95 b$ & $95 a$ & 98 \\
\hline & 2 & $100 a$ & $100 a$ & $99 \mathrm{~b}$ & $98 a b$ & $95 \mathrm{~b}$ & $96 a$ & 99 \\
\hline & 3 & $100 a$ & $100 a$ & $100 a$ & 99 a & 98 a & $96 a$ & 99 \\
\hline & 4 & $100 a$ & $100 \mathrm{a}$ & $100 \mathrm{~b}$ & $97 \mathrm{~b}$ & $96 \mathrm{~b}$ & $95 \mathrm{a}$ & 98 \\
\hline & Médias & 100 & 100 & 98 & 97 & 96 & 96 & \\
\hline & $\mathrm{CV}(\%)$ & 1,67 & 2,54 & 4,03 & 4,83 & 4,67 & 4,12 & \\
\hline \multirow[t]{6}{*}{90} & 1 & $100 a$ & $100 a$ & $98 \mathrm{a}$ & $95 \mathrm{~b}$ & $93 \mathrm{~b}$ & $94 a$ & 98 \\
\hline & 2 & $100 \mathrm{a}$ & $100 \mathrm{a}$ & $98 \mathrm{a}$ & $97 \mathrm{ab}$ & $94 \mathrm{~b}$ & 94 a & 98 \\
\hline & 3 & $100 \mathrm{a}$ & $100 a$ & 99 a & $99 \mathrm{a}$ & $97 a$ & 94 a & 99 \\
\hline & 4 & $100 a$ & $100 a$ & $98 \mathrm{a}$ & $96 \mathrm{~b}$ & $94 \mathrm{~b}$ & $93 a$ & 97 \\
\hline & Médias & 100 & 100 & 99 & 97 & 95 & 94 & \\
\hline & $\operatorname{CV}(\%)$ & 2,60 & 3,79 & 4,84 & 5,13 & 4,65 & 4,84 & \\
\hline \multirow[t]{6}{*}{85} & 1 & $100 a$ & $99 a$ & $97 b$ & $94 \mathrm{~b}$ & $90 b$ & $93 a$ & 96 \\
\hline & 2 & $100 \mathrm{a}$ & $100 a$ & $98 \mathrm{~b}$ & $95 \mathrm{~b}$ & $91 \mathrm{ab}$ & $93 a$ & 96 \\
\hline & 3 & $100 a$ & $100 a$ & 99 a & $98 \mathrm{a}$ & $95 \mathrm{a}$ & 92 a & 97 \\
\hline & 4 & $100 a$ & $100 a$ & $97 \mathrm{~b}$ & $95 \mathrm{~b}$ & $91 \mathrm{ab}$ & $91 \mathrm{a}$ & 97 \\
\hline & Médias & 100 & 100 & 98 & 95 & 92 & 92 & \\
\hline & $\operatorname{CV}(\%)$ & 3,09 & 3,92 & 4,23 & 4,81 & 5,74 & 4,06 & \\
\hline \multirow[t]{6}{*}{80} & 1 & $100 a$ & $99 \mathrm{~b}$ & $96 \mathrm{~b}$ & $92 b$ & $89 a$ & $91 \mathrm{a}$ & 95 \\
\hline & 2 & $100 \mathrm{a}$ & $99 \mathrm{ab}$ & $96 \mathrm{~b}$ & $92 \mathrm{~b}$ & $89 a$ & $91 \mathrm{a}$ & 95 \\
\hline & 3 & $100 \mathrm{a}$ & $100 \mathrm{a}$ & $98 \mathrm{a}$ & $96 a$ & $92 \mathrm{a}$ & $90 a$ & 96 \\
\hline & 4 & $100 a$ & $99 a b$ & $96 \mathrm{~b}$ & $93 \mathrm{ab}$ & $88 \mathrm{a}$ & $89 a$ & 94 \\
\hline & Médias & 100 & 99 & 97 & 93 & 90 & 89 & \\
\hline & $\mathrm{CV}(\%)$ & 3,66 & 3,91 & 3,91 & 5,27 & 5,38 & 5,26 & \\
\hline \multirow[t]{6}{*}{75} & 1 & $100 a$ & $98 \mathrm{a}$ & $94 \mathrm{~b}$ & $89 \mathrm{~b}$ & $86 b$ & $89 a$ & 93 \\
\hline & 2 & 99 a & 99 a & $94 \mathrm{~b}$ & $90 \mathrm{~b}$ & $84 \mathrm{~b}$ & $87 \mathrm{ab}$ & 92 \\
\hline & 3 & $100 \mathrm{a}$ & 99 a & $98 \mathrm{a}$ & 94 a & $90 \mathrm{a}$ & $87 \mathrm{ab}$ & 95 \\
\hline & 4 & $100 a$ & $98 \mathrm{a}$ & $94 \mathrm{~b}$ & $90 \mathrm{~b}$ & $84 b$ & $85 \mathrm{~b}$ & 92 \\
\hline & Médias & 100 & 99 & 95 & 91 & 86 & 87 & \\
\hline & CV(\%) & 4,12 & 3,95 & 4,66 & 5,66 & 5,54 & 4,19 & \\
\hline \multirow[t]{6}{*}{70} & 1 & $99 a$ & $98 \mathrm{a}$ & $93 \mathrm{ab}$ & $87 \mathrm{ab}$ & $83 a b$ & $86 a$ & 91 \\
\hline & 2 & $100 a$ & $98 a$ & $92 \mathrm{~b}$ & $86 \mathrm{~b}$ & $74 b$ & $83 \mathrm{ab}$ & 89 \\
\hline & 3 & $99 a$ & $99 a$ & $95 \mathrm{a}$ & $91 \mathrm{a}$ & $86 a$ & $84 a b$ & 92 \\
\hline & 4 & 99 a & 97 a & $92 \mathrm{~b}$ & $86 \mathrm{~b}$ & $80 \mathrm{ab}$ & $81 \mathrm{~b}$ & 89 \\
\hline & Médias & 99 & 98 & 93 & 88 & 81 & 84 & \\
\hline & $\mathrm{CV}(\%)$ & 3,73 & 3,71 & 4,97 & 6,22 & 13,99 & 4,52 & \\
\hline
\end{tabular}


continuação

Tabela 16. Condutividade elétrica individual (ASA-610): dados médios (\%) obtidos para os valores limites (VL) e periodos de embebição para os lotes de sementes de soja, cultivar IAC-15 e coeficientes de variação (médias de 4 épocas). Piracicaba, 1991.

\begin{tabular}{|c|c|c|c|c|c|c|c|c|}
\hline \multirow[t]{2}{*}{ VL(uA) } & \multirow[t]{2}{*}{ Lotes } & \multicolumn{7}{|c|}{ Períodos (h) } \\
\hline & & 4 & 8 & 12 & 16 & 20 & 24 & Médias \\
\hline \multirow[t]{6}{*}{65} & 1 & $99 a$ & $97 \mathrm{a}$ & $90 \mathrm{ab}$ & $84 a b$ & $80 \mathrm{a}$ & $84 a$ & 89 \\
\hline & 2 & $99 a$ & 97 a & $88 \mathrm{~b}$ & $82 \mathrm{~b}$ & $74 \mathrm{~b}$ & $77 \mathrm{bc}$ & 86 \\
\hline & 3 & $99 a$ & $97 \mathrm{a}$ & $92 \mathrm{a}$ & $88 \mathrm{a}$ & $83 a$ & $80 \mathrm{ab}$ & 90 \\
\hline & 4 & $98 \mathrm{a}$ & $97 \mathrm{a}$ & $88 \mathrm{~b}$ & $82 \mathrm{~b}$ & $74 \mathrm{~b}$ & $75 \mathrm{c}$ & 86 \\
\hline & Médias & 99 & 97 & 90 & 84 & 78 & 79 & \\
\hline & $\operatorname{CV}(\%)$ & 4,27 & 4,21 & 5,69 & 6,24 & 6,73 & 5,75 & \\
\hline \multirow[t]{6}{*}{60} & 1 & $98 \mathrm{a}$ & $96 \mathrm{a}$ & $88 \mathrm{ab}$ & $81 \mathrm{ab}$ & $76 a$ & $81 a$ & 87 \\
\hline & 2 & $97 \mathrm{a}$ & $95 \mathrm{a}$ & $83 \mathrm{~b}$ & $76 \mathrm{~b}$ & $64 \mathrm{~b}$ & $69 \mathrm{~b}$ & 81 \\
\hline & 3 & $98 \mathrm{a}$ & $96 \mathrm{a}$ & $90 a$ & $85 \mathrm{a}$ & $78 \mathrm{a}$ & $76 a$ & 87 \\
\hline & 4 & $98 \mathrm{a}$ & $95 \mathrm{a}$ & $85 \mathrm{~b}$ & $75 \mathrm{~b}$ & $65 \mathrm{~b}$ & $67 \mathrm{~b}$ & 81 \\
\hline & Médias & 98 & 95 & 87 & 79 & 71 & 73 & \\
\hline & $\mathrm{CV}(\%)$ & 3,97 & 4,39 & 5,29 & 6,90 & 7,66 & 6,94 & \\
\hline \multirow[t]{6}{*}{55} & 1 & $98 \mathrm{a}$ & $95 \mathrm{a}$ & $84 \mathrm{ab}$ & $76 \mathrm{a}$ & $71 a$ & $76 a$ & 85 \\
\hline & 2 & $96 \mathrm{a}$ & $93 a$ & $79 \mathrm{c}$ & $66 \mathrm{~b}$ & $51 \mathrm{~b}$ & $58 \mathrm{~b}$ & 64 \\
\hline & 3 & $97 \mathrm{a}$ & $93 \mathrm{a}$ & $86 a$ & $80 a$ & $70 a$ & $71 a$ & 83 \\
\hline & 4 & $97 \mathrm{a}$ & $93 \mathrm{a}$ & $80 \mathrm{bc}$ & $66 \mathrm{~b}$ & $53 \mathrm{~b}$ & $56 \mathrm{~b}$ & 74 \\
\hline & Médias & 97 & 94 & 82 & 72 & 61 & 66 & \\
\hline & $\operatorname{CV}(\%)$ & 4,27 & 4,65 & 5,33 & 7,77 & 9,25 & 7,80 & \\
\hline \multirow[t]{6}{*}{50} & 1 & $97 \mathrm{a}$ & $93 a$ & $81 \mathrm{a}$ & $72 a$ & $64 a$ & $71 a$ & 80 \\
\hline & 2 & $94 \mathrm{~b}$ & $91 \mathrm{ab}$ & $72 \mathrm{~b}$ & $50 \mathrm{~b}$ & $35 \mathrm{~b}$ & $42 \mathrm{c}$ & 64 \\
\hline & 3 & $96 a b$ & $92 a b$ & $81 \mathrm{a}$ & $72 a$ & $61 \mathrm{a}$ & $64 b$ & 78 \\
\hline & 4 & $95 \mathrm{ab}$ & $90 \mathrm{~b}$ & $72 \mathrm{~b}$ & $53 \mathrm{~b}$ & $39 \mathrm{~b}$ & $43 \mathrm{c}$ & 65 \\
\hline & Médias & 96 & 92 & 77 & 62 & 50 & 55 & \\
\hline & $\operatorname{CV}(\%)$ & 4,05 & 4,05 & 6,66 & 10,17 & 14,02 & 9,72 & \\
\hline \multirow[t]{6}{*}{45} & 1 & $96 \mathrm{a}$ & $92 a$ & $76 a$ & $61 \mathrm{a}$ & $52 \mathrm{a}$ & $58 \mathrm{a}$ & 73 \\
\hline & 2 & $92 \mathrm{~b}$ & $88 \mathrm{~b}$ & $58 \mathrm{~b}$ & $34 \mathrm{~b}$ & $18 \mathrm{~b}$ & $21 \mathrm{c}$ & 52 \\
\hline & 3 & $93 \mathrm{~b}$ & $89 a b$ & $75 \mathrm{a}$ & $61 \mathrm{a}$ & $47 \mathrm{a}$ & $49 \mathrm{~b}$ & 69 \\
\hline & 4 & $93 \mathrm{~b}$ & $87 \mathrm{~b}$ & $58 \mathrm{~b}$ & $40 \mathrm{~b}$ & $23 \mathrm{~b}$ & $25 \mathrm{c}$ & 54 \\
\hline & Médias & 94 & 89 & 67 & 49 & 35 & 38 & \\
\hline & $\operatorname{CV}(\%)$ & 3,84 & 3,97 & 8,57 & 11,02 & 15,60 & 13,82 & \\
\hline
\end{tabular}

em cada coluna, médias seguidas pela mesma letra não diferiram entre si, pelo teste de Tukey, ao nível de $5 \%$ de probabilidade. 
que ambas as metodologias foram eficientes no monitoramento dos exsudatos das sementes de soja, e conseqüentemente, na avaliação da qualidade fisiológica dos lotes.

\subsubsection{Lixiviação de potássio (KI e KII)}

Os resultados apresentados na Tabela 17 revelaram que os testes de lixiviação de potássio indicaram a superioridade do lote 1 tanto na sistema KI como no $\mathrm{KII}$, em todos os períodos de embebição estudados. Pelo método $\mathrm{Kl}$, verificou-se a possibilidade de classificação dos lotes em níveis de qualidade fisiológica já aos 60 minutos de embebição, com destaque para o melhor desempenho do lote 1 e a qualidade inferior do lote 2 , situando os lotes 3 e 4 numa posição intermediária. Resultados semelhantes foram obtidos com as avaliações feitas aos 90, 120 e 150 minutos indicando que todos os períodos de condicionamento mostraram-se eficientes para a separação dos quatro lotes. Entretanto, o coeficiente de variação de 19,20\% obtido com o período de 60 minutos foi considerado alto, demostrando grande variabilidade nas leituras. Este fato também foi observado para o cultivar IAC-8.

Por outro lado, a condução do teste com sementes fisicamente puras (KII) forneceu informações semelhantes aos 60, 90 e 120 minutos revelando o melhor potencial do lote 1 em relação aos lotes 2,3 e 4 , os quais não diferiram significativamente entre si. No entanto, a quantidade de potássio lixiviado, em termos absolutos, indica uma tendência de inferioridade para o lote 2 . Por sua vez, a avaliação realizada aos 150 minutos de embebição permitiu a ordenação dos lotes, mostrando-se mais sensível, destacando o alto desempenho do lote 1 e a inferioridade dos lotes 2 e 3 . Neste caso, o lote 4, classificado nos demais períodos como de qualidade inferior, ocupou posição intermediária (Tabela 17).

A Tabela 17 indica ainda, um aumento na quantidade de potássio lixiviado com o decorrer do tempo, em ambos os sistemas, com leituras mais elevadas para KII, conforme também comentado para o cultivar IAC-8.

Verificou-se, portanto, que informações mais detalhadas sobre a qualidade fisiológica dos lotes foram obtidas através do sistema KI, ao contrário dos resultados do cultivar IAC-8, onde o método II foi mais eficiente quanto à classificação dos lotes. 
Tabela 17. Lixiviação de potássio (KI e KII): valores médios ( $\mathrm{ppm} / \mathrm{g}$ ) obtidos para os lotes de sementes de soja, cultivar IAC-15, em cada período de embebição (média de 3 épocas) e coeficientes de variação. Piracicaba, 1991.

\begin{tabular}{|c|c|c|c|c|c|}
\hline \multirow[t]{2}{*}{ Lotes } & \multicolumn{4}{|c|}{ K I - Períodos (min.) } & \multirow[t]{2}{*}{ Médias } \\
\hline & 60 & 90 & 120 & 150 & \\
\hline 1 & $548 \mathrm{a}$ & $642 \mathrm{a}$ & $647 \mathrm{a}$ & $719 a$ & 639 \\
\hline 2 & $879 c$ & $897 \mathrm{c}$ & $866 \mathrm{c}$ & $913 \mathrm{c}$ & 889 \\
\hline 3 & $712 b$ & $778 \mathrm{~b}$ & $762 \mathrm{~b}$ & $858 \mathrm{~b}$ & 778 \\
\hline 4 & 798 bc & $838 \mathrm{bc}$ & $787 \mathrm{~b}$ & 895 bc & 830 \\
\hline Médias & 734 & 789 & 765 & 846 & \\
\hline CV (\%) & 19,20 & 10,87 & 8,33 & 5,77 & \\
\hline \multirow[t]{2}{*}{ Lotes } & \multicolumn{4}{|c|}{ K II - Periodos (min.) } & Médias \\
\hline & 60 & 90 & 120 & 150 & \\
\hline 1 & $556 \mathrm{a}$ & $668 \mathrm{a}$ & $737 \mathrm{a}$ & $860 \mathrm{a}$ & 710 \\
\hline 2 & 799 b & $853 \mathrm{~b}$ & $947 b$ & $972 b$ & 893 \\
\hline 3 & $707 \mathrm{~b}$ & $824 \mathrm{~b}$ & $895 \mathrm{~b}$ & $988 b$ & 854 \\
\hline 4 & $740 \mathrm{~b}$ & $849 \mathrm{~b}$ & $893 \mathrm{~b}$ & $928 \mathrm{ab}$ & 853 \\
\hline Médias & 701 & 804 & 868 & 937 & \\
\hline CV (\%) & 13,91 & 11,08 & 9,47 & 8,24 & \\
\hline
\end{tabular}

em cada coluna, médias seguidas pela mesma letra não diferiram entre si, pelo teste de Tukey, ao nível de $5 \%$ de probabilidade. 
$\dot{E}$ importante salientar que estes resultados indicam que a avaliação da quantidade de potássio presente nos exsudatos das sementes demanda período de tempo relativamente curto, ou seja, inferior a 150 minutos, permitindo que informações sobre a qualidade fisiológica dos lotes sejam obtidas rapidamente. MARCOS FILHO et al. (1982) caracterizaram a maturidade fisiológica de sementes de soja através da lixiviação de potássio. Por outro lado, MARCOS FILHO et al.(1984) e BARROS (1988) não obtiveram resultados promissores com o referido teste em sementes de soja.

Destacando as informações obtidas nos estudos de lixiviação de potássio (Tabela 17) e estabelecendo relações com a condutividade elétrica de massa (Tabela 15), verificou-se, de modo geral, concordância quanto à indicação da elevada qualidade do lote 1 , apesar do sistema de massa ter classificado nesta categoria também o lote 3. Da mesma forma, o teste de condutividade indicou, na maioria dos periodos de embebição, o pior desempenho dos lotes 2 e 4 , enquanto o método KI destacou condição inferior para o lote 2. Informações bastante próximas foram observadas entre CE II com 4 horas de embebição e $\mathrm{KI}$ em todos os períodos de condicionamento. Estudos realizados por HALLOIN (1975), com sementes de algodão, constataram que a concentração de ions $\mathrm{K}^{+}$mostrou correspondência com a condutividade elétrica dos exsudatos. Também trabalhando com algodão, WOODSTOCK et al. (1985) concluíram que a avaliação da quantidade de $\mathrm{K}^{+} \mathrm{e} \mathrm{Ca}^{++}$liberados pelas sementes embebidas mostrou-se um indicador de qualidade fisiológica mais eficiente do que a quantidade de eletrólitos totais.

Os resultados de lixiviação de potássio (Tabela 17) se relacionaram aos de condutividade individual (Tabela 16) apenas nos estudos conduzidos com os limites inferiores a $65 \mathrm{uA}$, os quais identificaram, de modo geral, os lotes 1 e 3 como superiores aos demais, enquanto os sistemas KI e KII destacaram apenas o lote 1. Assim, nas intensidades de corrente elétrica mais altas (acima de 70 uA) não houve concordância entre os referidos testes quanto à classificação dos lotes.

\subsubsection{Análise comparativa entre os testes para avaliação da qualidade fisiológica}

Analisando-se os resultados apresentados na Tabela 18, observase que em termos de germinação o lote 3 mostrou-se superior aos demais, apesar de estatisticamente semelhante ao lote 1 , que não diferiu do lote 4 . Este, por sua vez, foi significativamente semelhante ao lote 2 , revelado como de poder germinativo mais baixo. 
Tabela 18. Valores médios (\%) de germinação (TG), primeira contagem de germinação (PC), envelhecimento artificial (EA) e grau de umidade (GU) dos lotes de sementes de soja, cultivar IAC-15 e coeficientes de variação (médias de 4 épocas). Piracicaba, 1991.

\begin{tabular}{lcccc}
\hline LOTES & TG (\%) & PC (\%) & EA (\%) & GU (\%) \\
\hline 1 & $90 \mathrm{ab}$ & $88 \mathrm{a}$ & $84 \mathrm{a}$ & 10,8 \\
2 & $87 \mathrm{c}$ & $83 \mathrm{~b}$ & $69 \mathrm{~b}$ & 10,4 \\
3 & $92 \mathrm{a}$ & $86 \mathrm{ab}$ & $83 \mathrm{a}$ & 10,8 \\
4 & $88 \mathrm{bc}$ & $83 \mathrm{~b}$ & $71 \mathrm{~b}$ & 10,5 \\
\hline CV (\%) & 3,91 & 4,43 & 4,08 & - \\
\hline
\end{tabular}

em cada coluna, médias seguidas pela mesma letra não diferiram entre si, pelo teste de Tukey, ao nível de $5 \%$ de probabilidade.

O teste de primeira contagem de germinação identificou o lote 1 como de qualidade fisiológica superior, embora não diferindo estatisticamente do lote 3 , que mostrou-se semelhante aos lotes 2 e 4, indicados como os de pior desempenho. Já o teste de envelhecimento artificial relacionou os lotes 1 e 3 como superiores aos demais. Portanto, de um modo geral, os referidos testes classificaram os lotes em níveis de qualidade fisiológica, destacando desempenho superior para os lotes 1 e 3 e inferior para os lotes 2 e 4 (Tabela 18). É importante salientar que já por ocasião das determinações iniciais o lote 4 apresentou comportamento inferior aos demais, com base principalmente no teste de envelhecimento artificial.

A análise comparativa dos dados apresentados nas Tabelas $15 \mathrm{e}$ 18 indica que, de uma maneira geral, os resultados de condutividade CE I e II foram semelhantes às informações fornecidas pelos testes de primeira contagem e envelhecimento artificial em termos de separação dos lotes.

Comparando-se as Tabelas 16 e 18, observam-se tendências semelhantes nos resultados de condutividade elétrica individual (ASA-610), envelhecimento artificial e primeira contagem de germinação, quando foram empregados valores limites inferiores a $65 \mathrm{uA}$. Portanto, em termos de avaliação do vigor das sementes do cultivar IAC-15, os valores limites acima de 65uA não foram eficientes; o mesmo não foi verificado para o cultivar IAC-8, onde a separação dos lotes por este método não se revelou promissora. As intensidades de corrente elétrica acima de $70 \mathrm{uA}$ 
indicaram a superioridade do lote 3, caracterizando os lotes 2 e 4 como inferiores concordando, portanto, com os resultados de germinação.

Ainda de forma comparativa, os resultados de lixiviação de potássio (Tabela 17) também revelaram tendências semelhantes aos testes apresentados na Tabela 18, embora os estudos de potássio tenham indicado a superioridade do lote 1 em relação ao 3 , o que não foi detectado pela germinação, primeira contagem e envelhecimento artificial. Desse modo, a quantidade de potássio liberado por sementes em embebição mostrou-se sensivel quanto à separação de lotes em níveis de vigor, revelando maior precisão.

Com relação ao conteúdo de água das sementes (Tabela 18), apesar de os dados não terem sido analisados estatisticamente, verificou-se que, em geral, os valores mostraram-se semelhantes para todos os lotes, conforme observado também para o cultivar IAC-8.

\subsubsection{Considerações gerais}

Analisando de uma maneira geral os resultados obtidos na etapa 1, verificou-se para o cultivar IAC-8 que os testes de germinação, primeira contagem, envelhecimento artificial, condutividade elétrica de massa e lixiviação de potássio apresentaram tendências semelhantes na separação dos lotes, embora pequenas variações tenham ocorrido. Tais variações podem ser atribuídas às diferenças de qualidade pouco pronunciadas entre os lotes. Porém, as informações fornecidas pelo ASA-610 mostraramse pouco relacionadas com os demais testes, especialmente quanto à identificação de lotes de qualidade fisiológica elevada nos limites mais baixos; esta metodologia, apesar de ter indicado o lote 3 como inferior aos demais, selecionou o lote 2 , classificado pelos outros testes como deficiente, como sendo de alto vigor.

Em contrapartida, para o cultivar IAC-15, todos os testes de vigor empregados demonstraram aptidão para separar os lotes em niveis de qualidade fisiológica.

Assim, com relação especificamente ao teste de condutividade elétrica individual (ASA-610) houve eficiência variável em termos de separação dos lotes quanto ao vigor, de acordo com o cultivar estudado. Observou-se ainda, que os valores limites de 80 e $70 \mathrm{uA}$ forneceram indicações mais próximas à viabilidade, enquanto 
aqueles situados abaixo de $60 \mathrm{uA}$ possibilitaram obter informações mais relacionadas ao vigor das sementes. Para sementes de soja a AGROSCIENCES (1979) recomendou o emprego de 90 uA para a determinação da viabilidade e 45 uA para vigor.

Analisando-se a sensibilidade dos periodos de embebição em detectar diferenças entre os lotes nos estudos de condutividade "bulk" notou-se, de modo geral, que as avaliações feitas com 4 horas apresentaram tendências nesta direção. Contudo, as diferenças entre os lotes foram mais acentuadas com o decorrer do processo de embebição. Desta forma, levando-se em conta que para a utilização rotineira do referido teste as diferenças nos valores de condutividade devem ser bastante nítidas, foram considerados como mais adequados os periodos de embebição supeirores a 8 horas.

Por outro lado, nos estudos com o ASA-610, informações mais precisas sobre a qualidade dos lotes foram obtidas, geralmente, nos periodos mais longos (após 12 horas). Notou-se ainda, que a possibilidade de se conhecer o potencial relativo de cada lote, em curto período de tempo (4 horas), só foi viável quando foram adotadas intensidades de corrente elétrica inferiores a $50 \mathrm{uA}$. Este valor de corrente foi indicado por KRZYZANOWSKI et al. (1991) como adequado para avaliação do vigor de sementes de soja.

Nos testes de lixiviação de potássio, resultados consistentes foram obtidos em todos os periodos de condicionamento. Entretanto, com o decorrer do processo de embebição, acréscimos significativos na concentração de potássio dificultaram a realização das leituras diretamente no exsudato sendo necessário, portanto, efetuar diluição. Tal procedimento além de comprometer a precisão das avaliações, envolve um maior periodo de tempo para a obtenção dos resultados, devendo ser, quando possível, evitado. Com base nestas considerações não foi considerada interessante a realização de leituras após 150 minutos de embebição. Assim, ambos os métodos (KI e KII) mostraram-se eficientes, especialmente nas avaliações feitas aos 60 , 90 e 120 minutos de embebição.

Portanto, os resultados promissores obtidos nesta primeira etapa de testes, ou seja, os procedimentos que forneceram indicações consistentes e promissoras a respeito da qualidade fisiológica das sementes, foram avaliados em um segundo experimento (etapa 2), através de estudos comparativos em relação a outros testes de vigor considerados eficientes para sementes de soja. 


\subsection{Etapa 2}

\subsubsection{Cultivar IAC-8}

Com base na Tabela 18, o exame dos valores de $F$ obtidos nas análises estatísticas, permitiu verificar que ocorreram efeitos significativos de lotes e de épocas em praticamente todos os estudos com exceção para os efeitos de lotes nos testes de lixiviação de potássio (método KII) com 60 minutos de embebição. Já a interação lotes x épocas foi significativa somente no sistema CE II, com 20 horas de embebição e em KI após 90 minutos de condicionamento.

Com relação ao teste de condutividade individual (ASA-610), verificou-se efeito significativo de lotes e épocas, principalmente nos estudos empregando valores limites inferiores a 80uA, conforme a Tabela 19.

A análise de variância dos dados referentes aos testes empregados para avaliação da qualidade fisiológica das sementes revelou valores de $\mathrm{F}$ significativos e épocas para praticamente todos os parâmetros, exceto para efeitos de lotes e de épocas nos testes de germinação (Tabela 20).

Cabe ressaltar que as variações entre as épocas de testes não constituiram fator relevante para a interpretação dos resultados, conforme abordado anteriormente para os estudos da etapa 1; desta forma, serão apresentadas apenas as médias dos dados obtidos nas três épocas de avaliações.

\subsubsection{Condutividade elétrica de massa - CE I e CE II}

Examinando a Tabela 21, observa-se que houve acréscimos significativos nas leituras de condutividade elétrica com o decorrer da embebição das sementes tanto para o método envolvendo escolha de sementes (CE I) como para o sistema II. $\mathrm{O}$ aumento gradual da quantidade de eletrólitos liberados durante o período de condicionamento das sementes também foi constatado por SIMON \& RAJA-HARUN (1972), KEYS (1982), LOEFFLER et al. (1988), MARCOS FILHO et al. (1990) e BRUGGINK et al. (1991).

É importante ressaltar que os valores mais elevados para as leituras obtidas no sistema $\mathrm{CE}$ II devem ser atribuídas à temperatura de condicionamento mais alta ( 50 sementes à $25^{\circ} \mathrm{C}$ ) em relação ao $\mathrm{CE} \mathrm{I}(25$ sementes/amostra condicionadas à $20^{\circ} \mathrm{C}$ ), aliado ao fato de que neste método, foram descartadas sementes apresentando danificações. 
Tabela 18- Valores de $\mathrm{F}$ obtidos nas análises de variância dos dados referentes aos testes de condutividade elétrica (CE I e II) e de lixiviação de potássio (KI e KII), para os lotes do cultivar IAC-8. Piracicaba, 1992.

\begin{tabular}{|c|c|c|c|}
\hline \multirow[t]{2}{*}{ Testes } & \multicolumn{3}{|c|}{ Valores de F } \\
\hline & Lotes (L) & Épocas (E) & Interação (L x E) \\
\hline CE I - $8 \mathrm{~h}$ & $10,81 * *$ & $10,24 * *$ & $0,94^{\mathrm{ns}}$ \\
\hline $\mathrm{CE} \mathrm{I}-12 \mathrm{~h}$ & $6,07 * *$ & $29,02 * *$ & $0,96^{\mathrm{ns}}$ \\
\hline CE I - $16 \mathrm{~h}$ & $4,61^{* *}$ & $60,01 * *$ & $0,24^{\mathrm{ns}}$ \\
\hline CE I - $20 \mathrm{~h}$ & $4,01^{*}$ & $20,87^{* *}$ & $0,65^{n s}$ \\
\hline CE I - $24 h$ & $5,26 * *$ & $3,62^{*}$ & 0,29 ns \\
\hline CE II - $8 h$ & $2,35^{\mathrm{ns}}$ & $8,05 * *$ & $1,23^{\mathrm{ns}}$ \\
\hline CE II - $12 \mathrm{~h}$ & $2,21^{\text {ns }}$ & $23,18 * *$ & $2,22^{\mathrm{ns}}$ \\
\hline CE II - $16 h$ & $6,55^{* *}$ & $6,89 * *$ & $1,99 \mathrm{~ns}$ \\
\hline CE II - $20 \mathrm{~h}$ & $17,79 * *$ & $11,30^{* *}$ & $3,34^{*}$ \\
\hline CE II - $24 h$ & $4,97 * *$ & $1,85^{\mathrm{ns}}$ & $1,20^{\text {ns }}$ \\
\hline K I - 60 minutos & $4,68^{* *}$ & $13,96 * *$ & $0,29 \mathrm{~ns}$ \\
\hline K I - 90 minutos & $21,92 * *$ & $51,91^{* *}$ & $2,47^{*}$ \\
\hline $\mathrm{K}$ I - 120 minutos & $26,61 * *$ & $40,23 * *$ & $2,20^{\mathrm{ns}}$ \\
\hline K II - 60 minutos & $1,19^{\text {ns }}$ & $6,94 * *$ & $1,67^{\mathrm{ns}}$ \\
\hline K II - 90 minutos & $5,83 * *$ & $18,85^{* *}$ & $1,26^{\mathrm{ns}}$ \\
\hline K II - 120 minutos & $7,86^{* *}$ & $17,13^{* *}$ & $1,28^{\mathrm{ns}}$ \\
\hline
\end{tabular}

* - significativo ao nível de $5 \%$ de probabilidade

** - significativo ao nivel de $1 \%$ de probabilidade

ns - não significativo 
Tabela 19- Valores de F obtidos nas análises de variância dos dados referentes aos testes de condutividade elétrica individual (ASA-610), para os lotes do cultivar IAC8. Piracicaba, 1992.

\begin{tabular}{|c|c|c|c|}
\hline \multirow[t]{2}{*}{ Testes } & \multicolumn{3}{|c|}{ Valores de F } \\
\hline & Lotes $(L)$ & Épocas (E) & Interação (L x E) \\
\hline ASA $90-8 h$ & $1,01^{\mathrm{ns}}$ & $0,61^{\mathrm{ns}}$ & $0,38^{\mathrm{ns}}$ \\
\hline ASA $90-12 h$ & $2,99 *$ & $2,67^{\mathrm{ns}}$ & 0,39 ns \\
\hline ASA $90-16 \mathrm{~h}$ & $5,71^{* *}$ & $3,41 *$ & $1,09^{\text {ns }}$ \\
\hline ASA $90-20 h$ & $5,16^{* *}$ & $5,52^{* *}$ & $1,21^{\mathrm{ns}}$ \\
\hline ASA $90-24 h$ & $2,31^{\mathrm{ns}}$ & $2,58^{\mathrm{ns}}$ & $0,72^{n s}$ \\
\hline ASA $80-8 h$ & $0,99 \mathrm{~ns}$ & $0,68^{n s}$ & $0,17^{\text {ns }}$ \\
\hline ASA $80-12 \mathrm{~h}$ & $5,59 * *$ & $9,40 * *$ & $0,32^{\mathrm{ns}}$ \\
\hline ASA $80-16 h$ & $3,74 *$ & $4,63^{*}$ & $0,72^{\mathrm{ns}}$ \\
\hline ASA $80-20 h$ & $7,13^{* *}$ & $3,86^{*}$ & $1,57^{\mathrm{ns}}$ \\
\hline ASA $80-24 h$ & $9,60 * *$ & $4,30^{*}$ & $2,23^{\mathrm{ns}}$ \\
\hline ASA $70-8 h$ & $3,24^{*}$ & $0,67^{n s}$ & $0,46^{\mathrm{ns}}$ \\
\hline ASA $70-12 h$ & $4,45 * *$ & $11,10^{* *}$ & $0,28^{n s}$ \\
\hline ASA $70-16 h$ & $13,22 * *$ & $7,88^{* *}$ & $2,36^{\mathrm{nS}}$ \\
\hline ASA $70-20 h$ & $13,07 * *$ & $3,92^{*}$ & $1,42^{\mathrm{ns}}$ \\
\hline ASA $70-24 h$ & $10,58^{* *}$ & $4,06^{*}$ & $1,10^{\mathrm{ns}}$ \\
\hline ASA $60-8 h$ & $4,47 * *$ & $1,15^{\mathrm{ns}}$ & $0,58^{\text {ns }}$ \\
\hline ASA $60-12 h$ & $10,10 * *$ & $13,75^{* *}$ & $0,67^{\text {ns }}$ \\
\hline ASA $60-16 \mathrm{~h}$ & $16,05^{* *}$ & $11,21 * *$ & $5,12^{*}$ \\
\hline ASA $60-20 h$ & $7,77 * *$ & $2,52^{\mathrm{ns}}$ & $0,97^{\mathrm{ns}}$ \\
\hline ASA $60-24 h$ & $6,35 * *$ & $6,50^{* *}$ & $0,78^{\mathrm{ns}}$ \\
\hline ASA $55-8 h$ & $4,58 * *$ & $4,79 * *$ & $1,36^{\mathrm{ns}}$ \\
\hline ASA $55-12 h$ & $11,92 * *$ & $19,96 * *$ & $1,06^{\mathrm{ns}}$ \\
\hline ASA $55-16 h$ & $11,21^{* *}$ & $10,55 * *$ & $2,73^{*}$ \\
\hline ASA $55-20 \mathrm{~h}$ & $6,12^{* *}$ & $4,40^{*}$ & $1,43^{\mathrm{ns}}$ \\
\hline ASA $55-24 h$ & $5,16^{* *}$ & $7,53 * *$ & $1,24^{\mathrm{ns}}$ \\
\hline ASA $50-8 h$ & $3,73^{*}$ & $9,59 * *$ & $1,46^{\mathrm{ns}}$ \\
\hline ASA $50-12 \mathrm{~h}$ & $5,00 * *$ & $15,41 * *$ & $0,58^{\mathrm{ns}}$ \\
\hline ASA $50-16 h$ & $14,86^{* *}$ & $12,21 * *$ & $1,77^{\mathrm{ns}}$ \\
\hline ASA $50-20 h$ & $10,93^{* *}$ & $9,20 * *$ & $3,21^{*}$ \\
\hline ASA $50-24 h$ & $6,74 * *$ & $6,60 * *$ & $2,33^{\text {ns }}$ \\
\hline ASA $45-8 h$ & $3,59 *$ & $9,17^{* *}$ & $2,99 *$ \\
\hline ASA $45-12 \mathrm{~h}$ & $3,28^{*}$ & $16,27 * *$ & $1,54^{\mathrm{ns}}$ \\
\hline ASA $45-16 h$ & $15,43^{* *}$ & $15,21 * *$ & $2,62 *$ \\
\hline ASA $45-20 h$ & $17,25^{* *}$ & $10,03^{* *}$ & $3,59 * *$ \\
\hline ASA $45-24 \mathrm{~h}$ & $7,76^{* *}$ & $7,86^{* *}$ & $2,59 *$ \\
\hline
\end{tabular}

* - significativo ao nível de $5 \%$ de probabilidade

** - significativo ao nível de $1 \%$ de probabilidade

ns - não significativo 
Tabela 21- Condutividade elétrica (CE I e II): valores médios (umhos/cm/g) para os lotes de sementes de soja, cultivar IAC-8, em cada período de embebição (médias de 3 épocas) e coeficientes de variação. Piracicaba, 1992.

\begin{tabular}{|c|c|c|c|c|c|c|}
\hline \multirow[t]{2}{*}{ Lotes } & \multicolumn{5}{|c|}{ CE I - Periodos (h) } & \multirow[t]{2}{*}{ Médias } \\
\hline & 8 & 12 & 16 & 20 & 24 & \\
\hline 1 & $42,40 \mathrm{a}$ & 48,07 a & $50,40 \mathrm{a}$ & $61,14 \mathrm{a}$ & $63,05 \mathrm{a}$ & 53,01 \\
\hline 2 & $44,06 \mathrm{~b}$ & $49,64 \mathrm{ab}$ & $53,48 \mathrm{ab}$ & $64,48 \mathrm{ab}$ & $66,11 \mathrm{ab}$ & 55,47 \\
\hline 3 & $44,90 \mathrm{~b}$ & $51,35 \mathrm{~b}$ & $54,94 \mathrm{~b}$ & $66,69 b$ & $68,90 \mathrm{~b}$ & 57,35 \\
\hline 4 & $42,21 \mathrm{a}$ & $47,42 \mathrm{a}$ & $52,98 \mathrm{ab}$ & $64,66 \mathrm{ab}$ & $65,09 \mathrm{ab}$ & 54,47 \\
\hline Médias & 43,40 & 49,12 & 52,95 & 64,13 & 65,79 & \\
\hline CV $(\%)$ & 3,16 & 5,02 & 5,77 & 6,18 & 5,58 & \\
\hline \multirow[t]{2}{*}{ Lotes } & \multicolumn{5}{|c|}{ CE II - Periodos (h) } & Médias \\
\hline & 8 & 12 & 16 & 20 & 24 & \\
\hline 1 & $51,96 \mathrm{a}$ & $59,05 \mathrm{a}$ & $59,74 \mathrm{a}$ & $65,85 \mathrm{a}$ & $72,47 \mathrm{a}$ & 61,81 \\
\hline 2 & $49,73 \mathrm{a}$ & $56,55 \mathrm{a}$ & $61,35 \mathrm{a}$ & $72,11 \mathrm{~b}$ & $72,80 \mathrm{a}$ & 62,51 \\
\hline 3 & 53,07 a & 60,48 a & $67,52 \mathrm{~b}$ & $80,18 \mathrm{c}$ & $81,44 \mathrm{~b}$ & 68,54 \\
\hline 4 & 50,67 a & $57,41 \mathrm{a}$ & $63,03 \mathrm{ab}$ & $76,44 \mathrm{bc}$ & $76,56 \mathrm{ab}$ & 64,82 \\
\hline Médias & 51,36 & 58,38 & 62,90 & 73,65 & 75,82 & \\
\hline CV (\%) & 6,43 & 6,93 & 7,22 & 6,86 & 8,57 & \\
\hline
\end{tabular}

em cada coluna, médias seguidas pela mesma letra não diferiram entre si, pelo teste de Tukey, ao nível de $5 \%$ de probabilidade. 
Assim, notou-se uma tendência do método II em identificar lotes de qualidade elevada, separando-os daquele de desempenho inferior, não tendo sido consistentes com relação aos lotes de qualidade intermediária. A possível razão desta dificuldade deve-se ao fato de os mesmos não apresentarem, de um modo geral, diferenças pronunciadas em termos de qualidade fisiológica. Vários autores consideraram o teste de condutividade elétrica como adequado para a separação eficiente de lotes de sementes com diferentes níveis de qualidade fisiológica (BEDFORD, 1974; KULIK \& YAKLICH, 1982; MARCOS FILHO et al., 1985 e BARROS, 1988). Por outro lado, HEPBURN et al. (1984) obtiveram uma ordenação deficiente de lotes de sementes de soja, com diferentes níveis de vigor, utilizando o referido teste.

Estes resultados (Tabela 21) indicam, portanto, que a condução do teste com sementes fisicamente puras, apesar de torná-lo menos subjetivo e de requerer menor tempo no preparo das amostras, exigiu período de condicionamento mais longo para possibilitar uma classificação adequada dos lotes em termos de vigor, em relação ao CE I. Nota-se ainda, que o comportamento deficiente do lote 3 já era evidenciado nas avaliações de 8 horas. Sabe-se que a liberação inicial de eletrólitos é intensa tanto pelas sementes intactas e vigorosas como pelas danificadas, dificultando a identificação de possíveis diferenças de qualidade entre os lotes logo no início da embebição. No entanto, com o decorrer deste processo, a quantidade de exsudatos liberados pelas sementes vigorosas vai se estabilizando devido, principalmente, à reorganização das membranas, favorecendo à ordenação dos lotes em níveis de qualidade, de forma que as diferenças se tornam mais visíveis.

Com base nos resultados da Tabela 21, verificou-se que ambas as metodologias mostraram, de um modo geral, concordância quanto à ordenação de lotes diferindo apenas quanto ao período de tempo necessário para a separação dos lotes em niveis de vigor. Assim, quando houver necessidade de informações sobre a qualidade fisiológica dos lotes, em curto período de tempo, os resultados indicam ser recomendável o sistema CE I. OLIVEIRA et al. (1984) e LOEFFLER et al. (1988) criticaram a remoção de sementes danificadas da amostra e recomendaram a utilização de sementes puras de soja. Por outro lado, FRATIN (1987) trabalhando com sementes de milho, obteve resultados coerentes quanto à classificação de lotes em termos de vigor, embora tenha constatado reduções nos coeficientes de variação quando sementes danificadas foram eliminadas do teste. Pela Tabela 21, verificou-se, de modo geral, que o emprego de sementes puras contribuiu para uma pequena elevação nos valores dos coeficientes de 
variação, indicando maior variabilidade entre as repetições. Por sua vez, LOEFFLER et al. (1988) observaram redução no coeficiente de variação quando número de sementes avaliadas aumentou de 25 para 50 por amostra.

\subsubsection{Condutividade elétrica individual}

A Tabela 22 contém os resultados referentes à distribuição das avaliações da condutividade obtidas com o ASA-610. Tais informações são relevantes para se selecionar valores limites capazes de distinguir sementes viáveis das não viáveis e que possam ser utilizados para estimar a viabilidade e o vigor das sementes.

Observou-se no limite de $90 \mathrm{uA}$, que as avaliações feitas com 8 e 24 horas de embebição não permitiram detectar diferenças estatísticas entre os lotes, embora no periodo de 24 horas os valores numéricos indicassem a inferioridade do lote 3 , que também foi revelada nos estudos realizados com 12, 16 e 20 horas de embebição.

As leituras realizadas com $80 \mathrm{uA}$, após 12 e 16 horas de condicionamento, exibiram classificação de lotes semelhante, destacando os lotes 1 e 3 como de melhor e pior desempenho, respectivamente; já os periodos de 20 e 24 horas apenas destacaram a inferioridade do lote 3 em relação aos demais, enquanto as avaliações feitas após 8 horas mostraram-se ineficientes para a separação dos lotes em niveis de qualidade

fisiológica. É importante observar que nos estudos com 90 e $80 \mathrm{uA}$, a porcentagem de exsudatos apresentando niveis de corrente elétrica inferiores ao limite testado foi relativamente alta, mesmo após 24 horas de embebição (Tabela 22).

Por sua vez, os valores limites de 70 e $60 \mathrm{uA}$ revelaram nos períodos iniciais de embebição, sensibilidade em detectar diferenças significativas de vigor entre os lotes, embora os valores absolutos tenham indicado diferenças mais acentuadas entre os lotes nas avaliações de 16 horas em diante, conforme mostra a Tabela 24 .

A análise dos resultados obtidos com a regulagem de $55 \mathrm{uA}$ (Tabela 22) revelou eficiência no sentido de identificar a qualidade inferior do lote 3 , já nas leituras feitas na $8 \underline{\text { a }}$ hora. Entretanto, não houve concordância entre os diferentes periodos de embebição quanto aos lotes de desempenho superior, ocorrendo certa alternância na classificação dos lotes 1, 2 e 4. De fato, a separação de lotes de sementes apresentando diferenças de qualidade pouco acentuadas foi considerada problemática por diversos autores ( McDONALD Jr. \& WILSON, 1979; KULIK \& YAKLICH, 1982; MARCOS FILHO et al., 1984; 1985). Porém, as avaliações realizadas com 8 horas indicaram maior vigor para o lote 1 , já destacado anteriormente. 
Tabela 22. Condutividade elétrica individual (ASA-610): valores médios (\%) obtidos para os valores limites (VL) e períodos de embebição para os lotes de sementes de soja, cultivar IAC-8 e coeficientes de variação (médias de 3 épocas). Piracicaba, 1992.

\begin{tabular}{|c|c|c|c|c|c|c|c|}
\hline \multirow[t]{2}{*}{ VL (uA) } & \multirow[t]{2}{*}{ Lotes } & \multicolumn{5}{|c|}{ Períodos (h) } & \multirow[b]{2}{*}{ Médias } \\
\hline & & 8 & 12 & 16 & 20 & 24 & \\
\hline \multirow[t]{6}{*}{90} & 1 & $100 a$ & $99 a$ & $98 \mathrm{a}$ & $97 a$ & $96 \mathrm{a}$ & 98 \\
\hline & 2 & $99 a$ & $98 \mathrm{ab}$ & $98 \mathrm{a}$ & $96 a$ & 95 a & 98 \\
\hline & 3 & $98 \mathrm{a}$ & $98 \mathrm{~b}$ & $96 \mathrm{~b}$ & $94 \mathrm{~b}$ & $92 a$ & 96 \\
\hline & 4 & 99 a & $98 \mathrm{ab}$ & $98 \mathrm{a}$ & $97 \mathrm{a}$ & $96 \mathrm{a}$ & 98 \\
\hline & Médias & 99 & 98 & 97 & 96 & 95 & \\
\hline & $\mathrm{CV}(\%)$ & 4,69 & 4,32 & 3,67 & 4,12 & 5,18 & \\
\hline \multirow[t]{6}{*}{80} & 1 & $98 \mathrm{a}$ & $97 \mathrm{a}$ & $96 a$ & $95 a$ & $93 a$ & 96 \\
\hline & 2 & $97 a$ & $97 \mathrm{ab}$ & $95 \mathrm{ab}$ & $94 \mathrm{a}$ & $91 \mathrm{a}$ & 95 \\
\hline & 3 & $97 a$ & $95 \mathrm{~b}$ & $92 \mathrm{~b}$ & $89 \mathrm{~b}$ & $87 \mathrm{~b}$ & 92 \\
\hline & 4 & $98 \mathrm{a}$ & $96 \mathrm{ab}$ & $96 \mathrm{a}$ & $94 \mathrm{a}$ & $93 \mathrm{a}$ & 96 \\
\hline & Médias & 97 & 96 & 95 & 93 & 91 & \\
\hline & CV $(\%)$ & 4,49 & 3,56 & 4,76 & 4,43 & 4,35 & \\
\hline \multirow[t]{6}{*}{70} & 1 & $96 a$ & $94 a$ & $92 \mathrm{a}$ & $91 \mathrm{a}$ & $89 a$ & 93 \\
\hline & 2 & $95 \mathrm{ab}$ & $94 \mathrm{ab}$ & $92 \mathrm{a}$ & $89 a$ & $86 a$ & 91 \\
\hline & 3 & $93 \mathrm{~b}$ & $90 \mathrm{~b}$ & $85 \mathrm{~b}$ & $83 \mathrm{~b}$ & $82 \mathrm{~b}$ & 87 \\
\hline & 4 & $95 \mathrm{ab}$ & $93 \mathrm{ab}$ & $92 \mathrm{a}$ & $90 a$ & $89 a$ & 92 \\
\hline & Médias & 95 & 93 & 91 & 88 & 86 & \\
\hline & $\mathrm{CV}(\%)$ & 3,91 & 4,87 & 4,22 & 3,94 & 4,33 & \\
\hline \multirow[t]{6}{*}{60} & 1 & $93 a$ & $88 a$ & $86 a$ & $84 a$ & $81 \mathrm{a}$ & 87 \\
\hline & 2 & $91 \mathrm{ab}$ & $91 \mathrm{a}$ & $88 \mathrm{a}$ & $84 a$ & $81 \mathrm{a}$ & 87 \\
\hline & 3 & $89 \mathrm{~b}$ & $84 \mathrm{~b}$ & $80 \mathrm{~b}$ & $77 \mathrm{~b}$ & $74 \mathrm{~b}$ & 81 \\
\hline & 4 & $92 \mathrm{ab}$ & $89 a$ & $87 \mathrm{a}$ & $84 \mathrm{a}$ & $82 \mathrm{a}$ & 87 \\
\hline & Médias & 91 & 88 & 85 & 82 & 80 & \\
\hline & $\operatorname{CV}(\%)$ & 4,08 & 4,39 & 3,84 & 4,54 & 5,06 & \\
\hline \multirow[t]{6}{*}{55} & 1 & $90 \mathrm{a}$ & $85 \mathrm{ab}$ & $81 \mathrm{a}$ & $75 \mathrm{ab}$ & $70 \mathrm{~b}$ & 81 \\
\hline & 2 & $88 \mathrm{ab}$ & $88 \mathrm{a}$ & $85 \mathrm{a}$ & $79 a$ & $77 \mathrm{a}$ & 84 \\
\hline & 3 & $84 \mathrm{~b}$ & $79 \mathrm{c}$ & $79 \mathrm{~b}$ & $71 \mathrm{~b}$ & $67 \mathrm{~b}$ & 76 \\
\hline & 4 & $88 \mathrm{ab}$ & $83 \mathrm{~b}$ & $83 \mathrm{a}$ & $79 \mathrm{a}$ & $72 a b$ & 82 \\
\hline & Médias & 88 & 84 & 82 & 76 & 72 & \\
\hline & CV $(\%)$ & 4,56 & 4,63 & 4,87 & 5,63 & 6,78 & \\
\hline
\end{tabular}


Continuação

Tabela 22. Condutividade elétrica individual (ASA-610): valores médios (\%) obtidos para os valores limites (VL) e períodos de embebição para os lotes de sementes de soja, cultivar IAC-8 e coeficientes de variação (médias de 3 épocas). Piracicaba, 1991.

\begin{tabular}{|c|c|c|c|c|c|c|c|}
\hline \multirow[t]{2}{*}{ VL $(u A)$} & \multirow[t]{2}{*}{ Lotes } & \multicolumn{5}{|c|}{ Periodos (h) } & \multirow[b]{2}{*}{ Médias } \\
\hline & & 8 & 12 & 16 & 20 & 24 & \\
\hline \multirow[t]{6}{*}{50} & 1 & $84 a$ & $77 \mathrm{ab}$ & $65 b$ & $55 \mathrm{c}$ & $48 \mathrm{~b}$ & 66 \\
\hline & 2 & $84 a$ & $81 \mathrm{a}$ & $78 \mathrm{a}$ & $71 a$ & $64 \mathrm{a}$ & 76 \\
\hline & 3 & $79 \mathrm{~b}$ & $72 b$ & $66 \mathrm{~b}$ & $61 \mathrm{ab}$ & $52 \mathrm{~b}$ & 66 \\
\hline & 4 & $83 a b$ & $75 \mathrm{ab}$ & $75 a$ & $66 \mathrm{ab}$ & $57 \mathrm{ab}$ & 71 \\
\hline & Médias & 80 & 77 & 71 & 63 & 55 & \\
\hline & CV $(\%)$ & 4,53 & 6,18 & 6,13 & 8,27 & 11,33 & \\
\hline \multirow[t]{6}{*}{45} & 1 & $74 \mathrm{ab}$ & $53 \mathrm{~b}$ & $38 \mathrm{c}$ & $25 \mathrm{c}$ & $21 \mathrm{~b}$ & 42 \\
\hline & 2 & $76 \mathrm{a}$ & $64 \mathrm{a}$ & $58 \mathrm{a}$ & $49 a$ & $39 \mathrm{a}$ & 57 \\
\hline & 3 & $70 \mathrm{~b}$ & $59 \mathrm{ab}$ & $49 \mathrm{~b}$ & $39 \mathrm{~b}$ & $28 \mathrm{~b}$ & 49 \\
\hline & 4 & $71 \mathrm{ab}$ & $59 \mathrm{ab}$ & $53 \mathrm{ab}$ & $36 \mathrm{~b}$ & $27 \mathrm{~b}$ & 49 \\
\hline & Médias & 73 & 59 & 50 & 37 & 29 & \\
\hline & $\operatorname{CV}(\%)$ & 5,43 & 10,60 & 10,15 & 13,34 & 18,78 & \\
\hline
\end{tabular}

em cada coluna, médias seguidas pela mesma letra não diferiram entre si, pelo teste de Tukey, ao nível de $5 \%$ de probabilidade. 
Ainda na Tabela 22, observou-se que os limites de 50 e $45 \mathrm{uA}$ exibiram variações na classificação dos lotes de acordo com a duração do período de embebição, ocorrendo situações que indicaram pior desempenho para o lote 1, identificado nos demais valores limites como de elevada qualidade fisiológica. Dessa forma, foi possivel observar que a regulagem de 45 uA não mostrou eficiência no sentido de identificar o lote menos vigoroso. Complementando estas informações, observou-se ainda, um aumento nos coeficientes de variação, especialmente para as leituras em $50 \mathrm{uA}$, realizadas com 20 e 24 horas e em 45uA, a partir de 12 horas de embebição.

Uma análise global dos resultados obtidos com o ASA-610 (Tabela 22), permitiu observar que os valores limites mais altos destacaram com segurança, o lote de pior qualidade (lote 3). Para HERTER \& BURRIS (1989) a estimativa da viabilidade de sementes de milho através deste aparelho é mais segura nos lotes de baixa qualidade fisiológica. Ademais, informações mais consistentes sobre o desempenho dos lotes foram obtidas, principalmente, nas fases iniciais do processo de embebição ( 8 horas) empregando-se as regulagens de 70,60 e 55uA, as quais podem ser consideradas como promissoras para a avaliação do vigor em curto período de tempo.

Os resultados da Tabela 22 mostraram ainda, que a adoção de limites mais altos (90 e $80 \mathrm{uA}$ ) requer um maior período de condicionamento das sementes (12 horas) para uma classificação eficiente dos lotes. Por outro lado, HEPBURN et al. (1984) não obtiveram resultados satisfatórios com sementes de soja e de ervilha.

Comparando-se as Tabelas 21 e 22 verifica-se que tanto as avaliações individuais de condutividade como os sistemas de massa foram eficientes no sentido de indicar a inferioridade do lote 3 , excluindo-se o valor limite de $45 \mathrm{uA}$. Com relação aos lotes de qualidade superior, enquanto o sistema CE I revelou o melhor desempenho do lote 1, a partir de 16 horas de embebição, o método II incluiu nesta categoria também o lote 2, exceto no período de 20 horas. Dessa forma, de modo geral, foi possível constatar coerência entre os sistemas de massa e individual, apesar de pequenas variações na identificação dos lotes de alto vigor em função do período embebição das sementes.

Complementando estas informações, através da análise de correlação (Tabela 23), nota-se que coeficientes de correlação negativos e significativos foram obtidos principalmente entre as leituras feitas com 16 horas, no sistema CE I e com 12 horas nos limites de 90, 80, 70 e 55uA, no ASA-610; também no método II, o período de 16 horas mostrou correspondência com as avaliações feitas com $90,80,70,60,55$ e 50uA. 
Tabela 23- Coeficientes de correlação simples (r) entre os dados obtidos nos testes de condutividade elétrica individual (ASA-610) e CE I e II para os lotes de sementes de soja, cultivar IAC-8. Piracicaba, 1992.

\begin{tabular}{|c|c|c|c|c|c|c|c|c|c|c|}
\hline \multirow{2}{*}{$\begin{array}{l}\text { ASA- } \\
610\end{array}$} & \multicolumn{5}{|c|}{ CE I } & \multicolumn{5}{|c|}{ CE II } \\
\hline & 8 & 12 & 16 & 20 & 24 & 8 & 12 & 16 & 20 & 24 \\
\hline $90-8 h$ & $-0,33$ & $-0,49$ & $-0,10$ & $-0,71^{* *}$ & $-0,70^{* *}$ & $-0,16$ & $-0,26$ & $-0,11$ & $-0,36$ & $-0,75^{* *}$ \\
\hline $90-12 h$ & $-0,41$ & $-0,28$ & $-0,73^{* *}$ & $-0,27$ & $-0,42$ & $-0,47$ & $-0,55$ & $-0,77^{* *}$ & $-0,11$ & $-0,43$ \\
\hline $90-16 h$ & $-0,42$ & $-0,10$ & $-0,56$ & $-0,14$ & $-0,38$ & $-0,10$ & $-0,10$ & $-0,70^{* *}$ & $-0,17$ & $-0,15$ \\
\hline $90-20 h$ & $-0,51$ & $-0,10$ & $-0,64^{*}$ & $-0,10$ & $-0,49$ & $-0,10$ & $-0,14$ & $-0,72^{* *}$ & $-0,24$ & $-0,22$ \\
\hline $90-24 h$ & $-0,48$ & $-0,10$ & $-0,67^{*}$ & $-0,10$ & $-0,45$ & $-0,12$ & $-0,23$ & $-0,70^{* *}$ & $-0,19$ & $-0,23$ \\
\hline $80-8 h$ & $-0,14$ & $-0,12$ & $-0,10$ & $-0,10$ & $-0,13$ & $-0,21$ & $-0,10$ & $-0,42$ & $-0,50$ & $-0,40$ \\
\hline $80-12 h$ & $-0,41$ & $-0,38$ & $-0,81^{* *}$ & $-0,43$ & $-0,36$ & $-0,41$ & $-0,52$ & $-0,87^{* *}$ & $-0,11$ & $-0,31$ \\
\hline $80-16 h$ & $-0,59^{*}$ & $-0,10$ & $-0,66^{*}$ & $-0,10$ & $-0,58^{*}$ & $-0,10$ & $-0,13$ & $-0,72^{* *}$ & $-0,21$ & $-0,23$ \\
\hline $80-20 h$ & $-0,52$ & $-0,10$ & $-0,67^{*}$ & $-0,10$ & $-0,61^{*}$ & $-0,10$ & $-0,13$ & $-0,61^{*}$ & $-0,24$ & $-0,26$ \\
\hline $80-24 h$ & $-0,52$ & $-0,10$ & $-0,59^{*}$ & $-0,10$ & $-0,53$ & $-0,15$ & $-0,13$ & $-0,66^{*}$ & $-0,29$ & $-0,27$ \\
\hline $70-8 h$ & $-0,43$ & $-0,10$ & $-0,38$ & $-0,16$ & $-0,60^{*}$ & $-0,11$ & $-0,10$ & $-0,72^{* *}$ & $-0,61^{*}$ & $-0,45$ \\
\hline $70-12 h$ & $-0,34$ & $-0,41$ & $-0,83^{* *}$ & $-0,40$ & $-0,36$ & $-0,34$ & $-0,49$ & $-0,84^{* *}$ & $-0,10$ & $-0,22$ \\
\hline $70-16 h$ & $-0,41$ & $-0,10$ & $-0,53$ & $-0,10$ & $-0,56$ & $-0,10$ & $-0,11$ & $-0,69^{*}$ & $-0,25$ & $-0,41$ \\
\hline $70-20 h$ & $-0,44$ & $-0,10$ & $-0,50$ & $-0,10$ & $-0,52$ & $-0,10$ & $-0,13$ & $-0,63^{*}$ & $-0,34$ & $-0,39$ \\
\hline $70-24 h$ & $-0,40$ & $-0,10$ & $-0,39$ & $-0,10$ & $-0,46$ & $-0,10$ & $-0,10$ & $-0,59^{*}$ & $-0,37$ & $-0,37$ \\
\hline $60-8 h$ & $-0,62^{*}$ & $-0,10$ & $-0,56$ & -0.11 & $-0,63^{*}$ & $-0,13$ & $-0,10$ & $-0,77^{* *}$ & $-0,61^{*}$ & $-0,36$ \\
\hline $60-12 h$ & $-0,10$ & $-0,30$ & $-0,51$ & $-0,24$ & $-0,13$ & $-0,10$ & $-0,23$ & $-0,66^{*}$ & $-0,10$ & $-0,10$ \\
\hline $60-16 h$ & $-0,22$ & $-0,10$ & $-0,45$ & $-0,10$ & $-0,38$ & $-0,19$ & $-0,10$ & $-0,64^{*}$ & $-0,22$ & $-0,37$ \\
\hline $60-20 h$ & $-0,35$ & $-0,10$ & $-0,45$ & $-0,10$ & $-0,42$ & $-0,17$ & $-0,10$ & $-0,66^{*}$ & $-0,32$ & $-0,32$ \\
\hline $60-24 h$ & $-0,29$ & $-0,13$ & $-0,51$ & $-0,16$ & $-0,29$ & $-0,10$ & $-0,22$ & $-0,68^{*}$ & $-0,26$ & $-0,23$ \\
\hline $55-8 h$ & $-0,37$ & $-0,20$ & $-0,57^{*}$ & $-0,19$ & $-0,36$ & $-0,18$ & $-0,32$ & $-0,80^{* *}$ & $-0,40$ & $-0,17$ \\
\hline $55-12 h$ & $-0,18$ & $-0,42$ & $-0,70^{* *}$ & $-0,37$ & $-0,29$ & $-0,15$ & $-0,35$ & $-0,71^{* *}$ & $-0,10$ & $-0,10$ \\
\hline $55-16 h$ & $-0,10$ & $-0,28$ & $-0,35$ & $-0,30$ & $-0,10$ & $-0,10$ & $-0,17$ & $-0,40$ & $-0,10$ & $-0,19$ \\
\hline $55-20 h$ & $-0,19$ & $-0,19$ & $-0,45$ & $-0,29$ & $-0,11$ & $-0,10$ & $-0,15$ & $-0,55$ & $-0,10$ & $-0,10$ \\
\hline $55-24 h$ & $-0,10$ & $-0,41$ & $-0,53$ & $-0,39$ & $-0,10$ & $-0,14$ & $-0,35$ & $-0,50$ & $-0,10$ & $-0,10$ \\
\hline
\end{tabular}


continuação

Tabela 23- Coeficientes de correlação simples ( $r$ ) entre os dados obtidos nos testes de condutividade elétrica individual (ASA-610) e CE I e II para os lotes de sementes de soja, cultivar IAC-8. Piracicaba, 1992.

\begin{tabular}{|c|c|c|c|c|c|c|c|c|c|c|}
\hline \multirow{2}{*}{$\begin{array}{l}\text { ASA- } \\
610 \\
\end{array}$} & \multicolumn{5}{|c|}{ CE I } & \multicolumn{5}{|c|}{ CE II } \\
\hline & 8 & 12 & 16 & 20 & 24 & 8 & 12 & 16 & 20 & 24 \\
\hline $50-8 h$ & $-0,24$ & $-0,42$ & $-0,69^{*}$ & $-0,39$ & $-0,23$ & $-0,32$ & $-0,47$ & $-0,78^{* *}$ & $-0,19$ & $-0,10$ \\
\hline $50-12 h$ & $-0,17$ & $-0,53$ & $-0,79^{* *}$ & $-0,51$ & $-0,18$ & $-0,26$ & $-0,42$ & $-0,79^{* *}$ & $-0,10$ & $-0,10$ \\
\hline $50-16 h$ & $-0,10$ & $-0,36$ & $-0,46$ & $-0,47$ & $-0,10$ & $-0,10$ & $-0,21$ & $-0,33$ & $-0,28$ & $-0,22$ \\
\hline $50-20 h$ & $-0,14$ & $-0,44$ & $-0,35$ & $-0,50$ & $-0,23$ & $-0,10$ & $-0,21$ & $-0,20$ & $-0,32$ & $-0,43$ \\
\hline $50-24 h$ & $-0,10$ & $-0,53$ & $-0,51$ & $-0,54$ & $-0,20$ & $-0,34$ & $-0,40$ & $-0,19$ & $-0,46$ & $-0,47$ \\
\hline $45-8 h$ & $-0,24$ & $-0,33$ & $-0,71^{* *}$ & $-0,20$ & $-0,33$ & $-0,38$ & $-0,37$ & $-0,34$ & $-0,10$ & $-0,10$ \\
\hline $45-12 h$ & $-0,23$ & $-0,39$ & $-0,64^{*}$ & $-0,53$ & $-0,10$ & $-0,26$ & $-0,25$ & $-0,28$ & $-0,45$ & $-0,33$ \\
\hline $45-16 h$ & $-0,10$ & $-0,48$ & $-0,40$ & $-0,59^{*}$ & $-0,23$ & $-0,11$ & $-0,24$ & $-0,12$ & $-0,52$ & $-0,48$ \\
\hline $45-20 h$ & $-0,33$ & $-0,52$ & $-0,27$ & $-0,49$ & $-0,36$ & $-0,10$ & $-0,21$ & $-0,10$ & $-0,46$ & $-0,53$ \\
\hline $45-24 h$ & $-0,13$ & $-0,43$ & $-0,43$ & $-0,39$ & $-0,14$ & $-0,17$ & $-0,23$ & $-0,13$ & $-0,40$ & $-0,38$ \\
\hline
\end{tabular}

* significativo pelo teste $\mathrm{t}$ ao nivel de $5 \%$ de probabilidade.

** significativo pelo teste $t$ ao nivel de $1 \%$ de probabilidade. 


\subsubsection{Lixiviação de potássio - K I e K II}

Os resultados obtidos com o teste de lixiviação de potássio (Tabela 24) indicaram um aumento na quantidade de potássio liberado com o decorrer da embebição das sementes, nas duas metodologias (K I e K II).

O método KI (Tabela 24), por sua vez, revelou, no período de embebição de 60 minutos, superioridade para o lote 1 enquanto os lotes 2 e 4 apresentaram desempenho intermediário. Já as avaliações realizadas aos 90 e 120 minutos de condicionamento forneceram resultados estatisticamente semelhantes, destacando os lotes 1 e 2 como superiores e o lote 4 como de qualidade intermediária.

Estes resultados indicam, portanto, eficiência do método I em classificar os lotes em niveis de qualidade fisiológica, contrariando observações efetuadas por MARCOS FILHO et al. (1984) e BARROS (1988), também com sementes de soja.

De um modo geral, o teste revelou eficiência no sentido de identificar o lote 3 como inferior aos demais, exceto na metodologia que envolveu a utilização de sementes puras (KII) para as leituras feitas aos 60 minutos de embebição, que não detectou diferenças significativas entre os lotes; no entanto, numericamente, observou-se que os lotes 1 e 4 liberaram menor quantidade de potássio.

Também no sistema KII, houve correspondência entre as informações obtidas aos 90 e 120 minutos de embebição; verificou-se ainda, que a utilização de sementes puras dificultou a deteç̧ão de diferenças significativas entre os lotes 1,2 e 4 . No entanto, os valores numéricos indicaram menor quantidade de potássio nos exsudatos das sementes dos lotes 1 e 4 em relação as do lote 2 , indicando menor organização do sistema de membranas das sementes deste lote (Tabela 24).

Portanto, verificou-se que houve concordância entre os métodos I e II quanto à qualidade elevada do lote 1 , o mesmo não ocorrendo com relação aos lotes 2 e 4, classificados ora como apresentando alto vigor, ora qualidade intermediária. De fato, a identificação destes lotes pode sofrer variações em função da metodologia adotada, principalmente em se tratando de lotes com diferenças de qualidade pouco pronunciadas conforme McDONALD Jr. \& WILSON, 1979; KULIK \& YAKLICH, 1982; MARCOS FILHO et al., 1984; 1985). 
Tabela 24- Lixiviação de potássio (KI e KII): valores médios (ppm/g) obtidos para os lotes de sementes de soja, cultivar IAC-8, em cada período de embebição (médias de 3 épocas) e coeficientes de variação. Piracicaba, 1992.

\begin{tabular}{lcccc}
\hline Lotes & \multicolumn{3}{c}{ K I - Períodos (min.) } & Médias \\
\cline { 2 - 4 } & $\mathbf{6 0}$ & $\mathbf{9 0}$ & $\mathbf{1 2 0}$ & \\
\hline $\mathbf{1}$ & $676 \mathrm{a}$ & $790 \mathrm{a}$ & $853 \mathrm{a}$ & 773 \\
2 & $718 \mathrm{ab}$ & $806 \mathrm{a}$ & $865 \mathrm{a}$ & 796 \\
$\mathbf{3}$ & $797 \mathrm{~b}$ & $882 \mathrm{~b}$ & $944 \mathrm{c}$ & 874 \\
$\mathbf{4}$ & $735 \mathrm{ab}$ & $846 \mathrm{~b}$ & $910 \mathrm{~b}$ & 830 \\
\hline Médias & 732 & 831 & 893 & \\
\hline CV (\%) & 11,02 & 3,66 & 8,19 & \\
\hline Lotes & & K I - Períodos (min.) & & Médias \\
& 60 & 90 & 120 & \\
\hline $\mathbf{1}$ & $779 \mathrm{a}$ & $868 \mathrm{a}$ & $917 \mathrm{a}$ & 854 \\
$\mathbf{2}$ & $802 \mathrm{a}$ & $881 \mathrm{a}$ & $936 \mathrm{a}$ & 873 \\
$\mathbf{3}$ & $804 \mathrm{a}$ & $939 \mathrm{~b}$ & $1013 \mathrm{~b}$ & 919 \\
$\mathbf{4}$ & $758 \mathrm{a}$ & $866 \mathrm{a}$ & $924 \mathrm{a}$ & 849 \\
\hline Médias & 786 & 889 & 946 & \\
\hline CV (\%) & 8,71 & 5,58 & 5,74 & \\
\hline
\end{tabular}

em cada coluna, médias seguidas pela mesma letra não diferiram entre si, pelo teste de Tukey, ao nível de $5 \%$ de probabilidade. 
Destacando as principais informações obtidas com este teste (Tabela 24), pode-se afirmar que a eliminação de sementes danificadas da amostra (KI), apesar da subjetividade e da necessidade de maior tempo na instalação do teste, contribuiu para uma separação mais eficiente dos lotes em níveis de vigor, já com 60 minutos de embebição, embora os coeficientes de variação, de modo geral, tenham sido mais altos neste método. A maior variabilidade associada a estes resultados pode estar relacionada, de modo geral, a possível ocorrência de sementes danificadas e não identificadas influenciando a fidelidade das amostras.

Por outro lado, o emprego de sementes fisicamente puras (KII) permitiu apenas a identificação do lote 3 como inferior aos demais, porém, os valores numéricos indicaram desempenho superior para os lotes 1 e 4, conforme a Tabela 24.

Comparando-se estes resultados (Tabela 24) com os de condutividade elétrica de massa (Tabela 21 ), cujos princípios são semelhantes, pode-se constatar, de modo geral, que houve concordância quanto à identificação da superioridade do lote 1 e da inferioridade do lote 3 , tanto nos estudos com sementes submetidas à escolha (CE I e KI) como naqueles realizados com sementes puras (CE II e $\mathrm{KII}$ ), embora tais constatações não tenham sido constantes em todos os períodos de embebição estudados. Também SIMON \& RAJA-HARUN (1972) e HALLOIN (1975) observaram estreita correspondência entre os resultados de condutividade elétrica e quantidade de potássio lixiviado durante a embebição de sementes de ervilha e algodão, respectivamente. Por outro lado, BARROS (1988) constatou divergência entre as informações proporcionadas pelos dois testes em questão, trabalhando com sementes de soja.

É importante salientar, que o lote 3 apresentou elevada proporção de sementes danificadas (23\%), conforme consta na Tabela 27 , e mesmo quando tais sementes foram eliminadas (CE I e KI), o referido lote continuou apresentando comportamento deficiente. Isto indica que o principal fator responsável por este desempenho não foi, provavelmente, a existência de danos visiveis nos tegumentos das sementes. Pode-se inferir portanto, que o lote 3 encontrava-se em estádio de deterioração mais avançado em relação aos demais, com maior desorganização do seu sistema de membranas. 
A análise de correlação entre os referidos testes (Tabela 25) evidenciou coeficientes de correlação positivos e altamente significativos entre as avaliações feitas com 90 e 120 minutos (KI) e as leituras de condutividade elétrica realizadas com 16 horas de embebição nos sistemas I e II; já para o método KII, houve correpondência somente entre a quantidade de potássio liberado com 90 e 120 minutos e a condutividade elétrica avaliada com 16 horas de embebição pelo método CE II.

Ainda de modo comparativo, verificou-se que o teste de lixiviação de potássio (Tabela 24) se relacionou com o de condutividade individual (Tabela 22) principalmente com relação ao lote de pior qualidade (lote 3 ). Com referência aos lotes de desempenho superior, pode-se afirmar que houve razoável correspondência entre os testes em questão, ocorrendo alternâncias na classificação em virtude de diferenças pouco pronunciadas entre estes lotes.

Corroborando estas informações, a Tabela 26 mostra coeficientes de correlação negativos e significativos, especialmente entre as avaliações feitas até o limite de $50 \mathrm{uA}$ e a quantidade de potássio lixiviado aos 90 e 120 minutos, tanto em KI como em KII. Já os resultados obtidos aos 60 minutos praticamente não mostraram associação com os de condutividade individual.

\subsubsection{Análise comparativa entre os testes para avaliação da qualidade fisiológica}

Pela Tabela 27 verifica-se que não foram detectadas diferenças estatísticas entre os valores de germinação obtidos para os quatro lotes ao longo do período experimental. Assim, o teste de germinação não se revelou capaz de mostrar diferenças entre a qualidade fisiológica dos lotes. Entretanto, foi observada uma ligeira tendência de inferioridade para o lote 3.

Observando-se os coeficientes de correlação simples apresentados na Tabela 28, nota-se a existência de correlações positivas e altamente significativas entre os dados de germinação, primeira contagem e tetrazólio 1-5. Resultados semelhantes foram obtidos por MARCOS FILHO et al. (1982) e por BARROS \& MARCOS FILHO (1990) com sementes de soja. A existência de correlação positiva entre germinação e primeira contagem já era, de certo modo, esperada, pois os testes foram conduzidos simultaneamente. Deve ser observado ainda, que houve correspondência entre o teste de germinação e os testes de vigor, inclusive emergência de plântulas em campo, embora os coeficientes de correlação tenham sido relativamente baixos. 
Tabela 25- Coeficientes de correlação simples (r) entre os dados obtidos nos testes de condutividade elétrica (CE I e II), de lixiviação de potássio e de avaliação da qualidade fisiológica dos lotes de sementes de soja, cultivar IAC-8. Piracicaba, 1992.

\begin{tabular}{|c|c|c|c|c|c|c|c|c|c|c|}
\hline & \multicolumn{5}{|c|}{ CE 1} & \multicolumn{5}{|c|}{ CE II } \\
\hline & 8 & 12 & 16 & 20 & 24 & 8 & 12 & 16 & 20 & 24 \\
\hline KI $60^{\prime}$ & $0,59^{*}$ & 0,20 & $0,62^{*}$ & 0,11 & 0,43 & 0,26 & 0,12 & 0,52 & 0,19 & 0,18 \\
\hline KI 90' & 0,43 & 0,33 & $0,87^{* *}$ & 0,30 & 0,47 & 0,29 & 0,37 & $0,80^{* *}$ & 0,11 & 0,18 \\
\hline KI $120^{\circ}$ & 0,24 & 0,36 & $0,74^{* *}$ & 0,27 & 0,36 & 0,19 & 0,38 & $0,81^{* *}$ & 0,22 & 0,32 \\
\hline KII $60^{\prime}$ & 0,46 & 0,09 & $0,57^{*}$ & 0,33 & 0,24 & 0,27 & 0,26 & 0,26 & 0,25 & 0,20 \\
\hline KII 90' & 0,25 & 0,35 & $0,65^{*}$ & 0,45 & 0,15 & 0,22 & 0,45 & $0,77^{* *}$ & 0,10 & 0,22 \\
\hline KII 120 & 0,11 & 0,24 & 0,46 & 0,26 & 0,12 & 0,20 & 0,31 & $0,65^{*}$ & 0,18 & 0,34 \\
\hline CE I 8h & - & 0,48 & 0,44 & 0,23 & $0,80^{* *}$ & 0,10 & $0,71^{* *}$ & $0,68^{*}$ & $0,60^{*}$ & 0,10 \\
\hline $\mathrm{CE} I 12 \mathrm{~h}$ & - & - & 0,53 & $0,85^{*}$ & 0,44 & 0,19 & $0,86^{* *}$ & $0,68^{*}$ & $0,73^{* *}$ & 0,17 \\
\hline CE I $16 \mathrm{~h}$ & - & - & - & 0,54 & 0,38 & 0,48 & 0,14 & $0,64^{*}$ & 0,25 & 0,37 \\
\hline CE I 20h & - & - & - & - & 0,49 & 0,24 & 0,55 & 0,24 & $0,62^{*}$ & 0,35 \\
\hline CE I 24h & - & - & - & - & - & 0,31 & 0,49 & 0,10 & $0,62^{*}$ & $0,63^{*}$ \\
\hline CE II $8 \mathrm{~h}$ & - & - & - & - & - & - & $0,92^{* *}$ & 0,30 & 0,53 & 0,30 \\
\hline CE II $12 \mathrm{~h}$ & - & - & - & - & - & - & - & 0,19 & 0,52 & 0,26 \\
\hline CE II $16 \mathrm{~h}$ & - & - & - & - & - & - & - & - & 0,41 & 0,27 \\
\hline CE II $20 \mathrm{~h}$ & - & - & - & - & - & - & - & - & - & $0,63^{*}$ \\
\hline Germin ação & $-0,62^{*}$ & $-0,15$ & $-0,55$ & -0.10 & $-0,61^{*}$ & $-0,10$ & $-0,10$ & $-0,76^{* *}$ & $-0,36$ & $-0,58$ \\
\hline TZ $1-5$ & $-0,28$ & $-0,32$ & $-0,72^{*}$ & $-0,16$ & $-0,45$ & $-0,28$ & $-0,32$ & $-0,72^{* *}$ & $-0,17$ & $-0,24$ \\
\hline TZ 1-3 & $-0,45$ & $-0,18$ & $-0,73^{* *}$ & $-0,16$ & $-0,49$ & $-0,15$ & $-0,10$ & $-0,68^{*}$ & $-0,32$ & $-0,41$ \\
\hline P. Con t. & $-0,61^{*}$ & $-0,19$ & $-0,41$ & $-0,15$ & $-0,47$ & $-0,05$ & $-0,05$ & $-0,06$ & $-0,68^{*}$ & $-0,30$ \\
\hline En v.Artif. & $-0,59^{*}$ & $-0,18$ & $-0,78^{* *}$ & $-0,19$ & $-0,61^{*}$ & $-0,32$ & $-0,31$ & $-0,76^{* *}$ & $-0,17$ & $-0,22$ \\
\hline Class. Vig or & $-0,68^{*}$ & $-0,16$ & $-0,78^{* *}$ & $-0,27$ & $-0,58^{*}$ & $-0,35$ & $-0,27$ & $-0,64^{*}$ & $-0,10$ & $-0,02$ \\
\hline E. Campo & $-0,63^{*}$ & $-0,21$ & $-0,83^{* *}$ & $-0,30$ & $-0,53$ & $-0,46$ & $-0,32$ & $-0,56$ & $-0,14$ & $-0,10$ \\
\hline
\end{tabular}

*significativo pelo teste $t$ ao nível de $5 \%$ de probabilidade.

** significativo pelo teste $t$ ao nivel de $1 \%$ de probabilidade. 
Tabela 26. Coeficientes de correlação simples ( $\mathrm{r}$ ) entre os dados obtidos nos testes de condutividade elétrica individual (ASA-610) e de lixiviação de potássio para os lotes de sementes de soja, cultivar IAC-8. Piracicaba, 1992.

\begin{tabular}{|c|c|c|c|c|c|c|}
\hline \multirow[t]{2}{*}{ ASA-610 } & \multicolumn{3}{|c|}{ KI - Periodos (min.) } & \multicolumn{3}{|c|}{ KII - Períodos (min.) } \\
\hline & 60 & 90 & 120 & 60 & 90 & 120 \\
\hline $90-8 h$ & $-0,18$ & $-0,12$ & $-0,11$ & $-0,06$ & 0,15 & 0,04 \\
\hline $90-12 h$ & $-0,39$ & $-0,73 * *$ & $-0,76 * *$ & $-0,36$ & $0,80^{* *}$ & $-0,67^{*}$ \\
\hline $90-16 h$ & $-0,43$ & $-0,74^{* *}$ & $-0,74 * *$ & $-0,29$ & $-0,72 * *$ & $-0,72 * *$ \\
\hline $90-20 h$ & $-0,50$ & $-0,78 * *$ & $-0,78 * *$ & $-0,42$ & $-0,75 * *$ & $-0,75^{* *}$ \\
\hline $90-24 h$ & $-0,44$ & $-0,79 * *$ & $-0,80 * *$ & $-0,44$ & $-0,81^{* *}$ & $-0,81 * *$ \\
\hline $80-8 h$ & $-0,09$ & $-0,12$ & $-0,30$ & $-0,09$ & $-0,47$ & $-0,56$ \\
\hline $80-12 h$ & $-0,57^{*}$ & $-0,86^{* *}$ & $-0,87^{* *}$ & $-0,48$ & $-0,87^{* *}$ & $-0,73 * *$ \\
\hline $80-16 h$ & $-0,43$ & $-0,79 * *$ & $-0,77 * *$ & $-0,38$ & $-0,73^{* *}$ & $-0,71^{* *}$ \\
\hline $80-20 h$ & $-0,52$ & $-0,82 * *$ & $-0,78 * *$ & $-0,38$ & $-0,62 *$ & $-0,64 *$ \\
\hline $80-24 h$ & $-0,38$ & $-0,72^{* *}$ & $-0,74 * *$ & $-0,37$ & $-0,72 * *$ & $-0,75^{* *}$ \\
\hline $70-8 h$ & $-0,17$ & $-0,57$ & $-0,63^{*}$ & $-0,12$ & $-0,48$ & $-0,51$ \\
\hline $70-12 h$ & $-0,43$ & $-0,92 * *$ & $-0,93 * *$ & $-0,40$ & $-0,83^{* *}$ & $-0,76^{* *}$ \\
\hline $70-16 h$ & $-0,33$ & $-0,75^{* *}$ & $-0,84 * *$ & $-0,45$ & $-0,86^{* *}$ & $-0,90 * *$ \\
\hline $70-20 h$ & $-0,30$ & $-0,66^{*}$ & $-0,73 * *$ & $-0,31$ & $-0,74 * *$ & $-0,81 * *$ \\
\hline $70-24 h$ & $-0,13$ & $-0,54$ & $-0,64^{*}$ & $-0,24$ & $-0,70^{*}$ & $-0,78 * *$ \\
\hline $60-8 h$ & $-0,54$ & $-0,66^{*}$ & $-0,61^{*}$ & $-0,12$ & $-0,39$ & $-0,33$ \\
\hline $60-12 h$ & $-0,07$ & $-0,70^{*}$ & $-0,77^{* *}$ & $-0,09$ & $-0,73 * *$ & $0,74 * *$ \\
\hline $60-16 h$ & $-0,30$ & $-0,76^{* *}$ & $-0,85^{* *}$ & $-0,33$ & $-0,75^{* *}$ & $-0,81 * *$ \\
\hline $60-20 h$ & $-0,25$ & $-0,67^{*}$ & $-0,76^{* *}$ & $-0,24$ & $-0,75 * *$ & $-0,82 * *$ \\
\hline $60-24 h$ & $-0,26$ & $-0,66^{*}$ & $-0,75^{* *}$ & $-0,21$ & $-0,79 * *$ & $-0,84^{* *}$ \\
\hline $55-8 h$ & $-0,23$ & $-0,62^{*}$ & $-0,67^{*}$ & $-0,03$ & $-0,64^{*}$ & $-0,60^{*}$ \\
\hline $55-12 h$ & $-0,24$ & $-0,86^{* *}$ & $-0,88 * *$ & $-0,24$ & $-0,75^{* *}$ & $-0,69 *$ \\
\hline $55-16 h$ & $-0,34$ & $-0,56$ & $-0,68^{*}$ & $-0,40$ & $0,71^{*}$ & $-0,77 * *$ \\
\hline $55-20 h$ & $-0,32$ & $-0,60 *$ & $-0,65^{*}$ & $-0,24$ & $-0,70^{*}$ & $-0,72 * *$ \\
\hline $55-24 h$ & $-0,25$ & $-0,64^{*}$ & $-0,69^{*}$ & $-0,12$ & $-0,66^{*}$ & $-0,67^{*}$ \\
\hline $50-8 h$ & $-0,29$ & $-0,72 * *$ & $-0,74 * *$ & $-0,02$ & $-0,66^{*}$ & $-0,59 *$ \\
\hline $50-12 h$ & $-0,52$ & $-0,90 * *$ & $-0,88^{* *}$ & $-0,38$ & $-0,74^{* *}$ & $-0,66^{*}$ \\
\hline $50-16 h$ & $-0,27$ & $-0,52$ & $-0,50$ & $-0,24$ & $-0,52$ & $-0,49$ \\
\hline $50-20 h$ & $-0,17$ & $-0,38$ & $-0,36$ & $-0,09$ & $-0,36$ & $-0,36$ \\
\hline $50-24 h$ & $-0,27$ & $-0,46$ & $-0,38$ & $-0,14$ & $-0,35$ & $-0,27$ \\
\hline $45-8 h$ & $-0,70^{*}$ & $-0,73^{* *}$ & $-0,63^{*}$ & $-0,36$ & $-0,37$ & $-0,33$ \\
\hline $45-12 h$ & $-0,62$ & $-0,63^{*}$ & $-0,44$ & $-0,56$ & $-0,34$ & $-0,18$ \\
\hline $45-16 h$ & $-0,22$ & $-0,39$ & $-0,33$ & $-0,28$ & $-0,35$ & $-0,29$ \\
\hline $45-20 h$ & $-0,08$ & $-0,31$ & $-0,28$ & $-0,04$ & $-0,22$ & $-0,21$ \\
\hline $45-24 h$ & $-0,28$ & $-0,47$ & $-0,40$ & $-0,15$ & $-0,28$ & $-0,26$ \\
\hline
\end{tabular}

*significativo pelo teste $t$ ao nivel de $5 \%$ de probabilidade.

** significativo pelo teste $t$ ao nível de $1 \%$ de probabilidade. 
Tabela 27- Valores médios (\%) e coeficientes de variação obtidos nos testes de germinação (TG), primeira contagem de germinação (PC), envelhecimento artificial (EA), classificação do vigor de plântulas (CLV), tetrazólio 1-3 e 1-5, emergência das plântulas em campo (EC), identificação de danos mecânicos (DM) e determinação do grau de umidade (GU) realizados nos lotes de sementes de soja, cultivar IAC-8 (médias de 3 épocas). Piracicaba, 1992.

\begin{tabular}{|c|c|c|c|c|c|c|c|c|c|}
\hline \multirow[t]{2}{*}{ Lotes } & \multirow{2}{*}{$\begin{array}{l}\text { TG } \\
\text { (\%) }\end{array}$} & \multirow{2}{*}{$\begin{array}{l}\text { PC } \\
(\%)\end{array}$} & \multirow{2}{*}{$\begin{array}{l}\text { EA } \\
(\%)\end{array}$} & \multirow{2}{*}{$\begin{array}{l}\text { CLV } \\
(\%)\end{array}$} & \multicolumn{2}{|c|}{ Tetrazólio (\%) } & \multirow{2}{*}{$\begin{array}{l}\text { EC } \\
(\%)\end{array}$} & \multirow{2}{*}{$\begin{array}{l}\text { DM } \\
(\%)\end{array}$} & \multirow{2}{*}{$\begin{array}{l}\text { GU } \\
\text { (\%) }\end{array}$} \\
\hline & & & & & $1-3$ & $1-5$ & & & \\
\hline 1 & $94 \mathrm{a}$ & $89 a$ & $87 a$ & $87 a$ & $82 a$ & $91 \mathrm{a}$ & $83 \mathrm{ab}$ & 9,0 & 10,9 \\
\hline 2 & $93 \mathrm{a}$ & $88 \mathrm{a}$ & $84 \mathrm{ab}$ & $87 a$ & $83 \mathrm{a}$ & $91 \mathrm{a}$ & $84 a$ & 12,0 & 11,1 \\
\hline 3 & $90 \mathrm{a}$ & $83 \mathrm{~b}$ & $74 \mathrm{c}$ & $82 \mathrm{~b}$ & $76 \mathrm{~b}$ & $86 \mathrm{~b}$ & $77 \mathrm{~b}$ & 23,0 & 10,7 \\
\hline 4 & $93 \mathrm{a}$ & $87 \mathrm{ab}$ & $80 \mathrm{bc}$ & $86 \mathrm{ab}$ & $77 \mathrm{~b}$ & $86 \mathrm{~b}$ & $80 \mathrm{ab}$ & 11,0 & 11,0 \\
\hline CV(\%) & 5,03 & 4,69 & 5,99 & 4,91 & 2,90 & 3,91 & 7,29 & - & - \\
\hline
\end{tabular}

em cada coluna, médias seguidas pela mesma letra não diferiram entre si, pelo teste de Tukey, ao nivel de $5 \%$ de probabilidade.

Os resultados obtidos com 0 teste de primeira contagem de germinação (Tabela 27) indicaram pior desempenho para o lote 3, que não diferiu significativamente do lote 4; em contrapartida, os lotes 1 e 2 apresentaram o melhor potencial embora estatisticamente semelhantes ao lote 4 , caracterizado nesta avaliação como de qualidade intermediária. Este teste tem recebido críticas de diversos pesquisadores (McDONALD Jr., 1975; AOSA, 1983), no sentido de que o parâmetro em que se baseia (velocidade de germinação) pode ser afetado por variações de temperatura e umidade. Além disso, apresenta baixa sensibilidade, não distinguindo, muitas vezes, pequenas diferenças de vigor entre os lotes. No entanto, no presente estudo demonstrou capacidade em separar os lotes em diferentes niveis de qualidade fisiológica. Estes resultados relacionaram-se com os demais testes de vigor, especialmente com relação ao tetrazólio 1-3 e envelhecimento artificial, onde os coeficientes de correlação obtidos foram positivos e altamente significativos (Tabela 28). 
Tabela 28. Coeficientes de correlação simples (r) entre os dados obtidos nos testes de lixiviação de potássio (KI eKII) e de avaliação da qualidade fisiológica dos lotes de sementes de soja, cultivar IAC-8. Piracicaba, 1992.

\begin{tabular}{|c|c|c|c|c|c|c|c|c|c|c|c|c|}
\hline & \multicolumn{3}{|c|}{ K I } & \multicolumn{3}{|c|}{ K II } & \multirow[t]{2}{*}{ Germ } & \multicolumn{2}{|c|}{ Tetrazólio } & \multirow{2}{*}{$\begin{array}{c}\text { P. } \\
\text { Cont. } \\
\end{array}$} & \multirow{2}{*}{$\begin{array}{l}\text { Env. } \\
\text { Artif. } \\
\end{array}$} & \multirow{2}{*}{$\begin{array}{c}\text { C. } \\
\text { Vigor } \\
\end{array}$} \\
\hline & $60^{\prime}$ & $90^{\prime}$ & $120^{\prime}$ & $60^{\prime}$ & $90^{\prime}$ & $120^{\prime}$ & & $1-5$ & $1-3$ & & & \\
\hline KI 60' & - & $0,65^{*}$ & 0,49 & $0,60^{*}$ & 0,33 & 0,19 & $-0,70^{*}$ & $-0,43$ & $-0,51$ & $-0,45$ & $-0,49$ & $-0,59^{*}$ \\
\hline KI 90' & - & - & $0,94^{* *}$ & 0,51 & $0,75^{* *}$ & $0,65^{*}$ & $0,80^{* *}$ & $0,87^{* *}$ & $0,90^{* *}$ & $-0,58^{*}$ & $0,81^{* *}$ & $-0,72^{* *}$ \\
\hline KI 120' & - & - & - & 0,40 & $0,85^{* *}$ & $0,82^{*}$ & $0,78^{* *}$ & $0,83^{* *}$ & $0,79^{* *}$ & $-0,52$ & $0,70^{*}$ & $-0,52$ \\
\hline KII 60' & - & - & - & - & 0,54 & 0,42 & $-0,50$ & $-0,15$ & $-0,32$ & $-0,33$ & $-0,29$ & $-0,29$ \\
\hline KII 90' & - & - & - & - & - & $0,95^{*}$ & $-0,69^{*}$ & $-0,52$ & $-0,52$ & $-0,49$ & $-0,51$ & $-0,39$ \\
\hline KII 120' & - & - & - & - & - & - & $-0,64^{*}$ & $-0,43$ & $-0,42$ & $-0,36$ & $-0,35$ & $-0,16$ \\
\hline Germ. & - & - & - & - & - & - & - & $0,72^{* *}$ & $0,66^{*}$ & $0,76^{* *}$ & $0,65^{*}$ & $0,62^{*}$ \\
\hline TZ 1-5 & - & - & - & - & $\because$ & - & - & - & $0,93^{* *}$ & $0,64^{*}$ & $0,87^{* *}$ & $0,70^{*}$ \\
\hline TZ 1-3 & - & - & - & - & - & - & - & - & - & $0,87^{* *}$ & $0,78^{* *}$ & $0,82^{* *}$ \\
\hline P. Cont. & - & - & - & - & - & - & - & - & - & - & $0,79 * *$ & $0,64^{*}$ \\
\hline E. Artif. & - & - & - & - & - & - & - & - & - & - & - & $0,85^{* *}$ \\
\hline $\begin{array}{l}\text { Emerg. } \\
\text { Campo }\end{array}$ & $0,73^{* *}$ & $0,76^{* *}$ & $-0,53$ & $-0,44$ & $-0,35$ & $-0,12$ & $0,63^{*}$ & $0,72^{* *}$ & $0,81^{* *}$ & $0,65^{*}$ & $0,83^{* *}$ & $0,94^{* *}$ \\
\hline
\end{tabular}

*significativo pelo teste $t$ ao nível de $5 \%$ de probabilidade.

** significativo pelo teste $t$ ao nível de $1 \%$ de probabilidade. 
$\mathrm{O}$ teste de envelhecimento artificial revelou eficiência no sentido de indicar os lotes 1 e 3 como os de melhor e pior desempenho, respectivamente. Por sua vez, os lotes 2 e 4 , demonstraram desempenho intermediário, com tendência de superioridade para o lote 2, que não diferiu estatisticamente do lote 1. Assim, a maior sensibilidade às condições de elevada temperatura e umidade relativa exibida pelo lote 3 , indica que o mesmo encontrava-se num estádio mais avançado de deterioração em relação aos demais lotes (Tabela 27). Este teste exibiu correlação positiva e altamente significativa com praticamente todos os demais, exceto com relação ao de germinação, onde apesar de significativa, a correlação foi relativamente baixa, conforme Tabela 28. A correlação entre o teste de envelhecimento artificial e a emergência das plântulas em campo foi destacada por TEKRONY \& EGLI (1977), KULIK \& YAKLICH (1982), mas não confirmada por JOHNSON \& WAX (1978) em trabalhos com sementes de soja.

Por sua vez, o teste de classificação de vigor de plântulas (Tabela 27) revelou a mesma tendência do teste de primeira contagem de germinação quanto à separação dos lotes em niveis de qualidade fisiológica, ou seja, qualidade superior para os lotes 1 e 2 e inferior para o lote 3 . Estes resultados indicam portanto, que o referido teste pode fornecer informações importantes sobre o vigor relativo dos lotes de sementes de soja, em concordância com YAKLICH \& KULIK (1979), embora as avaliações possam ser consideradas subjetivas. De fato, a classificação das plântulas requer a participação pessoal do analista; no entanto, apresenta a vantagem de poder ser conduzido conjuntamente com o teste padrão de germinação (MARCOS FILHO et al., 1987). A análise de correlação (Tabela 28) indicou comportamento semelhante entre este teste e os testes de tetrazólio 1-3, de envelhecimento artificial e de emergência em campo.

Com referência aos resultados do teste de tetrazólio (Tabela 27) observou-se comportamento semelhante tanto para a determinação da viabilidade (1-5) como para vigor (1-3) em termos de identificação dos lotes, classificando os lotes 1 e 2 como superiores aos lotes 3 e 4 .

Ainda na Tabela 27, comparando-se os resultados de tetrazólio 15 com os de germinação, observou-se pequenas diferenças em termos numéricos a favor de teste de germinação. Segundo FRANÇA NETO et al. (1986), diferenças de até 5\% entre os dois testes para sementes de soja, podem ser consideradas normais. Por outro lado, a porcentagem de germinação exibida pelo lote 4 foi superior em $7 \%$ à viabilidade obtida com o tetrazólio 1-5; este teste mostrou que o principal fator responsável pela perda de viabilidade no referido lote foi a presença de danificações mecânicas. 
Os resultados revelaram portanto, que o teste de germinação apresentou tendência de superestimar a viabilidade de sementes ao longo do período experimental, enquanto o tetrazólio 1-5 mostrou-se mais sensível que aquele detectando alterações nas sementes com maior grau de deterioração.

Uma das principais vantagens do teste de tetrazólio é a possibilidade de avaliação da qualidade fisiológica das sementes em poucas horas, além de ser menos influenciado durante a sua execução, pelas condições do ambiente e pela presença de microorganismos (FRANÇA NETO et al., 1988). Entretanto, a subjetividade pode gerar dificuldades na interpretação do teste. Desse modo, as diferenças entre os resultados de germinação e tetrazólio 1-5, constatadas no presente estudo, podem ser atribuidas, em grande parte, aos julgamentos subjetivos nos quais o teste se baseia.

Conforme a Tabela 28, os dados de tetrazólio 1-5 correlacionaram-se com os de germinação, de tetrazólio 1-3, de envelhecimento artificial e de emergência das plântulas em campo, de forma positiva e altamente significativa, indicando correspondência entre estas avaliações. Também JOHNSON \& WAX (1978), YAKLICH \& KULIK, 1979 e BARROS \& MARCOS FILHO (1990) encontraram correlações semelhantes entre tetrazólio 1-5 e emergência em campo.

Com relação ao teste de tetrazólio para avaliação do vigor (TZ 13), as informações obtidas mostraram-se muito próximas àquelas fornecidas pelos outros testes de vigor, especialmente com referência aos lotes de qualidade superior, conforme indica a Tabela 27. Já quanto à identificação de lotes de pior desempenho, verifica-se que o tetrazólio 1-3 não detectou diferenças significativas entre os lotes 3 e 4, enquanto os demais testes (primeira contagem de germinação, envelhecimento acelerado e classificação de vigor de plântulas) destacaram a inferioridade do lote 3 , embora estatisticamente semelhante ao lote 4. O teste de tetrazólio 1-3 exibiu coeficientes de correlação positivos e altamente significativos com praticamente todos os testes empregados. Correlações significativas entre tetrazólio 1-3 e emergência das plântulas em campo foram relatadas por BARROS \& MARCOS FILHO, (1990).

Ainda na Tabela 27, pode-se observar que o teste de emergência das plântulas em campo destacou a superioridade do lote 2 que mostrou-se estatisticamente semelhante aos lotes 1 e 4 confirmando o lote 3 como inferior aos demais, embora não diferindo significativamente dos lotes 1 e 4 . Contudo, nota-se através dos valores absolutos que a diferença entre a emergência dos lotes 1 e 2 foi de 
apenas $1 \%$; desse modo, pode-se considerar que ambos os lotes mostraram comportamento semelhante no campo.

Destacando-se as principais informações obtidas com os testes para avaliação do vigor (Tabela 27) e estabelecendo relações com a emergência das plântulas em campo, verificou-se que a correspondência entre os dados fornecidos pelas avaliações de laboratório e os de emergência em campo, sempre foi positiva e significativa, especialmente para os testes de tetrazólio 1-3, envelhecimento artificial e classificação do vigor de plântulas. Estes resultados indicam, portanto, que os referidos testes forneceram, de modo geral, informações semelhantes em termos de potencial relativo dos lotes, principalmente com relação à emergência das plântulas em campo.

Analisando de forma comparativa os resultados das Tabelas 21 e 27 , verificou-se, de modo geral, que o teste de condutividade elétrica pelo método de massa revelou sensibilidade em classificar os lotes em niveis de qualidade fisiológica, fornecendo informações semelhantes aos demais testes de vigor empregados.

Conforme mostra a Tabela 25 , para o sistema CE I, as leituras feitas com 8 horas de embebição correlacionaram-se negativa e significativamente com as avaliações de germinação, primeira contagem de germinação, envelhecimento artificial; classificação de vigor de plântulas e emergência das plântulas em campo, enquanto que a correlação com o teste de tetrazólio $1-5$ e $1-3$ não foi significativa. Verificou-se ainda, que o período de embebição de 16 horas exibiu coeficientes de correlação negativos e altamente significativos com os testes de tetrazólio, envelhecimento artificial, classificação de vigor e emergência de plântulas em campo; por sua vez, as leituras feitas após 24 horas apenas se correlacionaram com germinação, envelhecimento artificial e classificação de vigor de plântulas. Já no sistema II, houve correspondência entre as avaliações realizadas com 16 horas e a maioria dos testes de laboratório e de campo, exceto o de primeira contagem de germinação.

Portanto, observou-se que as informações obtidas com o teste de condutividade elétrica, de modo geral, corresponderam aos testes de vigor empregados, especialmente quanto ao desempenho dos lotes em termos de emergência de plântulas em campo; a associação entre estes dois parâmetros também foi observada nos trabalhos de YAKLICH et al. (1979); KULIK \& YAKLICH (1982); OLIVEIRA et al.(1984); MARCOS FILHO et al. (1985) e BARROS (1988), com sementes de soja.

Comparando-se os resultados obtidos com o ASA-610 (Tabela 22) e os demais teste de vigor (Tabela 27) constatou-se que, de modo geral, os testes 
apresentaram tendências de fornecerem informações próximas sobre a qualidade fisiológica dos lotes. Os valores limites de 90, 80, 70 e 60uA identificaram os lotes 1, 2 e 4 como superiores ao lote 3 , classificado como o de pior desempenho demonstrando, portanto, sensibilidades semelhantes no sentido de destacar o lote de qualidade inferior.

Já o valor limite de $55 \mathrm{uA}$ exibiu resultados mais próximos aos fornecidos pelos demais testes de vigor empregados, especialmente com relação à emergência das plântulas em campo, proporcionando uma separação dos lotes de qualidade superior e intermediária.

Complementando estas informações, através da análise de correlação (Tabela 29) observou-se, de maneira geral, que as correlações entre germinação e condutividade individual foram mais elevadas nos valores limites de 90, 80 70 e $60 \mathrm{uA}$, indicando que tais limites devem ser considerados quando o objetivo for a estimativa da viabilidade das sementes.

De acordo com as recomendações do fabricante do ASA-610 (AGROSCIENCES, 1979) e do Comitê de Vigor da Associação Brasileira de Tecnologia de Sementes (KRZYZANOWSKI et al., 1991) o limite de 90uA deve ser utilizado para se estimar a viabilidade das sementes de soja. Também McDONALD Jr. \& WILSON (1979) utilizaram este limite como referencial para promover a separação entre sementes germináveis e não germináveis.

Da mesma forma, para a avaliação do vigor, os estudos realizados com as regulagens de $80 \mathrm{uA}$ com 16 horas de embebição e $70 \mathrm{uA}$ (12 horas de embebição) mostraram associação com todos os testes de vigor utilizados no presente trabalho; já as leituras feitas com 12 horas, no limite de 55uA, indicaram coeficientes de correlação positivos e significativos com praticamente todos os testes de vigor, com exceção do teste de primeira contagem de germinação. Comportamento semelhante foi exibido pelo valor limite de 50uA, após 8 horas de condicionamento, embora este estudo também não tenha apresentado correlação com a emergência das plântulas em campo (Tabela 29).

Verificou-se, de uma maneira geral, que as associações entre os dados fornecidos pelo ASA-610 e os de emergência em campo (Tabela 29) foram esparsas e pouco acentuadas; neste contexto, o coeficiente de correlação mais alto foi obtido com 12 horas de embebição, no limite de $45 \mathrm{uA}$, o qual foi recomendado pela AGROSCIENCES (1979), como mais adequado para a estimativa do vigor de sementes de soja. 
Tabela 29- Coeficientes de correlação simples (r) entre os dados obtidos nos testes de condutividade elétrica individual (ASA-610) e de avaliação da qualidade fisiológica dos lotes de sementes de soja, cultivar IAC-8. Piracicaba, 1992.

\begin{tabular}{|c|c|c|c|c|c|c|c|}
\hline \multirow{2}{*}{$\begin{array}{l}\text { ASA- } \\
610\end{array}$} & \multirow{2}{*}{$\begin{array}{l}\text { Germi- } \\
\text { nação }\end{array}$} & \multirow{2}{*}{$\begin{array}{c}\text { Primeira } \\
\text { Cont. }\end{array}$} & \multirow{2}{*}{$\begin{array}{r}\text { Envelh. } \\
\text { Artif. }\end{array}$} & \multirow{2}{*}{$\begin{array}{l}\text { Classif. } \\
\text { Vigor }\end{array}$} & \multicolumn{2}{|c|}{ Tetrazólio } & \multirow{2}{*}{$\begin{array}{l}\text { Emerg } \\
\text { Campo }\end{array}$} \\
\hline & & & & & 1-3 & $1-5$ & \\
\hline $90-8 h$ & 0,37 & 0,31 & 0,22 & 0,10 & 0,21 & 0,25 & 0,17 \\
\hline $90-12 \mathrm{~h}$ & $0,70^{* *}$ & $0,68 *$ & $0,77^{* *}$ & $0,60^{*}$ & $0,60^{*}$ & $0,71^{* *}$ & $0,58^{*}$ \\
\hline $90-16 h$ & $0,71^{* *}$ & 0,31 & 0,44 & 0,55 & $0,59^{*}$ & 0,48 & 0,43 \\
\hline $90-20 h$ & $0,72^{* *}$ & 0,32 & 0,50 & 0,52 & $0,58^{*}$ & 0,49 & 0,43 \\
\hline $90-24 h$ & $0,72^{* *}$ & 0,39 & 0,53 & 0,50 & $0,62 *$ & 0,55 & 0,44 \\
\hline $80-8 h$ & 0,25 & 0,38 & 0,55 & 0,17 & 0,21 & 0,14 & 0,32 \\
\hline $80-12 h$ & $0,78^{* *}$ & $0,67^{*}$ & $0,79^{* *}$ & $0,67^{*}$ & $0,69^{*}$ & $0,74^{* *}$ & $0,67^{*}$ \\
\hline $80-16 h$ & $0,72^{* *}$ & 0,42 & $0,61^{*}$ & $0,62^{*}$ & $0,67^{*}$ & 0,57 & 0,51 \\
\hline $80-20 h$ & $0,71^{* *}$ & 0,35 & $0,59^{*}$ & $0,58^{*}$ & $0,70^{*}$ & $0,61^{*}$ & 0,53 \\
\hline $80-24 h$ & $0,66^{*}$ & 0,33 & 0,51 & 0,46 & 0,56 & 0,48 & 0,36 \\
\hline $70-8 h$ & $0,48^{* *}$ & 0,39 & $0,63^{*}$ & 0,37 & 0,48 & 0,54 & 0,22 \\
\hline $70-12 h$ & $0,76^{* *}$ & $0,66^{*}$ & $0,82^{* *}$ & $0,70^{* *}$ & $0,84^{* *}$ & $0,86^{* *}$ & $0,67^{*}$ \\
\hline $70-16 h$ & $0,78^{* *}$ & 0,43 & 0,48 & 0,39 & 0,58 & 0,52 & 0,31 \\
\hline $70-20 h$ & $0,65^{*}$ & 0,30 & 0,45 & 0,38 & 0,45 & 0,41 & 0,25 \\
\hline $70-24 h$ & 0,51 & 0,23 & 0,39 & 0,24 & 0,34 & 0,32 & 0,10 \\
\hline $60-8 h$ & $0,59^{*}$ & $0,59^{*}$ & $0,81^{* *}$ & 0,62 & $0,62^{*}$ & $0,66^{*}$ & 0,56 \\
\hline $60-12 h$ & 0,51 & 0,31 & 0,46 & 0,41 & $0,66^{*}$ & $0,65^{*}$ & 0,41 \\
\hline $60-16 h$ & $0,75^{* *}$ & 0,35 & 0,41 & 0,33 & $0,65^{*}$ & $0,61^{*}$ & 0,28 \\
\hline $60-20 h$ & $0,66^{*}$ & 0,29 & 0,41 & 0,37 & 0,50 & 0,44 & 0,23 \\
\hline $60-24 h$ & $0,62^{*}$ & 0,35 & 0,46 & 0,42 & 0,48 & 0,45 & 0,27 \\
\hline $55-8 h$ & 0,45 & 0,42 & $0,69^{*}$ & 0,54 & 0,50 & 0,55 & 0,53 \\
\hline $55-12 h$ & $0,64^{*}$ & 0,50 & $0,71^{* *}$ & $0,64^{*}$ & $0,85^{* *}$ & $0,83^{* *}$ & $0,58^{*}$ \\
\hline $55-16 h$ & 0,57 & 0,10 & 0,10 & 0,14 & 0,29 & 0,25 & 0,12 \\
\hline $55-20 h$ & 0,56 & 0,23 & 0,29 & 0,42 & 0,44 & 0,34 & 0,31 \\
\hline $55-24 h$ & 0,48 & 0,22 & 0,36 & 0,45 & 0,53 & 0,49 & 0,38 \\
\hline $50-8 h$ & 0,47 & 0,42 & $0,72^{* *}$ & $0,64^{*}$ & $0,62^{*}$ & $0,67^{*}$ & 0,51 \\
\hline $50-12 h$ & $0,64^{*}$ & 0,36 & $0,61^{*}$ & $0,64^{*}$ & $0,77^{* *}$ & $0,73^{* *}$ & $0,63^{*}$ \\
\hline $50-16 h$ & 0,41 & 0,15 & 0,24 & 0,48 & 0,43 & 0,29 & 0,40 \\
\hline $50-20 h$ & 0,17 & 0,14 & 0,10 & 0,30 & 0,28 & 0,15 & 0,23 \\
\hline $50-24 h$ & 0,21 & 0,10 & 0,18 & 0,45 & 0,42 & 0,33 & 0,46 \\
\hline $45-8 h$ & 0,56 & 0,20 & 0,46 & $0,59 *$ & $0,61^{*}$ & $0,58 *$ & $0,68^{*}$ \\
\hline $45-12 h$ & 0,45 & 0,27 & 0,37 & $0,61^{*}$ & $0,61^{*}$ & 0,43 & $0,72 * *$ \\
\hline $45-16 h$ & 0,19 & 0,11 & 0,10 & 0,33 & 0,33 & 0,15 & 0,33 \\
\hline $45-20 h$ & 0,10 & 0,25 & 0,10 & 0,17 & 0,26 & 0,17 & 0,17 \\
\hline $45-24 h$ & 0,25 & 0,10 & 0,10 & 0,35 & 0,43 & 0,33 & 0,38 \\
\hline
\end{tabular}

*significativo pelo teste $t$ ao nivel de $5 \%$ de probabilidade.

**significativo pelo teste $\mathrm{t}$ ao nível de $1 \%$ de probabilidade. 
No entanto, tais informações não corresponderam àquelas observadas durante o confronto das médias (Tabela 22). De fato, conforme afirmaram TEKRONY \& EGLI (1977) e MARCOS FILHO et al. (1984) a correlação significativa revela simplesmente uma tendência de variação semelhante entre os dois parâmetros, não fornecendo, contudo, indicações consistentes quanto às diferenças de vigor entre os lotes.

Os resultados obtidos na determinação de danos mecânicos e do grau de umidade das sementes (Tabela 27) não foram submetidos à análise estatística; contudo, os valores numéricos revelam alta incidência de sementes danificadas no lote 3 , indicado na maioria dos testes como de pior desempenho. Por outro lado, o grau de umidade das sementes foi semelhante para todos os lotes, no decorrer do periodo experimental; tal fato é relevante na execução dos testes, considerando-se que a uniformização do grau de umidade das sementes é imprescindivel para a padronização das avaliações e confiabilidade dos resultados (MATTHEWS, 1981).

\subsubsection{Cultivar IAC-15}

$\mathrm{O}$ exame dos valores de $\mathrm{F}$ obtidos nas análises de variância (Tabela 30) permite constatar que ocorreram efeitos significativos de lotes para praticamente todos os estudos, exceto nos testes de condutividade elétrica CE II realizados após 8 e 12 horas de embebição. Com relação aos efeitos de épocas, houve significância apenas para as avaliações feitas com 16, 20 e 24 horas, no sistema CE I, nas leituras de 16 horas com o método CE II e nos testes de lixiviação de potássio (KI eKII) realiza-dos aos 60 minutos de embebição. $\mathrm{A}$ interação lotes $\mathrm{x}$ épocas exibiu valores de $\mathrm{F}$ significativos somente para os estudos CE II, com 8 horas e KI com 60 e 90 minutos de condicionamento.

A análise de variância dos dados referentes à condutividade individual revelou efeitos significativos de lotes nos limites de 80, 60, 55, 50 e 45uA nas avaliações feitas com 24 horas de embebição, sendo que para $45 \mathrm{uA}$, também houve significância para lotes no periodo de 12 horas. Quanto aos efeitos de épocas, de modo geral, verificaram-se valores de $\mathrm{F}$ significativos em todos os periodos, na regulagem de 70uA, e nos limites inferiores a $60 \mathrm{uA}$, nos periodos de 8 e 24 horas (Tabela 31 ).

Os valores de $\mathrm{F}$ obtidos para os testes de avaliação da qualidade fisiológica das sementes (Tabela 32), indicaram efeitos significativos de lotes em praticamente todos os testes, exceto no de germinação, enquanto que para épocas só não foi constatada significância nos testes de germinação e primeira contagem de germinação. 
Tabela 30- Valores de F obtidos nas análises de variância dos dados referentes aos testes de condutividade elétrica (CE I e II) e de lixiviação de potássio (KI e KII), para os lotes do cultivar IAC-15. Piracicaba, 1992.

\begin{tabular}{|c|c|c|c|}
\hline \multirow[t]{2}{*}{ Testes } & \multicolumn{3}{|c|}{ Valores de F } \\
\hline & Lotes (L) & Épocas (E) & Interação (L x E) \\
\hline CE I - $8 \mathrm{~h}$ & $4,35^{*}$ & $2,71^{\text {ns }}$ & $0,30^{\text {ns }}$ \\
\hline $\mathrm{CE} \mathrm{I}-12 \mathrm{~h}$ & $8,02^{* *}$ & $0,51^{\mathrm{ns}}$ & $0,16^{\mathrm{ns}}$ \\
\hline CE I- $16 h$ & $5,85^{* *}$ & $7,45^{* *}$ & $0,34^{\text {ns }}$ \\
\hline $\mathrm{CE} \mathrm{I}-20 \mathrm{~h}$ & $5,49 * *$ & $7,27^{* *}$ & $0,23^{\text {ns }}$ \\
\hline $\mathrm{CE} \mathrm{I}-24 \mathrm{~h}$ & $5,65 * *$ & $6,87 * *$ & $0,76^{\mathrm{ns}}$ \\
\hline CE II $-8 h$ & $0,43^{\text {ns }}$ & $2,76^{\mathrm{ns}}$ & $2,42^{*}$ \\
\hline CE II $-12 \mathrm{~h}$ & $2,56^{\mathrm{ns}}$ & $0,59 \mathrm{~ns}$ & $0,40^{\text {ns }}$ \\
\hline CE II - $16 h$ & $7,94^{* *}$ & $4,69 *$ & $0,93^{\text {ns }}$ \\
\hline CE II - 20 h & $8,29 * *$ & 2,49 ns & $0,53^{\mathrm{ns}}$ \\
\hline CE II - $24 h$ & $3,08^{*}$ & $0,37^{\text {ns }}$ & $0,69^{n s}$ \\
\hline K I - 60 minutos & $3,10^{*}$ & $15,26 * *$ & $6,88^{* *}$ \\
\hline K I - 90 minutos & $6,09 * *$ & $2,16^{\mathrm{ns}}$ & $2,87^{*}$ \\
\hline $\mathrm{K}$ I - 120 minutos & $3,11^{*}$ & $2,09^{n s}$ & $0,96^{\mathrm{ns}}$ \\
\hline K II - 60 minutos & $5,03 * *$ & $9,32 * *$ & $1,23^{\mathrm{ns}}$ \\
\hline K II - 90 minutos & $8,24^{* *}$ & $2,37^{\mathrm{ns}}$ & $0,58^{\text {ns }}$ \\
\hline $\mathrm{K}$ II -120 minutos & $10,58 * *$ & $1,13^{\mathrm{ns}}$ & $0,79^{\text {ns }}$ \\
\hline
\end{tabular}

* - significativo ao nivel de $5 \%$ de probabilidade.

** - significativo ao nivel de $1 \%$ de probabilidade.

ns - não significativo. 
Tabela 31- Valores de $\mathrm{F}$ obtidos nas análises de variância dos dados referentes aos testes de condutividade elétrica individual (ASA-610), para os lotes do cultivar IAC15. Piracicaba, 1992.

\begin{tabular}{|c|c|c|c|}
\hline \multirow[t]{2}{*}{ Testes } & \multicolumn{3}{|c|}{ Valores de F } \\
\hline & Lotes $(\mathrm{L})$ & Épocas (E) & Interação (L × E) \\
\hline ASA $90-8 h$ & $1,88^{\mathrm{ns}}$ & $0,40^{\mathrm{ns}}$ & $0,21^{\mathrm{ns}}$ \\
\hline ASA $90-12 \mathrm{~h}$ & $0,06^{\mathrm{ns}}$ & $2,34^{\mathrm{ns}}$ & $0,21^{\text {ns }}$ \\
\hline ASA $90-16 \mathrm{~h}$ & $0,43^{\text {ns }}$ & $3,66^{*}$ & $0,65^{\text {ns }}$ \\
\hline ASA $90-20 h$ & $1,20^{\mathrm{ns}}$ & $11,08 * *$ & $2,00^{\mathrm{ns}}$ \\
\hline ASA $90-24 h$ & $0,88^{\mathrm{ns}}$ & $20,34 * *$ & $1,00^{\mathrm{ns}}$ \\
\hline ASA $80-8 h$ & $2,11^{n s}$ & $0,87^{\mathrm{ns}}$ & $0,79^{\mathrm{ns}}$ \\
\hline ASA $80-12 h$ & $0,61^{n s}$ & $1,35^{\mathrm{ns}}$ & $0,89^{\text {ns }}$ \\
\hline ASA $80-16 h$ & $0,65^{\mathrm{ns}}$ & $3,80^{\mathrm{ns}}$ & $2,46^{*}$ \\
\hline ASA $80-20 h$ & $2,28^{\mathrm{ns}}$ & $10,49 * *$ & $2,93^{*}$ \\
\hline ASA $80-24 h$ & $2,90 *$ & $6,79 * *$ & $2,46^{*}$ \\
\hline ASA $70-8 h$ & $1,37^{\mathrm{ns}}$ & $3,71^{*}$ & $0,94^{\mathrm{ns}}$ \\
\hline ASA $70-12 h$ & $1,67^{\mathrm{ns}}$ & $6,11^{* *}$ & $5,03 * *$ \\
\hline ASA $70-16 h$ & $1,23^{\mathrm{ns}}$ & $3,62 *$ & $1,70^{\mathrm{ns}}$ \\
\hline ASA $70-20 h$ & $0,89^{\text {ns }}$ & $4,39 *$ & $0,83^{\mathrm{ns}}$ \\
\hline ASA $70-24 h$ & $2,14^{\mathrm{ns}}$ & $7,51 * *$ & $2,04^{\mathrm{ns}}$ \\
\hline ASA $60-8 h$ & $0,74^{\mathrm{ns}}$ & $7,15^{* *}$ & $1,93^{\text {ns }}$ \\
\hline ASA $60-12 \mathrm{~h}$ & $1,77^{\mathrm{ns}}$ & $1,36^{\mathrm{ns}}$ & $1,94^{\mathrm{ns}}$ \\
\hline ASA $60-16 \mathrm{~h}$ & $1,38^{\mathrm{ns}}$ & $0,76^{\mathrm{ns}}$ & $1,31^{\mathrm{ns}}$ \\
\hline ASA $60-20 h$ & $2,43^{\text {ns }}$ & $2,21^{\mathrm{ns}}$ & $1,01^{\mathrm{ns}}$ \\
\hline A $A 60-24 h$ & $9,03 * *$ & $15,95 * *$ & $3,45^{* *}$ \\
\hline ASA $55-8 h$ & $1,01^{\mathrm{ns}}$ & $8,37 * *$ & $2,31^{\text {ns }}$ \\
\hline ASA $55-12 \mathrm{~h}$ & $0,96^{\mathrm{ns}}$ & $0,94^{\mathrm{ns}}$ & $1,15^{\mathrm{ns}}$ \\
\hline ASA $55-16 h$ & $2,62^{\mathrm{ns}}$ & $1,45^{\mathrm{ns}}$ & $1,72^{\mathrm{ns}}$ \\
\hline ASA $55-20 \mathrm{~h}$ & $2,45^{n s}$ & $1,99 \mathrm{~ns}$ & $1,42^{\mathrm{ns}}$ \\
\hline ASA $55-24 h$ & $4,62^{* *}$ & $7,27 * *$ & $1,94^{\mathrm{ns}}$ \\
\hline ASA $50-8 \mathrm{~h}$ & $0,78^{\mathrm{ns}}$ & $6,04^{* *}$ & $2,32^{\mathrm{ns}}$ \\
\hline ASA $50-12 \mathrm{~h}$ & $1,93^{\mathrm{ns}}$ & $0,80^{\mathrm{ns}}$ & $1,19^{\mathrm{ns}}$ \\
\hline ASA $50-16 \mathrm{~h}$ & $2,04^{\mathrm{ns}}$ & $1,14^{\mathrm{ns}}$ & $2,05^{\mathrm{ns}}$ \\
\hline ASA $50-20 \mathrm{~h}$ & $2,12^{\mathrm{ns}}$ & $3,42^{*}$ & $2,23^{\mathrm{ns}}$ \\
\hline ASA $50-24 \mathrm{~h}$ & $6,43 * *$ & $15,31^{* *}$ & $1,11^{\mathrm{ns}}$ \\
\hline ASA $45-8 h$ & $1,10^{\mathrm{ns}}$ & $5,45^{* *}$ & $1,73^{\mathrm{ns}}$ \\
\hline ASA $45-12 \mathrm{~h}$ & $4,30^{*}$ & $0,63^{\mathrm{ns}}$ & $1,23^{\mathrm{ns}}$ \\
\hline ASA $45-16 \mathrm{~h}$ & $1,23^{\mathrm{ns}}$ & $0,88^{\mathrm{ns}}$ & $1,34^{\mathrm{ns}}$ \\
\hline ASA $45-20 \mathrm{~h}$ & $2,48^{\mathrm{ns}}$ & $1,92^{\mathrm{ns}}$ & $1,92^{\mathrm{ns}}$ \\
\hline ASA $45-24 \mathrm{~h}$ & $3,38^{\mathrm{ns}}$ & $7,60 * *$ & $1,79^{\mathrm{ns}}$ \\
\hline
\end{tabular}

* - significativo ao nivel de $5 \%$ de probabilidade

** - significativo ao nível de $1 \%$ de probabilidade

ns - não significativo 
Tabela 32- Valores de F obtidos nas análises de variância dos dados referentes aos testes de laboratório e de campo, realizados com os lotes do cultivar IAC-15. Piracicaba, 1992.

\begin{tabular}{|c|c|c|c|c|c|c|c|}
\hline $\begin{array}{l}\text { Causas de } \\
\text { Variação }\end{array}$ & $\begin{array}{l}\text { Germi- } \\
\text { nação }\end{array}$ & $\begin{array}{l}1 \text { a contagem } \\
\text { germinação }\end{array}$ & $\begin{array}{l}\text { Envelhec. } \\
\text { Artificial }\end{array}$ & $\begin{array}{l}\text { Classificação } \\
\text { Vigor Plânt. }\end{array}$ & $\begin{array}{l}\text { Emergência } \\
\text { em Campo }\end{array}$ & $\begin{array}{c}\text { Tetrazólio } \\
1-3\end{array}$ & $\begin{array}{c}\text { Tetrazólio } \\
1-5\end{array}$ \\
\hline Lotes (L) & $1,09^{\mathrm{ns}}$ & $3,09 *$ & $13,67^{* *}$ & $3,91^{*}$ & $13,22^{* *}$ & $13,22 * *$ & $10,38^{* *}$ \\
\hline Épocas(E) & $1,24^{\mathrm{ns}}$ & $0,25^{\mathrm{ns}}$ & $42,69 * *$ & $13,48 * *$ & $33,54 * *$ & $30,51 * *$ & $8,68^{* *}$ \\
\hline LXE & $0,91^{\text {ns }}$ & $1,50^{\text {ns }}$ & $0,44^{\mathrm{ns}}$ & $2,18^{n s}$ & $1,03^{\mathrm{ns}}$ & $2,26^{\mathrm{ns}}$ & $0,94^{\mathrm{ns}}$ \\
\hline
\end{tabular}

* - significativo ao nível de $5 \%$ de probabilidade

** - significativo ao nivel de $1 \%$ de probabilidade

ns - não significativo

\subsubsection{Condutividade elétrica - CE I e CE 11}

Os resultados dos testes de condutividade elétrica CE I e II são apresentados na Tabela 33. Verificou-se um aumento nas leituras de condutividade com o decorrer da embebição das sementes, sendo obtidos valores mais elevados no estudo II (sem a remoção de sementes danificadas da amostra), conforme também observado e discutido nos testes com o cultivar IAC-8.

Pela Tabela 33, observa-se que a realização do teste de condutividade de massa sem a presença de sementes danificadas (CE I) revelou maior sensibilidade, indicando, já no período de embebição de 8 horas, uma classificação dos lotes em termos de qualidade fisiológica. Este periodo, identificou o lote 4 como superior, enquanto os lotes 1 e 2 apresentaram desempenho inferior, apesar de não diferirem estatisticamente do lote 3 , revelado como sendo de qualidade intermediária. Observando-se as médias referentes ao periodo de embebição de 12 horas (CE I), nota-se que houve um agrupamento dos lotes 3 e 4 e dos lotes 1 e 2 , os quais apresentaram respectivamente, melhor e pior desempenho. Por sua vez, os estudos realizados a partir de 16 horas de embebição, apresentaram resultados semelhantes, destacando a superioridade do lote 1 em relação aos demais. 
Tabela 33- Condutividade elétrica (CE I e II): valores médios (umhos/cm/g) para os lotes de sementes de soja, cultivar IAC-15, em cada período de embebição (médias de 3 épocas) e coeficientes de variação. Piracicaba, 1992.

\begin{tabular}{|c|c|c|c|c|c|c|}
\hline \multirow[t]{2}{*}{ Lotes } & \multicolumn{5}{|c|}{ CE I - Periodos (h) } & \multirow[t]{2}{*}{ Médias } \\
\hline & 8 & 12 & 16 & 20 & 24 & \\
\hline 1 & $38,10 \mathrm{~b}$ & $42,52 \mathrm{~b}$ & $49,51 \mathrm{~b}$ & $57,02 \mathrm{~b}$ & $61,18 \mathrm{~b}$ & 49,67 \\
\hline 2 & $37,82 \mathrm{~b}$ & $43,26 \mathrm{~b}$ & $49,54 \mathrm{~b}$ & $56,82 \mathrm{~b}$ & $62,51 \mathrm{~b}$ & 49,99 \\
\hline 3 & $35,83 \mathrm{ab}$ & 38,85 a & $49,64 \mathrm{~b}$ & $57,60 \mathrm{~b}$ & $61,02 \mathrm{~b}$ & 48,59 \\
\hline 4 & $35,08 \mathrm{a}$ & $37,95 \mathrm{a}$ & $45,01 \mathrm{a}$ & $52,17 \mathrm{a}$ & $55,48 \mathrm{a}$ & 45,14 \\
\hline Médias & 36,71 & 40,65 & 48,43 & 55,95 & 57,55 & \\
\hline CV $(\%)$ & 6,68 & 7,94 & 6,72 & 6,64 & 7,57 & \\
\hline \multirow[t]{2}{*}{ Lotes } & \multicolumn{5}{|c|}{ CE II - Períodos (h) } & Médias \\
\hline & 8 & 12 & 16 & 20 & 24 & \\
\hline 1 & $45,01 \mathrm{a}$ & $53,13 \mathrm{a}$ & $57,71 \mathrm{~b}$ & $67,83 \mathrm{~b}$ & $73,02 \mathrm{ab}$ & 59,34 \\
\hline 2 & $45,83 \mathrm{a}$ & $52,32 \mathrm{a}$ & $56,70 \mathrm{~b}$ & $67,51 \mathrm{~b}$ & $71,84 \mathrm{ab}$ & 58,84 \\
\hline 3 & $44,23 \mathrm{a}$ & $50,83 \mathrm{a}$ & $59,29 \mathrm{~b}$ & $71,12 b$ & $73,70 \mathrm{~b}$ & 59,83 \\
\hline 4 & $44,28 \mathrm{a}$ & $47,74 \mathrm{a}$ & $50,63 \mathrm{a}$ & $60,92 \mathrm{a}$ & $66,54 \mathrm{a}$ & 54,02 \\
\hline Médias & 44,84 & 51,01 & 56,08 & 66,85 & 71,28 & \\
\hline CV $(\%)$ & 8,85 & 10,10 & 8,30 & 7,70 & 9,01 & \\
\hline
\end{tabular}

em cada coluna, médias seguidas pela mesma letra não diferiram entre si, pelo teste de Tukey, ao nivel de $5 \%$ de probabilidade. 
Portanto, pelo sistema I, foi possivel se obter uma ordenação dos lotes quanto ao vigor, especialmente, no periodo de condicionamento mais curto, ou seja, 8 horas; com o decorrer da embebição, o método revelou eficiência apenas no sentido de identificar o lote de melhor qualidade (lote 4) separando-o dos demais, não permitindo a obtenção de informações mais detalhadas sobre o potencial fisiológico dos lotes. MARCOS FILHO et al. (1990) obtiveram indicações mais precisas sobre o vigor dos lotes nos períodos de embebição mais longos. É importante ressaltar, que estes resultados discordam daqueles verificados com os lotes do 'IAC-8', onde a separação eficiente dos lotes pelo método CE I foi obtida principalmente, com as avaliações realizadas a partir de 16 horas de embebição.

Por outro lado, as informações fornecidas pelo sistema CE II (Tabela 33) não confirmaram a possibilidade de redução do período de condicionamento das sementes de soja, uma vez que os menores periodos ( 8 e 12 horas) não identificaram diferenças significativas entre os lotes estudados. Entretanto, os valores numéricos obtidos principalmente no período de 12 horas, revelaram menores leituras de condutividade para o lote 4. Assim, de um modo geral, pode-se considerar que tal período pode ser utilizado para a obtenção de informações pouco detalhadas à respeito da qualidade fisiológica dos lotes, fato este também observado nos testes com o cultivar IAC-8.

Por sua vez, os periodos de 16 e 20 horas revelaram significância para as tendências indicadas com 12 horas de condicionamento, ou seja, superioridade para o lote 4 em relação aos demais. Porém, o exame da Tabela 33 indica que o método II mostrou-se mais sensivel às diferenças de qualidade entre os lotes, somente após 24 horas de embebição, ocorrendo um desagrupamento das médias, destacando o lote 4 como de melhor desempenho e o lote 3 como deficiente, enquanto os lotes 1 e 2 apresentaram qualidade intermediária. LOEFFLER et al. (1988) constataram que este método exibiu maior sensibilidade a partir de 12 horas de condicionamento.

Diante destes resultados da Tabela 33, foi possivel constatar que, apesar de ambos os sistemas (CE I e II) terem se mostrado consistentes quanto à indicação do melhor desempenho do lote 4 , não houve coerência entre eles com relação ao período de tempo mais adequado para a separação dos lotes em niveis de vigor. Neste contexto, o método I já revelava sensibilidade no período de 8 horas de embebição, que caracterizou os lotes 1 e 2 como inferiores em termos de vigor. 
Desse modo, a remoção de sementes danificadas da amostra (CE I) permitiu a obtenção de informações mais rápidas sobre o potencial fisiológico dos lotes revelando, ainda, coeficientes de variação inferiores aos fornecidos pelo sistema II, ao contrário do que foi observado por LOEFFLER et al. (1988).

\subsubsection{Condutividade elétrica individual}

Pelo exame da Tabela 34, verificou-se que não houve diferenças significativas entre os lotes nos estudos com os valores limites de 90 e $70 \mathrm{uA}$, enquanto as regulagens de 80 e $60 \mathrm{uA}$ revelaram informações semelhantes, ou seja, a superioridade do lote 4 e qualidade inferior para o lote 2, apenas nas avaliações feitas com 24 horas de embebição.

Por sua vez, os limites de 55 e 50uA também só permitiram uma ordenação de lotes quanto ao vigor com 24 horas de condicionamento, destacando o lote 4 em relação aos lotes 1 e 2 , classificados como inferiores. No entanto, os valores numéricos indicaram uma ligeira superioridade para o lote 4, nas avaliações feitas após 16 horas (Tabela 34).

Quando foi utilizada a intensidade de corrente elétrica de 45uA, diferenças estatísticas entre os lotes foram detectadas com 12 e 24 horas de embebição. Contudo, o período de 12 horas revelou o melhor desempenho do lote 2, identificado nas avaliações feitas com 24 horas como de potencial inferior. Assim, na maioria dos estudos, indicações sobre a qualidade fisiológica dos lotes foram obtidas principalmente com o período de 24 horas, exceto nos limites de 90 e 70 uA. No entanto, é importante observar através dos valores absolutos, que o melhor desempenho do lote 4 já era notado na fase inicial de embebição (8 horas).

Estes resultados revelam, portanto, que o teste de condutividade individual pode ser considerado um método promissor para a avaliação da qualidade fisiológica de sementes de soja, em concordância com McDONALD Jr. \& WLSON (1980).

Analisando de modo comparativo os resultados das Tabelas $35 \mathrm{e}$ 36, observou-se que, de modo geral, houve coerência quanto à indicação da superioridade do lote 4 , tanto nos sistemas de massa como na condutividade elétrica individual. 
Tabela 34. Condutividade elétrica individual (ASA-610): valores médios (\%) obtidos para os valores limites (VL) e periodos de embebição para os lotes de sementes de soja, cultivar IAC-15 e coeficientes de variação (médias de 3 épocas). Piracicaba, 1992.

\begin{tabular}{|c|c|c|c|c|c|c|c|}
\hline \multirow[t]{2}{*}{ VL (uA) } & \multirow[t]{2}{*}{ Lotes } & \multicolumn{5}{|c|}{ Períodos (h) } & \multirow[b]{2}{*}{ Médias } \\
\hline & & 8 & 12 & 16 & 20 & 24 & \\
\hline \multirow[t]{6}{*}{90} & 1 & $100 a$ & $100 a$ & $99 a$ & 99 a & $98 \mathrm{a}$ & 100 \\
\hline & 2 & $100 a$ & $100 a$ & $99 a$ & 99 a & $98 \mathrm{a}$ & 99 \\
\hline & 3 & $100 a$ & $100 a$ & 99 a & 98 a & $98 \mathrm{a}$ & 99 \\
\hline & 4 & $100 \mathrm{a}$ & $100 a$ & $99 \mathrm{a}$ & $99 a$ & $98 \mathrm{a}$ & 99 \\
\hline & Médias & 100 & 100 & 99 & 99 & 98 & \\
\hline & CV $(\%)$ & 3,16 & 4,00 & 3,94 & 3,39 & 3,80 & \\
\hline \multirow[t]{6}{*}{80} & 1 & $100 \mathrm{a}$ & $99 a$ & $99 a$ & $99 a$ & $97 \mathrm{ab}$ & 99 \\
\hline & 2 & $100 a$ & $99 a$ & $98 \mathrm{a}$ & 97 a & $95 \mathrm{~b}$ & 98 \\
\hline & 3 & $100 a$ & $99 a$ & $98 \mathrm{a}$ & $97 b$ & $96 \mathrm{ab}$ & 98 \\
\hline & 4 & $100 a$ & $99 \mathrm{a}$ & $98 \mathrm{a}$ & $98 \mathrm{a}$ & $98 \mathrm{a}$ & 99 \\
\hline & Médias & 100 & 99 & 98 & 98 & 96 & \\
\hline & $\mathrm{CV}(\%)$ & 3,73 & 4,41 & 3,22 & 3,69 & 4,80 & \\
\hline \multirow[t]{6}{*}{70} & 1 & $99 a$ & $99 a$ & $97 a$ & $95 \mathrm{a}$ & $94 \mathrm{a}$ & 97 \\
\hline & 2 & 99 a & $97 \mathrm{a}$ & $95 a$ & $94 a$ & $92 a$ & 96 \\
\hline & 3 & 99 a & $97 a$ & $95 \mathrm{a}$ & $94 \mathrm{a}$ & $93 a$ & 96 \\
\hline & 4 & $100 a$ & $97 \mathrm{a}$ & $97 \mathrm{a}$ & $96 \mathrm{a}$ & $95 \mathrm{a}$ & 97 \\
\hline & Médias & 99 & 98 & 96 & 95 & 94 & \\
\hline & $\mathrm{CV}(\%)$ & 4,38 & 3,77 & 4,64 & 5,31 & 5,49 & \\
\hline \multirow[t]{6}{*}{60} & 1 & $97 \mathrm{a}$ & $95 \mathrm{a}$ & $93 \mathrm{a}$ & $89 a$ & $88 \mathrm{bc}$ & 93 \\
\hline & 2 & $97 \mathrm{a}$ & 95 a & 92 a & 90 a & $85 \mathrm{c}$ & 92 \\
\hline & 3 & $97 \mathrm{a}$ & $93 a$ & $91 \mathrm{a}$ & $90 \mathrm{a}$ & $89 a b$ & 92 \\
\hline & 4 & $98 \mathrm{a}$ & $95 \mathrm{a}$ & $94 \mathrm{a}$ & $93 a$ & $92 \mathrm{a}$ & 95 \\
\hline & Médias & 97 & 95 & 93 & 90 & 89 & \\
\hline & CV (\%) & 3,99 & 4,16 & 4,07 & 4,81 & 4,09 & \\
\hline \multirow[t]{6}{*}{55} & 1 & $96 a$ & $92 a$ & $89 a$ & $86 a$ & $84 \mathrm{~b}$ & 90 \\
\hline & 2 & $96 \mathrm{a}$ & 93 a & $88 \mathrm{a}$ & $85 a$ & $83 \mathrm{~b}$ & 89 \\
\hline & 3 & $96 a$ & $90 \mathrm{a}$ & 87 a & $87 a$ & $86 \mathrm{ab}$ & 89 \\
\hline & 4 & $97 \mathrm{a}$ & $93 a$ & $91 \mathrm{a}$ & $89 a$ & $89 \mathrm{a}$ & 92 \\
\hline & Médias & 96 & 92 & 89 & 86 & 85 & \\
\hline & $\operatorname{CV}(\%)$ & 4,12 & 4,50 & 4,42 & 4,74 & 5,09 & \\
\hline
\end{tabular}


Continuação

Tabela 34. Condutividade elétrica individual (ASA-610): valores médios (\%) obtidos para os valores limites (VL) e periodos de embebição para os lotes de sementes de soja, cultivar IAC-15 e coeficientes de variação (médias de 3 épocas). Piracicaba, 1991.

\begin{tabular}{|c|c|c|c|c|c|c|c|}
\hline \multirow[t]{2}{*}{ VL (uA) } & \multirow[t]{2}{*}{ Lotes } & \multicolumn{5}{|c|}{ Períodos (h) } & \multirow[b]{2}{*}{ Médias } \\
\hline & & 8 & 12 & 16 & 20 & 24 & \\
\hline \multirow[t]{6}{*}{50} & 1 & $93 a$ & $89 a$ & $85 a$ & $80 a$ & $79 \mathrm{~b}$ & $\overline{86}$ \\
\hline & 2 & $94 a$ & $90 \mathrm{a}$ & $84 a$ & $80 a$ & $76 \mathrm{~b}$ & 85 \\
\hline & 3 & $94 a$ & $87 a$ & $83 a$ & $82 a$ & $82 a b$ & 86 \\
\hline & 4 & $95 \mathrm{a}$ & $90 \mathrm{a}$ & $87 a$ & $85 a$ & $85 \mathrm{a}$ & 89 \\
\hline & Médias & 94 & 89 & 85 & 81 & 81 & \\
\hline & CV (\%) & 4,79 & 4,80 & 4,91 & 5,40 & 5,45 & \\
\hline \multirow[t]{6}{*}{45} & 1 & $91 \mathrm{a}$ & $86 \mathrm{ab}$ & $80 a$ & $75 a$ & $73 \mathrm{ab}$ & 82 \\
\hline & 2 & $90 \mathrm{a}$ & $88 a$ & $79 a$ & $72 a$ & $70 \mathrm{~b}$ & 80 \\
\hline & 3 & $89 a$ & $82 \mathrm{~b}$ & $79 a$ & $77 a$ & $76 \mathrm{ab}$ & 81 \\
\hline & 4 & $93 \mathrm{a}$ & $85 \mathrm{ab}$ & $83 \mathrm{a}$ & $79 a$ & $77 \mathrm{a}$ & 84 \\
\hline & Médias & 91 & 85 & 81 & 76 & 74 & \\
\hline & CV (\%) & 4,75 & 4,83 & 5,79 & 6,70 & 6,53 & \\
\hline
\end{tabular}

em cada coluna, médias seguidas pela mesma letra não diferiram entre si, pelo teste de Tukey, ao nivel de $5 \%$ de probabilidade. 
Porém, com relação aos lotes de qualidade inferior, os resultados dos referidos testes (Tabelas 33 e 34) exibiram algumas variações na classificação dos lotes, ou seja, não houve consistência entre os períodos de embebição nos métodos de massa com relação à inferioridade do lote 2 , indicada em praticamente todos os estudos com o ASA-610. Isto se deve, provavelmente, à dificuldade já relatada na literatura (McDONALD Jr. \& WILSON, 1979; KULIK \& YAKLICH, 1982; MARCOS FILHO et al., $1984 ; 1990)$ de se detectar diferenças de qualidade entre amostras com níveis médios de vigor.

Observou-se ainda, em termos de avaliação do vigor, que os limites inferiores à $60 \mathrm{uA}$ nas leituras realizadas com 24 horas de embebição revelaram, de um modo geral, correspondência com os estudos de condutividade elétrica CE I com 8 horas de condicionamento. Entretanto, a Tabela 35 mostra, de um modo geral, que houve associação entre a maioria dos estudos com o ASA-610 e os de condutividade CE I, nas leituras feitas com 16 horas, conforme indicado pelos coeficientes de correlação negativos e significativos. Por outro lado, o sistema II praticamente não mostrou correlação com a condutividade individual.

\subsubsection{Lixiviação de potássio - KI e KII}

O teste de lixiviação de potássio (Tabela 36) revelou tendências semelhantes para os dois métodos (KI e KII) com relação ao aumento da quantidade de potássio liberado no decorrer da embebição.

Com base nos resultados obtidos no sistema KI, observou-se que os períodos de embebição de 60 e 120 minutos não permitiram diferenciar estatisticamente os 4 lotes estudados, embora, os valores numéricos tenham indicado uma tendência de destaque para o lote 4 . Nota-se ainda, que os coeficientes de variação obtidos nestes dois períodos foram, de modo geral, superiores ao revelado com 90 minutos. Este, por sua vez, proporcionou uma classificação adequada dos lotes, identificando a superioridade do lote 4 e o desempenho inferior dos lotes 2 e 3, situando o lote 1 numa posição intermediária. Desse modo, as avaliações feitas com 90 minutos de condicionamento, no sistema I, mostraram eficiência quanto à ordenação dos lotes em níveis de qualidade fisiológica. 
Tabela 35. Coeficientes de correlação simples (r) entre os dados obtidos nos testes de condutividade elétrica individual (ASA-610) e CE I e II para os lotes de sementes de soja, cultivar IAC-15. Piracicaba, 1992.

\begin{tabular}{|c|c|c|c|c|c|c|c|c|c|c|}
\hline \multirow{2}{*}{$\begin{array}{l}\text { ASA- } \\
610\end{array}$} & \multirow[b]{2}{*}{8} & \multicolumn{3}{|c|}{ CE I } & \multicolumn{6}{|c|}{ CE II } \\
\hline & & 12 & 16 & 20 & 24 & 8 & 12 & 16 & 20 & 24 \\
\hline $90-8 h$ & $-0,15$ & $-0,29$ & $-0,21$ & $-0,05$ & 0,05 & $-0,16$ & $-0,02$ & $-0,21$ & 0,10 & 0,04 \\
\hline $90-12 h$ & $-0,23$ & $-0,43$ & $-0,68^{*}$ & 0,02 & $-0,01$ & 0,14 & $-0,22$ & $-0,35$ & 0,05 & $-0,08$ \\
\hline $90-16 h$ & 0,41 & 0,28 & $-0,29$ & 0,32 & 0,32 & 0,53 & 0,53 & 0,14 & 0,53 & 0,15 \\
\hline $90-20 h$ & 0,14 & 0,31 & $-0,58^{*}$ & 0,37 & 0,18 & 0,27 & 0,16 & $-0,04$ & 0,34 & $-0,05$ \\
\hline $90-24 h$ & $-0,07$ & 0,13 & $-0,59^{*}$ & 0,40 & 0,12 & 0,14 & $-0,22$ & $-0,01$ & 0,35 & $-0,16$ \\
\hline $80-8 h$ & $-0,23$ & $-0,45$ & $-0,28$ & $-0,36$ & $-0,59$ & 0,10 & $-0,44$ & $-0,24$ & $-0,32$ & $-0,40$ \\
\hline $80-12 h$ & 0,26 & 0,11 & $-0,52$ & 0,52 & $0,59^{*}$ & 0,31 & 0,27 & $-0,01$ & 0,56 & 0,19 \\
\hline $80-16 h$ & 0,13 & 0,02 & $-0,36$ & 0,25 & 0,21 & 0,11 & 0,38 & $-0,01$ & 0,28 & 0,17 \\
\hline $80-20 h$ & 0,14 & 0,15 & $-0,63^{*}$ & 0,34 & 0,06 & 0,12 & 0,14 & $-0,33$ & 0,11 & $-0,01$ \\
\hline $80-24 h$ & $-0,11$ & 0,11 & $-0,68^{*}$ & 0,24 & $-0,29$ & 0,04 & $-0,23$ & $-0,39$ & $-0,05$ & $-0,29$ \\
\hline $70-8 h$ & $-0,48$ & $-0,34$ & $-0,82^{* *}$ & 0,03 & $-0,38$ & $-0,12$ & $-0,59^{*}$ & $-0,39$ & $-0,17$ & $-0,49$ \\
\hline $70-12 h$ & 0,39 & 0,14 & $-0,33$ & 0,28 & 0,23 & 0,32 & 0,50 & 0,04 & 0,36 & 0,25 \\
\hline $70-16 h$ & $-0,04$ & 0,05 & $-0,73^{* *}$ & 0,19 & 0,01 & 0,10 & 0,02 & $-0,41$ & $-0,04$ & $-0,16$ \\
\hline $70-20 h$ & $-0,14$ & 0,20 & $-0,72^{* *}$ & 0,21 & 0,01 & $-0,10$ & 0,08 & $-0,38$ & $-0,08$ & $-0,23$ \\
\hline $70-24 h$ & $-0,22$ & $-0,06$ & $0,70^{*}$ & 0,28 & $-0,23$ & 0,02 & $-0,25$ & $-0,27$ & 0,09 & $-0,21$ \\
\hline $60-8 h$ & 0,12 & $-0,03$ & $-0,69^{*}$ & 0,10 & $-0,17$ & 0,32 & $-0,24$ & $-0,61$ & $-0,18$ & $-0,44$ \\
\hline $60-12 h$ & $0,59^{*}$ & 0,23 & $-0,18$ & $-0,01$ & $-0,03$ & 0,53 & 0,54 & $-0,16$ & 0,03 & 0,05 \\
\hline $60-16 h$ & 0,08 & 0,14 & $-0,49$ & 0,10 & $-0,01$ & 0,03 & 0,18 & $-0,36$ & $-0,13$ & $-0,13$ \\
\hline $60-20 h$ & $-0,34$ & $-0,11$ & $-0,90^{* *}$ & $-0,08$ & $-0,16$ & 0,03 & $-0,33$ & $-0,66^{*}$ & $-0,32$ & $-0,57^{*}$ \\
\hline $60-24 h$ & $-0,22$ & $-0,21$ & $-0,77^{* *}$ & 0,20 & $-0,25$ & 0,08 & $-0,32$ & $-0,39$ & 0,01 & $-0,34$ \\
\hline $55-8 h$ & 0,18 & 0,20 & $-0,56$ & 0,31 & $-0,08$ & 0,28 & $-0,10$ & $-0,22$ & 0,16 & 0,19 \\
\hline $55-12 h$ & 0,49 & 0,22 & $-0,29$ & $-0,19$ & $-0,16$ & $0,67^{*}$ & 0,33 & $-0,43$ & $-0,21$ & $-0,16$ \\
\hline $55-16 h$ & $-0,04$ & 0,10 & $-0,70^{*}$ & $-0,25$ & $-0,22$ & 0,32 & $-0,01$ & $-0,53$ & $-0,33$ & $-0,48$ \\
\hline $55-20 h$ & $-0,39$ & $-0,32$ & $-0,87^{* *}$ & $-0,14$ & $-0,18$ & 0,07 & $-0,38$ & $-0,52$ & $-0,24$ & $-0,43$ \\
\hline $55-24 h$ & $-0,50$ & $-0,40$ & $-0,87^{* *}$ & 0,18 & $-0,25$ & 0,13 & $-0,55$ & $-0,39$ & $-0,05$ & $-0,35$ \\
\hline
\end{tabular}


continuação

Tabela 35. Coeficientes de correlação simples ( $r$ ) entre os dados obtidos nos testes de condutividade elétrica individual (ASA-610) e CE I e II para os lotes de sementes de soja, cultivar IAC-15. Piracicaba, 1992.

\begin{tabular}{|c|c|c|c|c|c|c|c|c|c|c|}
\hline \multirow{2}{*}{$\begin{array}{l}\text { ASA- } \\
610 \\
\end{array}$} & \multicolumn{5}{|c|}{ CE I } & \multicolumn{5}{|c|}{ CE II } \\
\hline & 8 & 12 & 16 & 20 & 24 & 8 & 12 & 16 & 20 & 24 \\
\hline $50-8 h$ & 0,05 & 0,01 & $-0,71^{*}$ & 0,23 & $-0,18$ & 0,28 & $-0,18$ & $-0,37$ & 0,03 & $-0,29$ \\
\hline $50-12 h$ & 0,39 & 0,31 & $-0,42$ & $-0,18$ & $-0,07$ & $0,64^{*}$ & 0,29 & $-0,35$ & $-0,17$ & $-0,26$ \\
\hline $50-16 h$ & $-0,28$ & 0,06 & $-0,65^{*}$ & $-0,28$ & $-0,14$ & 0,04 & $-0,21$ & $-0,27$ & $-0,28$ & $-0,42$ \\
\hline $50-20 h$ & $-0,51$ & $-0,25$ & $-0,72^{* *}$ & $-0,10$ & $-0,09$ & $-0,10$ & $-0,43$ & $-0,26$ & $-0,14$ & $-0,32$ \\
\hline $50-24 h$ & $-0,43$ & $-0,30$ & $-0,84^{* *}$ & 0,28 & $-0,20$ & $-0,16$ & $-0,51$ & $-0,35$ & 0,02 & $-0,24$ \\
\hline $45-8 h$ & 0,11 & 0,11 & $-0,77^{* *}$ & 0,17 & $-0,17$ & 0,35 & $-0,10$ & $-0,50$ & $-0,05$ & $-0,35$ \\
\hline $45-12 h$ & $0,59^{*}$ & 0,47 & $-0,06$ & $-0,28$ & 0,09 & $0,62^{*}$ & 0,48 & $-0,09$ & $-0,13$ & $-0,09$ \\
\hline $45-16 h$ & $-0,52$ & $-0,23$ & $-0,72^{* *}$ & $-0,34$ & $-0,29$ & $-0,05$ & $-0,40$ & 0,44 & $-0,40$ & $-0,54$ \\
\hline $45-20 h$ & $-0,50$ & $-0,45$ & $-0,58^{*}$ & $-0,08$ & $-0,19$ & $-0,09$ & $-0,41$ & $-0,01$ & $-0,04$ & $-0,11$ \\
\hline $45-24 h$ & $-0,32$ & $-0,34$ & $-0,70^{*}$ & 0,29 & $-0,22$ & $-0,07$ & $-0,43$ & $-0,18$ & 0,12 & $-0,07$ \\
\hline
\end{tabular}

* significativo pelo teste $t$ ao nível de $5 \%$ de probabilidade.

** significativo pelo teste $t$ ao nivel de $1 \%$ de probabilidade. 
Tabela 36- Lixiviação de potássio (KI e KII): valores médios (ppm/g) obtidos para os lotes de sementes de soja, cultivar IAC-15, em cada período de embebição (médias de 3 épocas) e coeficientes de variação. Piracicaba, 1992.

\begin{tabular}{lcccc}
\hline Lotes & \multicolumn{3}{c}{ K I - Períodos (min.) } & Médias \\
\cline { 2 - 4 } & $\mathbf{6 0}$ & $\mathbf{9 0}$ & $\mathbf{1 2 0}$ & \\
\hline $\mathbf{1}$ & $573 \mathrm{a}$ & $643 \mathrm{ab}$ & $732 \mathrm{a}$ & 649 \\
$\mathbf{2}$ & $569 \mathrm{a}$ & $684 \mathrm{~b}$ & $783 \mathrm{a}$ & 679 \\
$\mathbf{3}$ & $569 \mathrm{a}$ & $663 \mathrm{~b}$ & $784 \mathrm{a}$ & 672 \\
$\mathbf{4}$ & $517 \mathrm{a}$ & $618 \mathrm{a}$ & $727 \mathrm{a}$ & 621 \\
\hline Médias & 557 & 652 & 757 & \\
\hline CV (\%) & 9,37 & 6,04 & 8,14 & \\
\hline Lotes & & K II - Períodos (min.) & & Médias \\
& $\mathbf{6 0}$ & $\mathbf{9 0}$ & $\mathbf{1 2 0}$ & \\
\hline $\mathbf{1}$ & $584 \mathrm{ab}$ & $712 \mathrm{ab}$ & $806 \mathrm{~b}$ & 681 \\
$\mathbf{2}$ & $583 \mathrm{ab}$ & $715 \mathrm{ab}$ & $805 \mathrm{~b}$ & 701 \\
$\mathbf{3}$ & $638 \mathrm{~b}$ & $770 \mathrm{~b}$ & $859 \mathrm{~b}$ & 756 \\
$\mathbf{4}$ & $532 \mathrm{a}$ & $657 \mathrm{a}$ & $733 \mathrm{a}$ & 641 \\
\hline Médias & 584 & 714 & 801 & \\
\hline CV (\%) & 11,43 & 7,76 & 6,86 & \\
\hline
\end{tabular}

em cada coluna, médias seguidas pela mesma letra não diferiram entre si, pelo teste de Tukey, ao nível de $5 \%$ de probabilidade. 
Ainda na Tabela 36, verifica-se que o método KII revelou maior sensibilidade às diferenças de qualidade entre os lotes, caracterizada pela tendência de desagrupamento das médias, especialmente nos estudos realizados com 60 e 90 minutos, cujos comportamentos foram semelhantes. Estes períodos, destacaram o melhor e pior desempenho dos lotes 4 e 3, respectivamente, considerando os lotes 1 e 2 como intermediários. Já o período de 120 minutos, possibilitou apenas a identificação do lote de melhor qualidade (lote 4), exibindo uma concentração das médias dos demais lotes ( 1 , 2 e 3). No entanto, numericamente, observou-se que maior quantidade de potássio foi liberada pelas sementes do lote 3, indicando assim, de acordo com SIMON \& RAJAHARUM (1972) maior desorganização do sistema de membranas e conseqüentemente, menor qualidade fisiológica.

A análise global dos resultados de lixiviação de potássio (Tabela 36) mostrou concordância entre os métodos KI e KII quanto à indicação de melhor desempenho para o lote 4. Observou-se ainda, aos 90 minutos no sistema KI , a inferioridade do lote 3, o que também foi confirmado pelo método KII, em todos os períodos de embebição; assim, a realização do teste com sementes fisicamente puras (KII) mostrou maior eficiência no sentido de classificar os lotes em níveis de qualidade fisiológica, ao contrário do que foi constatado para os lotes do cultivar IAC-8.

Confrontando os resultados da Tabela $36 \mathrm{com}$ os de condutividade elétrica de massa (Tabela 33), verificou-se, de maneira geral, que os dois testes forneceram informações semelhantes quanto ao comportamento do lote 4 , na maioria dos períodos estudados. Por outro lado, com relação aos lotes de baixo e médio desempenho, apesar das variações entre os resultados, foi observada uma estreita correspondência entre as leituras feitas com 24 horas no sistema CE II e aquelas realizadas com 60 e 90 minutos no método KII (Tabela 37). SIMON \& RAJA-HARUM (1972) afirmaram que a avaliação do potássio lixiviado proporciona praticamente as mesmas informações fornecidas pelo teste de condutividade elétrica, uma vez que baseiam-se em princípio semelhante. Porém, BARROS (1988) não obteve resultados coerentes com os dois testes.

Comparando as Tabelas 34 e 36 verificou-se, de modo geral, consistência entre o ASA-610 e a lixiviação de potássio com relação à identificação do lote de qualidade superior (lote 4) ao contrário do que foi observado com o cultivar IAC-8. 
Tabela 37. Coeficientes de correlação simples (r) entre os dados obtidos nos testes de condutividade elétrica (CE I e II), de lixiviação de potássio e de avaliação da qualidade fisiológica dos lotes de sementes de soja, cultivar IAC-15. Piracicaba, 1992.

\begin{tabular}{|c|c|c|c|c|c|c|c|c|c|c|}
\hline & \multicolumn{5}{|c|}{ CE I } & \multicolumn{5}{|c|}{ CE II } \\
\hline & 8 & 12 & 16 & 20 & 24 & 8 & 12 & 16 & 20 & 24 \\
\hline $\mathrm{KI} 60^{\prime}$ & 0,49 & 0,15 & 0,42 & 0,05 & 0,17 & 0,38 & 0,55 & 0,18 & 0,31 & 0,38 \\
\hline $\mathrm{KI} 90^{\prime}$ & 0,35 & 0,34 & $0,62^{*}$ & 0,08 & 0,21 & 0,16 & 0,46 & 0,46 & 0,36 & 0,32 \\
\hline KI 120' & $-0,08$ & 0,06 & 0,45 & $-0,09$ & 0,08 & 0,05 & 0,06 & $0,64^{*}$ & 0,34 & 0,09 \\
\hline KIl 60' & 0,49 & $-0,10$ & 0,44 & 0,18 & 0,34 & 0,52 & 0,52 & 0,20 & 0,50 & 0,36 \\
\hline KII 90' & $-0,14$ & $-0,39$ & $-0,29$ & 0,15 & 0,28 & 0,09 & 0,05 & $0,67^{*}$ & $0,64^{*}$ & 0,48 \\
\hline KII 120 & 0,15 & $-0,03$ & 0,56 & 0,43 & 0,49 & $-0,03$ & 0,28 & $0,79^{* *}$ & $0,74^{* *}$ & 0,55 \\
\hline CE I $8 \mathrm{~h}$ & - & 0,55 & 0,38 & 0,30 & 0,50 & $0,59^{*}$ & $0,83^{* *}$ & 0,15 & 0,38 & 0,46 \\
\hline $\mathrm{CE} I 12 \mathrm{~h}$ & - & - & 0,18 & 0,14 & 0,27 & 0,22 & 0,45 & 0,07 & 0,03 & $-0,04$ \\
\hline CE I $16 \mathrm{~h}$ & - & - & - & $-0,04$ & 0,23 & 0,03 & 0,53 & $0,65^{*}$ & 0,27 & 0,53 \\
\hline CE I 20h & - & - & - & - & $0,75^{* *}$ & $-0,26$ & 0,25 & 0,13 & $0,69^{*}$ & $0,64^{*}$ \\
\hline CE I $24 \mathrm{~h}$ & - & - & - & - & - & 0,03 & $0,57^{*}$ & 0,31 & $0,75^{* *}$ & $0,65^{*}$ \\
\hline $\mathrm{CE}$ II $8 \mathrm{~h}$ & - & - & - & . & - & - & 0,49 & 0,04 & 0,16 & $-0,07$ \\
\hline $\mathrm{CE}$ II $12 \mathrm{~h}$ & - & - & - & - & - & - & . & 0,39 & 0,54 & 0,56 \\
\hline CE II $16 \mathrm{~h}$ & - & - & - & - & - & - & - & - & $0,66^{*}$ & $0,61^{*}$ \\
\hline $\mathrm{CE}$ II $20 \mathrm{~h}$ & - & - & - & - & - & - & - & - & - & $0,78^{* *}$ \\
\hline Gernninação & $-0,33$ & 0,32 & $-0,30$ & -0.08 & $-0,18$ & $-0,43$ & $-0,47$ & $-0,29$ & $-0,46$ & $-0,48$ \\
\hline TZ $1-5$ & $-0,15$ & $-0,34$ & $-0,65^{*}$ & $-0,13$ & $-0,24$ & $-0,25$ & $-0,34$ & $-0,45$ & $-0,32$ & $-0,41$ \\
\hline TZ 1-3 & $-0,18$ & 0,37 & $-0,67^{*}$ & 0,27 & 0,15 & $-0,34$ & $-0,31$ & $-0,46$ & $-0,23$ & $-0,38$ \\
\hline P. Cont. & 0,31 & 0,49 & $-0,17$ & 0,16 & $-0,03$ & $-0,05$ & $-0,03$ & $-0,46$ & $-0,31$ & $-0,25$ \\
\hline Env. Artif. & 0,07 & 0,52 & 0,28 & 0,10 & $-0,22$ & $-0,19$ & $-0,13$ & $-0,06$ & $-0,22$ & $-0,48$ \\
\hline Class. Vigor & $-0,01$ & 0,40 & $-0,42$ & 0,46 & $-0,34$ & $-0,17$ & 0,08 & $-0,32$ & 0,15 & $-0,09$ \\
\hline E. Campo & $-0,10$ & 0,36 & $-0,69^{*}$ & 0,49 & 0,26 & $-0,17$ & $-0,19$ & $-0,35$ & 0,06 & $-0,24$ \\
\hline
\end{tabular}

* significativo pelo teste $t$ ao nivel de $5 \%$ de probabilidade.

** significativo pelo teste $t$ ao nível de $1 \%$ de probabilidade. 
Quanto aos lotes de baixo e médio desempenho, as variações observadas podem ser atribuidas à qualidade fisiológica semelhante apresentada pelos lotes 1, 2 e 3 . Assim, a condutividade elétrica individual destacou a inferioridade do lote 2 , na maioria dos limites como ocorreu em KI aos 90 minutos de embebição e em KII aos 120 minutos, embora nestes estudos o lote 3 também tenha sido incluido nesta categoria. $\dot{E}$ importante ressaltar, que nos testes com o ASA-610, o referido lote somente foi classificado como inferior nas leituras de 12 horas, no limite de $45 \mathrm{uA}$ (Tabelas 34 e 36).

Complementando estas informações através da análise de correlação (Tabela 38) observou-se coeficientes de correlação negativos e altamente significativos entre as leituras realizadas aos 90 minutos no método KI e após 20 horas, nos limites de 55, 50 e 45uA, incluindo neste último também o periodo de 16 horas. Já os resultados fornecidos pelo método KII revelaram ausência de associação com o ASA-610, sendo que a existência de correlação altamente significativa só foi observada entre KII aos 120 minutos e o valor limite de 55uA, nas leituras com 16 horas de embebição.

\subsubsection{Análise comparativa entre os testes para avaliação da qualidade fisiológica}

Os valores médios obtidos nos testes de germinação (Tabela 39) indicam que os quatro lotes não diferiram significativamente entre si, ao longo do período experimental, conforme também constatado para os lotes do cultivar IAC-8. Portanto, o referido teste não se mostrou sensivel para detectar diferenças entre os lotes. Observouse ainda, pela Tabela 40 que apesar da existência de correlação significativa entre germinação e primeira contagem, envelhecimento artificial e tetrazólio 1-3, os coeficientes obtidos apresentaram valores relativamente baixos.

Os testes de primeira contagem de germinação e de classificação do vigor de plântulas (Tabela 39) revelaram um ordenação de médias semelhantes, caracterizando o lote 2 como de qualidade fisiológica superior e o lote 3 como inferior. De fato, já por ocasião das determinações iniciais, realizadas com o objetivo de caracterizar fisiologicamente os quatro lotes, notou-se uma ligeira tendência de pior desempenho para o lote 3. A análise de correlação (Tabela 40) indicou correspondência entre os testes de classificação do vigor de plântulas e o desempenho dos lotes em termos de emergência das plântulas em campo, enquanto o de primeira contagem se relacionou apenas com a germinação. Este fato já era, de certo modo esperado, uma vez que estas duas avaliações foram realizadas simultaneamente. 
Tabela 38. Coeficientes de correlação simples (r) entre os dados obtidos nos testes de condutividade elétrica individual (ASA-610) e de lixiviação de potássio para os lotes de sementes de soja, cultivar IAC-15. Piracicaba, 1992.

\begin{tabular}{|c|c|c|c|c|c|c|}
\hline \multirow[t]{2}{*}{ ASA-610 } & \multicolumn{3}{|c|}{ KI - Períodos (min.) } & \multicolumn{3}{|c|}{ KII - Periodos (min.) } \\
\hline & 60 & 90 & 120 & 60 & 90 & 120 \\
\hline $90-8 h$ & 0,49 & $-0,08$ & $-0,24$ & 0,19 & $-0,12$ & $-0,23$ \\
\hline $90-12 h$ & 0,02 & $-0,23$ & $-0,19$ & $-0,15$ & 0,24 & $-0,43$ \\
\hline $90-16 h$ & 0,09 & $-0,07$ & $-0,16$ & 0,20 & $-0,01$ & 0,10 \\
\hline $90-20 h$ & $-0,19$ & $-0,27$ & $-0,27$ & $-0,14$ & $-0,13$ & $-0,06$ \\
\hline $90-24 h$ & $-0,20$ & $-0,14$ & 0,11 & $-0,02$ & 0,08 & 0,21 \\
\hline $80-8 h$ & 0,01 & $-0,29$ & $-0,10$ & 0,12 & $-0,21$ & $-0,12$ \\
\hline $80-12 h$ & $-0,08$ & $-0,19$ & $-0,13$ & 0,03 & 0,17 & 0,07 \\
\hline $80-16 h$ & $-0,16$ & $-0,41$ & $-0,50$ & $-0,17$ & $-0,18$ & $-0,17$ \\
\hline $80-20 h$ & $-0,17$ & $-0,47$ & $-0,66^{*}$ & $-0,25$ & $-0,40$ & $-0,39$ \\
\hline $80-24 h$ & $-0,18$ & $-0,32$ & $-0,39$ & $-0,19$ & $-0,38$ & $-0,29$ \\
\hline $70-8 h$ & $-0,39$ & $-0,37$ & $-0,06$ & $-0,32$ & $-0,09$ & $-0,21$ \\
\hline $70-12 h$ & $-0,07$ & $-0,23$ & $-0,40$ & $-0,06$ & $-0,16$ & $-0,15$ \\
\hline $70-16 h$ & $-0,26$ & $-0,60$ * & $-0,69^{*}$ & $-0,32$ & $-0,38$ & $-0,50$ \\
\hline $70-20 h$ & $-0,40$ & $-0,59 *$ & $-0,62^{*}$ & $-0,54$ & $-0,44$ & $-0,49$ \\
\hline $70-24 h$ & $-0,19$ & $-0,29$ & $-0,28$ & $-0,15$ & $-0,16$ & $-0,17$ \\
\hline $60-8 h$ & $-0,05$ & $-0,24$ & $-0,23$ & 0,08 & $-0,36$ & $-0,31$ \\
\hline $60-12 h$ & 0,19 & $-0,02$ & $-0,33$ & 0,04 & $-0,34$ & 0,32 \\
\hline $60-16 h$ & $-0,36$ & $-0,50$ & $-0,63^{*}$ & $-0,44$ & $-0,48$ & $-0,48$ \\
\hline $60-20 h$ & $-0,47$ & $-0,65 *$ & $-0,52$ & $-0,44$ & $-0,37$ & $-0,62^{*}$ \\
\hline $60-24 h$ & $-0,30$ & $-0,47$ & $-0,35$ & $-0,09$ & $-0,23$ & $-0,18$ \\
\hline $55-8 h$ & 0,06 & 0,01 & $-0,01$ & 0,05 & $-0,16$ & $-0,04$ \\
\hline $55-12 h$ & 0,15 & $-0,09$ & $-0,44$ & 0,05 & $-0,33$ & $-0,59^{*}$ \\
\hline $55-16 h$ & $-0,27$ & $-0,60 *$ & $-0,65^{*}$ & $-0,35$ & 0,49 & $-0,71^{* *}$ \\
\hline $55-20 h$ & $-0,45$ & $-0,76^{* *}$ & $-0,55$ & $-0,42$ & $-0,18$ & $-0,59^{*}$ \\
\hline $55-24 h$ & $-0,50$ & $-0,56$ & $-0,29$ & $-0,31$ & $-0,05$ & $-0,22$ \\
\hline $50-8 h$ & $-0,19$ & $-0,22$ & $-0,18$ & $-0,06$ & $-0,19$ & $-0,18$ \\
\hline $50-12 h$ & $-0,14$ & $-0,25$ & $-0,40$ & $-0,16$ & $-0,31$ & $-0,52$ \\
\hline $50-16 h$ & $-0,42$ & $-0,65^{*}$ & $-0,45$ & $-0,64^{*}$ & $-0,30$ & $-0,57^{*}$ \\
\hline $50-20 h$ & $-0,61^{*}$ & $-0,77 * *$ & $-0,43$ & $-0,55$ & $-0,02$ & $-0,39$ \\
\hline $50-24 h$ & $-0,47$ & $-0,58^{*}$ & $-0,38$ & $-0,33$ & $-0,08$ & $-0,21$ \\
\hline $45-8 h$ & $-0,15$ & $-0,30$ & $-0,37$ & $-0,09$ & $-0,35$ & $-0,37$ \\
\hline $45-12 h$ & 0,11 & $-0,01$ & $-0,18$ & $-0,13$ & $-0,26$ & $-0,41$ \\
\hline $45-16 h$ & $-0,57$ & $-0,76^{* *}$ & $-0,50$ & $-0,58 *$ & $-0,25$ & $-0,60^{*}$ \\
\hline $45-20 h$ & $-0,58 *$ & $-0,78 * *$ & $-0,46$ & $-0,46$ & $-0,12$ & $-0,27$ \\
\hline $45-24 h$ & $-0,42$ & $-0,55$ & $-0,35$ & $-0,25$ & $-0,03$ & $-0,09$ \\
\hline
\end{tabular}

* significativo pelo teste $\mathrm{t}$ ao nivel de $5 \%$ de probabilidade.

** significativo pelo teste $t$ ao nível de $1 \%$ de probabilidade. 
Tabela 39. Valores médios (\%) e coeficientes de variação obtidos nos testes de germinação (TG), primeira contagem de germinação (PC), envelhecimento artificial (EA), classificação do vigor de plântulas (CLV), tetrazólio 1-3 e 1-5, emergência das plântulas em campo (EC), identificação de danos mecânicos (DM) e determinação do grau de umidade (GU) realizados nos lotes de sementes de soja, cultivar IAC-15 (médias de 3 épocas). Piracicaba, 1992.

\begin{tabular}{|c|c|c|c|c|c|c|c|c|c|}
\hline \multirow[t]{2}{*}{ Lotes } & \multirow{2}{*}{$\begin{array}{l}\text { TG } \\
\text { (\%) }\end{array}$} & \multirow{2}{*}{$\begin{array}{l}\text { PC } \\
(\%)\end{array}$} & \multirow{2}{*}{$\begin{array}{l}\text { EA } \\
(\%)\end{array}$} & \multirow{2}{*}{$\begin{array}{l}\text { CLV } \\
(\%)\end{array}$} & \multicolumn{2}{|c|}{ Tetrazólio (\%) } & \multirow{2}{*}{$\begin{array}{l}\text { EC } \\
(\%)\end{array}$} & \multirow{2}{*}{$\begin{array}{l}\text { DM } \\
(\%)\end{array}$} & \multirow{2}{*}{$\begin{array}{l}\text { GU } \\
(\%)\end{array}$} \\
\hline & & & & & $1-3$ & $1-5$ & & & \\
\hline 1 & $94 \mathrm{a}$ & $90 \mathrm{ab}$ & $87 \mathrm{a}$ & $85 \mathrm{ab}$ & $85 \mathrm{a}$ & $92 \mathrm{a}$ & $83 \mathrm{ab}$ & 14,0 & 10,8 \\
\hline 2 & $96 a$ & $93 a$ & $90 \mathrm{a}$ & $89 a$ & $86 a$ & $88 \mathrm{~b}$ & $85 \mathrm{ab}$ & 17,0 & 10,9 \\
\hline 3 & $94 \mathrm{a}$ & $87 \mathrm{~b}$ & $80 \mathrm{~b}$ & $83 b$ & $78 \mathrm{~b}$ & $86 b$ & $80 \mathrm{~b}$ & 14,0 & 11,4 \\
\hline 4 & $96 a$ & $90 a b$ & $88 \mathrm{a}$ & $87 \mathrm{ab}$ & $87 a$ & $93 \mathrm{a}$ & $86 a$ & 12,0 & 11,2 \\
\hline $\operatorname{CV}(\%)$ & 5,43 & 6,01 & 5,61 & 5,49 & 4,24 & 4,30 & 5,66 & - & - \\
\hline
\end{tabular}

em cada coluna, médias seguidas pela mesma letra não diferiram entre si, pelo teste de Tukey, ao nível de $5 \%$ de probabilidade.

Ainda com base na Tabela 39, pode-se verificar que o teste de envelhecimento artificial revelou desempenho superior para os lotes 1,2 e 4 confirmando a inferioridade do lote 3 , também apontada nos dois testes anteriormente mencionados. Neste caso, os efeitos do envelhecimento artificial mostraram-se mais drásticos para o referido lote. MARCOS FILHO et al. (1984) e CALIARI \& MARCOS FILHO (1990) trabalhando respectivamente, com sementes de soja e ervilha, constataram a tendência deste teste em identificar lotes de qualidade elevada e agrupar os demais em níveis muito baixos. Por outro lado, KULIK \& YAKLICH (1982) destacaram a eficiência do envelhecimento em classificar corretamente os lotes de melhor qualidade e os piores. Os resultados obtidos no presente estudo indicam um agrupamento dos lotes de maior vigor, embora os valores absolutos sugiram uma ligeira superioridade do lote 2 em relação aos lotes 1 e 4 . O teste de envelhecimento artificial mostrou coeficientes de correlação positivos e altamente signficativos com os de tetrazólio 1-3 e emergência das plântulas em campo, indicando tendência de variação semelhante entre eles. Resultados semelhantes foram obtidos por TEKRONY \& EGLI (1977) e KULIK \& YAKLICH (1982). 
Tabela 40. Coeficientes de correlação simples ( $r$ ) entre os dados obtidos nos testes de lixiviação de potássio (KI eKII) e de avaliação da qualidade fisiológica dos lotes de sementes de soja, cultivar IAC-15. Piracicaba, 1992.

\begin{tabular}{|c|c|c|c|c|c|c|c|c|c|c|c|c|}
\hline & \multicolumn{3}{|c|}{ K I } & \multicolumn{3}{|c|}{ K II } & \multirow[t]{2}{*}{ Germ } & \multicolumn{2}{|c|}{ Tetrazólio } & \multirow{2}{*}{$\begin{array}{c}\text { P. } \\
\text { Cont. }\end{array}$} & \multirow{2}{*}{$\begin{array}{l}\text { Env. } \\
\text { Artif. } \\
\end{array}$} & \multirow{2}{*}{$\begin{array}{c}\text { C. } \\
\text { Vigor }\end{array}$} \\
\hline & $60^{\prime}$ & $90^{\prime}$ & $120^{\prime}$ & $60^{\prime}$ & $90^{\prime}$ & $120^{\prime}$ & & $1-5$ & $1-3$ & & & \\
\hline KI 60' & - & $0,71^{* *}$ & 0,24 & $0,62^{*}$ & 0,14 & 0,25 & $-0,22$ & $-0,27$ & $-0,48$ & 0,16 & $-0,48$ & 0,15 \\
\hline KI 90' & - & - & $0,75^{* *}$ & 0,47 & 0,39 & $0,65^{*}$ & 0,14 & 0,44 & 0,42 & 0,29 & $-0,23$ & 0,20 \\
\hline KI 120' & - & - & - & 0,25 & $0,66^{*}$ & $0,82^{*}$ & 0,25 & 0,47 & $-0,32$ & 0,02 & $-0,12$ & $-0,04$ \\
\hline Kח 60' & - & - & - & - & 0,33 & 0,47 & $-0,63^{*}$ & $-0,56$ & $-0,67^{*}$ & 0,14 & $-0,72 * *$ & $-0,14$ \\
\hline KII 90' & - & - & - & - & - & $0,64^{*}$ & $-0,23$ & $-0,68^{*}$ & $-0,49$ & $-0,50$ & $-0,29$ & $-0,08$ \\
\hline KII 120' & - & - & - & - & - & - & $-0,28$ & $-0,46$ & $-0,38$ & $-0,29$ & $-0,21$ & $-0,21$ \\
\hline Germ. & - & - & - & - & - & - & - & 0,42 & $0,66^{*}$ & $0,67^{*}$ & $0,64^{*}$ & 0,47 \\
\hline TZ 1-5 & - & - & - & - & - & - & - & - & $0,76^{* *}$ & 0,42 & $0,69^{*}$ & 0,41 \\
\hline TZ 1-3 & - & - & - & - & - & - & - & - & - & $0,66^{*}$ & $0,87^{* *}$ & $0,62^{*}$ \\
\hline P. Cont. & - & - & - & - & - & - & - & - & - & - & 0,41 & 0,44 \\
\hline E. Artif. & - & - & - & - & - & - & - & - & - & - & - & 0,54 \\
\hline Emerg. & $-0,47$ & $-0,32$ & $-0,25$ & $-0,44$ & $-0,27$ & $-0,18$ & 0,45 & $0,64^{*}$ & $0,87^{* *}$ & 0,34 & $0,85^{* *}$ & $0,73^{* *}$ \\
\hline Campo & & & & & & & & & & & & \\
\hline
\end{tabular}

*significativo pelo teste $t$ ao nivel de $5 \%$ de probabilidade.

${ }^{* *}$ significativo pelo teste $t$ ao nível de $1 \%$ de probabilidade. 
O teste de tetrazólio 1-3 (Tabela 39) proporcionou informações semelhantes ao teste de envelhecimento artificial quanto à ordenação dos lotes. Cabe ressaltar que, a inferioridade do lote 3 pode ser atribuída principalmente, ao elevado índice de danos por "umidade" (15\%) observados nas sementes deste lote. Através da análise de correlação (Tabela 40), observou-se alta correspondência entre tetrazólio 1-3 e os testes de envelhecimento artificial e emergência em campo. Também BARROS \& MARCOS FILHO (1990) encontraram correlação significativa entre estes testes.

Por sua vez, as informações geradas pelo teste de tetrazólio 1-5 (Tabela 39) revelaram desempenho superior para os lotes 1 e 4 e qualidade inferior para os lotes 2 e 3. Comparando-se os resultados de germinação com os de viabilidade (1-5), observou-se que este último revelou diferenças mais pronunciadas entre os lotes, mostrando maior sensibilidade. Analisando os números absolutos constatou-se valores mais altos para os resultados de germinação nos quatro lotes, embora diferenças inferiores a $5 \%$ entre as duas avaliações sejam consideradas aceitáveis por FRANÇA NETO et al. (1986). No entando, verifica-se que para os lotes 2 e 3 tais diferenças foram de $8 \%$ a favor do teste de germinação. Os resultados do tetrazólio 1-5 revelaram que os principais fatores que acarretaram perda de viabilidade foram danos de origem mecânica e por umidade nos lotes 2 e 3, respectivamente. Além disso, estas diferenças entre os dois testes podem ser atribuídas à subjetividade da interpretação do tetrazólio, conforme discutido para o cultivar IAC-8. Conforme mostra a Tabela 40, os coeficientes de correlação obtidos indicaram falta de associação entre germinação e viabilidade (tetrazólio 1-5); este teste exibiu correlação altamente significativa apenas com o tetrazólio 1-3.

Os resultados referentes à emergência das plântulas em campo (Tabela 39) apontaram a melhor qualidade do lote 4, seguido pelos lotes 1 e 2 enquanto o lote 3 foi caracterizado como o de pior desempenho.

Tomando-se como base as comparações feitas entre os valores médios obtidos nos testes apresentados na Tabela 39, constatou-se que os resultados da maioria dos testes, exceto o de germinação, relacionaram-se aos da emergência das plântulas em campo, no sentido de identificar a inferioridade do lote 3. Quanto aos lotes de qualidade superior, ocorreram variações dependendo do teste considerado. A obtenção de informações mais precisas sobre o potencial fisiológico destes lotes foi dificultada principalmente, pela pequena diferença de qualidade entre eles. Nota-se, contudo, que os testes de primeira contagem de germinação e de classificação do vigor de plântulas apontaram melhor desempenho para o lote 2, que também foi destacado nos testes de 
envelhecimento artificial e tetrazólio 1-3, embora acompanhado também pelos lotes 1 e 4 . Já os resultados de emergência em campo revelaram qualidade superior para o lote 4, com $86 \%$ de emergência. Cabe ressaltar que, o lote 2 , classificado pela análise estatística como de médio vigor, mostrou, em termos de valores absolutos, semelhança com o lote 4, cuja emergência de plântulas em campo foi de $85 \%$.

Observando ainda a Tabela 39, pode-se notar pelos valores numéricos, que o lote 2 apresentou maior proporção de sementes danificadas em relação aos demais. No entanto, a maioria dos testes empregados situou o referido lote numa posição de destaque em termos de vigor. Desse modo, pode-se considerar que tais danos não se constituíram em fator relevante para o desempenho fisiológico do lote 2 .

Os dados obtidos na determinação do grau de umidade das sementes (Tabela 39), embora também não tenham sido analisados estatisticamente, foram, d modo geral, semelhantes em todos os lotes estudados, fato este de grande relevância para a condução de testes de vigor, conforme já abordado para o cultivar IAC-8.

Examinando de forma comparativa as Tabelas 33 e 39, observouse, de um modo geral, que as informações fornecidas pelos testes de condutividade elétrica de massa foram semelhantes àquelas obtidas com os testes de envelhecimento artificial, tetrazólio 1-3, 1-5 e emergência de plântulas em campo, principalmente no que se refere ao lote de maior vigor (lote 4), confirmando informações de YAKLICH et al. (1979), KULIK \& YAKLICH (1982), OLIVEIRA et al. (1984) e MARCOS FILHO et al. $(1985 ; 1990)$. Com relação a uma ordenação mais adequada dos lotes, verificou-se que o sistema CE II, com 24 horas de embebição, proporcionou resultados semelhantes aos de emergência. Também LOEFFLER et al. (1988) obtiveram informações semelhantes empregando esta metodologia. No entanto, examinando-se a Tabela 37, nota-se que as correlações entre condutividade pelo sistema de massa e os demais testes de vigor foram circunstanciais e pouco acentuadas, indicando significância apenas entre CE I (16 horas) e os testes de emergência em campo e tetrazólio.

Ainda de modo comparativo, verificou-se que o teste de condutividade com sementes individuais (Tabela 34) forneceu informações bastante próximas aos testes de envelhecimento artificial, tetrazólio 1-3 , 1-5 e emergência das plântulas em campo (Tabela 39), especialmente no sentido de destacar o lote 4 como sendo de elevada qualidade fisiológica. Em contrapartida, o lote 2, indicado na maioria dos estudos com o ASA-610, como inferior, apresentou desempenho razoável nos testes para avaliação do vigor, os quais destacaram, principalmente, o lote 3 como de pior potencial fisiológico. 
Assim, através da análise de correlação (Tabela 41), verificou-se que os resultados obtidos com o ASA-610 praticamente não se correlacionaram significativamente com os de germinação, primeira contagem e classificação do vigor de plântulas. Coeficientes de correlação altamente significativos foram constatados para poucos testes como, por exemplo, entre o limite de 90uA (20 horas) e tetrazólio 1-3, e entre 70uA (16 horas) e tetrazólio 1-3 e 1-5. Especificamente com relação à emergência das plântulas em campo, observou-se correlação significativa, ao nível de $1 \%$ de probabilidade, apenas para as leituras realizadas com $80 \mathrm{uA}$ ( 24 horas) e $70 \mathrm{uA}$ ( 20 horas).

Observando ainda a Tabela 39, notou-se elevada proporção de sementes danificadas no lote 2, principalmente em relação ao lote 4 . Este fato, provavelmente, contribuiu para que as sementes daquele lote exibissem alta porcentagem de exsudatos apresentando elevada condutividade, quando avaliadas individualmente através do ASA-610. Porém, observou-se que o lote 2, quando submetido aos demais testes para avaliação da qualidade fisiológica, inclusive o de condutividade "bulk", apresentou desempenho razoável, indicando, portanto, que a presença de danificações mecânicas não foi fator determinante de perda de vigor no referido lote. Neste aspecto, é importante considerar que, muitas vezes, dependendo da localização do dano, a qualidade fisiológica das sementes pode não ser afetada de modo drástico, principalmente, quando ele se restringe à rupturas no tegumento, sem atingir profundamente as áreas vitais.

Ainda de forma comparativa, observou-se que os resultados obtidos com a metodologia KII aos 60 e 90 minutos de embebição (Tabela 36) mostraram-se consistentes com as informações proporcionadas pelos testes de vigor relacionados na Tabela 39, especialmente coma emergência das plântulas em campo. MARCOS FILHO et al. (1984) e BARROS (1988), trabalhando com sementes de soja, constataram que o teste de lixiviação de potássio não foi eficiente para separar lotes de sementes em diferentes níveis de vigor.

Por outro lado, as informações fornecidas pelos métodos KI e KII, após 120 minutos de embebição (Tabela 36), não se relacionaram aos demais testes de vigor (Tabela 39) em termos de ordenação dos lotes, havendo coerência entre eles apenas quanto ao lote de melhor qualidade fisiológica (lote 4). Estes resultados mostraram-se divergentes daqueles obtidos para o cultivar IAC-8, onde, pela análise de correlação, o sistema KI apresentou correspondência com os demais testes de vigor. 
Tabela 41. Coeficientes de correlação simples ( $r$ ) entre os dados obtidos nos testes de condutividade elétrica individual (ASA-610) e de avaliação da qualidade fisiológica dos lotes de sementes de soja, cultivar IAC-15. Piracicaba, 1992.

\begin{tabular}{|c|c|c|c|c|c|c|c|}
\hline \multirow{2}{*}{$\begin{array}{l}\text { ASA- } \\
610\end{array}$} & \multirow{2}{*}{$\begin{array}{l}\text { Germi- } \\
\text { nação }\end{array}$} & \multirow{2}{*}{$\begin{array}{c}\text { Primeira } \\
\text { Cont. }\end{array}$} & \multirow{2}{*}{$\begin{array}{c}\text { Envelh. } \\
\text { Artif. }\end{array}$} & \multirow{2}{*}{$\begin{array}{c}\text { Classif. } \\
\text { Vigor }\end{array}$} & \multicolumn{2}{|c|}{ Tetrazólio } & \multirow{2}{*}{$\begin{array}{l}\text { Emerg } \\
\text { Campo }\end{array}$} \\
\hline & & & & & $1-3$ & $1-5$ & \\
\hline $90-8 h$ & $-0,16$ & $-0,13$ & $-0,30$ & 0,23 & $-0,15$ & 0,02 & 0,22 \\
\hline $90-12 h$ & 0,08 & $-0,05$ & 0,13 & 0,33 & 0,27 & 0,21 & 0,04 \\
\hline $90-16 h$ & $-0,39$ & $-0,14$ & 0,27 & 0,33 & 0,43 & 0,17 & 0,23 \\
\hline $90-20 h$ & $-0,09$ & $-0,02$ & $0,60 *$ & 0,48 & $0,73^{* *}$ & 0,46 & 0,56 \\
\hline $90-24 h$ & 0,16 & 0,15 & 0,52 & 0,37 & $0,65^{*}$ & 0,44 & 0,54 \\
\hline $80-8 h$ & $-0,13$ & 0,01 & $-0,31$ & 0,44 & 0,29 & $-0,17$ & 0,28 \\
\hline $80-12 h$ & $-0,08$ & $-0,02$ & 0,45 & 0,48 & $0,63^{*}$ & 0,44 & 0,19 \\
\hline $80-16 h$ & $-0,37$ & $-0,30$ & 0,27 & 0,27 & 0,40 & 0,25 & 0,28 \\
\hline $80-20 h$ & $-0,17$ & 0,02 & 0,48 & 0,44 & $0,63^{*}$ & 0,46 & $0,61^{*}$ \\
\hline $80-24 h$ & 0,05 & 0,21 & 0,45 & 0,41 & $0,62^{*}$ & 0,40 & $0,74^{* *}$ \\
\hline $70-8 h$ & 0,32 & $0,60 *$ & 0,38 & 0,26 & 0,51 & 0,44 & 0,52 \\
\hline $70-12 h$ & $-0,35$ & $-0,10$ & 0,29 & 0,25 & 0,34 & 0,20 & 0,30 \\
\hline $70-16 h$ & $-0,14$ & $-0,10$ & 0,46 & 0,43 & $0,64^{*}$ & 0,51 & $0,59 *$ \\
\hline $70-20 h$ & 0,11 & 0,01 & $0,68^{*}$ & 0,53 & $0,77^{* *}$ & $0,71^{* *}$ & $0,71^{* *}$ \\
\hline $70-24 h$ & 0,01 & 0,06 & 0,40 & 0,43 & $0,61^{*}$ & 0,34 & $0,62^{*}$ \\
\hline $60-8 h$ & 0,18 & 0,54 & 0,22 & 0,23 & 0,40 & 0,36 & 0,50 \\
\hline $60-12 h$ & $-0,21$ & 0,27 & 0,13 & 0,09 & 0,11 & 0,03 & 0,15 \\
\hline $60-16 h$ & $-0,04$ & 0,03 & 0,47 & 0,33 & 0,54 & 0,48 & 0,42 \\
\hline $60-20 h$ & 0,21 & 0,04 & 0,46 & 0,44 & $0,66^{*}$ & $0,66^{*}$ & 0,52 \\
\hline $60-24 h$ & $-0,08$ & 0,04 & 0,29 & 0,26 & 0,55 & 0,34 & $0,60^{*}$ \\
\hline $55-8 h$ & 0,17 & 0,48 & 0,42 & 0,36 & 0,51 & 0,33 & $0,59^{*}$ \\
\hline $55-12 h$ & $-0,17$ & 0,25 & 0,08 & 0,10 & 0,12 & 0,01 & 0,08 \\
\hline $55-16 h$ & $-0,05$ & $-0,06$ & 0,36 & 0,28 & 0,46 & 0,45 & 0,49 \\
\hline $55-20 h$ & 0,02 & $-0,23$ & 0,32 & 0,20 & 0,47 & 0,49 & 0,40 \\
\hline $55-24 h$ & 0,10 & $-0,04$ & 0,38 & 0,30 & 0,61 & 0,44 & 0,51 \\
\hline $50-8 h$ & 0,10 & 0,37 & 0,42 & 0,31 & $0,58^{*}$ & 0,35 & 0,51 \\
\hline $50-12 h$ & $-0,05$ & 0,17 & 0,34 & 0,15 & 0,35 & 0,25 & 0,17 \\
\hline $50-16 h$ & 0,17 & $-0,21$ & 0,52 & 0,18 & 0,44 & $0,59^{*}$ & 0,52 \\
\hline $50-20 h$ & 0,04 & $-0,43$ & 0,42 & 0,13 & 0,49 & 0,49 & 0,35 \\
\hline $50-24 h$ & 0,04 & $-0,07$ & 0,44 & 0,30 & $0,65^{*}$ & 0,44 & $0,59^{*}$ \\
\hline $45-8 h$ & 0,07 & 0,36 & 0,45 & 0,40 & $0,63^{*}$ & 0,43 & $0,60^{*}$ \\
\hline $45-12 h$ & 0,04 & 0,24 & 0,35 & 0,01 & 0,05 & 0,16 & 0,02 \\
\hline $45-16 h$ & 0,09 & $-0,31$ & 0,34 & 0,14 & 0,41 & 0,49 & 0,37 \\
\hline $45-20 h$ & $-0,23$ & $-0,61^{*}$ & 0,23 & 0,12 & 0,28 & 0,21 & 0,23 \\
\hline $45-24 h$ & $-0,13$ & $-0,16$ & 0,34 & 0,09 & 0,49 & 0,25 & 0,49 \\
\hline
\end{tabular}

* significativo pelo teste $t$ ao nivel de $5 \%$ de probabilidade.

** significativo pelo teste $t$ ao nível de $1 \%$ de probabilidade. 


\subsubsection{Considerações gerais}

Numa análise geral, observou-se que dentre os lotes de cada cultivar, um ou dois sempre apresentaram níveis de qualidade fisiológica superiores aos demais; no entanto a classificação dos lotes exibiu algumas variações em função do teste utilizado.

Considerando os testes de condutividade elétrica pelos sistemas de massa verificou-se, para os lotes do cultivar IAC-8, que ambas as metodologias empregadas (CE I e II) detectaram diferenças de vigor entre os lotes, diferenciando lotes com potencial elevado daqueles de qualidade fisiológica inferior. Tais informações mostraram-se relacionadas não só com a emergência das plântulas em campo, como também com os demais testes de vigor realizados. No entanto, ocorreram certas variações de acordo com o método e período de embebição utilizados; desta forma, as avaliações feitas com 8 e 12 horas, em amostras constituídas por sementes fisicamente puras (CE II), não permitiram a separação eficiente dos lotes, embora os valores numéricos tenham indicado uma ligeira tendência nesta direção. Por outro lado, com a eliminação de sementes danificadas da amostra (CE I), os períodos mais curtos propiciaram a diferenciação entre os lotes, embora pouco pronunciada. Observou-se ainda, para ambos os sistemas, que com o decorrer do condicionamento das sementes, o teste de condutividade elétrica tornou-se mais sensível às diferenças de qualidade entre os lotes.

Para os lotes do cultivar IAC-15, os sistemas de massa destacaram, com segurança, o lote de potencial elevado, proporcionando informações próximas à emergência das plântulas em campo. Entretanto, a separação eficiente dos outros três lotes só foi possível através da não remoção de sementes danificadas da amostra, após 24 horas, embora as principais tendências tenham indicado comportamento semelhante a partir de 16 horas de embebição.

Assim, a possibilidade de redução no período de condicionamento das sementes de soja no teste de condutividade elétrica foi variável em função do método empregado e do cultivar, sendo confirmada pelos resultados obtidos para o cultivar IAC-8, com sementes submetidas à escolha e para o 'IAC-15', através do sistema II.

Diante destes resultados, pode-se considerar que os menores períodos de embebição (8 e 12 horas) podem ser adotados quando se desejam 
informações menos detalhadas à respeito do potencial fisiológico dos lotes. Portanto, podem ser úteis em programas de controle de qualidade, fornecendo informações em período de tempo relativamente curto. Para a obtenção de indicações mais precisas, o condicionamento das sementes por 24 horas mostrou ser desnecessário, uma vez que diferenças mais acentuadas entre os lotes foram, de maneira geral, reveladas com 16 horas tanto no sistema I como no II, conforme ilustram as Figuras 1 e 2.

Com relação aos estudos de condutividade individual, através do ASA-610, constataram-se variações na classificação dos lotes de acordo com a intensidade de corrente elétrica (valor limite) e período de embebição utilizados. Os resultados obtidos com o cultivar IAC-8 revelaram, de modo geral, que os valores limite inferiores à $80 \mathrm{uA}$ promoveram a separação dos lotes, mostrando-se relacionados aos demais testes de vigor empregados. Porém, a adoção de limites mais altos requereu maior período de condicionamento para a obtenção de informações consistentes. A rapidez no fornecimento dos resultados só foi possível com os limites situados abaixo de 60uA. Notou-se ainda, que as intensidades de corrente de 45 e $50 \mathrm{uA}$, recomendadas para a avaliação do vigor em soja, respectivamente pela AGROSCIENCES (1979) e por KRZYZANOWSKI et al. (1991), não se mostraram compatíveis com os outros testes de vigor. Cabe ressaltar contudo, que com exceção do limite de 45uA, o ASA-610 revelou sensibilidade em identificar, com segurança, o lote de pior desempenho.

Por outro lado, para o cultivar IAC-15, a condutividade individual revelou, de modo geral, aptidão em destacar o lote de alta qualidade. A identificação correta dos demais lotes somente foi obtida no limite de $45 \mathrm{uA}$, com 12 horas de condicionamento. A dificil separação destes lotes pode ser atribuída ao fato de os mesmos não apresentarem diferenças marcantes, comportando-se, na realidade, como de vigor intermediário.

O teste de lixiviação de potássio mostrou, de modo geral, eficácia na determinação do potencial relativo dos lotes. A condução do teste com sementes escolhidas (KI) mostrou-se mais sensivel apenas para os lotes do cultivar IAC-8, embora o sistema II também tenha apontado tendências neste sentido. Nota-se que a elevada porcentagem de danos mecânicos nas sementes do lote de pior desempenho pode ter interferido na sensibilidade do método II. Particularmente com referência aos períodos de embebição utilizados observou-se que embora as diferenças tenham sido pouco acentuadas, o período de 90 minutos apresentou tendência de melhor desempenho em termos de classificação dos lotes, em todas as avaliações. 

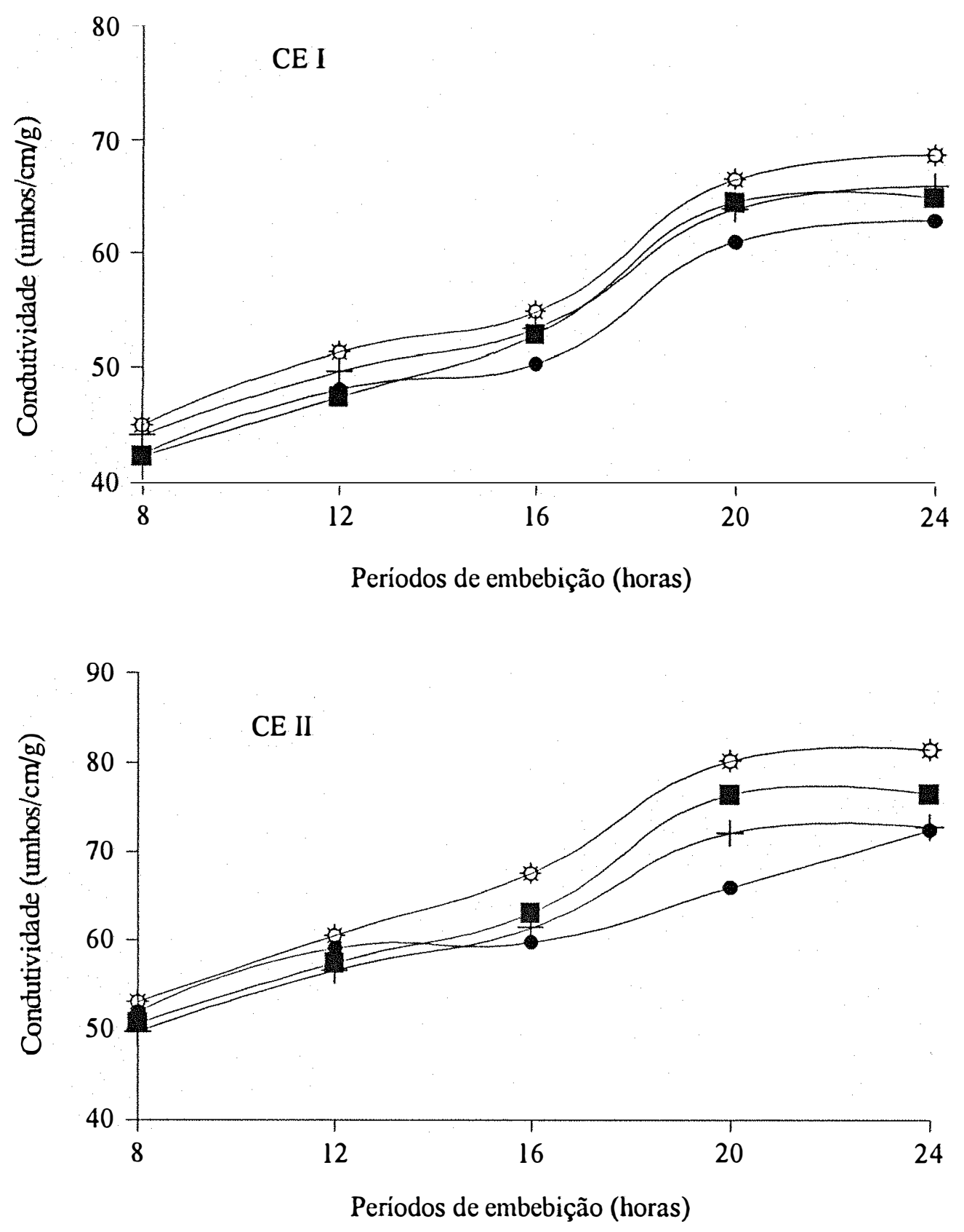

- Lote 1 +Lote 2 Lote 3 Lote 4

Figura 1. Representação gráfica da variação das médias de condutividade elétrica $(\mu \mathrm{mhos} / \mathrm{cm} / \mathrm{g}$ ) dos lotes de sementes de soja, cultivar IAC-8, nos diferentes periodos de embebição. Piracicaba, 1992. 

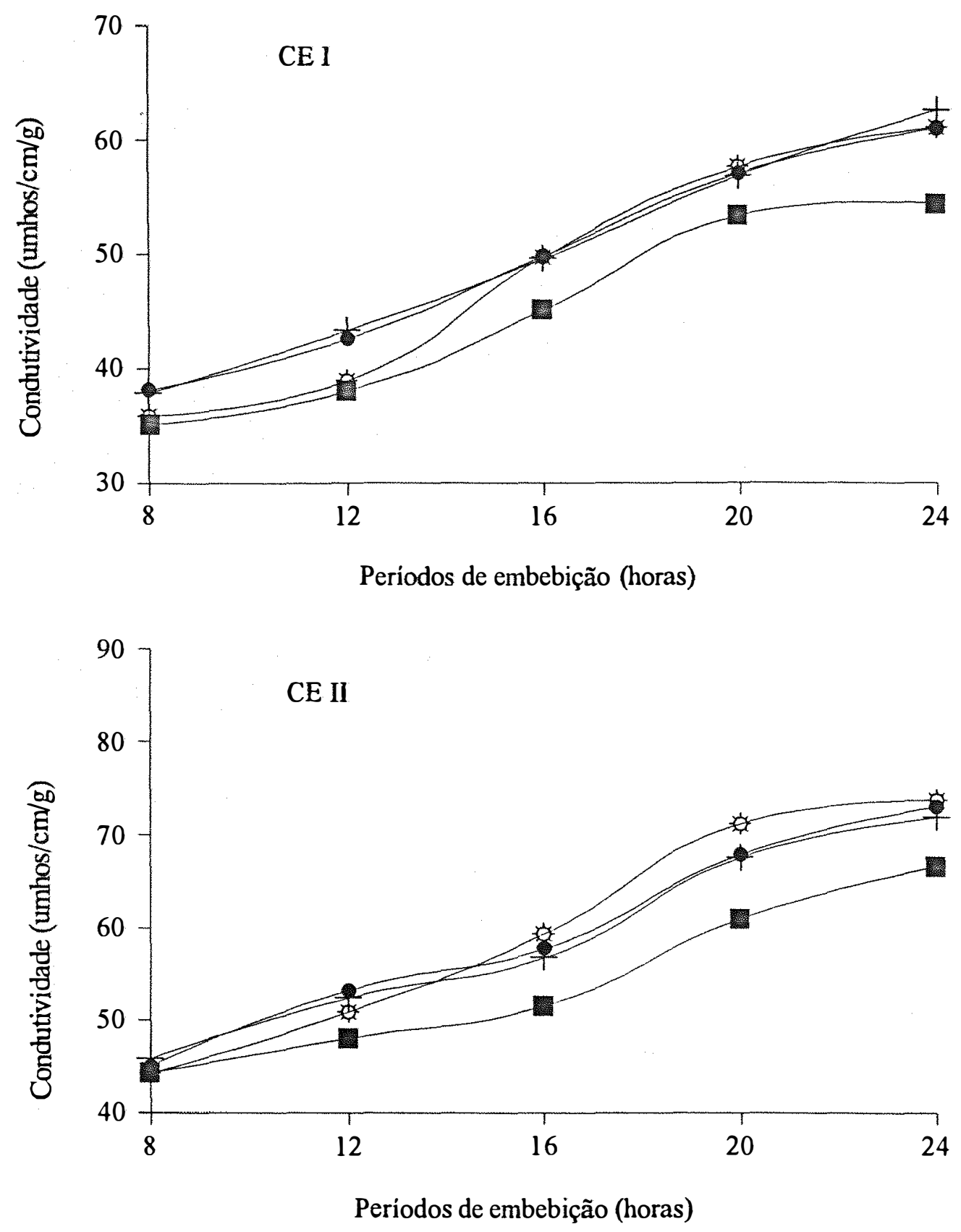

- Lote 1 +Lote 2 Lote 3 Lote 4

Figura 2. Representação gráfica da variação das médias de condutividade elétrica $(\mu \mathrm{mhos} / \mathrm{cm} / \mathrm{g}$ ) dos lotes de sementes de soja, cultivar IAC-15, nos diferentes periodos de embebição. Piracicaba, 1992. 
Analisando de forma conjunta os testes utilizados verificou-se, de maneira geral, que à exceção do teste de condutividade individual, os demais demonstraram aptidão em separar os lotes em niveis de vigor, além de fornecerem informações quanto ao potencial relativo de cada lote, em termos de emergência das plântulas em campo. É importante ressaltar que algumas variações observadas na ordenação dos lotes podem ser atribuídas às diferenças pouco acentuadas entre os mesmos aliado ao fato de que os diversos testes empregados avaliam diferentes aspectos do comportamento das sementes; desta forma, um mesmo lote pode exibir reações variáveis em função da característica que foi avaliada. Neste sentido, TEKRONY \& EGLI (1977), KULIK \& YAKLICH (1982) e MARCOS FILHO et al. $(1982,1984)$ destacaram a importância da utilização conjunta dos resultados de vários testes para avaliação do vigor de sementes de soja.

Portanto, considerando-se os resultados desta pesquisa, pode-se afirmar que testes de execução bastante simples e rápidos, como o de condutividade elétrica pelo sistema de massa e o de lixiviação de potássio, mostraram-se promissores para a avaliação da qualidade fisiológica das sementes, fornecendo informações de grande utilidade para os programas de controle de qualidade de sementes de soja. 


\section{CONCLUSŌES}

A análise dos dados e interpretação dos resultados do presente trabalho permitiram concluir que:

- a utilização dos testes de condutividade elétrica de massa e de lixiviação de potássio permitem a identificação de lotes com diferentes níveis de vigor e potencial de emergência de plântulas em campo, revelando sua importância para um programa de controle de qualidade mais dinâmico e efetivo;

- há possibilidade de redução no período de condicionamento das sementes de soja, no teste de condutividade elétrica pelo sistema de massa, sendo que períodos mais curtos (8 e 12 horas) podem ser utilizados para a identificação de diferenças mais acentuadas entre os lotes, enquanto que leituras realizadas a partir de 16 horas são mais sensiveis às variações de vigor das sementes;

- para a avaliação da quantidade de potássio lixiviado, pode ser considerado como método mais adequado o emprego de sementes fisicamente puras e período de embebição de 90 minutos;

- a avaliação da condutividade elétrica individual para fins de vigor, através do ASA-610, apresenta eficiência variável de acordo com o cultivar estudado. 


\section{REFERÊNCIAS BIBLIOGRÁFICAS}

ABDEL SAMAD, I.M. \& PEARCE, R.S. Leaching of ions, organic molecules, and enzymes from seeds of peanut (Arachis hypogaea L.) imbibing without testas or with intact testas. J. Exp. Bot., Oxford, 29(112): 1471-8, 1978.

ABDUL-BAKI, A.A. Biochemical aspects of seed vigor. HortSci., Alexandria, 15(6): 765-71, 1980.

ABDUL-BAKI, A.A. \& ANDERSON, J.D. Physiological and biochemical deterioration of seeds. In: KOZLOWSKI, T.T., ed. Seed Biology. New York, Academic Press, 1972. v.2, p.283-315.

ABDUL-BAKI, A.A. \& ANDERSON, J.D. Vigor determination in soybean seed by multiple criteria. Crop Sci., Madison, 13(6): 630-3, 1973.

AGRO SCIENCES. The automatic seed analyzers. Instrution Manual. Michigan, 1979. $32 \mathrm{p}$.

AMORIM, H.V. Aspectos bioquímicos e histoquímicos do grão de café verde relacionados com a deterioração da qualidade. Piracicaba, 1978. 85p. (LivreDocência - Escola Superior de Agricultura "Luiz de Queiroz"/ USP).

ASSOCIATION OF OFFICIAL SEED ANALYSTS. Seed vigor testing handbook. East Lasing, AOSA, 1983. 88p. (Handbook on seed testing. Contribution, 32).

BARROS, A.S.R. Testes para avaliação rápida da viabilidade e do vigor de sementes de soja (Glycine $\max$ (L.) Merrill). Piracicaba, 1988. 140p. (Mestrado - Escola Superior de Agricultura "Luiz de Queiroz"/USP).

BARROS, A.S.R. \& MARCOS FILHO, J. Testes para avaliação rápida da viabilidade de sementes de soja. Pesq. Agrop. Bras., Brasília, 25(10): 1447-59, 1990. 
BASAVARAJAPPA, B.S.; SHETTY, H.S.; PRAKASH, H.S. Membrane deterioration and other biochemical changes, associated with accelerated ageing of maize seeds. Seed Sci. \& Technol., Zürich, 19(2): 279-86, 1991.

BECWAR, M.R.; STANWOOD, P.C.; ROOS, E.E. Rehydratoin effects on imbibitional leakage from desiccation-sensitive seeds. Plant Physiol., Rockville, 69(5): 1132-35, 1982.

BEDFORD, L.V. Conductivity tests in commercial and hand harvested seed of pea cultivars and their relation to field establishment. Seed Sci. \& Technol. , Zürich, 2(3): 323-35, 1974.

BEWLEY, J.D. Membrane changes in seeds as related to germination and the perturbations resulting from deterioration in seed storage. In: McDONALD Jr., M.B. \& NELSON, C.J., ed. Physiology of the Seed Deterioration. CSSA, Madison, 1986. p. 27-46.

BEWLEY, J.D. \& BLACK, M. Seeds - Physiology of development and germination. Plenum Press, New York, 1985. 367p.

BHÉRING, M.C.; REIS, M.S.; SEDIYAMA, C.S.; SEDIYAMA, T.; ANDRADE, M.A.S. Influência de épocas de plantio sobre a qualidade fisiológica de sementes de soja (Glycine max (L.) Merrill). Rev. Ceres, Viçosa, 38(219):409-21, 1991.

BOCHICCHIO, A.; CORADESHI, M.A.; ZIENNA, P.; BERTOLINI, M.; VAZZANA, C. Imbibitional injury in maize seed independent of chilling temperature. Seed Sci. Res., Wallingford, 1(1): 85-90, 1991.

BRADNOCK, W.T. A method for predicting field emergence of peas. Proc. Ass. Off. Seed Anal., Lansing, 58: 70-5, 1968.

BRADNOCK, W.T. \& MATTHEWS, S. Assessing field emergence potential of wrinkleseeded peas. Hort. Res., Edinburg, 10: 50-8, 1970.

BRANTON, D. Membrane structure. An. Rev. Plant Physiol., Palo Alto, 20: 209-38, 1969.

BRASIL. Ministério da Agricultura. Regras para análise de sementes. Brasília, 1980. $188 \mathrm{p}$.

BRIGANTE, G.P. Efeitos da época e da localização da colheita na qualidade fisiológica de sementes de algodão (Gossypium hirsutum L.). Lavras, 1988. 113p. (Mestrado Escola Superior de Agricultura de Lavras). 
BROUWER, H.M. \& MULDER, J.C. Reduced steeping time for the condutivity vigor test of Phaseolus vulgaris L. seed. J. Seed Technol., Springfield, 7 (1): 84-96, 1982.

BRUGGINK, H.; KRAAK, H.L.; DIJEMA, M.H.G.E.; BEKENDAM, J. Some factors influencing eletrolyte leakage from maize (Zea mays L.) kernels. Seed Sci. Res., Wallingford, 1(1): 15-20, 1991.

CALIARI, M.F. \& MARCOS FILHO, J.M. Comparação entre métodos para avaliação da qualidade fisiológica de sementes de ervilha (Pisum sativum L.). Rev. Bras. Sem., Brasilia, 12(3): 52-75, 1990.

CARVALHO, N.M. Vigor de sementes. In: ATUALIZAÇÃO EM PRODUÇÃO DE SEMENTES. Campinas, Fundação Cargill, 1986. p.207-23.

CARVALHO, N.M. O conceito de vigor em sementes. In: VIEIRA, R.D. \& CARVALHO, N.M., ed. Testes de vigor em sementes. Jaboticabal, FUNEP/UNESP, 1994. p.1-30.

CARVALHO, N.M. \& NAKAGAWA, J. Sementes: Ciência, tecnologia e produção. Campinas, Fundação Cargill, 1988. 424p.

CHING, T.M. \& SCHOOLCRAFT, I. Physiological and chemical differences in aged seeds. Crop Sci., Madison, 8: 407-9, 1968.

COSTA, A.F.S. Avaliação da qualidade fisiológica das sementes de genótipos de soja (Glycine max (L.) Merrill) produzidas em cinco localidades do Estado de Minas Gerais. Viçosa, 1986. 110p. (Mestrado - Universidade Federal de Viçosa).

COSTA, J.A. \& MARCHEZAN, E. Características dos estádios de desenvolvimento da soja. Campinas, Fundação Cargill, 1982. 30p.

DELOUCHE, J.C. \& BASKIN, C.C. Accelerated aging techniques for predicting the relative storability of seed lots. Seed Sci. \& Technol., Zürich, 1(2): 427-52, 1973.

DESWAL, D.P. \& SHEORAN, I.S. A simple method for seed leakage measurement: applicable to single seeds of any size. Seed Sci. \& Technol., Zürich, 21(1):179-85, 1993.

DIAS, M.C.L.L. \& BARROS, A.S.R. Aferição de testes de vigor para sementes de feijão. Inform. ABRATES, Londrina, 3(1): 7-23, 1992. 
DUKE, S.H.; KAKEFUDA, G.; HARVEY, T.M. Differential leakage of intracellular substances from imbibing soybean seeds. Plant Physiol., Rockville, 72(4): 919-24, 1983.

EDJE, O.T. \& BURRIS, J.S. Seedling vigor in soybeans. Proc. Assoc. Off. Seed Anal., Springfield, 60: 149-57, 1970.

FLOOD, R.G. \& SINCLAIR, A. Fatty acid analysis of aged permeable and impermeable seed of Trifolium subterraneum. Seed Sci. \& Technol., Zürich, 9(2): 475-77, 1981.

FRAGA, A.C. Eficiência do teste de condutividade elétrica para predizer a qualidade fisiológica de sementes de algodão. In: REUNIÃO NACIONAL DE ALGODÃO, 5., Campina Grande, 1988. Resumos. Campina Grande, EMBRAPA-CNPA, 1988, p.120.

FRANÇA NETO, J.B.; PEREIRA, L.A.G.; COSTA, N.P. Metodologia do teste de tetrazólio em sementes de soja. EMBRAPA - CNPSo, Londrina, 1986. 35p. (Mimeografado).

FRANÇA NETO, J.B.; PEREIRA, L.A.G.; COSTA, N.P.; KRZYZANOWSKI, F.C.; HENNING, A.A. Metodologia do teste de tetrazólio em sementes de soja. EMBRAPA - CNPSo, Londrina, 1988. 58p.

FRATIN, P. Comparação entre métodos para a avaliação da qualidade fisiológica de sementes de milho (Zea mays L.). Piracicaba, 1987.191p. (Mestrado - Escola Superior de Agricultura "Luiz de Queiroz"/USP).

FURMAN, K.C.; WOODSTOCK, L.W.; SOLOMOS, T. Interfacing the ASAC-1000 seed analyser with an IBM-PC microcomputer using the basic program ASACST AT. J. Seed Technol., Lansing, 11(1): 79-87, 1987.

GILL, N.S. \& DELOUCHE, J.C. Deterioration of seed corn during storage. Proc. of Assoc. Off. Seed Anal., Lansing, 63(1): 35-50, 1973.

GIVELBERG, A.; HOROWITZ, M.; POLJAKOFF-MAYER, A. Solute leakage from Solanum nigrum $\mathrm{L}$. seeds exposed to high temperatures during imbibition. J. Exp. Bot., Oxford, 35(161): 1754-63, 1984.

GORECKI, R.J.; HARMAN, G.E.; MATTICK, L.R. The volatile exudates from germinating pea seeds of defferent viability and vigor. Can. J. Bot., Ottawa, 63(6): 1035-9, 1985. 
GRANQVIST, G.A. Leakage of cations from a carrot seed lot. Acta Hortic., The Hage, 215: 219-24, 1987.

HADAVIZADEH, A. \& GEORGE, R.A.T. The effect of mother plant nutrition on seed vigour as determined by the seed leachate conductivity in pea (Pisum sativum L.) cultivar Sprite. Seed Sci. \& Technol., Zürich, 16: 589-99, 1988.

HALLOIN, J.M. Solute loss from deteriorated cottonseed: Relationship between deterioration, seed moisture, and solute loss. Crop Sci., Madison, 15(1): 11-5, 1975.

HAMPTON, J.G.; JOHNSTONE, K.A.; EUA-UMPON, V. Bulk conductivity test variables for mungbean, soybean and French bean seed lots. Seed Sci. \& Technol., Zürich, 20(3): 677-86, 1992.

HARMAN, G. E. \& MATTICK, L.R. Association of lipid oxidation with seed ageing and death. Nature, London, 260(5549): 323-4, 1976.

HARRINGTON, J.F. Problems of seed storage. In: HEYDECKER, W.H., ed. Seed Ecology. Pennsylvania, The Pennsylvania State Univ. Press, 1973. p.251-65.

HEPBURN, H.A.; POWELL, A.A.; MATTHEWS, S. Problems associated with the routine application of electrical conductivity measurements of individual seeds in the germination testing of peas and soybeans. Seed Sci. \& Technol., Zürich, 12(2): 403-13, 1984.

HERTER, U. \& BURRIS, J.S. Evaluating drying injury on corn seed with a conductivity test. Seed Sci. \& Technol., Zürich, 17(2): 625-38, 1989.

HEYDECKER, W. The "vigour"of seeds. A review. Proc. Int. Seed Test. Ass., Zürich, 34(2): 201-19, 1969.

HEYDECKER, W. Vigour. In: ROBERTS, E.H., ed. Viability of seeds. Syracuse, Syracuse University Press, 1972. p.209-52.

HOPPER, N.W. \& HINTON, H.R. Electrical conductivity as a measure of planting seed quality in cotton. Agron. J., Madison, 79(1): 147-52, 1987.

HOY, D.J. \& GAMBLE, E.E. The effects of seed size and seed density on germination and vigor in soybean (Glycine $\max$ (L.) Merr.). Can. J. Plant Sci., Ottawa, 65 (1): 1-8, 1985.

ISELY, D. Vigor tests. Proc. Ass. Off. Seed Anal., Washington, 47: 176-82, 1957. 
JOHNSON, R.R. \& WAX, L.M. Relationship of soybean germination and vigor tests to field performance. Agron. J., Madison, 70(2): 273-8, 1978.

KEYS, R.D. Dinamic conductrometric analysis of peanut (Arachis hypogaea L.) seed leachate using the CASAS (Computerized Automatic Seed Analysis System). J. Seed Technol., Lansing, 7(1): 36-59, 1982.

KRZYZANOWSKI, F.C.; FRANÇA NETO. J.B.; HENNING, A.A. Relato dos testes de vigor disponiveis para as grandes culturas. Inform. ABRATES, Londrina, 1(2): 1537, 1991.

KRZYZANOWSKI, F.C. \& MIRANDA, Z.F.S. Relatório do comitê de vigor da ABRATES. Inform. ABRATES, Londrina, 1(1): 1-25, 1990.

KULICK, M.M. \& YAKLICH, R.W. Evaluation for vigor tests in soybean seeds: relationship of accelerated aging, cold, sand bench and speed of germination tests to field performance. Crop Sci., Madison, 22(4): 766-70, 1982.

KUO, W.H.J. Delayed-permeability of soybean seeds: characteristics and screening methodology. Seed Sci. \& Technol., Zürich, 17(1): 131-42, 1989.

LARSON, L.A. The effect of soaking pea seeds with or without seedcoats has on seedling growth. Plant Physiol., Rockville, 43(2): 255-9, 1968.

LIN, S.S. Alterações na lixiviação eletrolítica, germinação e vigor da semente de feijão envelhecida sob alta umidade relativa do ar e alta temperatura. Rev. Bras. Fisiol. Veg., Londrina, 2(2): 1-6, 1990.

LOEFFLER, T.M. The bulk conductivity test as an indicator of soybean seed quality. Lexington, 1981. 181p. (M.S. - University of Kentucky).

LOEFFLER, T.M.; TeKRONY; D.M.; EGLI, D.B. The bulk conductivity test as an indicator of soybean seed quality. J. Seed Technol., Lansing, 12(1): 37-53, 1988.

LOOMIS, E.L. \& SMITH, O.E. The effect of artificial ageing on the concentration of $\mathrm{Ca}, \mathrm{Mg}, \mathrm{Mn}, \mathrm{K}$, and $\mathrm{Cl}$ in imbibing cabbage seed. J. Amer. Soc. Hort. Sci., S. Joseph, 105(5): 647-50, 1980.

LOTT, J.N.A. ; CAVDEK, V.; CARSON, J. Leakage of $\mathrm{K}, \mathrm{Mg}, \mathrm{Cl}$, Ca and $\mathrm{Mn}$ from imbibing seeds grains and isolated seed parts. Seed Sci. Res., Wallingford, 1: 22933, 1991.

LUZZATI, V. \& HUSSON, F. The structure of the liquid-crystalline phases of lipidwater systems. J. Cell Biol., New York, 12(2): 207-20, 1962. 
MAGUIRE, J.D. Seed quality and germination. In: KHAN, A.A., ed. The physiology and biochemistry of seed dormance and germination. Amsterdam, NorthHolland Biomedical Press, 1977. p.219-35.

MAITI, R.K.; RAJU, P.S.; BIDINGER, F.R. Studies on germinability and some aspects of pre-harvest physiology of sorghum grain. Seed Sci. \& Technol., Zürich, 13(1): 27-35, 1985.

MARBACH, I. \& MAYER, A.M. The effect of temperature change on leakage from pea seeds. J. Exp. Bot., Oxford, 36(164):353-8, 1985.

MARCOS FILHO, J.; AMORIM, H.V.; SILVAROLLA, M.B.; PESCARIN, H.M.C. Relações entre germinação, vigor e permeabilidade das membranas celulares durante a maturação de sementes de soja. In: SEMINÁRIO NACIONAL DE PESQUISA DE SOJA, 2., Brasília, 1981. Anais. Londrina, EMBRAPA-CNPSo, 1982. p.676-88.

MARCOS FILHO, J.; CARVALHO, R.V.; CÍCERO, S.M.; DEMÉTRIO, C.G.B. Qualidade fisiológica e comportamento de sementes de soja [Glycine max (L.) Merrill] no armazenamento e no campo. Anais Esc. Sup. Agric. "Luiz de Queiroz", Piracicaba, 42: 195-249, 1985.

MARCOS FILHO, J.; CICERO, S.M.; SILVA, W.R. Avaliação da qualidade das sementes. Piracicaba, FEALQ, 1987. 230p.

MARCOS FILHO, J.; PESCARIN, H.M.C.; KOMATSU, Y.H.; DEMÉTRIO, C.G.B.; FANCELLI, A.L. Testes para avaliação do vigor de sementes de soja e sua relação com a emergência das plântulas em campo. Pesq. Agrop. Bras., Brasília, 19(5): 605-13, 1984.

MARCOS FILHO, J.; SILVA, W.R.; NOVEMBRE, A.D.C.L.; CHAMMA, H.M.C.P. Estudo comparativo de métodos para avaliação da qualidade fisiológica de sementes de soja, com ênfase ao teste de condutividade elétrica. Pesq. Agrop. Bras., Brasília, 25(12): 1805-15, 1990.

MATTHEWS, S. Evaluation of techniques for germination and vigor studies. Seed Sci. \& Technol., Zürich, 9(2): 543-51, 1981.

MATTHEWS, S. Physiology of seed ageing. Out. Agric., Grã-Bretanha, 14(2): 89-94, 1985. 
MATTHEWS, S. \& BRADNOCK, W.T. The detection of seed samples of wrinkleseeded peas (Pisum sativum L.) of potentially low planting value. Proc. Int. Seed Test. Assoc., Norway, 32: 553-63, 1967.

MATTHEWS, S. \& BRADNOCK, W.T. Relationship between seed exudation and field emergence in peas end french beans. Hort. Res., Edinburg, 8: 89-93, 1968.

MATTHEWS, S. \& CARVER, M.F.F. Further studies on rapid exudate tests indicative of potential field emergence. Proc. Int. Seed Test. Assoc., Norway, 36(2): 307-12, 1971.

MATTHEWS, S. \& POWELL, A.A. Electrical conductivity test. In: PERRY, D.A., ed. Handbook of vigor test methods. Zürich, ISTA, 1981. p.37-42.

MATTHEWS, S. \& ROGERSON, N.E. The influence of embryo condition on the leaching of solutes from peas seeds. J. Exp. Bot., Oxford, 27(100): 961-8, 1976.

MATTHEWS, S. \& WHITBREAD, R. Factors influencing pre-emergence mortality in peas 1 . An association between seed exudates and the incidence of pre-emergence mortality in wrinkle-seeded peas. Pl. Path., Oxford, 17(1): 11-7, 1968.

McDONALD Jr., M.B. A review and evaluation of seed vigor tests. Proc. Assoc. Off. Seed Anal., Lansing, 65: 109-39, 1975.

McDONALD Jr., M.B. Assessment fo seed quality. HortSci., Alexandria, 15(6): 784-8, 1980

McDONALD Jr., M.B.; TAO, K.L.; BASKIN, C.C.; GRABE, D.F.; HARRINGTON, J.F. AOSA vigor test subcommittee report 1978 vigor test "referee" program. The Newsl. AOSA, Lansing, 52(4): 31-42, 1978.

McDONALD Jr., M.B. \& WILSON, D.O. An assessment of the standardization and ability of the ASA-610 to rapidly predict potntial soybean germination. J. Seed Technol., Lansing, 4(1): 1-11, 1979.

McDONALD Jr., M.B. \& WILSON, D.O. ASA-610 ability to detect changes in soybean seed quality. J. Seed Technol., Lansing, 5(1): 56-66, 1980.

McKERSIE, B.D. \& STINSON, R.H. Effect of dehydration on leakage and membrane structure in Lotus corniculatus L. seeds. Plant Physiol., Rockville, 66(2): 316-20, 1980. 
MIRANDA, M.C. Evaluation of an electrical conductivity method for rapidly estimating germination and assessing deterioration of soybean (Glycine $\max (\mathrm{L}$.) Merrill) seed. Mississipi, 1981. 89p. (Ph.D.- Faculty of Mississipi State University).

MOSS, G.I. \& MULLET, J.H. Potassium release and seed vigour in germinating bean (Phaseolus vulgaris $\mathrm{L}$.) seed as influenced by temperature over the previous five generations. J. Exp. Bot., Oxford, 33(137): 1147-60, 1982.

MULLET, J.H. \& WILKINSON, R.J. The relationship between amounts of electrolyte lost on leaching seeds of Pisum sativum and some parameters of plant growth. Seed Sci. \& Technol., Zürich, 7(3): 393-8, 1979.

MURPHY, J.B. \& NOLAND, T.L. Temperature effects on seed imbibition and leakage mediated by viscosity and membranes. Plant Physiol., Rockvillle, 69(2): 428-31, 1982.

NASCIMENTO, W.M. \& CICERO, S.M. Qualidade de sementes de ervilha tratadas com fungicida. II: Qualidade fisiológica. Rev. Bras. Sem., Brasília, 13(1): 13-9, 1991.

OHLROGGE, J.B. \& KERNAN, T.P. Oxygen dependent aging of seeds. Plant Physiol., Rockville, 70(3): 791-6, 1982.

OLIVEIRA, J.A. Correlação entre a evolução de hexanal e de aldeídos totais, a lixiviação de íons e o potencial de germinação de sementes de soja. (Glycine max (L.) Merrill). Viçosa, 1990. 79p. (Mestrado - Universidade Federal de Viçosa).

OLIVEIRA, M.A.; MATTHEWS, S.; POWELL, A.A. The role of split seed coats in determining seed vigour to commercial seed lots of soybean, as measured by the electrical conductivity test. Seed Sci. \& Technol., Zürich, 12(2): 659-68, 1984.

PANDEY, D.K. Priming induced alleviation of the effects of natural ageing derived selective leakage of constituents in French bean seeds. Seed Sci. \& Technol., Zürich, 17(1): 391-7, 1989.

PARRISH, D.J. \& LEOPOLD, A.C. Transient changes during soybean imbibition. Plant Physiol., Rockville, 59(6): 1111-5, 1977.

PARRISH, D.J. \& LEOPOLD, A.C. On the mechanism of aging in soybean seeds. Plant Physiol., Rockville, 61(3): 365-8, 1978.

PEARCE, R.S. \& ABDEL SAMAD, I.M. Change in fatty acid content of polar lipids during ageing of seeds of peanut (Arachis hipogaea L.). J. Exp. Bot., Oxford, 31(124): 1283-90, 1980. 
PERRY, D.A. Report of vigor test comittee 1977-80. Seed Sci. \& Technol., Zürich, 9(1): 115-26, 1981.

PERRY, D.A. \& HARRISON, J.G. The deleterious effect of water and low temperature on germination of pea seed. J. Exp. Bot., Oxford, 21(67):504-12, 1970.

POLLOCK, B.M. \& ROSS, E.E. Seed and seedling vigor. In: KOZLOWSKI, T.T., ed. Seed Biology. New York, Academic Press, 1972. v.1, p. 313-87.

POWELL, A.A. Cell membranes and seed leachate conductivity in relation to the quality of seed for sowing. J. Seed Technol., Lansing, 10(2): 81-100, 1986.

POWELL, A.A. \& MATTHEWS, S. The damaging effect of water on dry pea embryos during imbibition. J. Exp. Bot., Oxford, 29(112): 1215-29, 1978.

POWELL, A.A. \& MATTHEWS, S. The influence of testa condition on the imbibition and vigor of pea seeds. J. Exp. Bot., Oxford, 30(114): 193-7, 1979.

POWELL, A.A. \& MATTHEWS, S. Association of phospholipid changes with early stages of seed ageing. Ann. Bot., 47(5): 709-12, 1981.

POWELL, A.A.; OLIVEIRA, M.A.; MATTHEWS, S. The role of imbibition damage in determining the vigor of white and coloured seed lots of Dwarf French beans (Phaseolus vulgaris). J. Exp. Bot., Oxford, 37(178): 716-22, 1986.

PRIESTLEY, D.A. \& LEOPOLD, A.C. Absence of lipid oxidation during accelerated aging of soybean seeds. Plant Physiol., Rockville, 63(4): 726-29, 1979.

PRIESTLEY, D.A.; McBRIDE, M.B.; LEOPOLD, A.C. Tocopherol and organic free radical levels in soybean seeds during natural and accelerated aging. Plant Physiol., Rockville, 66: 715-9, 1980.

PRIESTLEY, D.A. \& LEOPOLD, A.C. Lipid changes during natural aging soybean seeds. Physiol. Plant., Munskgaard, 59: 467-70, 1983.

PRIESTLEY, D.A.; WERNER, B.G.; LEOPOLD, A.C.; McBRIDE, M.B. Organic free radical levels in seeds and pollen: The effects of hydration and aging. Physiol. Plant., Munskgaard, 64(1): 88-94, 1985.

RACHIDIAN, Z. \& LE DEUNFF, Y. Qualité germinative des semences de pois. II- Suivi condutivimétrique des graines au cours de leur dévelippement; incidence du relargage des nutriments sur la croissance des plantules. Agronomie, Versailles, 6(7): 623-8, 1986. 
STEWART, R.R.C. \& BEWLEY, J.D. Lipid peroxidation associated with accelerated aging of soybean axes. Plant Physiol., Rockville, 65(2): 245-8, 1980.

STEERE, W.C.; LEVENGOOD, W.C.; BONDIE, J.M. An eletronic analyser for evaluating seed germination and vigor. Seed Sci. \& Technol., Zürich, 9(2): 567-76, 1981.

STOECKENIUS, M. Some electrom, icroscopical observations on liquid-cristalline phases in lipid-water systems. J. Cell Biol., New York, 12(2): 221-9, 1962.

SUBRAHMANYAM, P.; REDDY, M.N.; RAO, A.S. Exudation of certain organic compunds from seeds of groundnut. Seed Sci. \& Technol., Zürich, 11(2): 267-72, 1983.

SWAMY, P.M. \& NARASIMHA REDDY, S.B. Changes in the leakage of eletrolytes from groundnut seeds (Arachis hypogaea) during after-ripening. Seed Sci. \& Technol., Zürich, 5(4): 645-8, 1977.

TAKAYANAGI, K. \& MURAKAMI, K. Rapid germinability with exudates from seed. Nature, London, 218(4): 493-4, 1968.

TAO, K.L.J. Factors causing variations in the conductivity test for soybean seeds. J. Seed Technol., Lansing, 3(1): 10-8, 1978.

TAO, K.L.J. Vigor "referee" test for soybean and corn. The Newsl. Assoc. Off. Seed Anal., 54(1): 40-58, 1980.

TEKRONY, D.M. Seed vigor testing; 1982. J. Seed Technol., Lansing, 8(1):55-60, 1983

TEKRONY, D.M. \& EGLI. D.B. Relationship between laboratory indices of soybean seed vigor and field emergence. Crop Sci., Madison, 17(4): 573-7, 1977.

THOMAS, C.A. Permeability measurements of castor-bean seed indicative of cold-test performance. Science, London, 131: 1045-6, 1960.

TRACY, W.F. \& JUVIK, J·A. Electrolyte leakage and seed quality in a shrunken-2 maize selected for improved field emergence. HortSc., Alexandria, 23(2): 391-2, 1988.

TYAGI, C.S. Evaluating viability and vigour soybean seed with automatic seed analyzer. Seed Sci. \& Technol., Zürich, 20(3): 687-94, 1992.

VIEIRA, R.D.; TEKRONY, D.M.; EGLI. D.B. Effect of drought stress on soybean seed germination and vigor. J. Seed Technol., Springfield, 15(1): 12-21, 1991. 
VIEIRA, R.D.; TEKRONY, D.M.; EGLI, D.B. Effect of drought and defoliation stress in the field on soybean seed germination and vigor. Crop Sci., Madison, 32(2): 47175, 1992.

WANN, E.V. Leaching of metabolites during imbibition of sweet corn seed of different endosperm genotypes. Crop Sci., Madison, 26(4): 731-33, 1986.

WATERS Jr., L. \& BLANCHETTE, B.L. Prediction of sweet corn field emergence by conductivity and cold tests. J. Amer. Hort. Sci., S. Joseph, 108(5): 778-81, 1983.

WEBES, R. \& KARSSEN, C.M. The influence of redesiccation on dormancy and $\mathrm{K}^{+}$ leakage of primed lettuce seeds. Israel J. Bot., Jerusalem, 39(4-6): 327-36, 1990.

WILSON Jr., D.O.; ALLEYNE, B.S.; MOHAN, S.K. Combining vigor test results of final stand of shrunken-2 sweet corn seed. Crop Sci., Madison, 32(6): 1496-502, 1992.

WILSON Jr., D.O. \& McDONALD Jr., M.B. The lipid peroxidation model of seed ageing. Seed Sci. \& Technol., Zürich, 14(2): 269-300, 1986.

WILSON Jr., D.O. \& TRAWATHA, S.E. Physiological maturity and vigor in production of 'Florida Staysweet' shrunken-2 sweet corn seed. Crop Sci., Madison, 31: 1640-7, 1991.

WOODSTOCK, L.W. Physiological and biochemical tests for seed vigor. Seed Sci. \& Technol., Norway, 1(1): 127-57, 1973.

WOODSTOCK, L.W. Seed imbibition: a critical period for successful germination. J. Seed Technol., Lansing, 12(1): 1-15, 1988.

WOODSTOCK, L.W.; FURMAN, K.; LEFFLER, H.R. Relationship between weathering deterioration and germination, respiratory metabolism, and mineral leaching from cottonseeds. Crop Sci., Madison, 25(3): 459-66, 1985.

YAKLICH, R.W. \& ABDUL-BAKI, A.A. Variability in metabolism of individual axes of soybean seeds and its relationship to vigor. Crop Sci., Madison, 15(3): 424-6, 1975 .

YAKLICH, R.W. \& KULIK, M.M. Evaluation of vigor tests in soybean seeds: relationship of standard germination test, vigor classification, seedling lenght and tetrazolium staining, to field performance. Crop Sci., Madison, 19(2): 247-52, 1979. 
YAKLICH, R.W.; KULIK, M.M.; ANDERSON, J.D. Evaluation of vigor tests in soybean seeds; relationship of ATP, conductivity, and radioative tracer multiple critera laboratory tests for field performance. Crop Sci., Madison, 19(6): 806-10. 1979.

ZONTA, E.P.; MACHADO, A.D.; SILVEIRA Jr., P. Sistemas de análise estatística para microcomputadores - SANEST. Pelotas, UFPel, 1984. (Registro SEI no 06606-0 Categoria AO). 